Pontifícia Universidade Católica

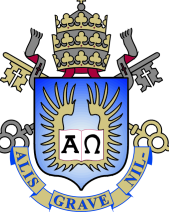

Jonatas dos Santos Grosman

LER: Anotação e classificação automática de entidades e relações

Dissertação de Mestrado

Dissertação apresentada como requisito parcial para obtenção do grau de Mestre pelo Programa de Pós-graduação em Informática da PUC-Rio.

Orientador: Prof. Hélio Côrtes Vieira Lopes 

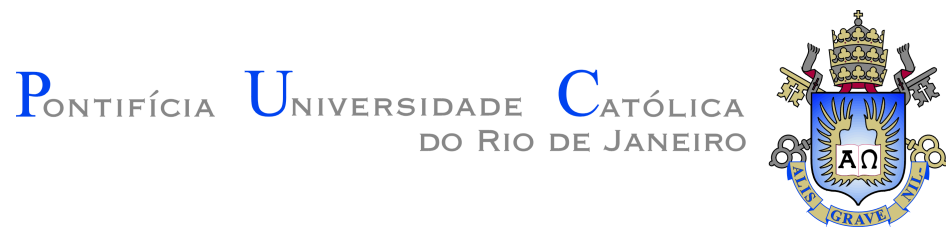

Jonatas dos Santos Grosman

\title{
LER: Anotação e classificação automática de entidades e relações
}

Dissertação apresentada como requisito parcial para obtenção do grau de Mestre pelo Programa de Pós-graduação em Informática da PUC-Rio. Aprovada pela Comissão Examinadora abaixo assinada.

\author{
Prof. Hélio Côrtes Vieira Lopes \\ Orientador \\ Departamento de Informática - PUC-Rio
}

Profa. Simone Diniz Junqueira Barbosa

Departamento de Informática - PUC-Rio

Profa. Maria Cláudia de Freitas

Departamento de Letras - PUC-Rio

Prof. Marcus Vinícius Soledade Poggi de Aragão

Departamento de Informática - PUC-Rio

Prof. Márcio da Silveira Carvalho

Coordenador Setorial do Centro Técnico Científico - PUC-Rio 
Todos os direitos reservados. É proibida a reprodução total ou parcial do trabalho sem autorização da universidade, do autor e do orientador.

\section{Jonatas dos Santos Grosman}

Graduou-se em Sistemas de Informação pela Faculdade de Educação Tecnológica do Estado Rio de Janeiro.

Ficha Catalográfica

Grosman, Jonatas dos Santos

LER: Anotação e classificação automática de entidades e relações / Jonatas dos Santos Grosman; orientador: Hélio Côrtes Vieira Lopes. - 2017.

v., 196 f: il. color. ; $30 \mathrm{~cm}$

Dissertação (mestrado) - Pontifícia Universidade Católica do Rio de Janeiro, Departamento de Informática.

Inclui bibliografia

1. Informatica - Teses. 2. Processamento de linguagem natural. 3. Aprendizado automático. 4. Extração de informação. 5. Ontologias. 6. Curadoria de dados. I. Lopes, Hélio Côrtes Vieira. II. Pontifícia Universidade Católica do Rio de Janeiro. Departamento de Informática. III. Título. 


\section{Agradecimentos}

Começarei pelo clichê.

Palavras não bastam para descrever tamanha gratidão que tenho pelas pessoas que fizeram parte do processo que culminou neste trabalho.

Agora ao menos clichê.

Eu poderia separar em três grupos as pessoas à agradecer, as que me fizeram entrar no mestrado, as que me fizeram continuar nele e, por fim, as que me fizeram concluí-lo. Inicialmente tentei transcrever os agradecimentos segundo essa divisão, mas me peguei em tantas intersecções que decidi escrever na ordem que encontrei algum sentido.

Pois bem, eu poderia começar o agradecimento regredindo muito no tempo, lembrando dos incentivos dos meus professores e colegas de faculdade, já que foi nesse tempo que minha paixão pela computação nasceu, mas só não o farei por intuito de brevidade, preferindo começar pelos meus primeiros passos fora dela. Foi nesse tempo que conheci as pessoas que mais contribuíram para eu entender onde estava me metendo e que rumo tomar. Começo pelo estágio, onde conheci um grande amigo, Lucas Bastos, que a seu jeito me fazia querer saber mais sobre computação. Indo para a minha primeira experiência científica fora da faculdade, no tempo que fiquei no Laboratório Nacional de Computação Científica, conheci pessoas brilhantes como Anderson Menezes, Antônio Tadeu, Artur Ziviani, Bruno Bastos, Bruno Correa, Iuri Malinoski, Thiago Cardozo e Vinicius Moreira. Eles podem nem fazer ideia do quanto tenho a agradecer pelas lições aprendidas, então escrevo aqui para que tenham ciência. Na minha passagem pelo Observatório Nacional, mesmo que breve, já que tive de abandoná-los para poder fazer o mestrado, conheci pessoas como Pedro Rocha e Selma Junqueira, que me ajudaram com o empurrão que faltava para querer enveredar pelo caminho que tomei. Tenho muito a agradecer (muito mesmo) aos meus grandes amigos Fábio Albuquerque, Felipe Gomes, Wesley Hinsch e Wendson Chaper, pessoas com quem trabalhei e me ajudaram a manter a sanidade em alguns momentos difíceis.

Entrando agora nos domínios da PUC-Rio, gostaria de falar sobre os amigos que sofreram comigo os pesares da pós-graduação, Bruno Pontes, Djalma Lúcio, Grazi Kapps, João Magela, Luiz Felipe Netto, Renato Moraes e Victor Thomaz, pois com eles o percurso foi, de qualquer modo, duro, porém alegre. Tenho de falar também dos amigos de laboratório, Cássio Almeida, Jefry 
Sastre, Sonia Fiol e William Fernandes, sempre dispostos a ajudar e rir quando eu estava em apuros. Agradeço também a todos os professores que influenciaram este trabalho, em especial Simone Diniz, Maria Cláudia e Marcus Poggi (não é por acaso a participação deles na banca examinadora). Reservo aqui um espaço para falar sobre duas pessoas que foram fundamentais para a conclusão deste trabalho, Pedro Furtado e Hélio Lopes, o primeiro um grande amigo, diria irmão, que fiz no departamento e o segundo outro grande amigo e por acaso também meu orientador. Se este trabalho merece aplausos, eu os divido com os ambos.

Por fim, porém não menos importante, já que se a ordem fosse determinante esta parte deveria vir na capa, gostaria de agradecer a minha família por todo apoio que me deram, dão e sei que darão. Cabe aqui fazer uma transcrição mais detalhada dos culpados. Aos meus pais Maria e Paulo, detentores da minha admiração e respeito por todo o sacrifício que fizeram para que eu pudesse realizar meus sonhos, ao meu irmão Felipe por seu apoio e admiração (gostaria de dizer "pelos conselhos", mas estes é melhor não seguir a risca). Agradeço também a minha esposa Júlia pelo amor, paciência e apoio dado durante o processo de construção deste trabalho (ainda espero conseguir que me libere para o doutorado), e minha cunhada Juliana e meus sogros Aníbal e Kátia pelo apoio e sincera admiração que me deram.

E depois de tantos nomes, era de se esperar que ao cabo pedisse desculpas por ter esquecido algum (o que não seria nenhum espanto, já que tenho lá minhas dúvidas se tão poucas linhas seriam suficientes para cobrir minha gratidão), então peço aqui minha absolvição, e digo que se isso de fato aconteceu, não me julgue mal. Se o seu nome fosse para estar aqui, é sinal de que me conhece bem e logo sabe o quão desmemoriado sou. 


\section{Resumo}

Grosman, Jonatas dos Santos; Lopes, Hélio Côrtes Vieira. LER:

Anotação e classificação automática de entidades e relações. Rio de Janeiro, 2017. 196p. Dissertação de Mestrado - Departamento de Informática, Pontifícia Universidade Católica do Rio de Janeiro.

Diversas técnicas para extração de informações estruturadas de dados em linguagem natural foram desenvolvidas e demonstraram resultados muito satisfatórios. Entretanto, para obterem tais resultados, requerem uma série de atividades que geralmente são feitas de modo isolado, como a anotação de textos para geração de corpora, etiquetamento morfossintático, engenharia e extração de atributos, treinamento de modelos de aprendizado de máquina etc., o que torna onerosa a extração dessas informações, dado o esforço e tempo a serem investidos. O presente trabalho propõe e desenvolve uma plataforma em ambiente web, chamada LER (Learning Entities and Relations) que integra o fluxo necessário para essas atividades, com uma interface que visa a facilidade de uso. Outrossim, o trabalho mostra os resultados da implementação e uso da plataforma proposta.

\section{Palavras-chave}

Processamento de linguagem natural; Aprendizado automático; Extração de informação; Ontologias; Curadoria de dados. 


\section{Abstract}

Grosman, Jonatas dos Santos; Lopes, Hélio Côrtes Vieira (Advisor). LER: Annotation and automatic classification of entities and relations. Rio de Janeiro, 2017. 196p. Dissertação de Mestrado - Departamento de Informática, Pontifícia Universidade Católica do Rio de Janeiro.

Many techniques for the structured information extraction from natural language data have been developed and have demonstrated their potentials yielding satisfactory results. Nevertheless, to obtain such results, they require some activities that are usually done separately, such as text annotation to generate corpora, Part-Of- Speech tagging, features engineering and extraction, machine learning models' training etc., making the information extraction task a costly activity due to the effort and time spent on this. The present work proposes and develops a web based platform called LER (Learning Entities and Relations), that integrates the needed workflow for these activities, with an interface that aims the ease of use. The work also shows the platform implementation and its use.

\section{Keywords}

Natural language processing; Automatic learning; Information extraction; Ontologies; Data curation. 


\section{Sumário}

1 Introdução $\quad 20$

2 Revisão bibliográfica $\quad \mathbf{2 4}$

2.1 Mineração de textos e processamento de linguagem natural 24

2.2 Anotação de dados textuais 28

$\begin{array}{lll}3 & \text { A plataforma } & 37\end{array}$

3.1 Arquitetura 40

3.2 Controle de usuários 43

3.3 Gerência de projetos 44

3.4 O ERAS 46

3.4.1 Gerência dos dados 48

$\begin{array}{lll}3.4 .2 & \text { Anotação } & 55\end{array}$

$\begin{array}{lll}3.4 .3 & \text { Estatísticas } & 59\end{array}$

$\begin{array}{lll}3.5 & \text { Aprendizado automático } & 68\end{array}$

$\begin{array}{lll}3.6 & \text { Publicação de serviços } & 77\end{array}$

4 Experimentos $\quad 81$

4.1 Experimento de anotação $\quad 81$

4.1.1 Metodologia $\quad 81$

4.1.2 Resultados $\quad 82$

4.2 Experimento de aprendizado automático $\quad 85$

4.2.1 Dados $\quad 86$

$\begin{array}{ll}\text { 4.2.2 Metodologia } & 95\end{array}$

\begin{tabular}{ll}
4.2 .3 & Resultados \\
\hline
\end{tabular}

$\begin{array}{lll}\text { 4.2.3.1 NER } & 97\end{array}$

$\begin{array}{lll}\text { 4.2.3.2 RE } & 102\end{array}$

$\begin{array}{ll}\text { 4.2.3.3 Uso dos modelos finais } & 105\end{array}$

5 Conclusão $\quad 111$

$\begin{array}{lr}\text { Referências bibliográficas } & 114\end{array}$

A Experimento de anotação: Guia de anotação 118

$\begin{array}{lll}\text { A.1 FERRAMENTA DE ANOTAÇÃO } & 118\end{array}$

A.1.1 PROCESSO DE ANOTAÇÃO 120

$\begin{array}{ll}\text { A.1.2 ATALHOS } & 127\end{array}$

A.2 TAREFA DE ANOTAÇÃO 127

$\begin{array}{ll}\text { A.2.1 RÓTULOS } & 127\end{array}$

$\begin{array}{ll}\text { A.2.1.1 Actor } & 128\end{array}$

$\begin{array}{lr}\text { A.2.1.2 Event } & 129\end{array}$

A.2.1.3 Location 131

A.2.1.4 Time 132

$\begin{array}{ll}\text { A.2.1.5 Tipos primitivos } & 132\end{array}$

$\begin{array}{ll}\text { A.2.2 RELAÇÕES } & 134\end{array}$ 
$\begin{array}{lll}\text { A.2.3 CONECTORES } & 138\end{array}$

$\begin{array}{lll}\text { A.2.4 EXEMPLOS } & 139\end{array}$

A.3 CONSIDERAÇÕES FINAIS 141

B Experimento de anotação: Comentários 143

C Experimento de anotação: Dados dos participantes 146

C.1 User 01(A,0,5) 146

C.2 User 02(A,0,5) 146

$\begin{array}{lll}\text { C.3 User 03(B, } 0,5) & 147\end{array}$

$\begin{array}{ll}\text { C.4 User 04(B, } 0,5) & 148\end{array}$

C.5 User 05(A,0,10) 149

C.6 User 06(A,0,10) 149

C.7 User 07(B,0,10) 150

C.8 User 08(B,0,10) 151

C.9 User 09(A,2,5) 151

C.10 User 10(A,2,5) 152

C.11 User 11(B,2,5) 153

C.12 User 12(A,2,10) 154

C.13 User 13(A,2,10) 154

C.14 User 14(B,2,10) 155

C.15 User 15(A,4,5) 156

C.16 User 16(A,4,5) 156

C.17 User 17(B,4,5) 157

C.18 User 18(A,4,10) 158

C.19 User 19(A,4,10) 159

C.20 User 20(B,4,10) 160

D Experimento de anotação: Tabelas e gráficos 162

E Experimento de aprendizado automático: Tabelas e gráficos $\quad 179$ 


\section{Lista de figuras}

1.1 Exemplos de dificuldades para ferramentas computacionais convencionais para tratamento de textos, ao lidarem com tweets: (a) abreviações de palavras e referência geográfica (Linha Amarela) usando um identificador de uma conta do Twitter (@LinhaAmarelaRJ); (b) horários e hyperlinks; (c) abreviações especiais do domínio do Twitter, como "RT" para representar "retweet".

2.1 Classes da ontologia TEDO e object properties (datatype properties omitidas para legibilidade) (6)

2.2 Resultado, em grafo, do fluxo proposto em (6) [Conforme figura do mesmo artigo, com adição das tags das relações, uma vez que no trabalho haviam números que faziam referência a uma tabela não apresentada aqui.]

2.3 Resultado, em RDF, do fluxo proposto em (6) [Figura obtida no referido trabalho.]

2.4 Processo de extração de informações do sistema TwitlE [Figura retirada de (22)]

2.5 Tela do ambiente de anotação do BRAT para uma aplicação específica de extração de eventos biomédicos.

2.6 Interface do WebAnno para configuração de projetos e definição do conjunto de tags. [Figura retirada de (23)]

2.7 Interface do WebAnno para curadoria de dados. [Figura retirada de (23)]

2.8 Interface do WebAnno para monitoração dos projetos. [Figura retirada de (23)]

3.1 Fluxo geral de estruturação de dados

3.2 Fluxo de curadoria dos dados

3.3 Fluxo de aprendizado automático

3.4 Fluxo de implantação dos modelos

3.5 LER

3.6 Arquitetura do LER

3.7 Exemplo de escalonamento vertical do LER

3.8 Exemplo de escalonamento horizontal do LER

3.9 Exemplo de escalonamento horizontal do LER utilizando cluster

3.10 Tela inicial da plataforma

3.11 Resumo do modelo de dados do LER

3.12 Menu da plataforma por níveis de acesso: (a) Administrador; (b) Usuário; (c) Colaborador

3.13 Criação de projetos

3.14 Descrição de verbos em português no Freeling 4.0

3.15 Área de projetos

3.16 Anotações usuário A: (a) anotação do documento 01.txt seguido de sua re-anotação; (b) anotação do documento 02.txt seguido de sua re-anotação 
3.17 Anotações usuário B: (a) anotação do documento 01.txt seguido de sua re-anotação; (b) anotação do documento 02.txt seguido de sua re-anotação

3.18 Ontologia: Entidades

3.19 Ontologia: Relações

3.20 Área de gerência de dados

3.21 Criação de pacotes

3.22 Gerenciamento de colaboradores

3.24 Perspectivas do documento

3.25 Perspectiva de validação: (a) estado inicial do documento; (b) estado após expansão da sentença

3.26 Perspectiva de validação com concordância total: (a) estado inicial do documento; (b) estado após expansão da sentença

3.27 Perspectiva de ações do colaborador: (a) estado inicial do documento; (b) estado após desfazer algumas ações do colaborador

3.28 Formato exportado

3.29 Tela de anotação

3.31 Processo de anotação de entidade: (a) área desejada selecionada; (b) acionando menu de contexto para seleção de entidade; (c) estado final da anotação

3.32 Processo de anotação de entidade com múltiplas palavras: (a) área desejada selecionada; (b) acionando menu de contexto para seleção de entidade; (c) estado final da anotação

3.33 Processo de anotação de relação: (a) entidade origem selecionada; (b) entidade destino alcançada; (c) estado final da anotação $\quad 57$

3.34 Exemplo de tentativa de anotação de relação inválida

3.35 Exemplo de anotação de relação quando há múltiplas relações possíveis entre as entidades

3.36 Processo de anotação de conector: (a) área desejada selecionada; (b) acionando menu de contexto para seleção de ação Connect; (c) relação desejada alcançada; (d) estado final da anotação

3.37 Processo de remoção de anotação: (a) menu de contexto acionado no elemento desejado para executar ação Remove; (b) estado final da remoção

3.38 Processo de remoção de anotação em uma área: (a) menu de contexto acionado após selecionada a área desejada para executar ação Remove; (b) estado final da remoção

3.39 Adicionando comentários no documento 59

3.40 Estatísticas de status $\quad 59$

3.41 Estatísticas de cobertura dos tokens $\quad 60$

3.42 Estatísticas de distribuição dos tokens nos documentos 60

3.43 Estatísticas de entidades por colaborador, também disponíveis para relações e conectores.

3.44 Estatísticas de distribuição das entidades no GSA, também disponíveis para relações e conectores. 
3.46 Tabela de ocorrências das palavras no GSA 62

3.47 Curva de frequência acumulada das palavras no GSA 62

3.48 Definição de entidades para cálculo de concordância: (a) anotação do usuário; (b) perspectiva criada para cálculo de concordância

3.49 Definição de relações para cálculo de concordância: (a) anotação do usuário; (b) perspectiva criada para cálculo de concordância

3.50 Definição de conectores para cálculo de concordância: (a) anotação do usuário; (b) perspectiva criada para cálculo de concordância

3.51 Tabela de classificação dos usuários A e B para os exemplos dados no capítulo

3.52 Mapa de concordância para o exemplo dado no capítulo: (a) entidades, relações e conectores; (b) apenas entidades; (c) apenas relações; (d) apenas conectores

3.53 Curva de concordância com o GSA ao longo do tempo 67

3.54 Curva de auto-concordância ao longo do tempo 67

3.55 Estatísticas básicas sobre colaboradores e documentos 68

3.56 Configurações gerais das tarefas 68

3.57 Configurações dos dados das tarefas $\quad 69$

3.58 Engenharia de atributos da tarefas $\quad 71$

3.59 Atributos disponíveis: (a) NER; (b) RE $\quad 71$

3.60 Exemplo de atributos para a tarefa de NER: (a) documento de entrada; (b) exemplo de uma matriz criada utilizando o documento de entrada

3.61 Exemplo de atributos para a tarefa de RE: (a) documento de entrada; (b) perspectiva do documento de entrada criada para geração da matriz de atributos; (c) exemplo simplificado de uma matriz criada utilizando o documento de entrada; (d) exemplo de uma matriz criada utilizando o documento de entrada

3.62 Configurações dos classificadores

3.63 Execução de tarefas: (a) estado inicial da tarefa; (b) tarefa em execução; (c) tarefas executando em paralelo

3.64 Log de execução da tarefa

3.65 Resultados da tarefa

3.66 Scores do modelo treinado 76

$\begin{array}{ll}3.67 \text { Criação do serviço } & 78\end{array}$

3.68 Serviços disponíveis $\quad 78$

$\begin{array}{ll}3.69 \text { Teste do serviço } & 79\end{array}$

$\begin{array}{ll}3.70 \text { Teste externo do serviço } & 79\end{array}$

4.1 Visões da ontologia usada na anotação dos dados: (a) entidades; (b) relações

4.2 Visões da ontologia usada na anotação dos dados para o experimento de aprendizado automático: (a) entidades; (b) relações

4.3 Estatísticas de tokens nos dados utilizados no experimento: (a) Cobertura dos tokens; (b) Histograma de distribuição de documentos por quantidade de tokens

4.4 Estatísticas de entidades nos dados utilizados no experimento: (a) Distribuição de entidades nos dados; (b) Histograma de distribuição de documentos por quantidade de entidades 
4.5 Estatísticas de relações nos dados utilizados no experimento: (a) Distribuição de relações nos dados; (b) Histograma de distribuição de documentos por quantidade de relações

4.6 Estatísticas de conectores nos dados utilizados no experimento: (a) Distribuição de conectores nos dados; (b) Histograma de distribuição de documentos por quantidade de conectores

4.7 Estatísticas de auto-concordância ano longo do tempo nos dados utilizados no experimento: (a) auto-concordância com entidades, relações e conectores; (b) auto-concordância com entidades; (c) auto-concordância com relações; (d) auto-concordância com conectores

4.8 Nuvem de palavras associadas às entidades nos dados utilizados no experimento

4.9 Curva de frequência acumulada de palavras associadas às entidades:

(a) todas entidades; (b) excluindo a entidade com mais ocorrências, neste caso Location

4.10 Nuvem de palavras associadas aos conectores nos dados utilizados no experimento

4.11 Curva de frequência acumulada de palavras associadas aos conectores: (a) todos conectores; (b) excluindo conector com mais ocorrências, neste caso hasEvent

4.12 Generalização e remoções usadas para redução das classes

4.13 Teste com resposta razoável: (a) tweet original; (b) anotação predita; (c) anotação esperada

4.14 Teste com resposta razoável: triplas RDF retornadas

4.15 Teste com boa resposta: (a) tweet original; (b) anotação predita; (c) anotação esperada

4.16 Teste com boa resposta: triplas RDF retornadas

4.17 Teste com resposta perfeita: (a) tweet original; (b) anotação predita; (c) anotação esperada

4.18 Teste com resposta perfeita: triplas RDF retornadas

A.1 Ferramenta de anotação

A.2 Resumo da ontologia de anotação 119

$\begin{array}{ll}\text { A.3 Adicionando comentários } & 119\end{array}$

$\begin{array}{lll}\text { A.4 Rotulação, passo } 1 & 120\end{array}$

$\begin{array}{lll}\text { A.5 Rotulação, passo 2 } & 121\end{array}$

A.6 Rotulação, resultado final 121

A.7 Relacionamento entre os rótulos (relação inválida) 122

A.8 Relação inválida de \#Car para \#Accident, porém válida de \#Accident para \#Car

A.9 Relacionamento entre os rótulos (relação válida) 122

A.10 Relacionamento entre os rótulos, resultado final 122

A.11 Relações entre sentenças $\quad 123$

A.12 Criação de conectores, passo $1 \quad 123$

A.13 Criação de conectores, passo 2

A.14 Criação de conectores, passo $3 \quad 124$

A.15 Criação de conectores, resultado final 124

A.16 Remoção de rótulos, relações e conectores 125 
A.17 Remoção por área de de rótulos, relações e conectores, passo $1 \quad 125$

A.18 Remoção por área de de rótulos, relações e conectores, passo $2 \quad 126$

A.19 Remoção por área de de rótulos, relações e conectores, resultado final

A.20 Hierarquia de classes da ontologia de eventos de trânsito 128

A.21 Exemplo de rotulação, Actor 128

A.22 Exemplo de rotulação, Car e Motorcycle $\quad 129$

A.23 Exemplo de rotulação, Interdiction e Event 129

A.24 Exemplo de rotulação, Protest e Interdiction 129

A.25 Exemplo de rotulação, RoadWork 130

A.26 Exemplo de rotulação, WeatherEvent 130

A.27 Exemplo de rotulação, Solution e Accident 130

A.28 Exemplo de rotulação, Breakdown 130

A.29 GoodTrafficSituation 130

A.30 HeavyTrafficSituation $\quad 131$

A.31 SlowTrafficSituation 131

A.32 Exemplo 1 de rotulação, Location 131

A.33 Exemplo 2 de rotulação, Location 131

A.34 Exemplo 1 de rotulação, Time 132

A.35 Exemplo 2 de rotulação, Time 132

$\begin{array}{ll}\text { A.36 Tipos primitivos } & 132\end{array}$

A.37 wayEffect:BothDirections 133

A.38 wayEffect:OneDirection $\quad 133$

A.39 wayEffect:Partially 133

A.40 xsd:unsignedlnt 133

$\begin{array}{ll}\text { A.41 xsd:string } & 134\end{array}$

$\begin{array}{ll}\text { A.42 causes } & 135\end{array}$

$\begin{array}{ll}\text { A.43 flowsTo } & 135\end{array}$

A.44 hasActor $\quad 135$

$\begin{array}{ll}\text { A.45 hasEvent } & 136\end{array}$

$\begin{array}{ll}\text { A.46 hasSupporter } & 136\end{array}$

$\begin{array}{ll}\text { A.47 hasTime } & 136\end{array}$

$\begin{array}{ll}\text { A.48 isAlternativeFor } & 137\end{array}$

A.49 isEdgeFor $\quad 137$

$\begin{array}{ll}\text { A.50 isReferenceFor } & 137\end{array}$

$\begin{array}{ll}\text { A.51 isRestrictedTo } & 137\end{array}$

$\begin{array}{ll}\text { A.52 hasNumericQuantity } & 138\end{array}$

$\begin{array}{ll}\text { A.53 hasStringQuantity } & 138\end{array}$

A.54 hasWayEffect 138

A.55 conectores 139

A.56 exemplo $1 \quad 139$

$\begin{array}{ll}\text { A.57 exemplo } 2 & 139\end{array}$

A.58 exemplo $3 \quad 140$

A.59 exemplo $4 \quad 140$

A.60 exemplo $5 \quad 140$

A.61 exemplo $6 \quad 140$

A.62 exemplo $7 \quad 141$

A.63 exemplo $8 \quad 141$ 
A.64 Tweet de evento ferroviário 142

A.65 Tweet de evento climático 142

A.66 Tweet de informação geral 142

A.67 Tweet fora de contexto 142

D.1 Experimento de anotação, tokens 163

D.2 Experimento de anotação, entidades 163

D.3 Experimento de anotação: relações 164

D.4 Experimento de anotação, conectores 164

D.5 Experimento de anotação, concordância com entidades, relações e conectores

D.6 Experimento de anotação, concordância com entidades 165

D.7 Experimento de anotação, concordância com relações 166

D.8 Experimento de anotação, concordância com conectores 166

D.9 Experimento de anotação, concordância com GSA ao longo do tempo do grupo $(0,5)$ : (a) entidades, relações e conectores; (b) entidades; (c) relações; (d) conectores

D.10 Experimento de anotação, auto-concordância ao longo do tempo do grupo $(0,5)$ : (a) entidades, relações e conectores; (b) entidades; (c) relações; (d) conectores

D.11 Experimento de anotação, concordância com GSA ao longo do tempo do grupo $(0,10)$ : (a) entidades, relações e conectores; (b) entidades; (c) relações; (d) conectores

D.12 Experimento de anotação, auto-concordância ao longo do tempo do grupo $(0,10)$ : (a) entidades, relações e conectores; (b) entidades; (c) relações; (d) conectores

D.13 Experimento de anotação, concordância com GSA ao longo do tempo do grupo $(2,5)$ : (a) entidades, relações e conectores; (b) entidades; (c) relações; (d) conectores

D.14 Experimento de anotação, auto-concordância ao longo do tempo do grupo (2,5): (a) entidades, relações e conectores; (b) entidades; (c) relações; (d) conectores

D.15 Experimento de anotação, concordância com GSA ao longo do tempo do grupo $(2,10)$ : (a) entidades, relações e conectores; (b) entidades; (c) relações; (d) conectores

D.16 Experimento de anotação, auto-concordância ao longo do tempo do grupo $(2,10)$ : (a) entidades, relações e conectores; (b) entidades; (c) relações; (d) conectores

D.17 Experimento de anotação, concordância com GSA ao longo do tempo do grupo $(4,5)$ : (a) entidades, relações e conectores; (b) entidades; (c) relações; (d) conectores

D.18 Experimento de anotação, auto-concordância ao longo do tempo do grupo $(4,5)$ : (a) entidades, relações e conectores; (b) entidades; (c) relações; (d) conectores

D.19 Experimento de anotação, concordância com GSA ao longo do tempo do grupo $(4,10)$ : (a) entidades, relações e conectores; (b) entidades; (c) relações; (d) conectores 
D.20 Experimento de anotação, auto-concordância ao longo do tempo do grupo $(4,10)$ : (a) entidades, relações e conectores; (b) entidades; (c) relações; (d) conectores 


\section{Lista de tabelas}

3.1 Concordâncias observadas e esperadas ao acaso no exemplo dado 65

4.1 Concordância com entidades, relações e conectores nos grupos 83

4.2 Concordância com entidades nos grupos 83

4.3 Concordância com relações nos grupos 83

4.4 Concordância com conectores nos grupos 83

4.5 Concordância com entidades, relações e conectores nos tipos de anotador 84

4.6 Concordância com entidades nos tipos de anotador 84

4.7 Concordância com relações nos tipos de anotador 84

4.8 Concordância com conectores nos tipos de anotador 84

4.9 Estatísticas de tempo do conjunto de dados usado no experimento de aprendizado automático $\quad 86$

$\begin{array}{ll}4.10 \text { Resultado NER passo } 5 & 97\end{array}$

4.11 Gridsearch no NER para o SVC no passo $5 \quad 97$

4.12 Resultado NER passo $6 \quad 98$

4.13 Gridsearch no NER para o Random Forest no passo $8 \quad 98$

4.14 Gridsearch no NER para o Stochastic Gradient Descent no passo 898

4.15 Gridsearch no NER para o SVC no passo $8 \quad 99$

$\begin{array}{ll}\text { 4.16 Resultado NER passo } 8 & 99\end{array}$

4.17 Resultado final detalhado: Random Forest (validação) 99

4.18 Resultado final detalhado: Random Forest (teste) 100

4.19 Resultado NER final 101

4.20 Resultado final detalhado: Random Forest (validação com redução de classes) 102

4.21 Resultado final detalhado: Random Forest (teste com redução de classes) 102

4.22 Resultado RE passo 5 103

4.23 Gridsearch no RE para o Frank Wolfe SSVM no passo 8

4.24 Gridsearch no RE para o Structured Perceptron no passo 8

4.25 Resultado RE passo $8 \quad 103$

4.26 Resultado final detalhado: Frank Wolfe SSVM (validação) 103

4.27 Resultado final detalhado: Frank Wolfe SSVM (teste) 104

4.28 Resultado RE final 104

4.29 Resultado final detalhado: Frank Wolfe SSVM (validação com redução de classes) 104

4.30 Resultado final detalhado: Frank Wolfe SSVM (teste com redução $\begin{array}{ll}\text { de classes) } & 105\end{array}$

C.1 Resumo das respostas dos participantes ao questionário do experimento de anotação 161

D.1 Resumo colaborações 162

E.1 Training scores: model-fscore-TEDO-NER-RF-0 179 
E.2 Revalidation scores: model-fscore-TEDO-NER-RF-0 180

E.3 Training scores: model-fscore-TEDO-NER-SGD-0 180

E.4 Revalidation scores: model-fscore-TEDO-NER-SGD-0 181

E.5 Training scores: model-fscore-TEDO-NER-SVC-0 181

E.6 Revalidation scores: model-fscore-TEDO-NER-SVC-0 182

E.7 Training scores: model-fscore-TEDO-NER-RF-1 182

E.8 Revalidation scores: model-fscore-TEDO-NER-RF-1 183

E.9 Training scores: model-fscore-TEDO-NER-SGD-1 183

E.10 Revalidation scores: model-fscore-TEDO-NER-SGD-1 184

E.11 Best parameters: model-fscore-TEDO-NER-SVC-1 184

E.12 Training scores: model-fscore-TEDO-NER-SVC-1 185

E.13 Revalidation scores: model-fscore-TEDO-NER-SVC-1 185

E.14 Best parameters: model-fscore-TEDO-NER-RF-2 186

E.15 Training scores: model-fscore-TEDO-NER-RF-2 186

E.16 Revalidation scores: model-fscore-TEDO-NER-RF-2 187

E.17 Best parameters: model-fscore-TEDO-NER-SGD-2 187

E.18 Training scores: model-fscore-TEDO-NER-SGD-2 188

E.19 Revalidation scores: model-fscore-TEDO-NER-SGD-2 188

E.20 Best parameters: model-fscore-TEDO-NER-SVC-2 189

E.21 Training scores: model-fscore-TEDO-NER-SVC-2 189

E.22 Revalidation scores: model-fscore-TEDO-NER-SVC-2 190

E.23 Training scores: model-fscore-TEDO-NER-RF-FINAL 190

E.24 Test scores: model-fscore-TEDO-NER-RF-FINAL 191

E.25 Training scores: model-fscore-TEDO-NER-RF-FINAL-AGRUPADO 191

E.26 Test scores: model-fscore-TEDO-NER-RF-FINAL-AGRUPADO 192

E.27 Training scores: model-fscore-TEDO-RE-SP-0 192

E.28 Revalidation scores: model-fscore-TEDO-RE-SP-0 192

E.29 Training scores: model-fscore-TEDO-RE-FWSSVM-0 193

E.30 Revalidation scores: model-fscore-TEDO-RE-FWSSVM-0 193

E.31 Best parameters: model-fscore-TEDO-RE-SP-1 193

E.32 Training scores: model-fscore-TEDO-RE-SP-1 193

E.33 Revalidation scores: model-fscore-TEDO-RE-SP-1 194

E.34 Best parameters: model-fscore-TEDO-RE-FWSSVM-1 194

E.35 Training scores: model-fscore-TEDO-RE-FWSSVM-1 194

E.36 Revalidation scores: model-fscore-TEDO-RE-FWSSVM-1 194

E.37 Training scores: model-fscore-TEDO-RE-FWSSVM-FINAL 195

E.38 Test scores: model-fscore-TEDO-RE-FWSSVM-FINAL 195

E.39 Training scores: model-fscore-TEDO-RE-FWSSVM-FINALAGRUPADO 195

E.40 Test scores: model-fscore-TEDO-RE-FWSSVM-FINAL-AGRUPADO 196 


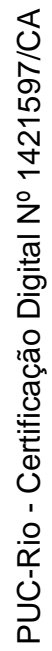

Call me Ishmael.

Herman Melville, Moby-Dick; or, The Whale. 


\section{1 \\ Introdução}

Um trabalho de 2014 (1) indicou o potencial de retorno econômico de técnicas de mineração de dados em geral. Estimou-se, por exemplo, que um melhor aproveitamento de dados com as técnicas apropriadas de mineração textual e não-textual permitiria ao sistema de saúde americano a criação de mais de US\$ 300 bilhões em valor anualmente. Igualmente, o uso eficiente de informações dos dados para melhorar operações e detectar fraudes poderia gerar para a administração do setor público europeu até US\$250 bilhões de valor potencial anual.

O volume de dados não-estruturados disponíveis em formato digital tem crescido de modo intenso nas últimas décadas. Empresas de diversas áreas percebem, cada vez mais claramente, o potencial econômico do uso inteligente dos dados de grandes repositórios, sobretudo de redes sociais (2). Algumas companhias têm usado ferramentas de mídia social como Facebook e Twitter para prover serviços e interagir com clientes, tendo como resultado uma enorme quantidade de conteúdo gerado por usuários disponível sem custos (3).

Há, portanto, um grande universo de dados não-estruturados, com elevado valor, passíveis de aquisição com custos relativamente baixos. O problema dos dados textuais, típicos de redes sociais e microblogs em geral, reside em sua intratabilidade computacional em seus formatos originais. Há diferenças de dificuldades mesmo entre as fontes. O Twitter, por exemplo, limitado a 140 caracteres, representa um grande desafio para as tecnologias convencionais de mineração de dados textuais em razão de conter linguagem informal, emoticons, hashtags e outras formas diferenciadas de escrita e expressão (4). A figura 1.1 ilustra essa realidade em tweets em português relacionados a questões de trânsito. 
Centro de Operações @ @operacoesRio · $18 \mathrm{~h}$

ATENÇÃO! Interdições p/ obras na @LinhaAmarelaRJ até 30 de abril. Saiba mais: bit.ly/2n7Y1KB

(a)

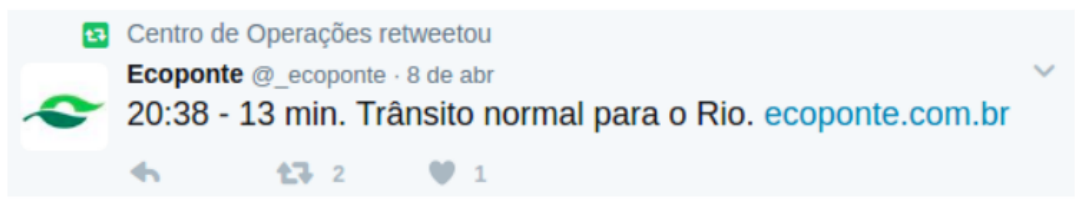

(b)

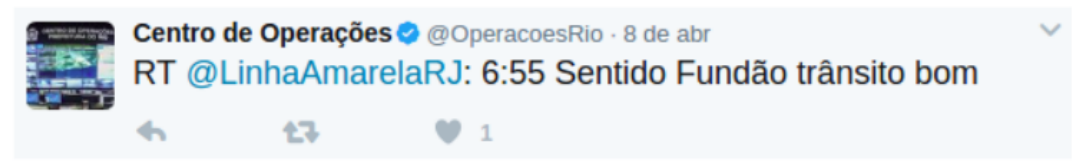

(c)

Figura 1.1: Exemplos de dificuldades para ferramentas computacionais convencionais para tratamento de textos, ao lidarem com tweets: (a) abreviações de palavras e referência geográfica (Linha Amarela) usando um identificador de uma conta do Twitter (@LinhaAmarelaRJ); (b) horários e hyperlinks; (c) abreviações especiais do domínio do Twitter, como "RT" para representar "retweet".

Diversas técnicas de Text Analytics (TA) foram desenvolvidas e demonstraram capacidade de extrair informações (2). Uma delas faz uso de ontologias de domínio como estrutura para a interpretação computacional de dados textuais, o que despertou um interesse diferenciado em razão da união entre dois grandes campos de pesquisa: ontologias e processamento de linguagem natural (NLP). Essa união tende a gerar bons resultados, como demonstrado por resultados de algumas pesquisas (5), (6).

Entretanto, os bons resultados gerados nestes trabalhos requerem uma série de atividades que geralmente são feitas de modo isolado, o que se torna uma dificuldade, tendo em vista o esforço e tempo a serem investidos. É um forte exemplo a etapa de anotação dos textos para geração dos conjuntos de dados de treinamento e teste: existem ferramentas de anotação disponíveis, grátis e até mesmo em código aberto, apresentando vantagens e desvantagens. Uma desvantagem comum é a falta de suporte ao uso de ontologias como geradores de tags, muito menos que levem em conta as propriedades (object properties e datatype properties) descritas nos arquivos de ontologias. Algumas ferramentas se mostram pouco atrativas no que tange à usabilidade, requerendo muitos e complicados passos para anotação, o que induz a erros. Além disso, a maioria das ferramentas de anotação não está integrada, em um mesmo ambiente, às ferramentas de modelagem e aprendizado de máquina. Não se tem um sistema geral que integre as etapas de coleta e armazenamento de dados; caracterização do texto; anotação colaborativa com base em ontologias; treinamento, teste e persistência de modelos e disponibilização final destas 
etapas como serviços automáticos de estruturação de dados textuais em ambiente de nuvem.

Assim, a contribuição deste trabalho é a criação deste sistema integrado no formato web, acessível via browser, com uma interface de anotação de uso mais simples, mantendo as principais vantagens dos mais conhecidos sistemas de anotação, integração com um conjunto de algoritmos de aprendizado de máquina e, como produto final, a hospedagem das etapas desenvolvidas como serviços de geração dados no formato RDF para os mais diversos domínios. Este sistema tem uma forma totalmente modular, no formato de serviços, o que permitirá a conexão, no futuro, de outras tarefas além de NER e RE.

Além do desenvolvimento do sistema, são implementadas alternativas para melhoria dos resultados já alcançados em trabalhos semelhantes (5), (7) pelo uso de outras estratégias de criação de features relacionadas às funções morfossintáticas das palavras e pela avaliação do sistema como um todo em um problema já tratado anteriormente (5), (6) com alguma melhoria na ontologia de eventos usada.

Os próximos capítulos deste trabalho tratarão da revisão bibliográfica (capítulo 2), da descrição da plataforma construída (capítulo 3), dos experimentos conduzidos para avaliação do processo de anotação e aprendizado automático (capítulo 4) e por fim das conclusões e sugestões para trabalhos futuros (capítulo 5). 
Ignorance is the parent of fear.

Herman Melville, Moby-Dick; or, The Whale. 


\section{Revisão bibliográfica}

Este capítulo apresenta a revisão bibliográfica dos trabalhos mais relevantes sobre mineração de textos (seção 2.1) e anotação de dados textuais (seção 2.2)

\section{1}

\section{Mineração de textos e processamento de linguagem natural}

Ittoo e colegas (2) discutem acerca dos principais desafios e tendências no campo de TA, termo usado para a união dos conceitos de Text Mining e NLP. São apresentados os resultados recentes mais importantes nas pesquisas acadêmicas em TA sob diversos aspectos. Uma das aplicações que merecem destaque, segundo os autores, é a descrita em (6), onde é proposta uma metodologia para a interpretação de tweets relacionados a eventos de trânsito na cidade do Rio de Janeiro. O artigo propõe e usa uma ontologia de eventos de trânsito denominada TEDO ( Traffic Event Domain Ontology) para modelar as situações de trânsito como eventos, compostos por atores, locais e horários. A TEDO se baseia nas noções de evento (8) e relações entre eventos (9), (10). A figura 2.1 mostra o esquema resumido desta ontologia.

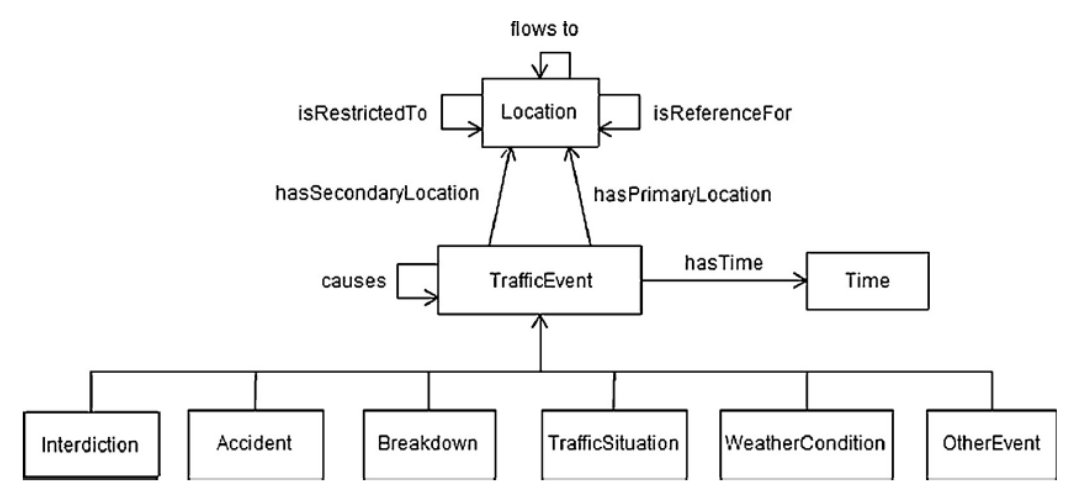

Figura 2.1: Classes da ontologia TEDO e object properties (datatype properties omitidas para legibilidade) (6)

A interpretação dos tweets envolve um conjunto de operações em série: (1) Tokenização dos tweets e etiquetagem morfossintática (Part-of-speech tagging); (2) Reconhecimento de entidades (Named Entity Recognition NER); (3) Geolocalização; (4) Extração de relações entre entidades (Relation Extraction RE); (5) Geração de triplas RDF (Resource Description Framework).

A etapa de tokenização e POS tagging gera atributos para o aprendizado de máquina que expressam as funções sintáticas dos tokens nas sentenças 
analisadas, usando para isso um algoritmo proprietário (formato Web service) chamado F-EXT (11). As informações dos tokens geradas por este algoritmo e usadas na construção de atributos no referido artigo são:

- Token $\left(\mathrm{W}_{i}\right)$ : o conteúdo do token $\mathrm{X}_{i}$;

- Simple Token $\left(\mathrm{SMW}_{i}\right)$ : o conteúdo simplificado do token $\mathrm{X}_{i}$ (em caixa baixa, sem quaisquer caracteres especiais ou pontuações);

- Simplified Token $\left(\mathrm{SW}_{i}\right)$ : o conteúdo simplificado do token $\mathrm{X}_{i}$ (em caixa baixa, sem quaisquer caracteres especiais, também removendo letras, pontuação e números de tamanho 1);

- Part-of-speech $\left(\mathrm{POS}_{i}\right)$ : a etiqueta morfossintática do token $\mathrm{X}_{i}$;

- Stemmed Word $\left(\mathrm{STW}_{i}\right)$ : a raiz da palavra presente no token $\mathrm{X}_{i}$. Exemplo: se $\mathrm{X}_{i}$ é blocked, $\mathrm{STW}_{i}$ é block.

Outros atributos foram construídos (feature engineering) e, unidos ao POS tagging, fornecem informações úteis à aplicação de algoritmos de aprendizado de máquina. A primeira etapa de aprendizado é a de NER, onde as entidades descritas na TEDO são usadas como classes em uma tarefa de classificação. Os atributos construídos para esta tarefa são:

- CurrT (X): o token da posição atual, X;

- PrevT (X, N): o token N posições antes do token X;

- NextT (X, N): o token N posições depois do token X;

- CurrWSC (X): indica se X começa em letra maiúscula e se há apenas uma letra maiúscula em todo o token;

- LocType $(\mathrm{X})$ : indica se a representação de X em letras minúsculas pertence a um determinado conjunto de palavras que designam localidades. Exemplos: "avenida", "av.", "rua", "estrada".

O classificador usado nesta tarefa é uma implementação SMO ( Sequential Minimal Optimization) (12) da família de métodos SVM (Support Vector Machine) do pacote Weka 3.6.5 (13). Uma das conclusões do trabalho é a de que o método SVM apresenta os melhores resultados para NER, frente a outros algoritmos testados.

Cita-se também uma etapa de geolocalização determina as coordenadas das entidades nomeadas identificadas, usando para isso o algoritmo SmartGeocode (7). Em seguida, as relações entre entidades são extraídas pela etapa de $\mathrm{RE}$, que cria uma árvore de dependências $\mathrm{G}_{T}$ a partir de um tweet $\mathrm{T}$ com entidades nomeadas. Para a extração de $\mathrm{G}_{T}$, são computados atributos dos pares de elementos textuais $\mathrm{K}$ e L, que são usados por um algoritmo para o aprendizado da natureza das (possíveis) relações entre K e L. A implementação de RE do referido trabalho usa um perceptron estruturado de margem larga (14) que estabelece um peso para cada aresta de um grafo dirigido completo (todas as relações entre todos os nós e em todas as direções). Em seguida, um algoritmo de Maximum Spanning Tree define, no grafo completo, a árvore final com as relações mais importantes.

Os atributos de nó usados no trabalho são: 
- Word (W): indica as palavras do nó K;

- Simplified Word(SW): as palavras simplificadas do nó K;

- Ruler Entity (RE): a entidade nomeada em K, em se tratando de entidade relevante. Se não relevante, usa-se a função morfossintática, POS;

- Named Entity (NE): a entidade nomeada em K, ignorada se não for uma entidade relevante;

- Punctuation (PUNCT): indica se há uma pontuação no texto em K.

Com estes atributos de nó, são construídos os atributos das relações, que são:

- PossRel: indica se os nós K e L podem ter uma relação;

- ConcT (Y): as palavras concatenadas dos nós K e L;

- $\operatorname{BetT}(\mathrm{Y})$ : a concatenação de todos os tokens entre K e L;

- Near $(\mathrm{Y}, \mathrm{N})$ : a concatenação de todos os $\mathrm{N}$ tokens antes de $\mathrm{K}$ e N tokens depois de L;

- AbsLocPair: indica se K e L têm uma relação, onde a entidade em K é $<$ restriction $>$ e em L é <location-name>. Se não há relação, nenhum valor é usado;

- MetaWithLoc: indica se K e L têm uma relação, onde a entidade em K é $<$ reference $>$ ou $<$ direction $>$ e em L é $<$ location-name $>$. Se não há relação, nenhum valor é usado.

Ao fim desse processo, a informação de entidades e relações é traduzida como triplas RDF e, dessa forma, o tweet em texto livre ganha uma estrutura semântica baseada na ontologia.

Como exemplo, apresenta-se um tweet em sua versão original e os resultados, respectivamente nas figuras 2.2 e 2.3 , do fluxo discutido acima em formato de grafo e em RDF:

Tweet: Acidente entre 2 carros na Av das Américas na pista sentido Grota Funda próximo ao número 19880 


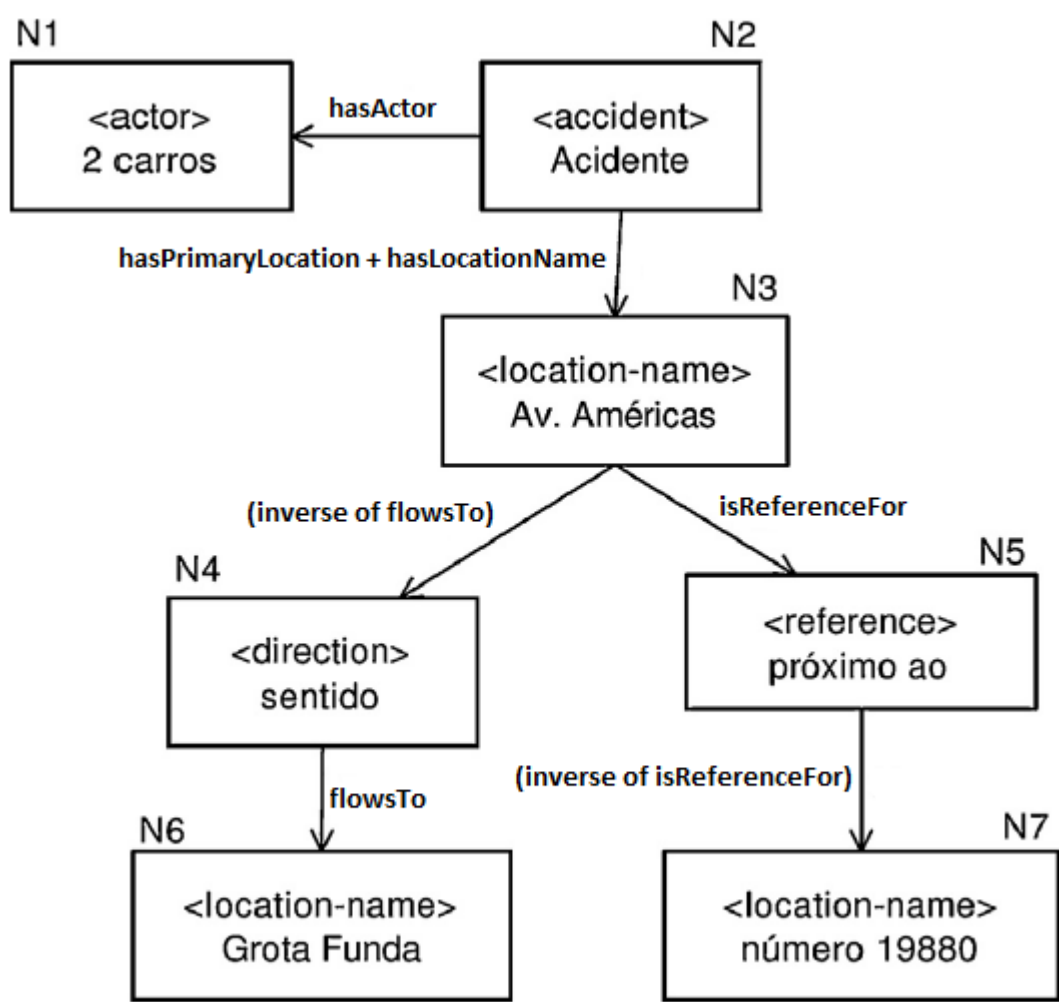

Figura 2.2: Resultado, em grafo, do fluxo proposto em (6) [Conforme figura do mesmo artigo, com adição das tags das relações, uma vez que no trabalho haviam números que faziam referência a uma tabela não apresentada aqui.] 


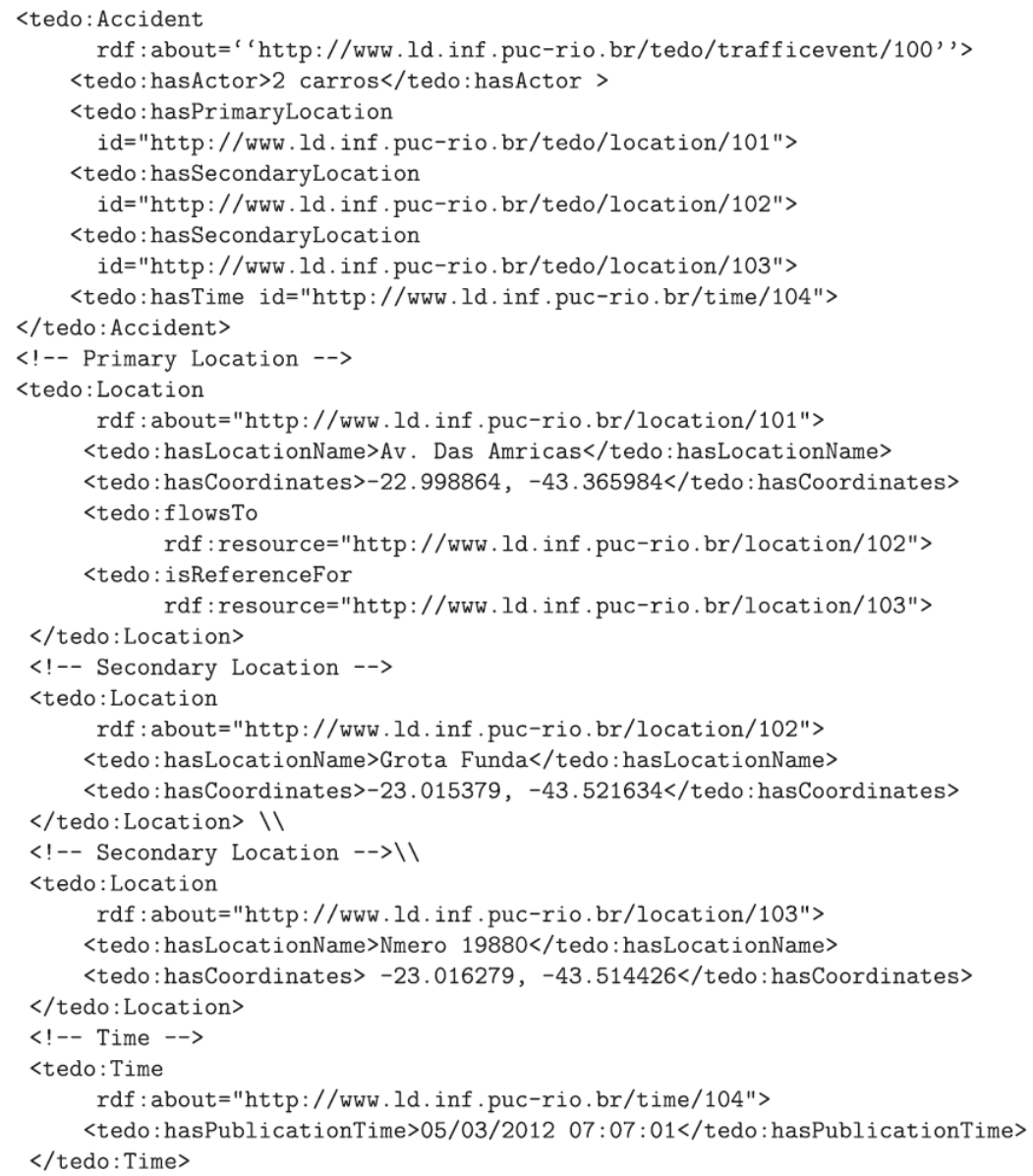

Figura 2.3: Resultado, em RDF, do fluxo proposto em (6) [Figura obtida no referido trabalho.]

\section{2}

\section{Anotação de dados textuais}

Sistemas de NLP se baseiam em técnicas de aprendizado supervisionado, que para bons resultados dependem de uma grande quantidade de dados anotados manualmente por especialistas do domínio a ser modelado. Em alguns casos, a falta de dados anotados para treino é um obstáculo ao desenvolvimento de ferramentas de NLP baseadas em aprendizado de máquina. O processo de anotação é altamente custoso em termos financeiros e de tempo. Contudo, a falta de dados anotados manualmente submetem os sistemas de NLP ao que se denomina "gargalo de aquisição de conhecimento" (15). Em anos recentes, um dos principais caminhos adotados para facilitar a aquisição destes dados é o uso de técnicas de crowdsourcing via web, isto é, pelo uso de anotadores não especializados recrutados na internet. A título de exemplo, em trabalho recente na Indonésia (16), propõe-se uma inovadora ferramenta móvel para a anotação colaborativa, avaliando-a em um experimento envolvendo 15 estudantes indonésios, que anotaram 1500 dados textuais através de seus smartphones. 
Hovy e Lavid (17) discutem sobre o fato da qualidade dos modelos treinados estar diretamente ligada à qualidade dos dados utilizados. Descrevem ainda a necessidade de haver no mínimo dois anotadores atuando sobre um mesmo documento, para que ao cabo da anotação, a concordância entre eles seja calculada, e sendo esta insatisfatória, há indícios de problemas na definição da tarefa, ou até mesmo, indique o fato de que a tarefa em questão seja muito difícil. Segundo os autores, as etapas que devem ser seguidas em um processo de anotação são:

1. Identificar e preparar uma seleção dos textos representativos como material de partida para o "corpus de treinamento";

2. Instanciar uma determinada teoria linguística ou conceito linguístico, especificar o conjunto de tags a usar, suas condições de aplicabilidade, etc. Esta etapa inclui o início da criação do guia de anotação;

3. Anotar parte do corpus de treinamento, a fim de determinar a viabilidade tanto da instanciação quanto do guia de anotação;

4. Medir os resultados (comparar as decisões dos anotadores) e decidir quais as medidas apropriadas, e como devem ser aplicadas;

5. Determinar que nível de concordância deve ser considerado satisfatório (baixa concordância significa pouca consistência na anotação para permitir que os algoritmos de aprendizado de máquina sejam treinados com sucesso). Se a concordância não é (ainda) satisfatória, o processo se repete a partir do passo 2, com as mudanças apropriadas à teoria, sua instanciação, o guia e as instruções do anotador. Caso contrário, o processo continua para o passo 6 .

6. Anotar uma grande parte do corpus, possivelmente ao longo de vários meses ou anos, com muitas verificações intermediárias, melhorias, etc.

7. Quando um material suficiente for anotado, treinar um modelo de aprendizado automático em parte do corpus, e posteriormente medir o desempenho do modelo na parte restante dos dados;

8. Se o desempenho do modelo for satisfatório, este pode ser utilizado para anotação automática de documentos de mesma natureza dos utilizados no treino. Se o desempenho não for satisfatório, o processo se repete, possivelmente a partir do passo 2 , ou a partir do passo 6 , se forem necessários mais dados de treinamento.

Para a execução do processo a pouco descrito, se faz necessário o uso de uma ferramenta de anotação. Há diversas ferramentas disponíveis, algumas de uso grátis. Uma das mais conhecidas e usadas, a GATE Teamware, faz parte de um programa de pesquisa de mais de 20 anos e é um dos muitos componentes da GATE (18), uma arquitetura geral para engenharia de textos (19), (20). Após anos de desenvolvimento e contribuições de pesquisadores e usuários de diversas áreas, a GATE se tornou um grande ecossistema, cobrindo de forma diferenciada todo o ciclo de vida de desenvolvimento de sistemas 
de análises de textos. Essa família de ferramentas tem crescido ao longo dos anos e hoje compreende uma aplicação desktop para desenvolvedores, uma aplicação web baseada em trabalho colaborativo, bibliotecas em Java, uma arquitetura e um processo bem definidos. A GATE Teamware pode ser baixada e instalada como um serviço para gestão de todo o projeto de anotação, desde o cadastro dos anotadores, passando por todo o processo de monitoração dos comportamentos dos anotadores e gerando um conjunto final de dados anotados, corrigidos e selecionados por um curador. Essa ferramenta parece ter um foco maior em integrar componentes para anotação automática e menor em prover interfaces para anotação manual. Também se trata de uma ferramenta complexa para usuários não especializados, requerendo um considerável tempo de treinamento, o que de certa forma limita a ideia de crowdsourcing para a anotação. Outro ponto importante a se destacar é que esse sistema permite o uso de ontologias para a anotação de entidades, mas não das relações entre elas, o que é fundamental para o caso tratado em (6). Mesmo com essas limitações da aplicação de anotação, a família GATE como um todo fornece muitas ferramentas e bibliotecas úteis para trabalhos futuros neste tema. Um exemplo interessante e no contexto de (6) é o do sistema TwitIE (22), dedicado ao clássico reconhecimento de entidades nomeadas (NER) e à extração de informações (IE) justamente em tweets, que pelo uso de módulos da GATE implementa um processo semelhante ao dos tweets de trânsito (ver figura 2.4). Cabe ressaltar que essa aplicação não se baseia em ontologias de domínio, como no caso do TEDO, mas busca por entidades nomeadas em geral em um ambiente reconhecidamente difícil e ruidoso, como são os microblogs em geral. 


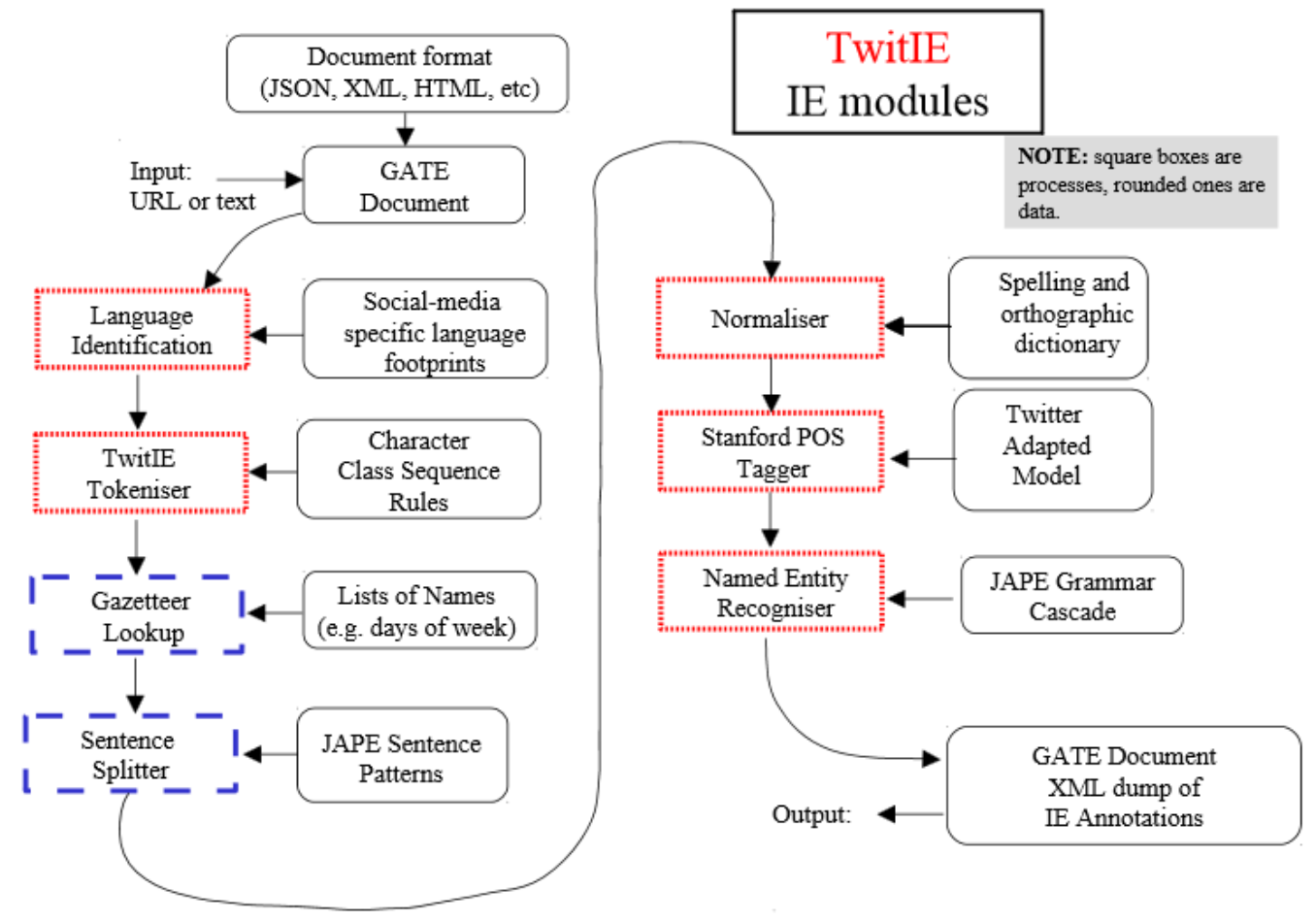

Figura 2.4: Processo de extração de informações do sistema TwitIE [Figura retirada de (22)]

Outra ferramenta de anotação é a BRAT (Brat Rapid Annotation Tool) (21), que foi a primeira ferramenta em código aberto para anotação totalmente baseada em web e suportando anotações colaborativas de múltiplas camadas simultaneamente em uma única cópia de documento. Ela apresenta algumas limitações, como a lentidão para processamento de documentos com mais de 100 sentenças, poucos formatos de arquivo suportados e, principalmente, impossibilidade de carregamento direto de um arquivo de ontologia para uso na identificação de entidades e relações. A figura 2.5 mostra um exemplo da tela do ambiente de anotação do BRAT para uma aplicação específica de extração de eventos biomédicos. 


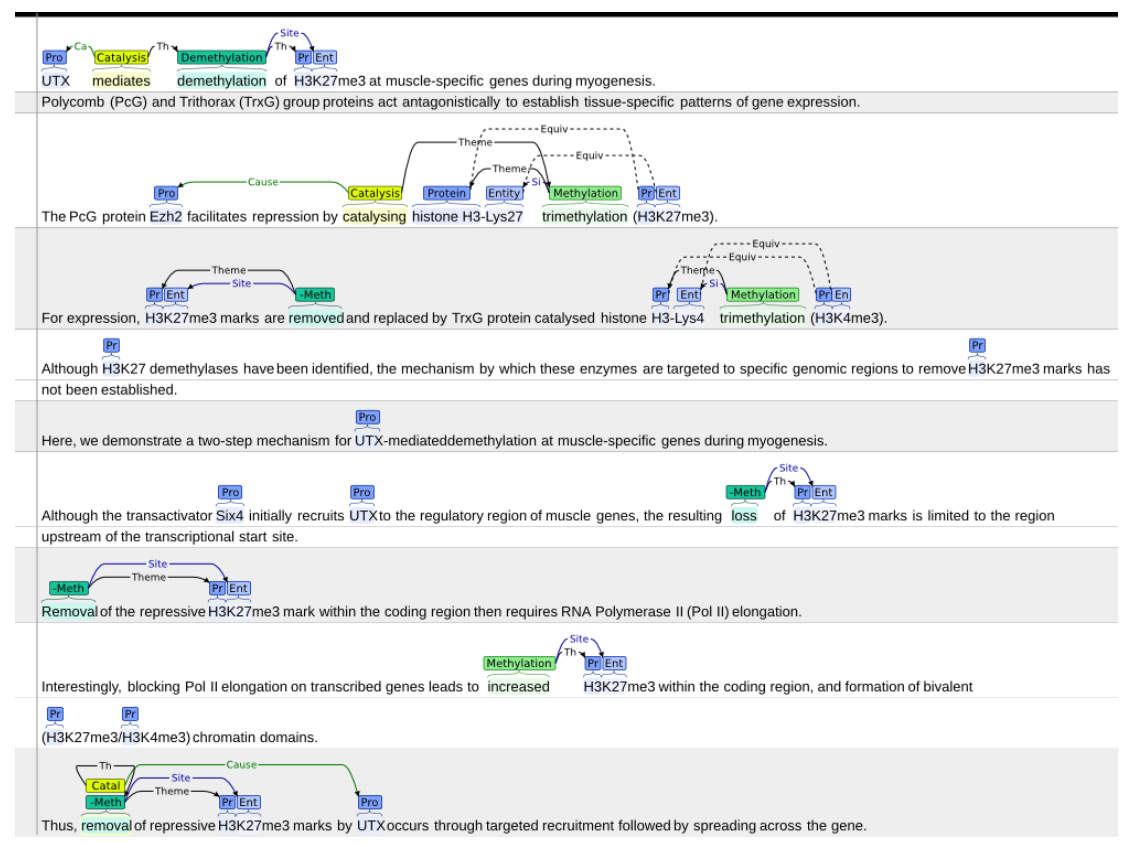

Figura 2.5: Tela do ambiente de anotação do BRAT para uma aplicação específica de extração de eventos biomédicos.

Há também a ferramenta WebAnno (23), que utiliza a BRAT como interface de frontend, mas substitui sua camada server para adicionar o suporte ao gerenciamento de usuários e da qualidade da anotação com os procedimentos de curadoria. A implementação da WebAnno também disponibiliza uma interface modificada da BRAT para facilitação da anotação em crowdsourcing. Semelhante às outras ferramentas, ela permite a anotação de relações de dependência, onde duas anotações de POS tag são conectadas por uma relação direta dentro de opções já definidas no sistema, anotações de co-referências, mas não permite o carregamento de uma ontologia para a anotação das entidades e suas relações. O mais próximo que esta chega de uma flexibilidade para os tipos de entidades é a possibilidade de se fornecer um conjunto de tags (tagset) a serem usadas na anotação. As figuras 2.6, 2.7 e 2.8 mostram telas do WebAnno para configuração de projeto, curadoria e monitoração de projeto. 


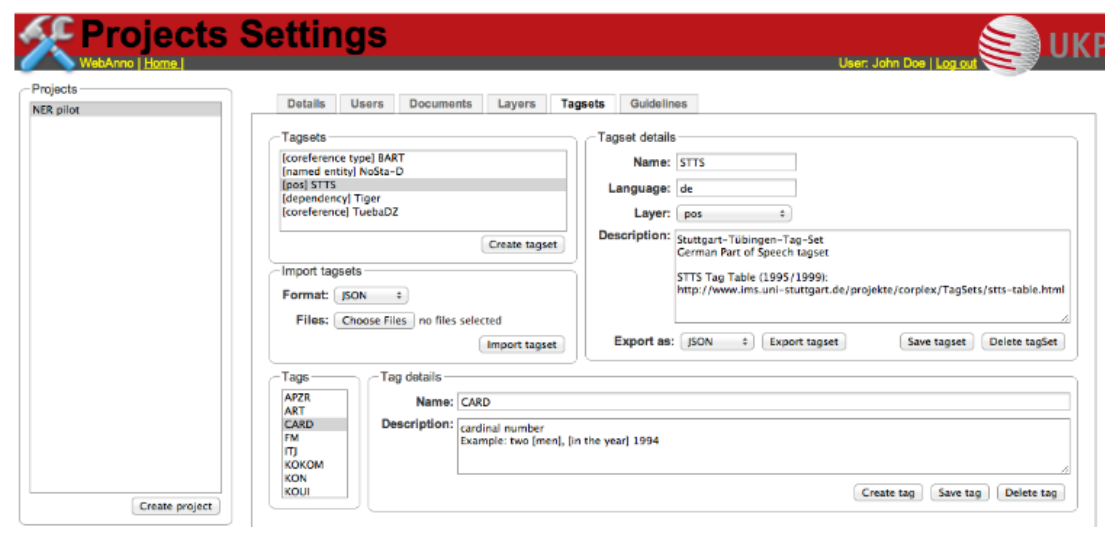

Figura 2.6: Interface do WebAnno para configuração de projetos e definição do conjunto de tags. [Figura retirada de (23)]

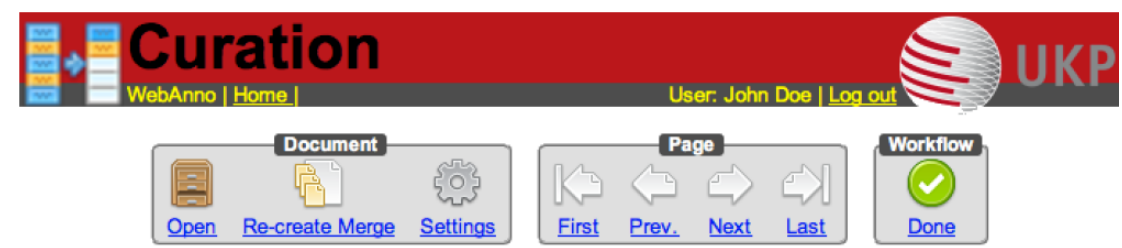
NER pilot/NER_deu_blocks $0 K 2$-aa.tcf

showing $1-10$ of 200 sentences

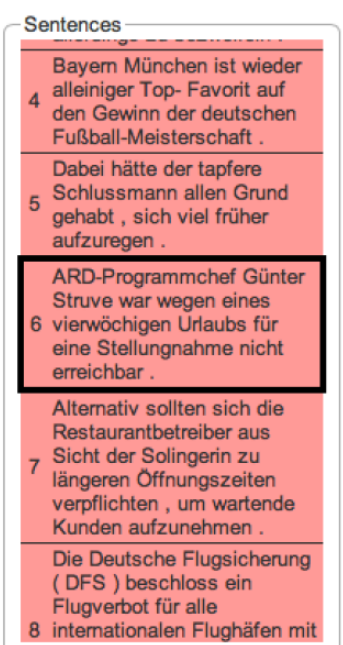

- Merged

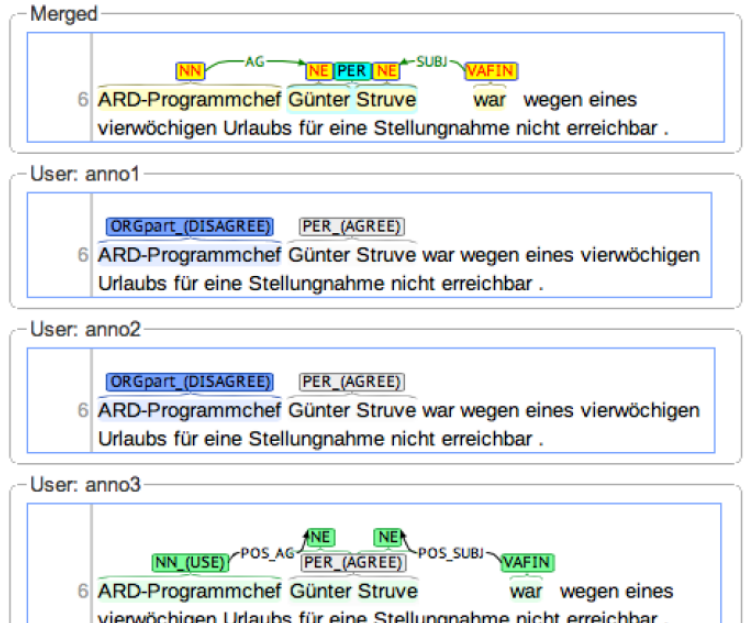

Figura 2.7: Interface do WebAnno para curadoria de dados. [Figura retirada de $(23)]$ 


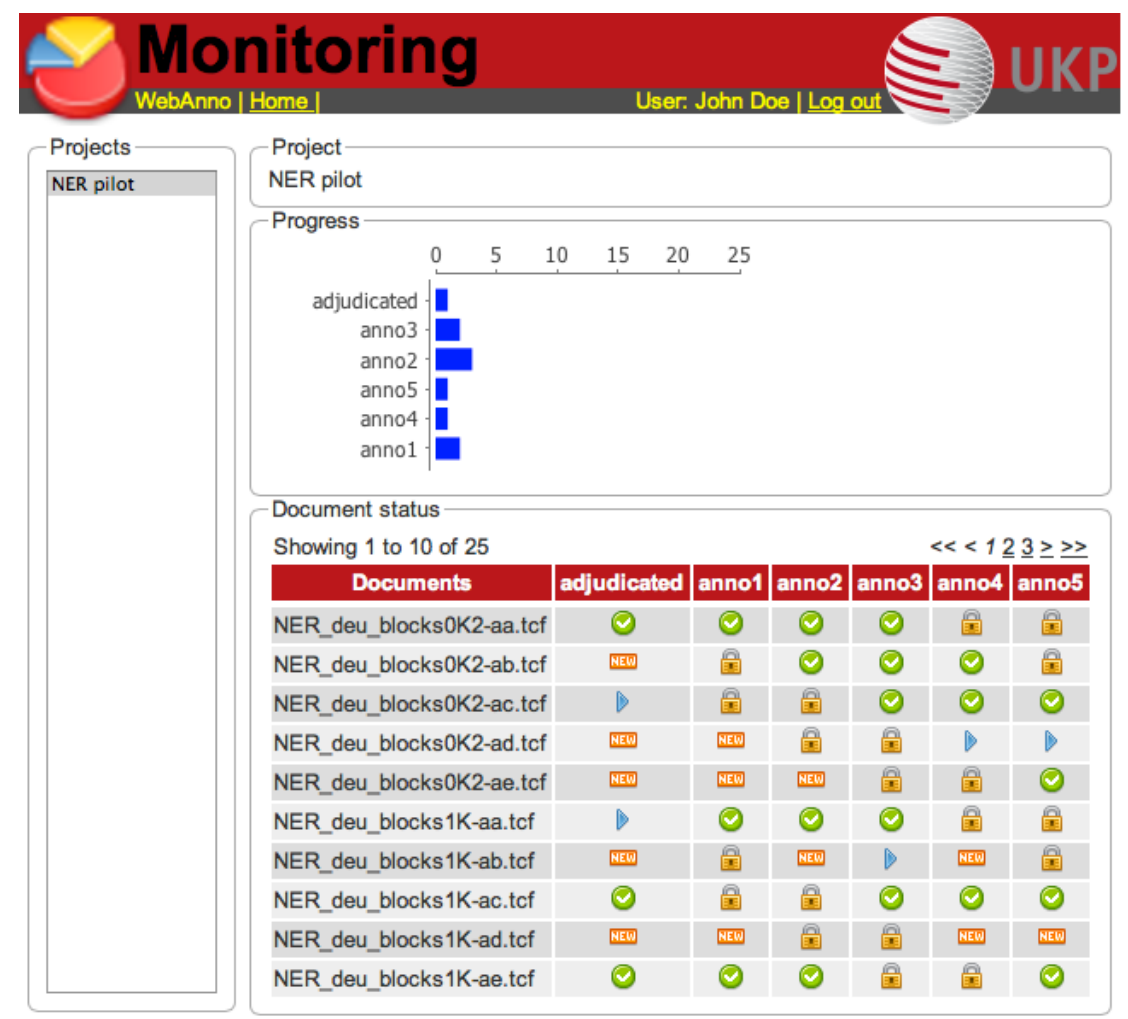

Figura 2.8: Interface do WebAnno para monitoração dos projetos. [Figura retirada de (23)]

Pode-se citar também ferramentas para anotações de propósito genérico, como a MMAX2 (24) ou a WordFreak (25), que como muitas outras, não são baseadas em web e não fornecem um ambiente para o gerenciamento do projeto de anotação, curadoria etc.

A análise das características destas ferramentas, seus pontos fortes e fracos, unida às demandas que a metodologia descrita em (6) levanta em termos de sistema, leva às seguintes conclusões sobre as características mais importantes em um sistema de preparação de dados e geração de modelos de NLP para reconhecimento de entidades e extração de informações com base em ontologias de domínio:

1. Deve ser uma ferramenta em ambiente web, para facilitação de acesso e centralização de dados;

2. Deve fornecer uma interface simples e direta para a anotação, onde pessoas não especializadas não tenham maiores dificuldades;

3. Deve fornecer um sistema robusto de gerenciamento de projetos de anotação;

4. Deve monitorar e registrar todas as ações de anotação, para uso destes dados em estudos posteriores e cálculos de métricas de anotação;

5. Deve permitir o carregamento direto de arquivos de ontologia (OWL, por exemplo) para seu uso como base de anotação tanto de entidades quanto de relações; 
6. Deve permitir o carregamento de arquivos e documentos que guiem as anotações (annotation guidelines);

7. Deve permitir o uso direto, também em ambiente web, dos dados anotados e selecionados como entradas para um sistema de construção de modelos de aprendizado de máquina.

Com vistas a executar todos os passos da metodologia de (6) em um só ambiente, usando as melhores e mais pertinentes filosofias dos sistemas de anotação estudados, contando também com um sistema que use os dados anotados e forneça uma interface simples de construção dos modelos de aprendizado de máquina, os próximos capítulos mostram a proposta, implementação, uso e avaliação de um novo sistema, totalmente baseado em nuvem. 
It is not down on any map; true places never are.

Herman Melville, Moby-Dick; or, The Whale. 


\section{A plataforma}

O objetivo do presente trabalho é, a partir da ideia descrita e testada em (6), desenvolver um sistema em nuvem, baseado em módulos de serviço, acessível via browser, que comporte em um único ambiente (do ponto de vista do usuário) todas as ferramentas necessárias para:

1. a manipulação e persistência de conjuntos de documentos textuais (fontes de dados);

2. o uso de bibliotecas de NLP com tokenizadores (tokenizers) e etiquetadores morfológicos (POS taggers) para a caracterização dos textos;

3. a anotação dos textos por diversos usuários cadastrados, com base em ontologias de domínio em formato OWL, carregáveis como uploads convencionais;

4. a curadoria dos documentos, por parte do "dono" do projeto, pela comparação das anotações e monitoração de parâmetros que indiquem os comportamentos dos anotadores;

5. o treinamento, a avaliação e a persistência de modelos de aprendizado de máquina para a tarefa de NER, que visam ao reconhecimento automático das entidades descritas nas ontologias;

6. o treinamento, a avaliação e a persistência de modelos de aprendizado de máquina para a tarefa de RE, que visam à construção automática de grafos de relações entre entidades, também baseada nas relações entre entidades descritas nas ontologias;

7. a construção e a disponibilização de serviços de leitura e estruturação, em formato RDF, de dados textuais com base em modelos de NER e RE gerados previamente.

As figuras 3.1, 3.2, 3.3 e 3.4 apresentam diagramas que descrevem alguns fluxos da plataforma, onde: as setas, ilustram a direção e fluxo de execução; os retângulos, os processos; as elipses, entradas e saídas; as nuvens, representam saídas instanciáveis.

Em um nível mais geral, como ilustrado na figura 3.1, o sistema deve ser composto por 3 grandes etapas: curadoria (gestão e preparação de dados), aprendizado de máquina (construção, treinamento e avaliação de modelos, tendo como base os dados da etapa anterior) e distribuição de serviços (compostos pelos modelos gerados na etapa anterior). 


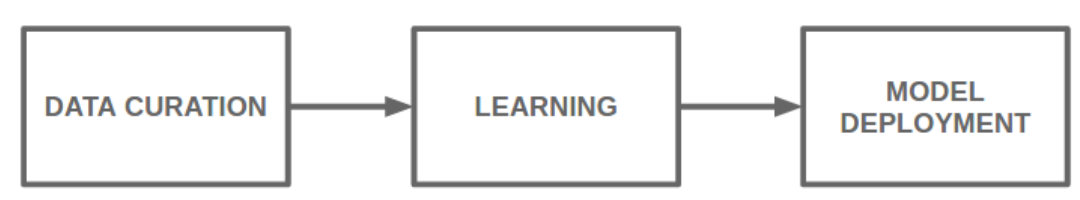

Figura 3.1: Fluxo geral de estruturação de dados

A figura 3.2 ilustra em maiores detalhes o fluxo da etapa de curadoria. Ela recebe dois inputs fundamentais: os dados textuais e a ontologia do domínio a ser modelado. O conjunto de textos alimentados passa por uma etapa de tokenização e POS Tagging, quando cada token separado é caracterizado quanto à sua função morfossintática. Os dados tokenizados são então disponibilizados em um ambiente de anotação, onde a ontologia alimentada serve de base para a disponibilização das tags (a partir de suas classes) e das relações (a partir de suas object properties e datatype properties). As anotações de todos os participantes são então validadas por um curador, cuja responsabilidade é comparará-las, corrigir os erros e definir o conjunto de anotações corretas, isto é, o Gold Standard Annotation (GSA). A GSA é, portanto, o conjunto de dados a ser usado na etapa de aprendizado de máquina.

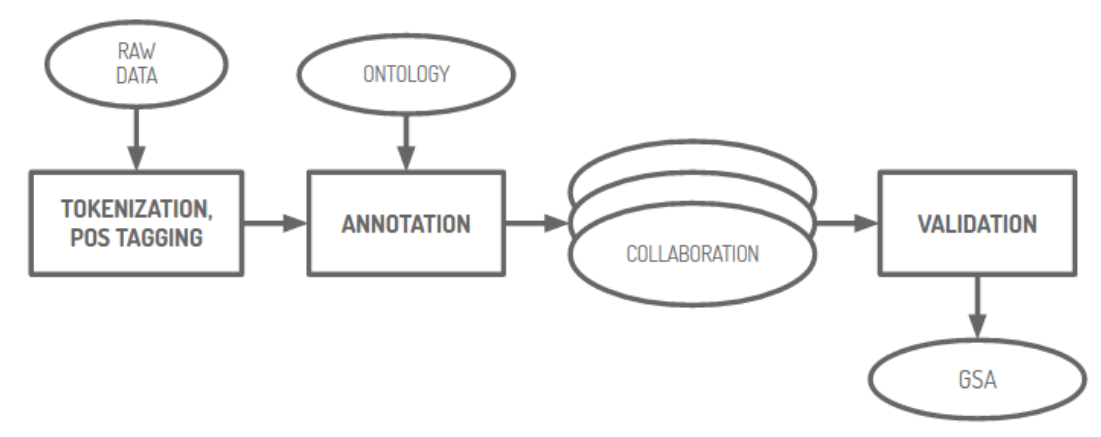

Figura 3.2: Fluxo de curadoria dos dados

A figura 3.3 ilustra o fluxo da etapa de aprendizado de máquina. Os dados GSA entram alimentam uma etapa de engenharia de atributos, onde servem como base para a criação, automática e manual, de atributos para os classificadores. Os atributos são então aplicados sobre os dados GSA e os transformam em dados numéricos, isto é, o formato esperado pelos algoritmos de classificação. O aprendizado acontece, então, na etapa seguinte, onde os modelos treinados são treinados e avaliados, fornecendo, como saída, os modelos definitivos capazes de processar automaticamente novos dados textuais puros. 


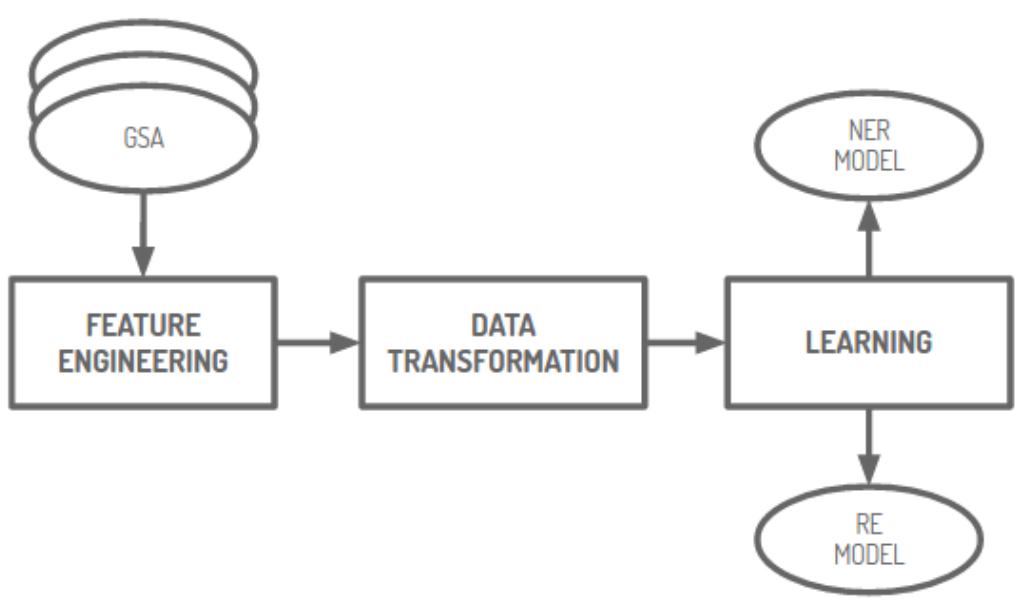

Figura 3.3: Fluxo de aprendizado automático

A terceira e última grande etapa, ilustrada em detalhes pela figura 3.4, recebe os modelos de NER e RE definidos na etapa anterior e são combinados em uma cadeia NER $\rightarrow$ RE. Essa cadeia de modelos é então disponibilizada como um serviço online que, recebendo dados textuais puros, identifica entidades e relações (pertencentes à ontologia usada) e exporta os resultados na forma de triplas $\mathrm{RDF}$.

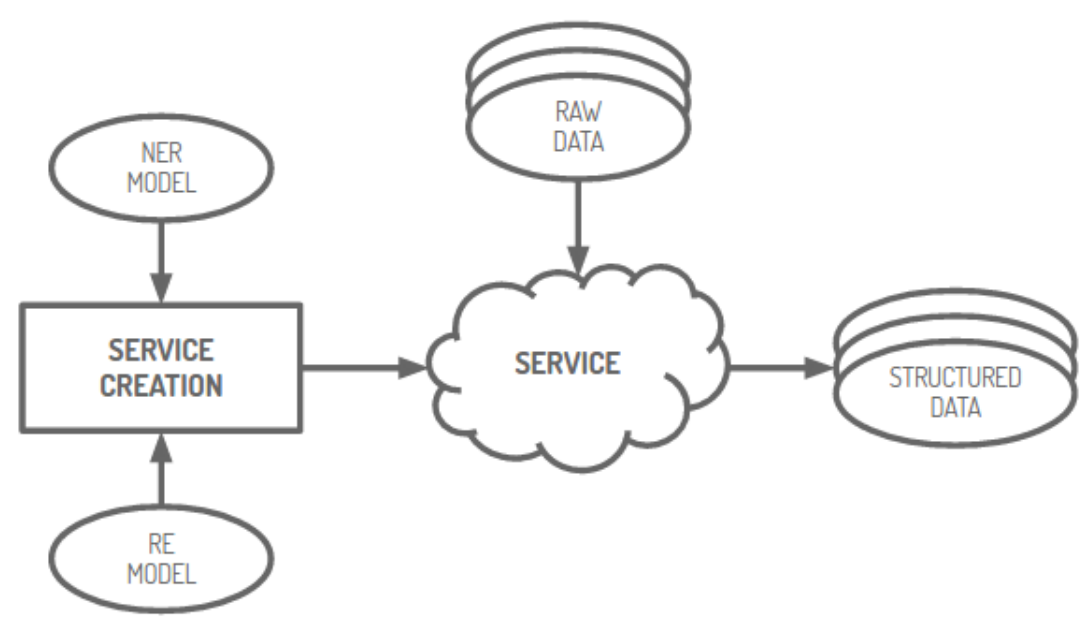

Figura 3.4: Fluxo de implantação dos modelos

Definidos os fluxos gerais, desenvolveu-se uma plataforma web denominada LER (Learning Entities and Relations) com módulos que reproduzem os fluxos descritos acima. Uma vez que a etapa de curadoria é uma das mais onerosas e importantes do fluxo (26), ela foi implementada como um subsistema do LER, sendo denominada ERAS (Entities and Relations Annotation System). Desse modo, a estrutura do sistema implementado por ser entendida pelo diagrama da figura 3.5. 


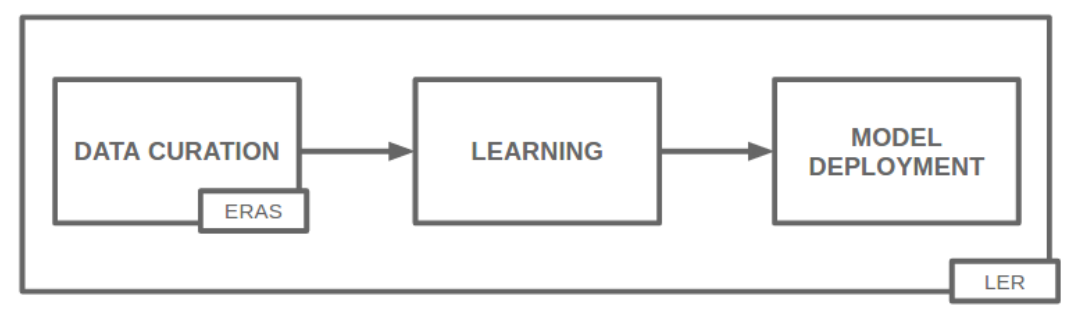

Figura 3.5: LER

\section{1}

\section{Arquitetura}

Para o desenvolvimento da plataforma, optou-se por um formato modularizado seguindo o modelo arquitetural REST, onde a comunicação entre os módulos se dá por meio do protocolo HTTP. O controle de acesso aos módulos da plataforma é feito por meio de tokens seguindo o padrão JWT (27), sendo estes transmitidos no cabeçalho das requisições entre os módulos. As principais tecnologias utilizadas para o desenvolvimento do LER foram:

- Python: Linguagem de programação utilizada para a construção do backend;

- MongoDB: SGBD (Sistema de Gerenciamento de Banco de Dados) utilizado para armazenamento dos dados gerados pela plataforma;

- Scikit-learn: Biblioteca utilizada para execução dos algorítimos de aprendizado automático;

- PyStruct: Biblioteca utilizada para execução dos algorítimos de aprendizado automático estruturado;

- Javascript: Linguagem de programação utilizada para a construção do frontend;

- AngularJS: Biblioteca responsável pelo controle dos componentes do frontend bem como as chamadas aos serviços do backend

Como pode ser visto na figura 3.6, a plataforma foi dividida em 5 módulos distintos:

- Authentication: Módulo responsável pelo controle de acesso dos usuários na plataforma, sendo o único módulo com acesso às credenciais destes e o responsável pela geração e verificação da sua validade;

- Data: Módulo responsável pelo controle de todos os dados da plataforma (com exceção dos dados de usuários, que estão no escopo do módulo Authentication);

- Learning: Módulo responsável pela execução de todos os métodos de aprendizado de automático da plataforma (Tokenization, POS Tagging, NER e RE); 
- Services: Módulo responsável pelo gerenciamento dos serviços que recebem textos puros e geram dados estruturados em triplas RDF através do uso dos modelos de NER e RE criados no módulo Learning;

- Client: Módulo que provê uma interface web da plataforma para o usuário.

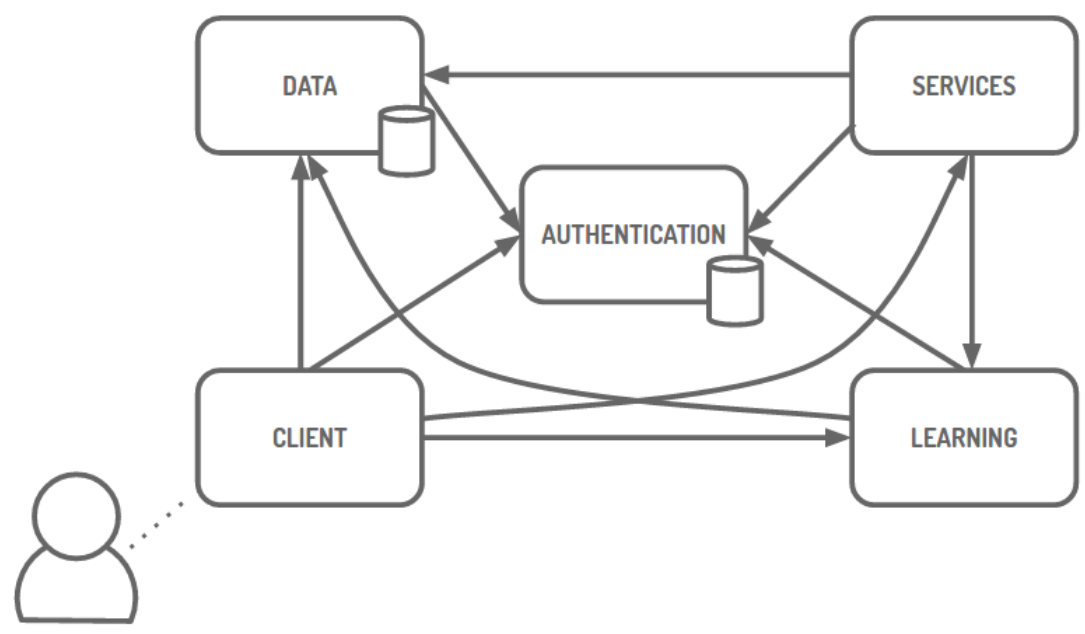

Figura 3.6: Arquitetura do LER

A vantagem desta modularização é a facilitação do escalonamento vertical e horizontal da plataforma em ambientes com alta demanda. Um escalonamento vertical, como exemplificado na figura 3.7, é apenas um upgrade nas configurações da máquina hospedeira da aplicação. Um aumento horizontal de escala pode ser obtido tanto separando os módulos em máquinas diferentes, podendo, por exemplo, deixar um módulo com maior demanda de processamento em uma máquina independente (ver figura 3.8), ou até mesmo criando um cluster de máquinas para aumentar o poder de processamento de quaisquer módulos (ver figura 3.9).

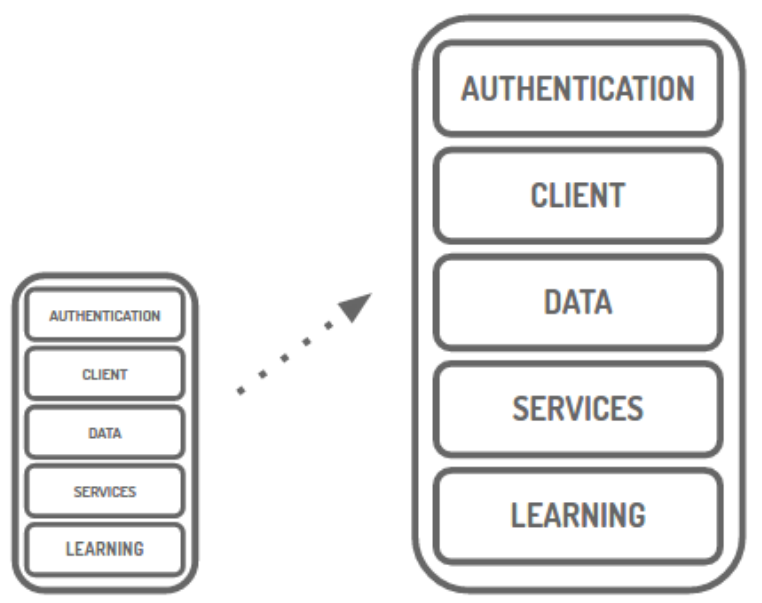

Figura 3.7: Exemplo de escalonamento vertical do LER 


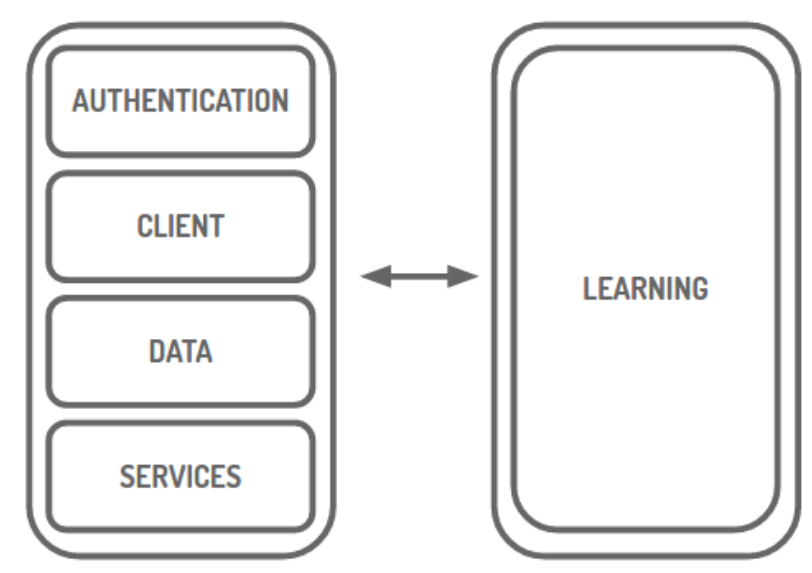

Figura 3.8: Exemplo de escalonamento horizontal do LER

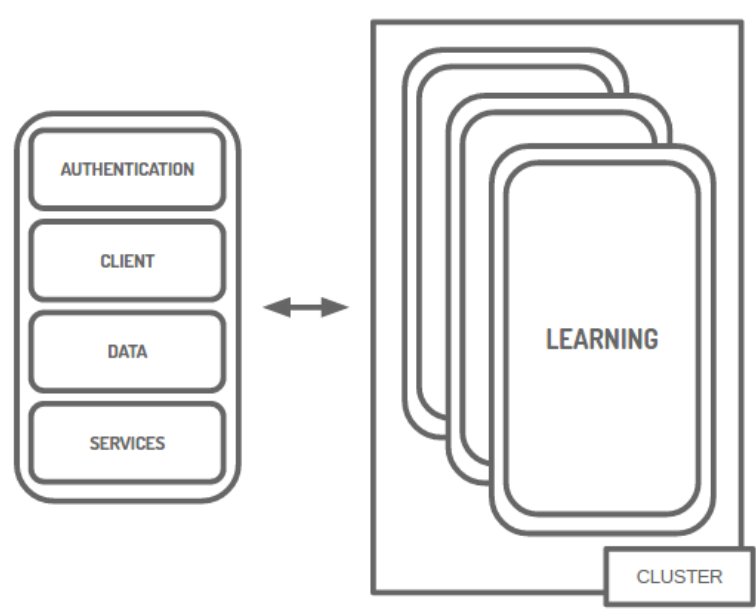

Figura 3.9: Exemplo de escalonamento horizontal do LER utilizando cluster

As principais funções da plataforma serão descritas nas próximas seções deste trabalho. Um exemplo do resultado final, no que diz respeito à interface de usuário, pode ser visto na figura 3.10. Um resumo do modelo de dados da plataforma na figura 3.11. 


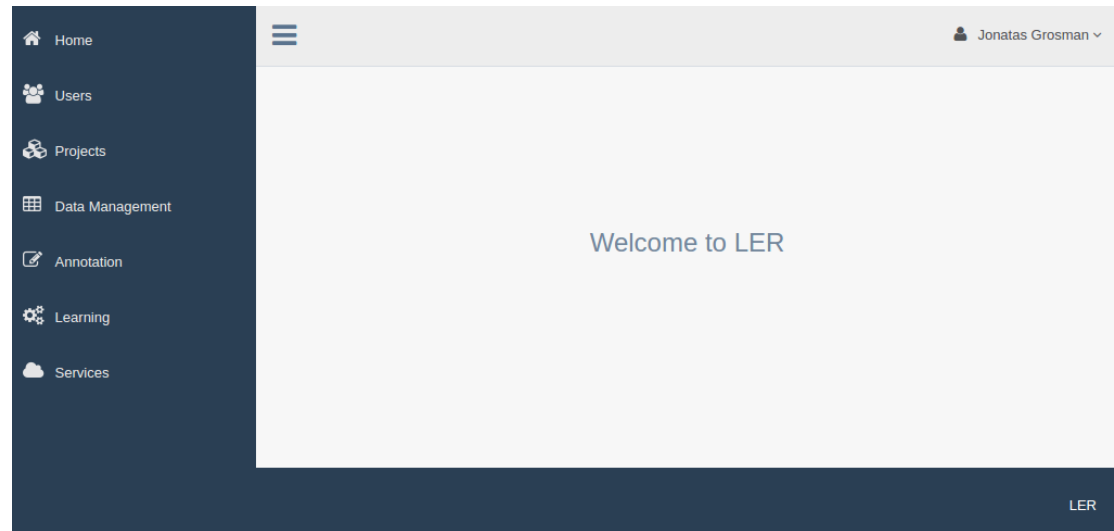

Figura 3.10: Tela inicial da plataforma

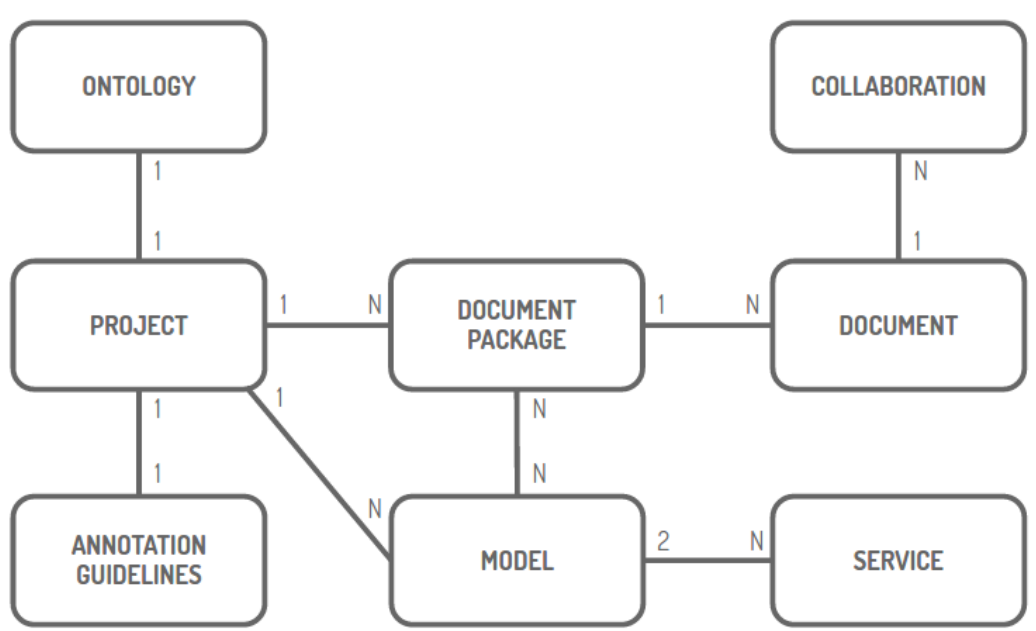

Figura 3.11: Resumo do modelo de dados do LER

\section{2}

\section{Controle de usuários}

O controle de usuários na plataforma é feito por meio de login e senha. Há 3 tipos distintos de usuários, com diferentes níveis de acesso à plataforma, como pode ser visto na figura 3.12. Os níveis de acesso disponíveis são:

- Administrador: Tem acesso a todas as áreas da plataforma;

- Usuário comum: Tem acesso a todas as áreas da plataforma com exceção da área de controle de usuários;

- Colaborador: Tem acesso apenas à tela inicial e à área de anotação. 


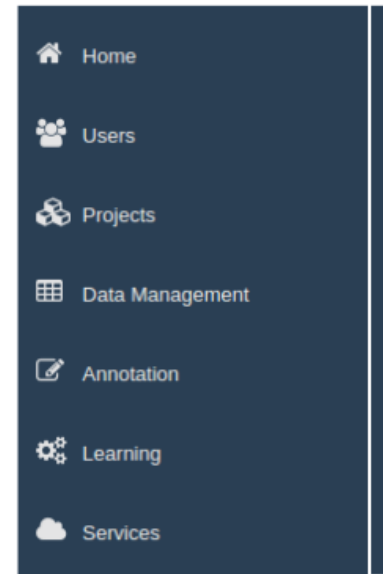

(a)

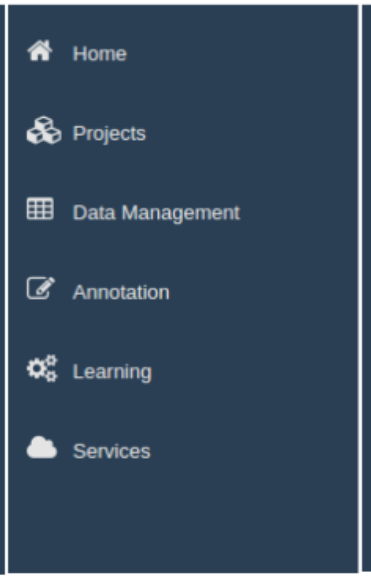

(b)

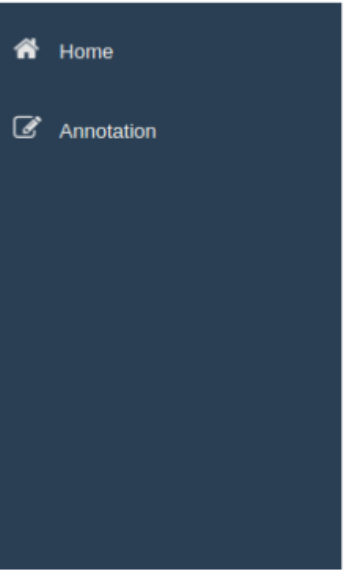

(c)

Figura 3.12: Menu da plataforma por níveis de acesso: (a) Administrador; (b) Usuário; (c) Colaborador

\section{3}

\section{Gerência de projetos}

A primeira etapa do fluxo de uso da plataforma trata da criação do projeto (ver figura 3.13), que congregará em si as tarefas de anotação e construção de modelos NER e RE. Ainda nesta etapa se definem, por upload, a ontologia no formato OWL (obrigatória) e o guia de anotação no formato PDF (opcional). É também obrigatória a escolha de um idioma para todo o projeto. Um elemento básico de diferenciação entre a presente implementação e a que foi adotada em (6) é justamente o POS Tagger utilizado. O LER adota o sistema Freeling 4.0 (28), explicado em resumo para uma versão anterior em (29). Esse POS Tagger apresenta algumas vantagens em relação à ferramenta F-EXT (11), que não está mais disponível para uso público e comercial, mas apenas para fins de pesquisa. Em primeiro lugar, o Freeling tem suporte para 12 idiomas além de português e inglês, únicos suportados pelo F-EXT. Além disso, o Freeling codifica a informação morfológica das POS tags tendo como base uma estrutura de etiquetas de tamanhos variáveis onde cada caractere corresponde a uma característica morfológica específica, sendo o primeiro sempre relativo à categoria (verbo, adjetivo etc.), de modo que um token que no F-EXT seria descrito simplesmente como um verbo, no Freeling em português, por exemplo, seria caracterizado em 6 níveis adicionais (ver figura 3.14). Essa abordagem multidimensional da função morfossintática do token possibilita a criação de mais dimensões nos atributos de POS, o que pode melhorar a capacidade de separação dos classificadores na etapa de aprendizado de máquina. 


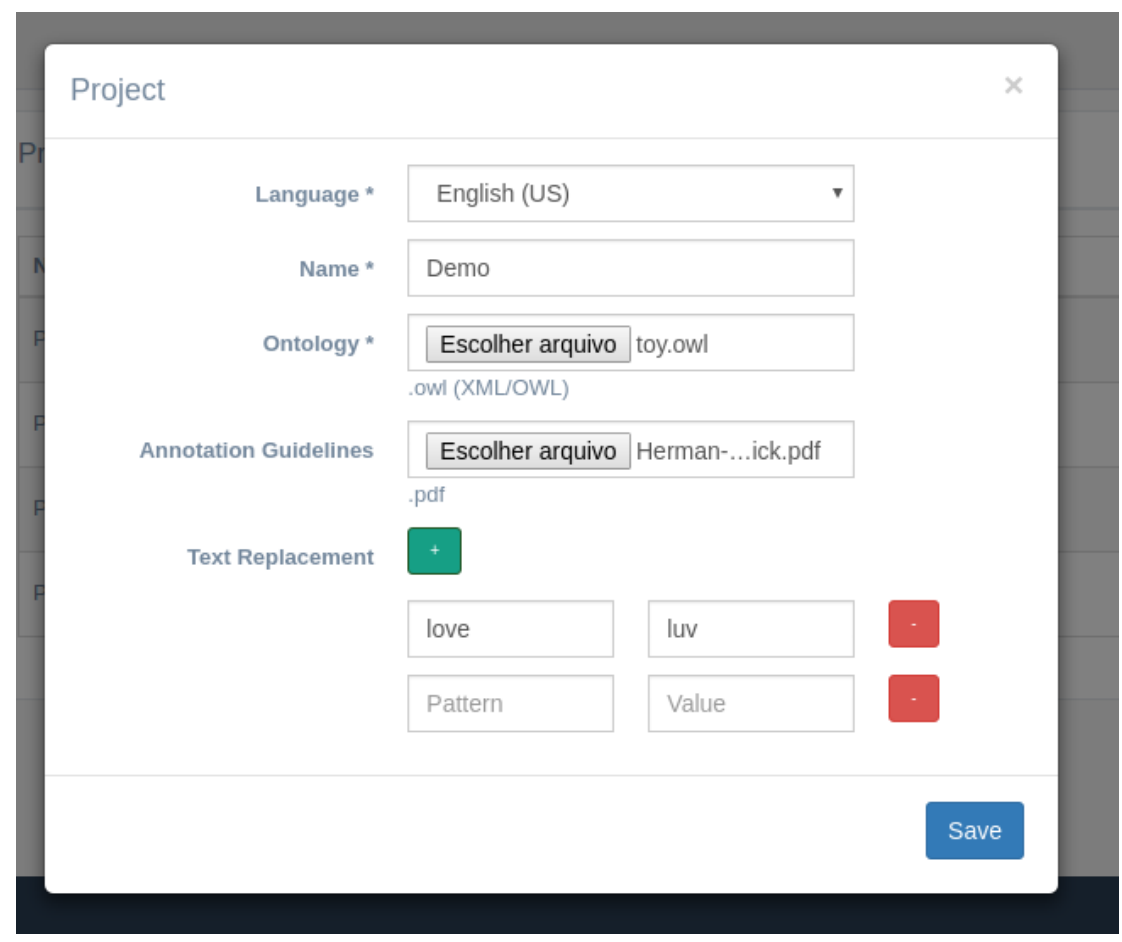

Figura 3.13: Criação de projetos

\begin{tabular}{|c|c|c|}
\hline Position & Atribute & Values \\
\hline 0 & category & V:verb \\
\hline 1 & type & M:main; A:auxiliary; S:semiauxiliary \\
\hline 2 & mood & $\begin{array}{l}\text { I:indicative; S:subjunctive; M:imperative; P:pastparticiple; G:gerund; } \\
\mathbf{N} \text { :infinitive }\end{array}$ \\
\hline 3 & tense & P:present; I:imperfect; F:future; S:past; C:conditional; M:plusquamperfect \\
\hline 4 & person & $1: 1 ; 2: 2 ; 3: 3$ \\
\hline 5 & num & $\mathbf{S}:$ singular; P:plural \\
\hline 6 & gen & F:feminine; M:masculine; C:common; N:neuter \\
\hline
\end{tabular}

Figura 3.14: Descrição de verbos em português no Freeling 4.0

A figura 3.15 mostra um exemplo de tela com vários projetos criados, onde o administrador ou usuário comum pode editá-los ou excluí-los. 


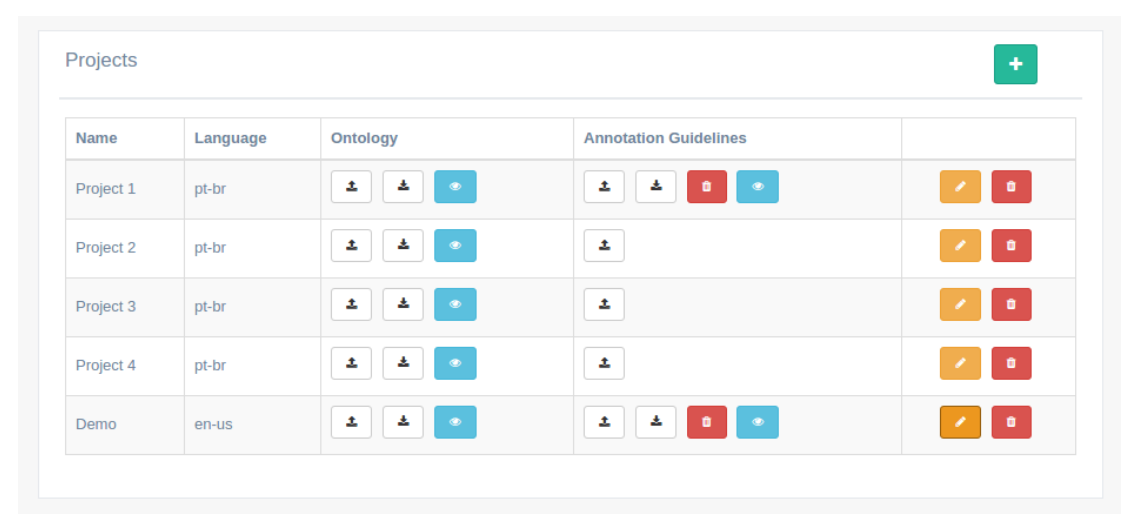

Figura 3.15: Área de projetos

\section{4}

\section{O ERAS}

Como comentado anteriormente, a tarefa de anotação e curadoria de dados é uma das mais custosas em tempo no fluxo de estruturação de dados, merecendo um sistema dedicado especialmente a ela. As seções a seguir descreverão como o sistema ERAS lida este processo, nas perspectivas do curador e dos colaboradores.

Com o intuito de tornar a descrição mais clara nos exemplos apresentados a seguir, será definido um cenário hipotético onde 2 usuários, A e B, realizaram a anotação e re-anotação das seguintes frases extraídas de (30):

- 01.txt: My body is but the lees of my better being;

- 02.txt: It is only his outside; a man can be honest in any sort of skin.

As figuras 3.16 e 3.17 mostram os resultados do cenário descrito acima, e as figuras 3.18 e 3.19 mostram as visões da ontologia que fôra utilizada para anotar os textos. 


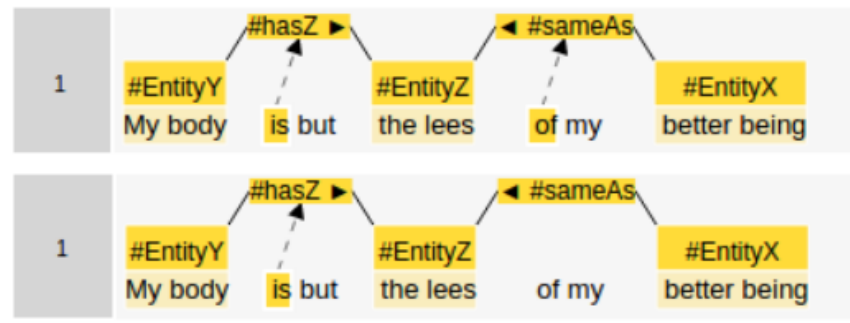

(a)

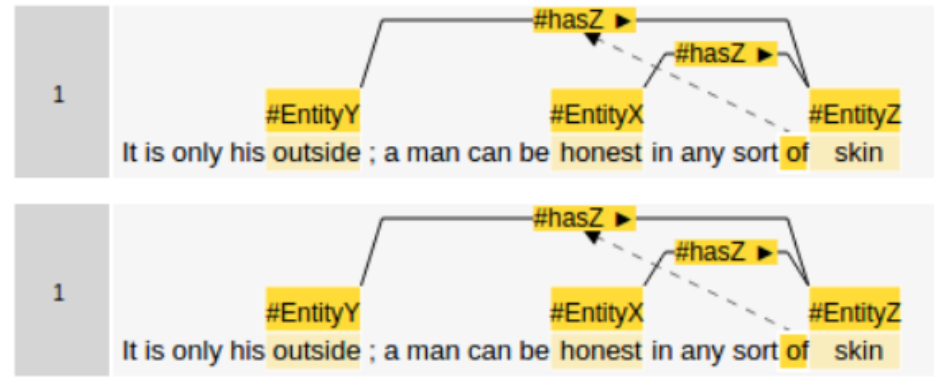

(b)

Figura 3.16: Anotações usuário A: (a) anotação do documento 01.txt seguido de sua re-anotação; (b) anotação do documento 02.txt seguido de sua re-anotação

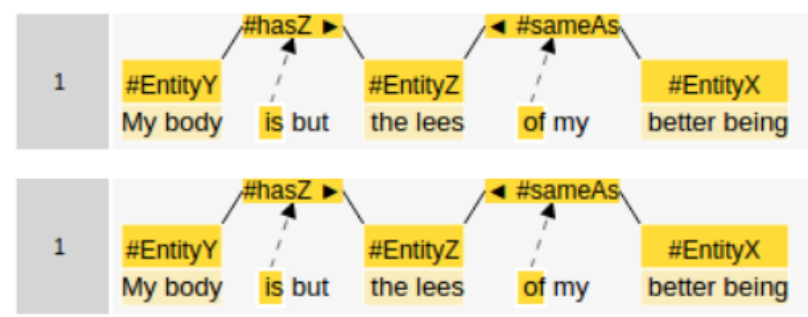

(a)

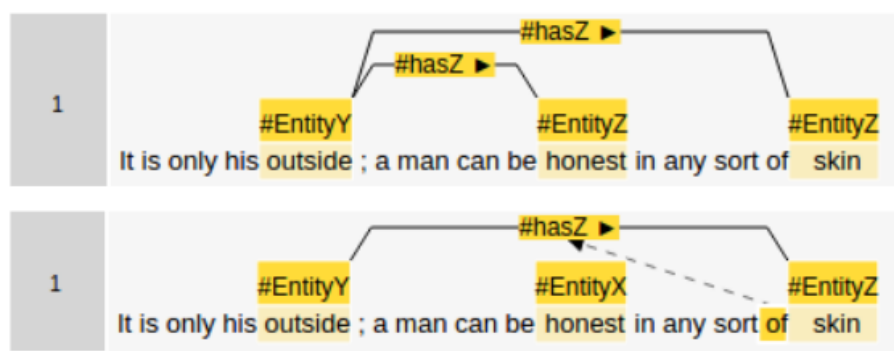

(b)

Figura 3.17: Anotações usuário B: (a) anotação do documento 01.txt seguido de sua re-anotação; (b) anotação do documento 02.txt seguido de sua re-anotação 


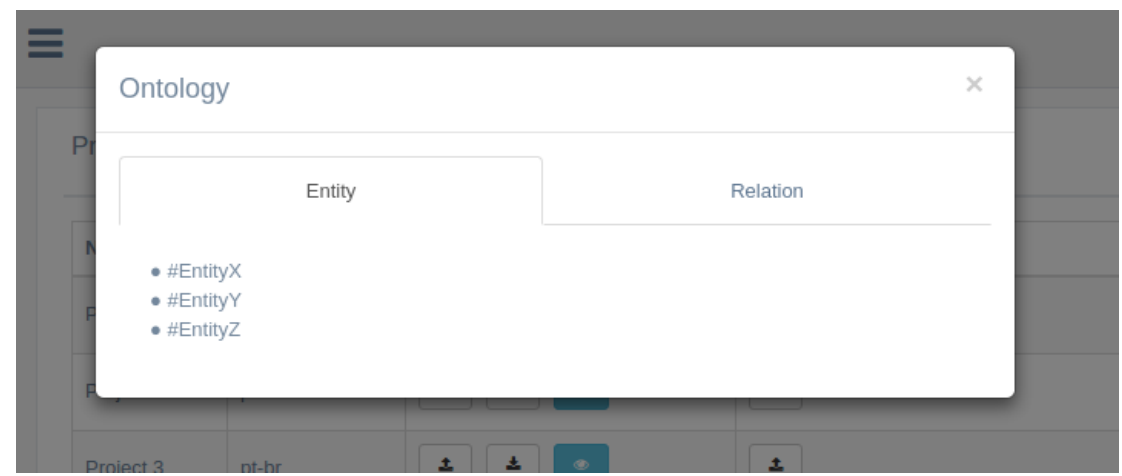

Figura 3.18: Ontologia: Entidades

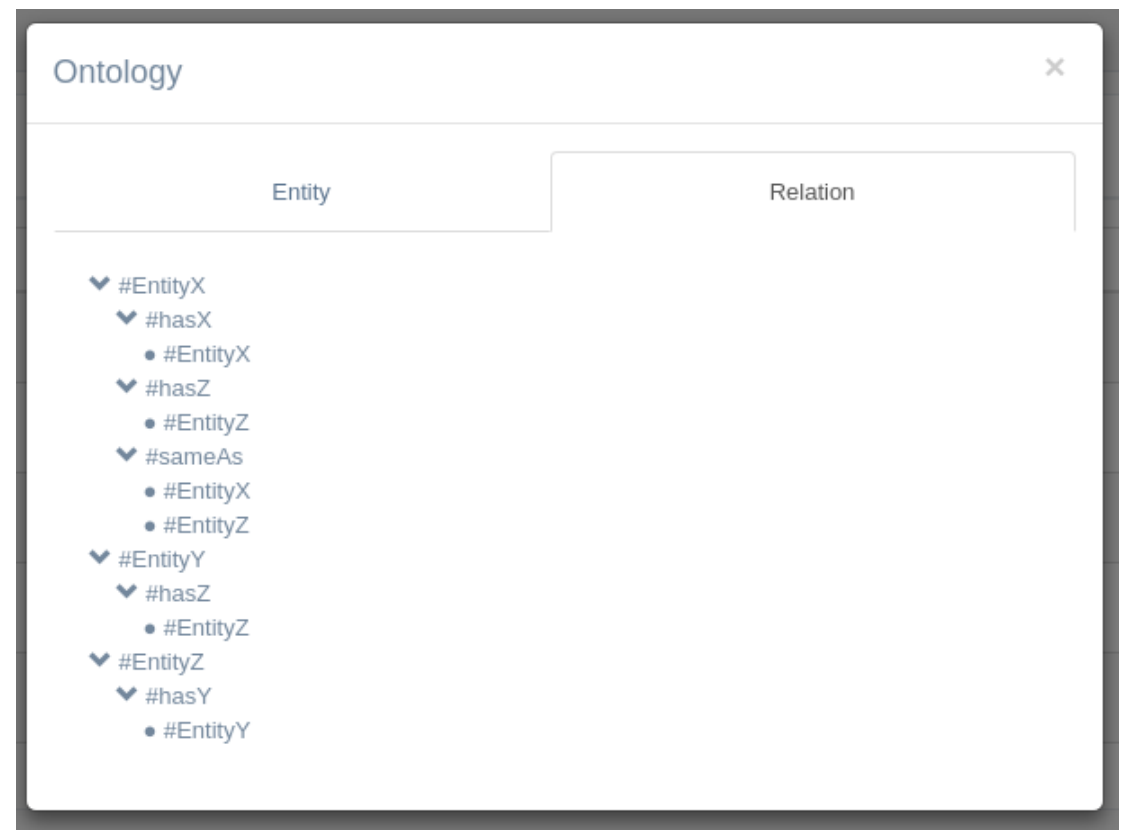

Figura 3.19: Ontologia: Relações

\subsection{1}

\section{Gerência dos dados}

Cada documento tem um estado dentre 3 possíveis: UNCHECKED, PRECHECKED e CHECKED. O estado UNCHECKED é o estado original de qualquer documento que é carregado no sistema e significa que ele está disponível para anotação. O estado PRECHECKED é um estado intermediário em que o documento não está disponível para anotação ou uso no aprendizado automático. O estado CHECKED significa que o documento faz parte do GSA a ser disponibilizado para uso na etapa de aprendizado de máquinas. A figura 3.20 mostra os documentos 01.txt e 02.txt com estados PRECHECKED e CHECKED, respectivamente. 


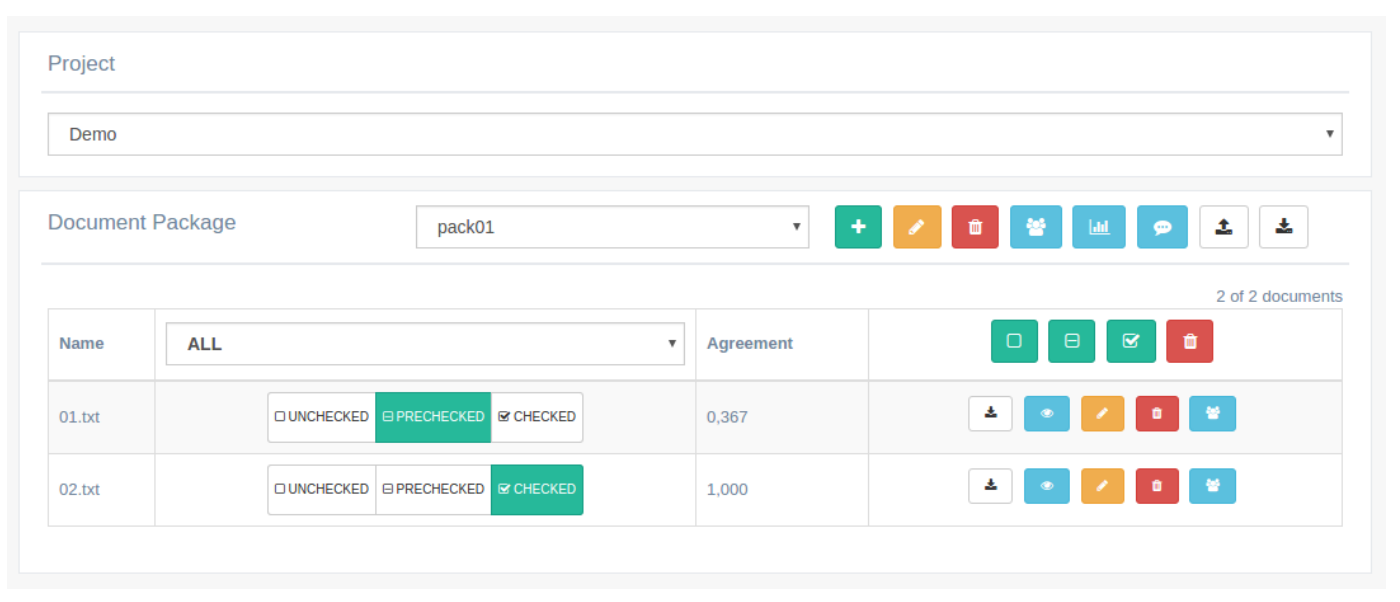

Figura 3.20: Área de gerência de dados

Cada documento precisa fazer parte de um determinado pacote. A criação dos pacotes também acontece na interface representada pela figura 3.20. A figura 3.21 apresenta os parâmetros da criação de um pacote. $O$ Precheck agreement threshold é um parâmetro que indica o mínimo valor de concordância entre 2 anotadores diferentes sobre um mesmo documento para que este seja automaticamente colocado no estado PRECHECKED, isto é, sem a necessidade de que todos os anotadores daquele pacote precisem anotar o tal documento. Esse threshold visa agilizar o processo de anotação pela eliminação da necessidade de que todos os anotadores anotem todos os documentos do pacote. Os botões seguintes indicam quais itens entre tag, relation e connector são considerados para o cálculo da concordância para o threshold.

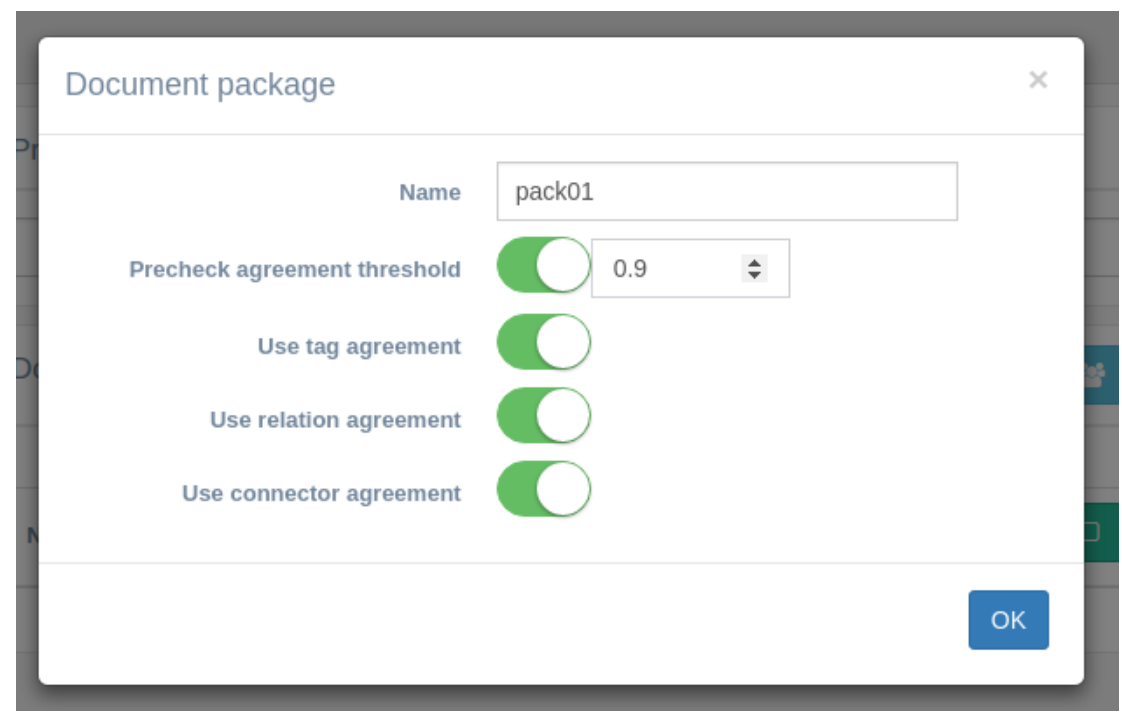

Figura 3.21: Criação de pacotes

A figura 3.22 apresenta a tela de gerenciamento dos colaboradores, onde o gestor do projeto constrói grupos aos quais cada anotador será alocado. 
Um anotador só pode fazer parte de um único grupo. Nesta tela também são definidos os parâmetros de re-anotação Warm up size, que corresponde ao número de documentos a serem anotados para mero "aquecimento" sem registro, e Reannotation step, que indica o número de anotações finalizadas após o qual o documento mais antigo depois da última re-anotação será repetido para o cálculo da auto-concordância, isto é, concordância do anotador consigo mesmo.

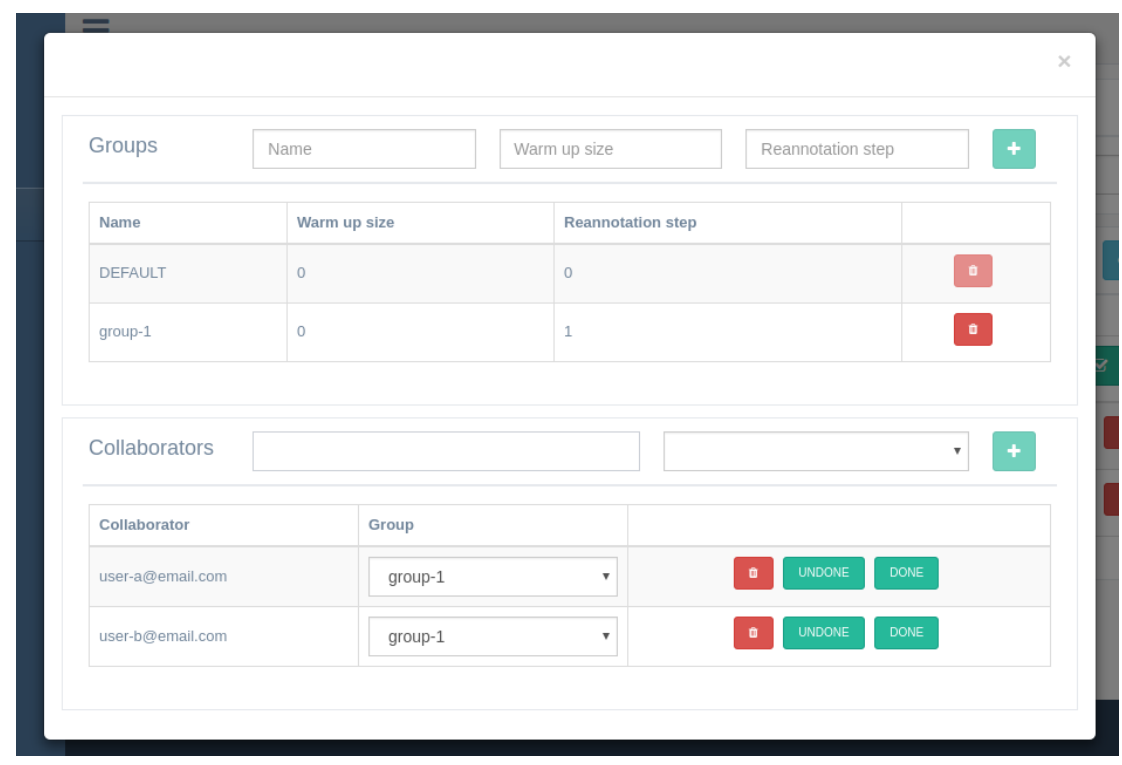

Figura 3.22: Gerenciamento de colaboradores

A figura 3.23 mostra uma interface onde o curador pode consultar todos os comentários de cada colaborador em cada documento. Esses comentários são colocados pelos colaboradores na interface de anotação.

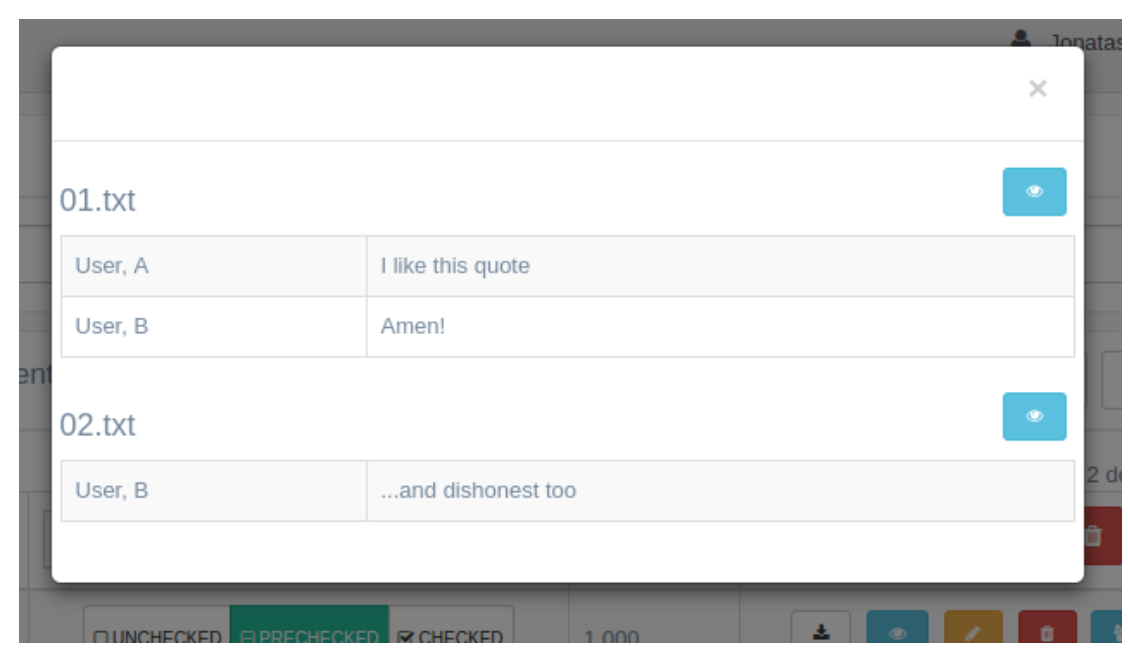

Figura 3.23: Comentários

A figura 3.24 apresenta um menu onde o curador pode selecionar qual perspectiva enxergar em determinado documento, podendo escolher o resul- 
tado de uma anotador específico ou uma visão conjunta de todas as anotações realizadas, pela seleção de Validation.

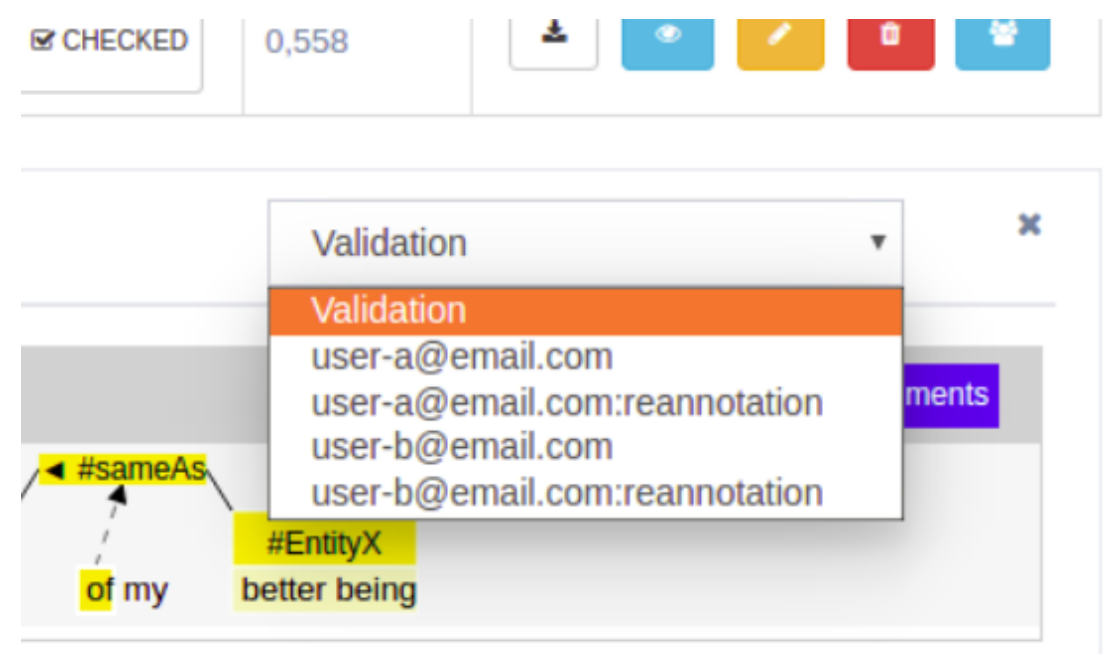

Figura 3.24: Perspectivas do documento

A figura 3.25 mostra o caso da seleção de Validation na figura 3.24. A cor avermelhada indica a existência de discordâncias entre os anotadores do documento em questão. O clique sobre esta região abre o quadro do documento colocando todas as anotações juntas, para que o curador possa, também via cliques e deleções, determinar a configuração final da anotação do tal documento. Há também um botão Auto Match que, se pressionado pelo curador, anotará o documento definitivo automaticamente com todas as tags e relações em que todos os anotadores concordaram. 


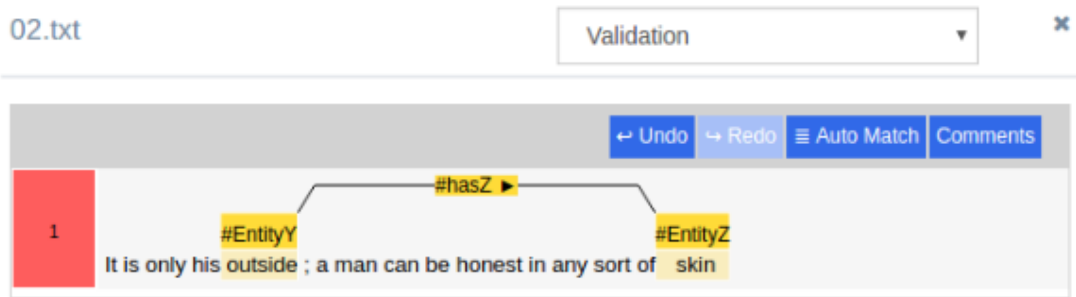

(a)

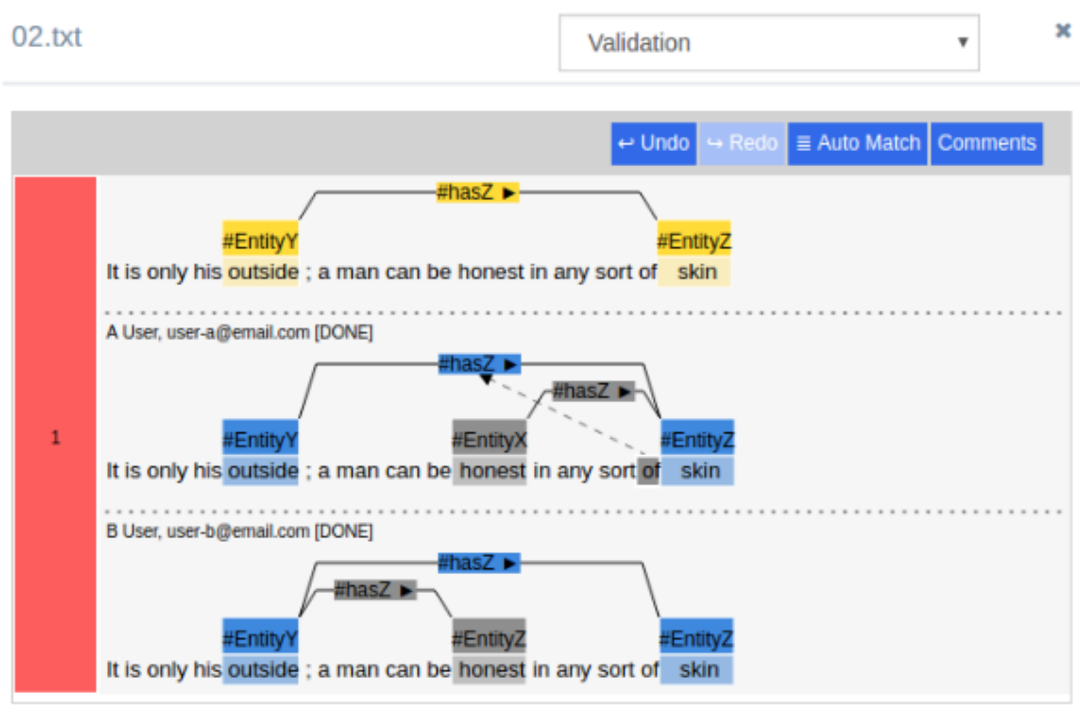

(b)

Figura 3.25: Perspectiva de validação: (a) estado inicial do documento; (b) estado após expansão da sentença

A figura 3.26 mostra um exemplo de documento sem a região avermelhada, indicando a concordância total entre os anotadores. 


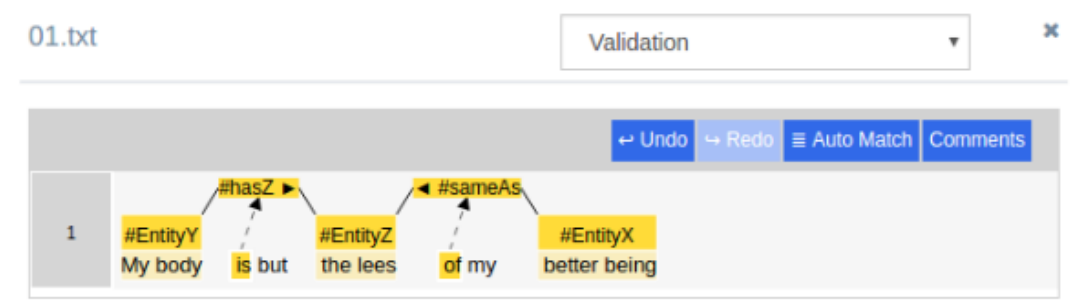

(a)
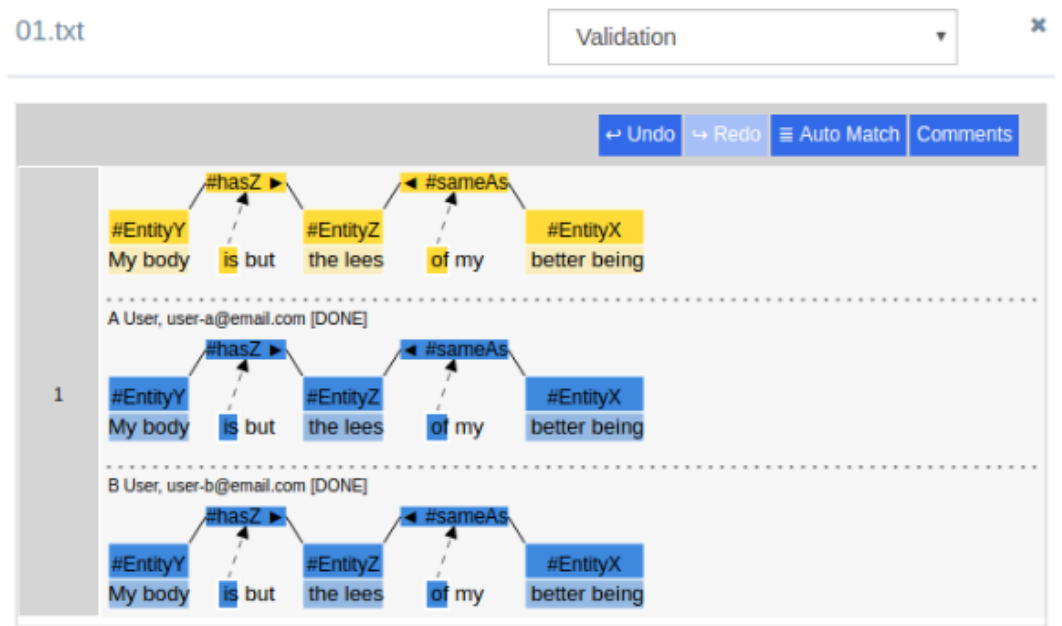

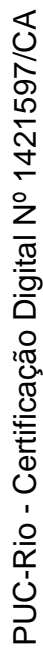

(b)

Figura 3.26: Perspectiva de validação com concordância total: (a) estado inicial do documento; (b) estado após expansão da sentença

A figura 3.27 mostra o log de ações de cada anotador sobre determinado documento. 

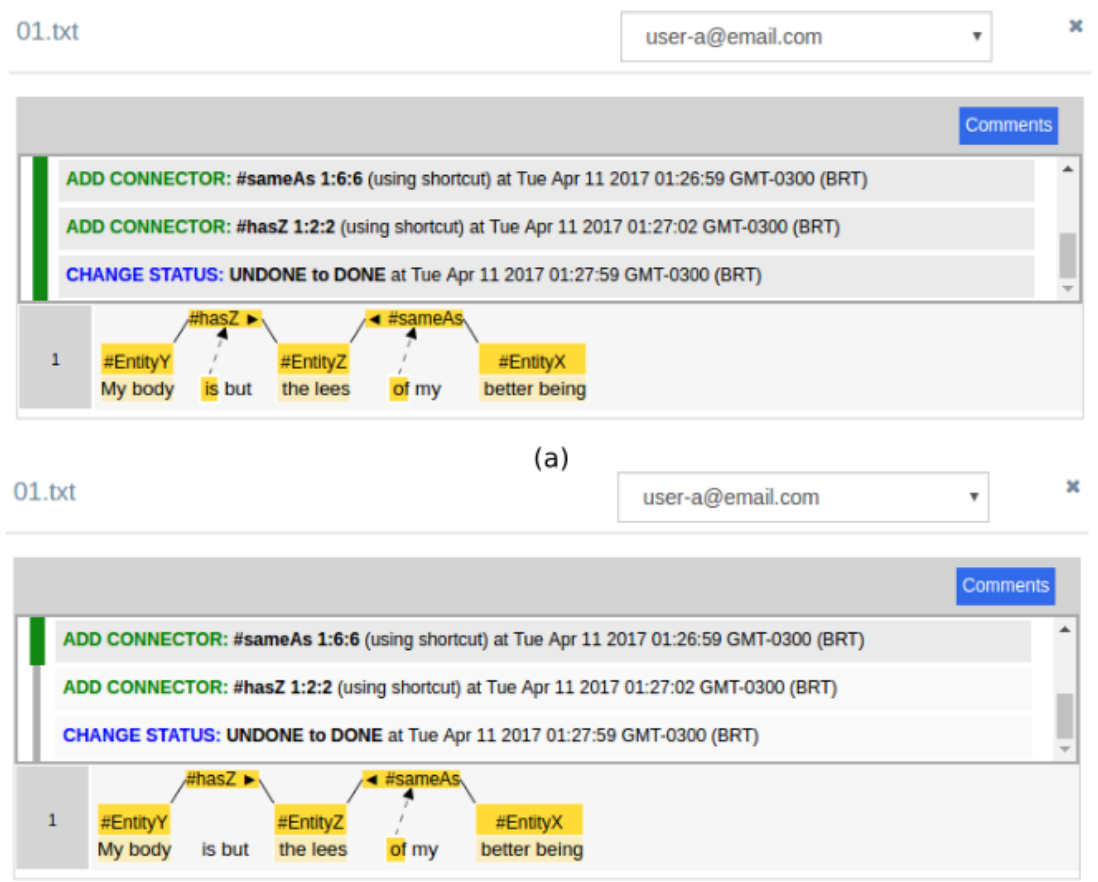

(b)

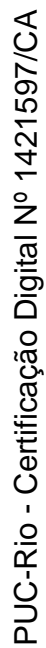

Figura 3.27: Perspectiva de ações do colaborador: (a) estado inicial do documento; (b) estado após desfazer algumas ações do colaborador

Por último, na perspectiva do curador, a figura 3.28 apresenta o formato do documento anotado, quando exportado por download. Este formato segue o padrão descrito em (31), com algumas adaptações. 


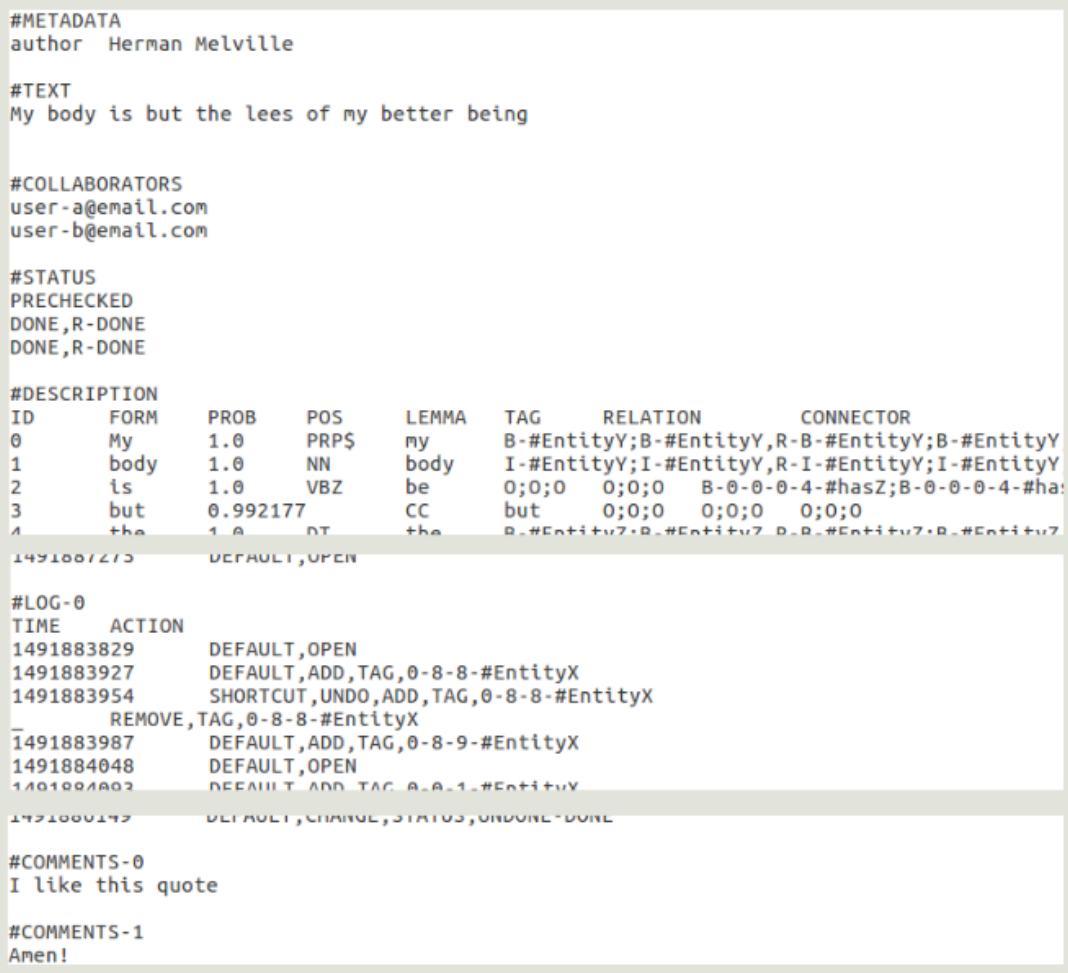

Figura 3.28: Formato exportado

\subsection{2}

\section{Anotação}

Os colaboradores enxergam apenas a interface de anotação, ilustrada pela figura 3.29.

Document package

\begin{tabular}{|l|l|l|l|l|l|}
\hline Demo - pack01 & $25 \%$ & $1 / 4$ \\
\hline Document & O Ontology & O Guidelines \\
\hline
\end{tabular}


O colaborador pode consultar a estrutura da ontologia e o guia durante a anotação, como ilustrado pelas figuras 3.18, 3.19 e 3.30 .

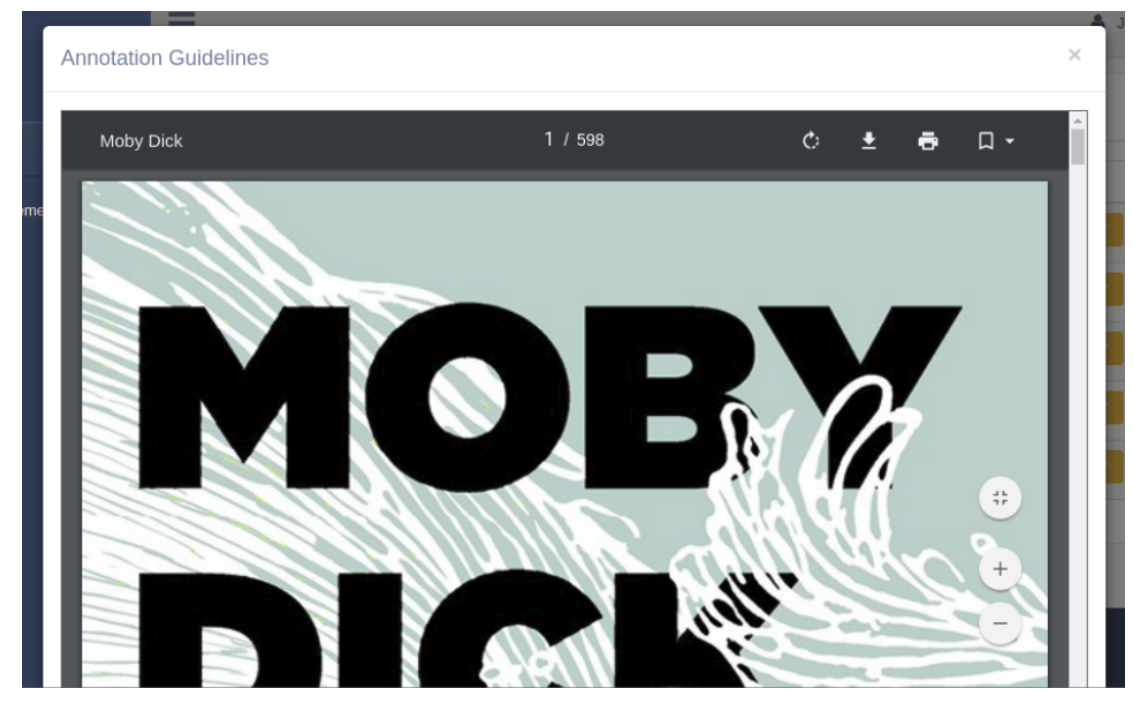

Figura 3.30: Guia de anotação

As figuras $3.31,3.32,3.33,3.34,3.35,3.36,3.37$ e 3.38 apresentam as ações de anotação disponíveis para o colaborador.

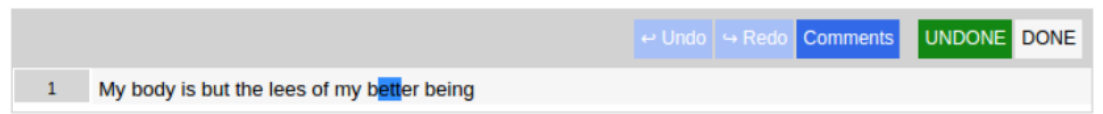

(a)

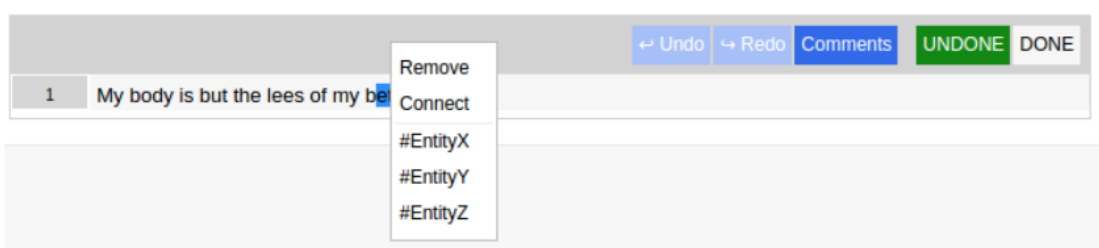

(b)

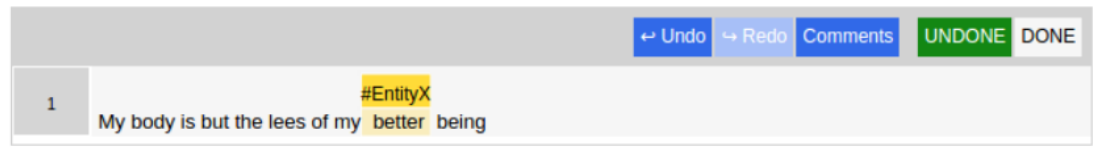

(c)

Figura 3.31: Processo de anotação de entidade: (a) área desejada selecionada; (b) acionando menu de contexto para seleção de entidade; (c) estado final da anotação 


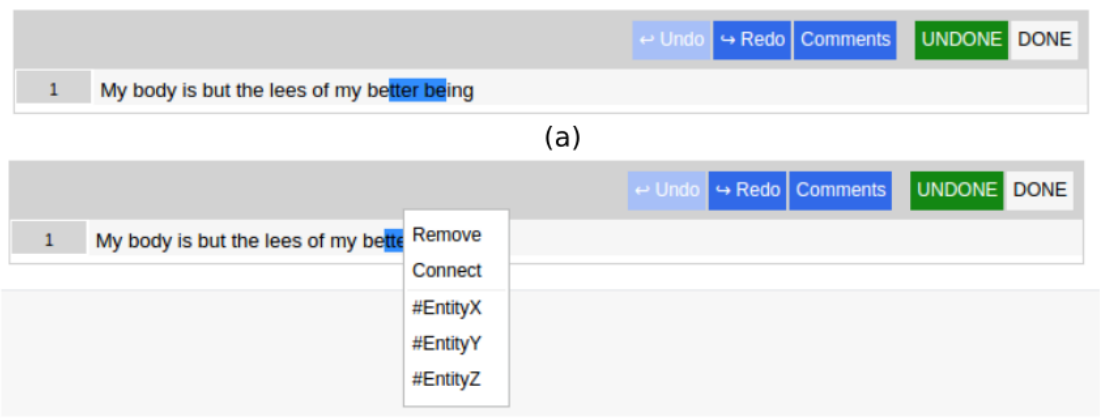

(b)

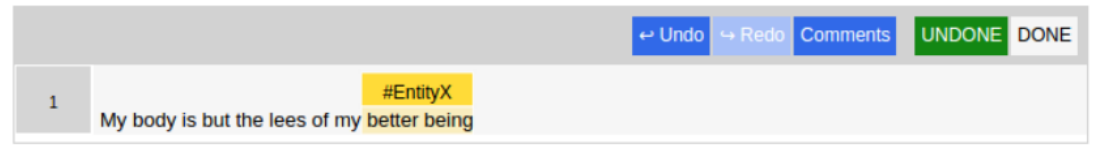

(c)

Figura 3.32: Processo de anotação de entidade com múltiplas palavras: (a) área desejada selecionada; (b) acionando menu de contexto para seleção de entidade; (c) estado final da anotação

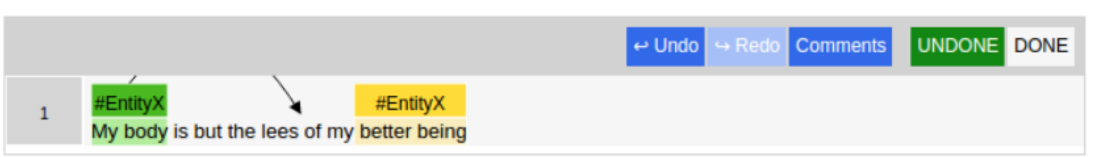

(a)

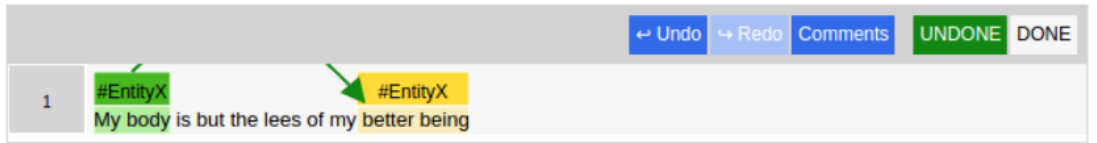

(b)

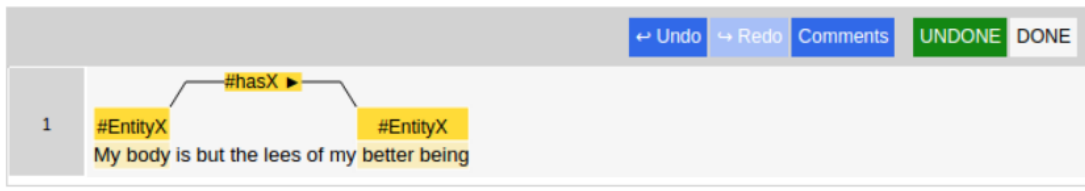

(c)

Figura 3.33: Processo de anotação de relação: (a) entidade origem selecionada; (b) entidade destino alcançada; (c) estado final da anotação

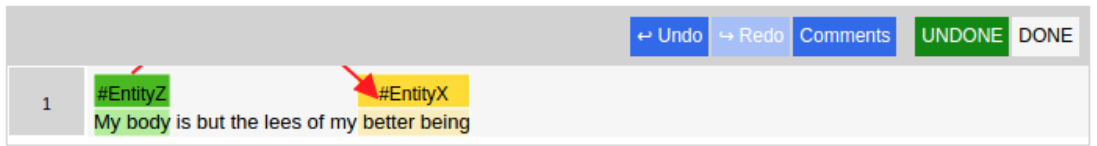

Figura 3.34: Exemplo de tentativa de anotação de relação inválida 


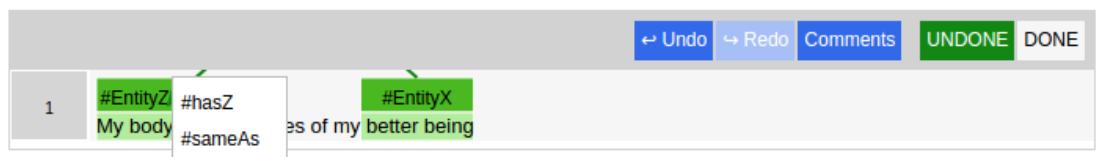

Figura 3.35: Exemplo de anotação de relação quando há múltiplas relações possíveis entre as entidades

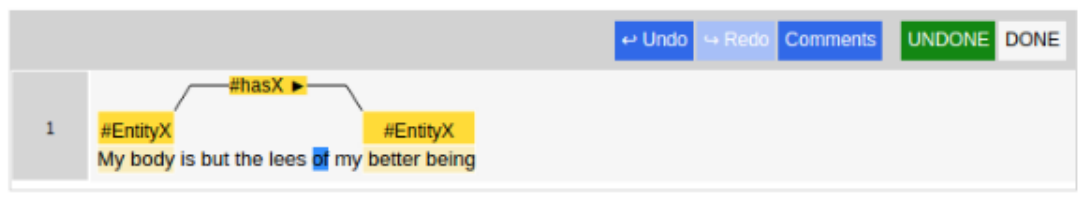

(a)

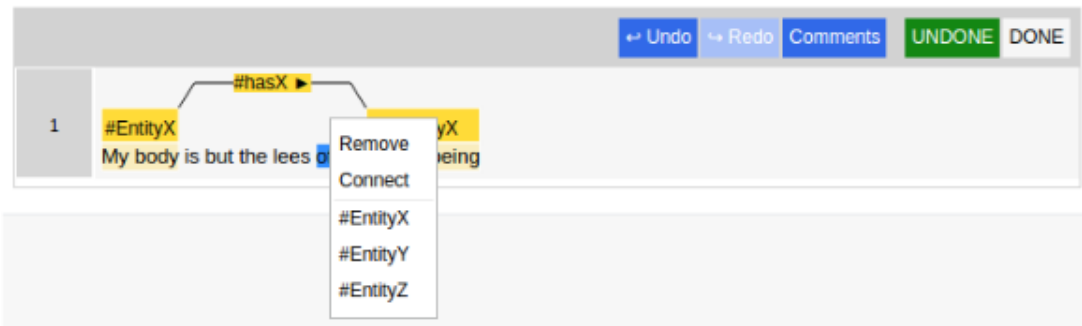

(b)

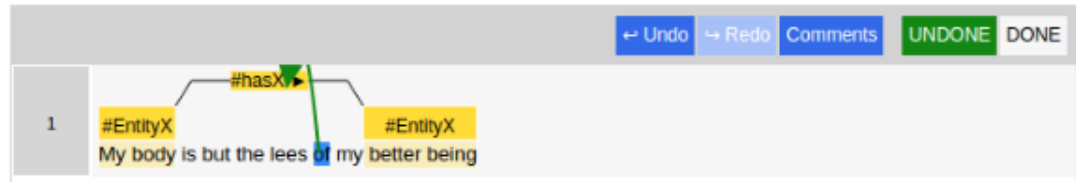

(c)

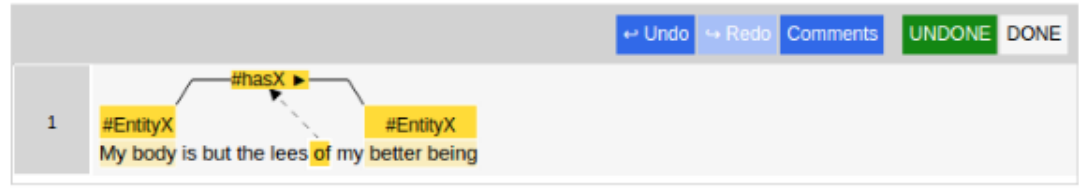

(d)

Figura 3.36: Processo de anotação de conector: (a) área desejada selecionada; (b) acionando menu de contexto para seleção de ação Connect; (c) relação desejada alcançada; (d) estado final da anotação

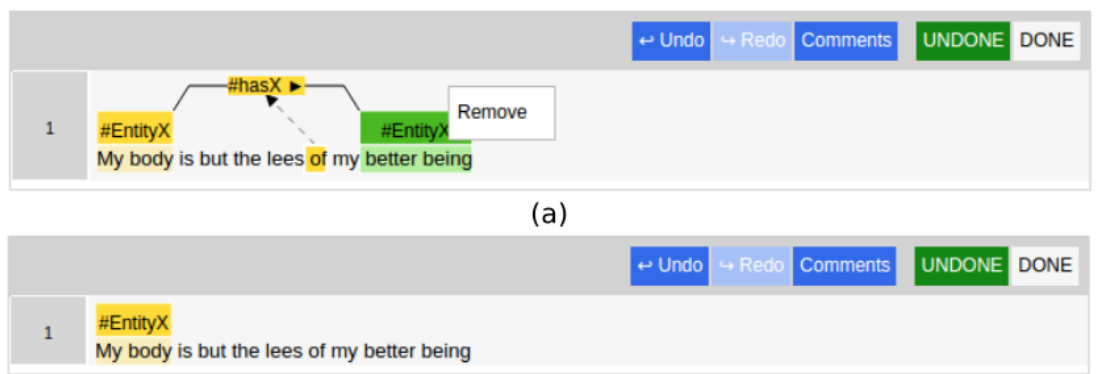

(b)

Figura 3.37: Processo de remoção de anotação: (a) menu de contexto acionado no elemento desejado para executar ação Remove; (b) estado final da remoção 


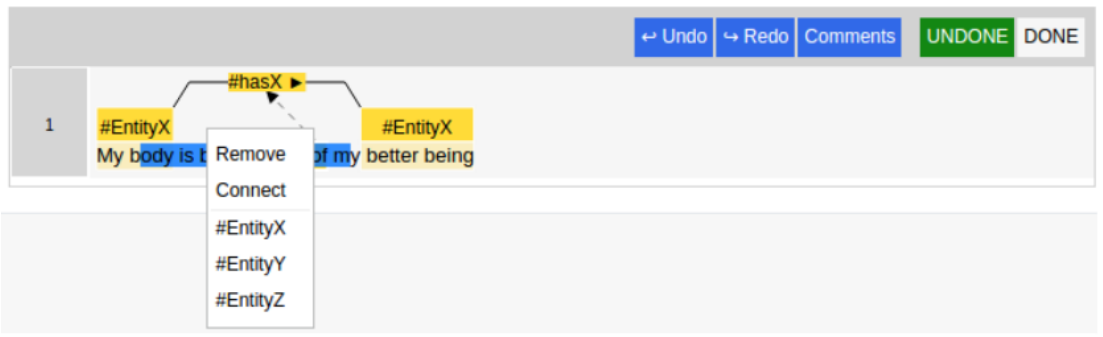

(a)

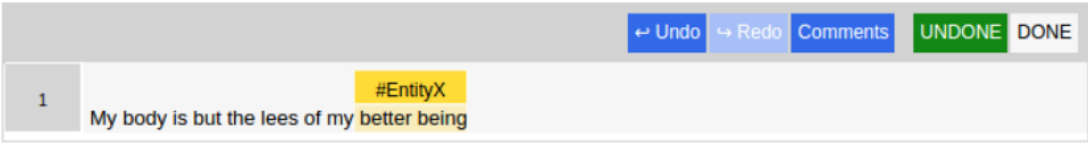

(b)

Figura 3.38: Processo de remoção de anotação em uma área: (a) menu de contexto acionado após selecionada a área desejada para executar ação Remove; (b) estado final da remoção

O colaborador pode adicionar comentários (ver figura 3.39) em cada documento, conforme já comentado na seção anterior.

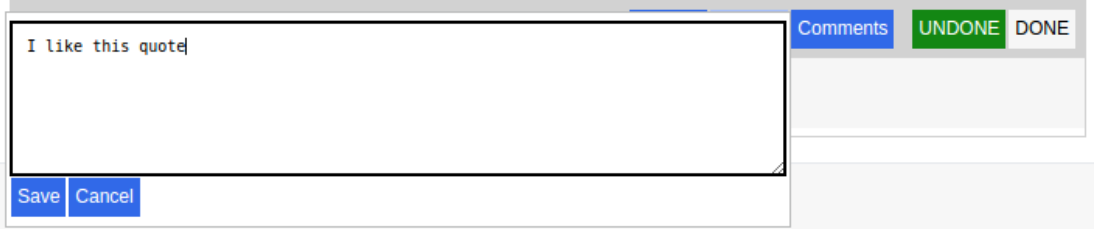

Figura 3.39: Adicionando comentários no documento

\subsection{3}

\section{Estatísticas}

O curador também tem acesso a estatísticas para cada pacotes, ilustradas nas figuras 3.40, 3.41, 3.42 e 3.43 .

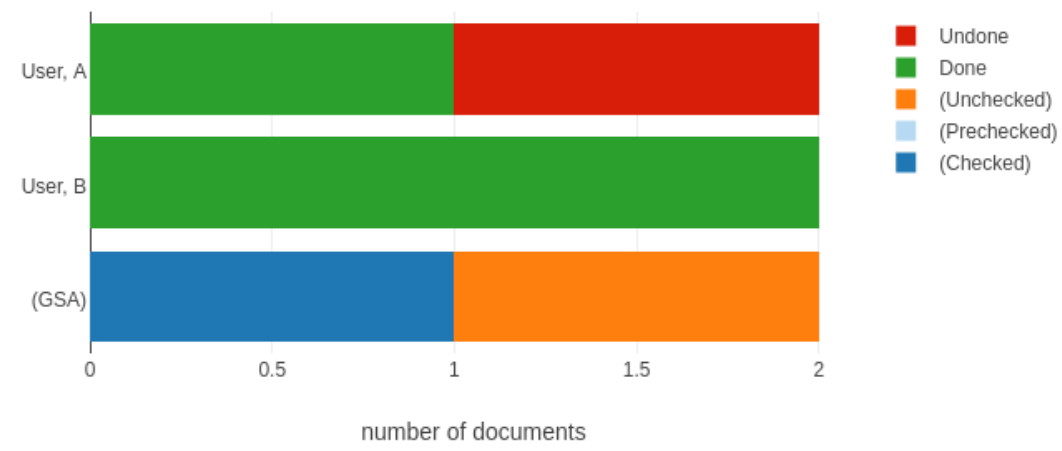

Figura 3.40: Estatísticas de status 


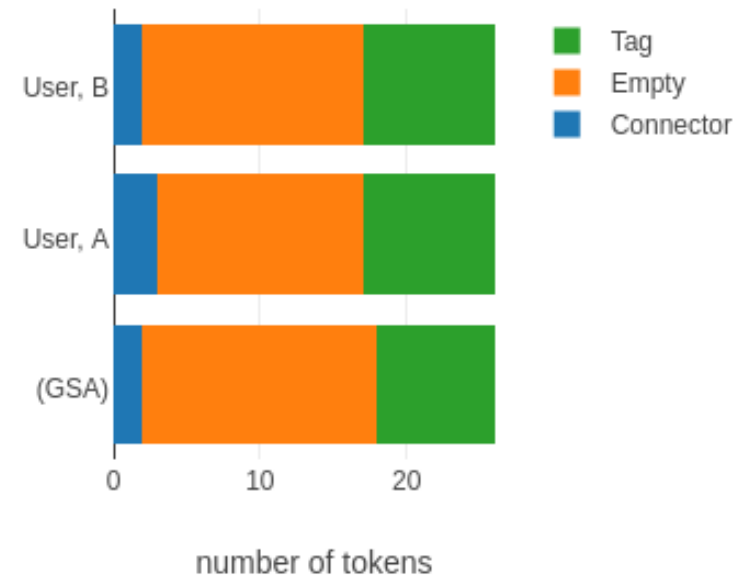

Figura 3.41: Estatísticas de cobertura dos tokens

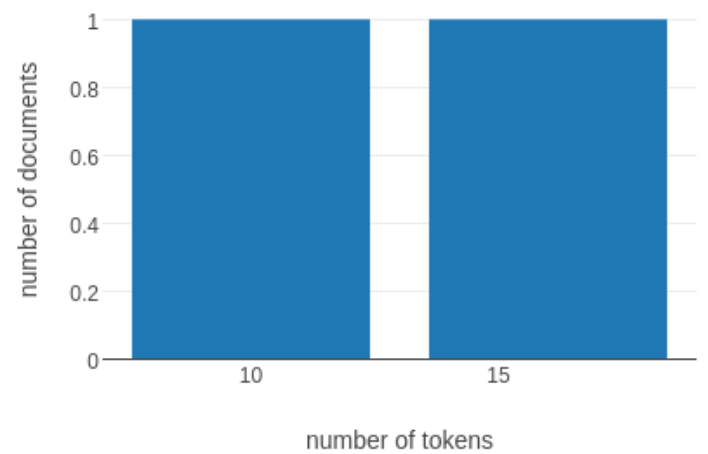

Figura 3.42: Estatísticas de distribuição dos tokens nos documentos

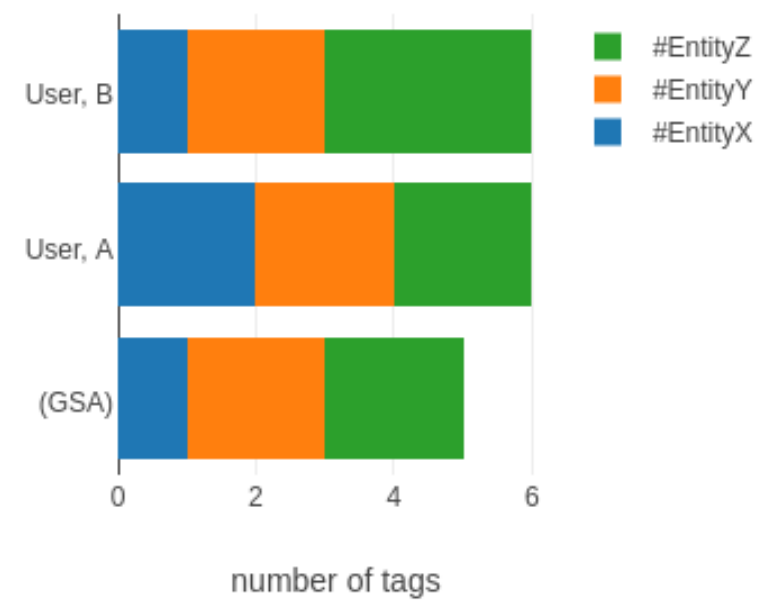

Figura 3.43: Estatísticas de entidades por colaborador, também disponíveis para relações e conectores. 


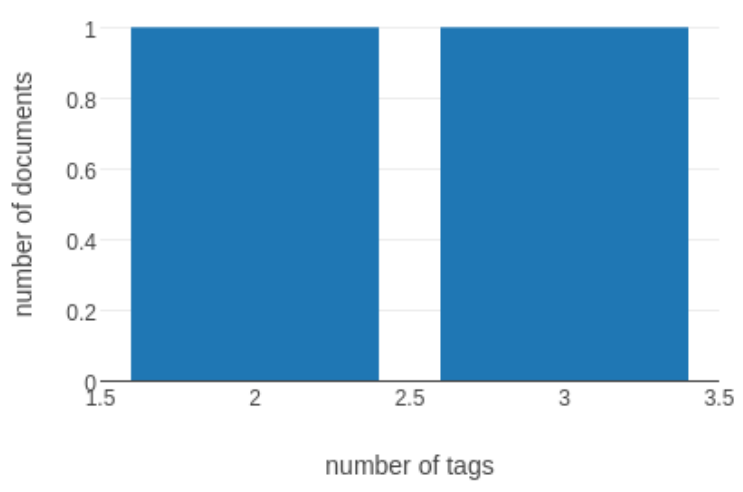

Figura 3.44: Estatísticas de distribuição das entidades no GSA, também disponíveis para relações e conectores.

Algumas funcionalidades importantes para a criação de atributos na etapa de aprendizado de máquina são ilustradas pelas figuras 3.45, 3.46 e 3.47. Essas visualizações estão disponíveis para as entidades, úteis para a tarefa NER, bem como para as relações, úteis para a tarefa RE.

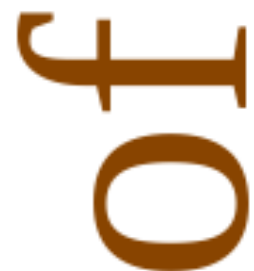

Figura 3.45: Nuvem de palavras do GSA 


\begin{tabular}{l|l|} 
Words & Occurrences \\
\hline of & 2 \\
\hline is & 1
\end{tabular}

Figura 3.46: Tabela de ocorrências das palavras no GSA

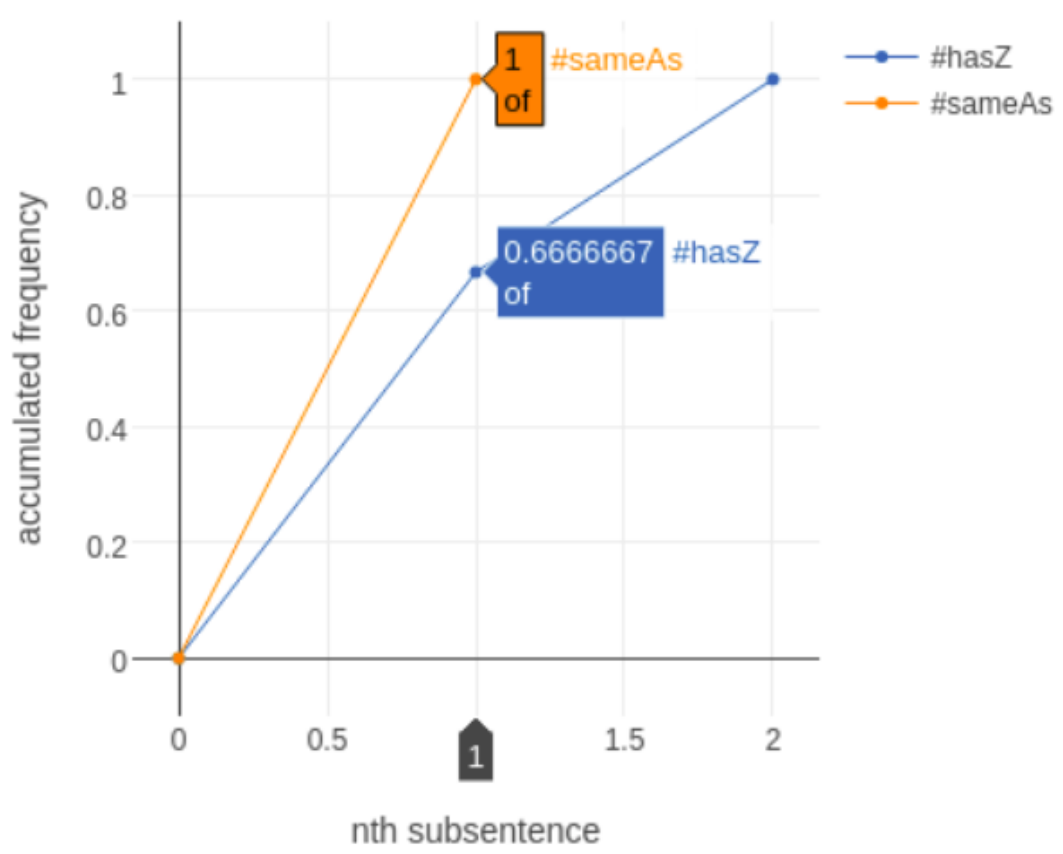

Figura 3.47: Curva de frequência acumulada das palavras no GSA

A concordância entre as anotações é calculada pelo índice kappa (32):

$$
K=\frac{P_{a}+P_{e}}{1-P_{e}}
$$

Onde:

$P_{a}$ — "Concordância observada"

$P_{e}$ — "Probabilidade de concordância ao acaso" equação:

O cálculo da probabilidade de concordância ao acaso é dado pela seguinte

$$
P_{e}=\frac{1}{|N|^{2}} \sum_{|K|} x_{k 1} x_{k 2}
$$

Onde:

$N$ — "Instâncias categorizadas"

$K$ - "Categorias disponíveis" 
$x_{k i}$ — "Número de vezes que o observador $i$ categorizou instâncias como sendo $k "$

As instâncias que serão avaliadas para o cálculo da concordância, são criadas a partir de chaves únicas dadas a fragmentos das anotações, definidas segundos regras particulares para cada tipo de anotação:

Entidades - T:<identificador do documento $>:<$ sentença do fragmento $>$ : $<$ índice do fragmento na sentença $>$, e.g., T:01.txt:0:0

Relações - R: $<$ identificador do documento $>$ : $<$ sentença do fragmento origem $>:<$ índice do fragmento origem na sentença $>:<$ classe do fragmento origem $>:<$ sentença do fragmento destino $>:<$ índice do fragmento destino na sentença $>:<$ classe do fragmento destino $>$, e.g., R:01.txt:0:0:\#EntityY:0:4:\#EntityZ

Conectores - C: $<$ identificador do documento $>:<$ sentença do fragmento origem $>:<$ índice do fragmento origem na sentença $>:<$ classe do fragmento origem $>:<$ sentença do fragmento destino $>:<$ índice do fragmento destino na sentença $>:<$ classe do fragmento destino $>:<$ sentença do fragmento $>:<$ índice do fragmento na sentença $>$, e.g., C:01.txt:0:0:\#EntityY:0:4:\#EntityZ:0:2

A figura 3.48 mostra como são definidas as instâncias no caso das entidades. A figura 3.48(a) mostra o texto anotado pelo usuário, e a figura 3.48(b) a perspectiva que será levada em consideração para o cálculo da concordância. Os fragmentos são definidos token a token com o intuito de minimizar a penalização de pequenos erros na anotação.

\section{\#EntityY \#Entityz \#EntityX \\ My body is but the lees of my better being}

(a)

\#EntityY\#EntityY \#EntityZ\#Entityz \#EntityX\#EntityX
My body is but the lees of my better being

(b)

Figura 3.48: Definição de entidades para cálculo de concordância: (a) anotação do usuário; (b) perspectiva criada para cálculo de concordância

A figura 3.49 mostra como são definidas as instâncias no caso das relações. A figura 3.49(a) mostra o texto anotado pelo usuário, e a figura 3.49(b) a perspectiva que será levada em consideração para o cálculo da concordância. É possível notar nessa imagem a criação de novas relações. Isso se deve ao fato de ser levado em conta a mesma lógica de penalização de erros adotada para o cálculo de concordância nas entidades. 


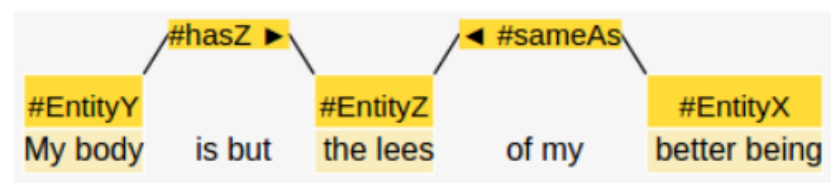

(a)

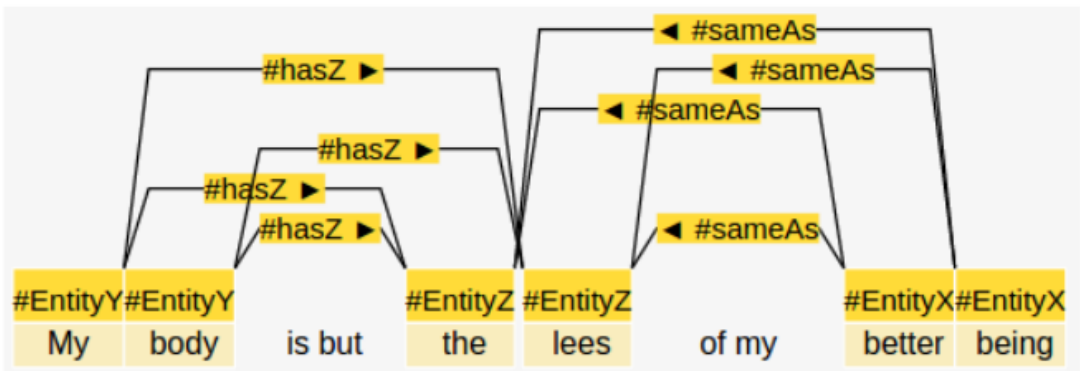

(b)

Figura 3.49: Definição de relações para cálculo de concordância: (a) anotação do usuário; (b) perspectiva criada para cálculo de concordância

A figura 3.50 mostra como são definidas as instâncias no caso dos conectores. A figura 3.50(a) mostra o texto anotado pelo usuário, e a figura 3.50(b) a perspectiva que será levada em consideração para o cálculo da concordância.

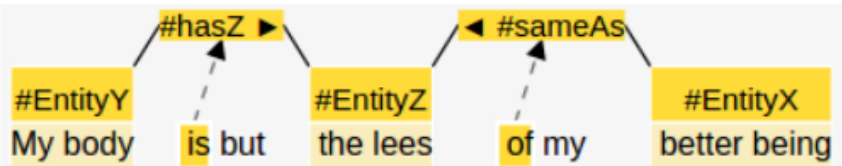

(a)

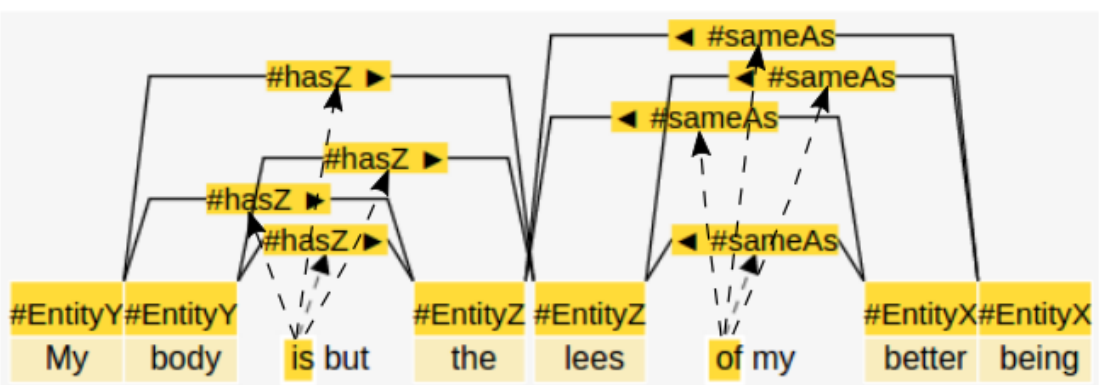

(b)

Figura 3.50: Definição de conectores para cálculo de concordância: (a) anotação do usuário; (b) perspectiva criada para cálculo de concordância

A classificação das instâncias definidas para o cálculo de concordância utiliza o tipo ( $\mathrm{T}$ para entidades, $\mathrm{R}$ para relações e $\mathrm{C}$ para conectores) e rótulo dado. Na ausência de classificação por parte de um anotador a uma instância, um rótulo especial (EMPTY) é atribuído a esta. A figura 3.51 mostra como 
ficaria uma tabela de classificação levando em consideração os exemplos de anotação mostrados nas figuras 3.16 e 3.17 .

\begin{tabular}{|c|c|c|c|c|c|c|c|c|c|c|c|c|}
\hline & \multicolumn{11}{|c|}{ USER-A } \\
\hline & & T:\#EntityX & T:\#EntityY & T:\#Entityz & T:EMPTY & R:\#hasz & R:\#sameAs & R:EMPTY & C:\#hasz & C:\#sameAs & C:EMPTY & TOTAL \\
\hline \multirow{11}{*}{ USER-B } & T:\#EntityX & 2 & 0 & 0 & 0 & 0 & 0 & 0 & 0 & 0 & 0 & 2 \\
\hline & T:\#EntityY & 0 & 3 & 0 & 0 & 0 & 0 & 0 & 0 & 0 & 0 & 3 \\
\hline & T:\#Entityz & 1 & 0 & 3 & 0 & 0 & 0 & 0 & 0 & 0 & 0 & 4 \\
\hline & T:EMPTY & 0 & 0 & 0 & 17 & 0 & 0 & 0 & 0 & 0 & 0 & 17 \\
\hline & R:\#hasz & 0 & 0 & 0 & 0 & 5 & 0 & 1 & 0 & 0 & 0 & 6 \\
\hline & R:\#sameAs & 0 & 0 & 0 & 0 & 0 & 4 & 0 & 0 & 0 & 0 & 4 \\
\hline & R:EMPTY & 0 & 0 & 0 & 0 & 1 & 0 & 0 & 0 & 0 & 0 & 1 \\
\hline & C:\#hasz & 0 & 0 & 0 & 0 & 0 & 0 & 0 & 4 & 0 & 0 & 4 \\
\hline & C:\#sameAs & 0 & 0 & 0 & 0 & 0 & 0 & 0 & 0 & 4 & 0 & 4 \\
\hline & C:EMPTY & 0 & 0 & 0 & 0 & 0 & 0 & 0 & 1 & 0 & 0 & 1 \\
\hline & TOTAL & 3 & 3 & 3 & 17 & 6 & 4 & 1 & 5 & 4 & 0 & 46 \\
\hline
\end{tabular}

Figura 3.51: Tabela de classificação dos usuários A e B para os exemplos dados no capítulo

Utilizando os dados mostrados na figura 3.51 é possível efetuar o cálculo dos valores de $P_{a}$ e $P_{e}$ para cada categoria, como pode ser visto na tabela 3.1.

Tabela 3.1: Concordâncias observadas e esperadas ao acaso no exemplo dado

\begin{tabular}{rrr} 
& $P_{a k}$ & $P_{e k}$ \\
\hline T:EntityX & 0.0435 & 0.0028 \\
T:EntityY & 0.0652 & 0.0043 \\
T:EntityZ & 0.0652 & 0.0057 \\
T:EMPTY & 0.3696 & 0.1366 \\
R:hasZ & 0.1087 & 0.0170 \\
R:sameAs & 0.0870 & 0.0076 \\
R:EMPTY & 0.0000 & 0.0005 \\
C:hasZ & 0.0870 & 0.0095 \\
C:sameAs & 0.0870 & 0.0076 \\
C:EMPTY & 0.0000 & 0.0000 \\
\hline & 0.9132 & 0.1916
\end{tabular}

Os valores finais para $P_{a}$ e $P_{e}$ no exemplo descrito são 0.9132 e 0.1916 respectivamente, o que leva a um valor de 0,8926 para o índice kappa.

Na figura 3.52 é possível ver os valores das concordâncias do modo que são visualizados na plataforma, no formato de um mapa de calor. Nota-se que além da concordância entre os anotadores $\mathrm{A}$ e B, há o cálculo da autoconcordância, essa comparação é feita utilizando os documentos re-anotados pelo próprio usuário caso o mesmo tenha um passo de re-anotação definido (ver seção 3.4.1), outro cálculo também feito é a concordância entre o anotador e a anotação ideal (que no exemplo aqui mostrado será o documento resultante das anotações que coincidiram entre ambos anotadores). No ERAS esses valores são calculados apenas com base nos documentos em estado CHECKED. 


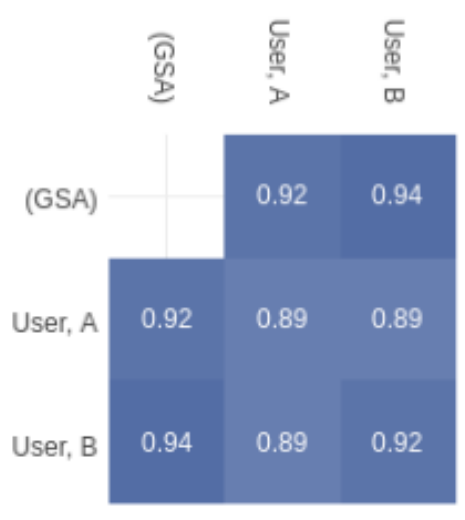

(a)

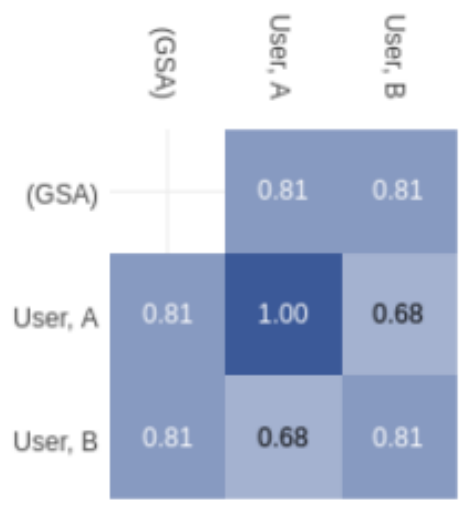

(c)

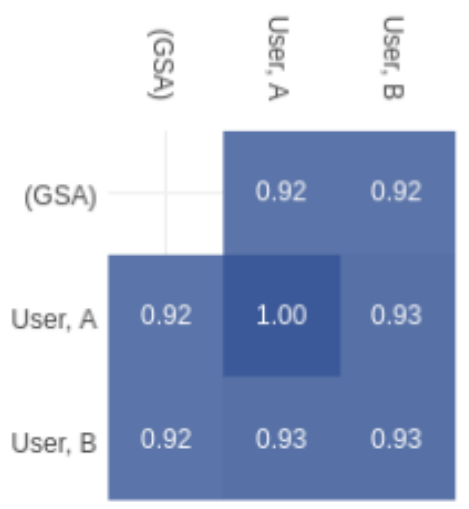

(b)

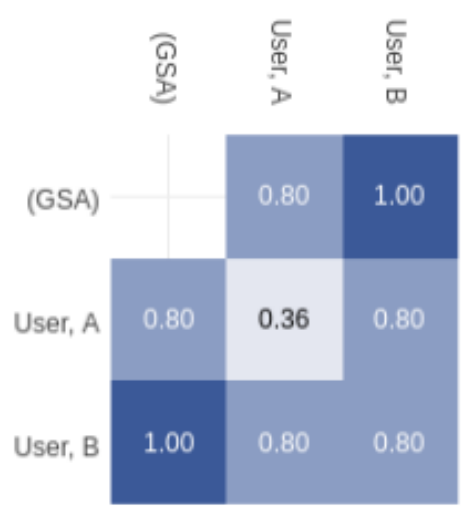

(d)

Figura 3.52: Mapa de concordância para o exemplo dado no capítulo: (a) entidades, relações e conectores; (b) apenas entidades; (c) apenas relações; (d) apenas conectores

Uma característica interessante presente no ERAS e, até onde pesquisado, não percebida em outros sistemas de anotação, é ilustrada pelas figuras 3.53 e 3.54. Trata-se da visualização da evolução temporal das concordâncias dos anotadores em relação ao GSA e em relação a eles mesmos. 


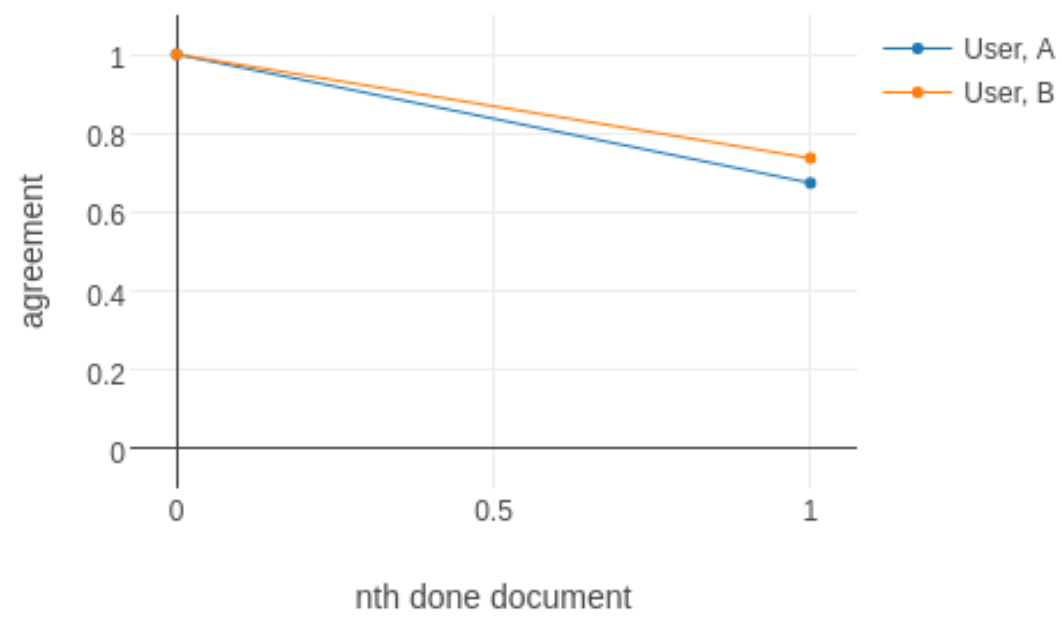

Figura 3.53: Curva de concordância com o GSA ao longo do tempo

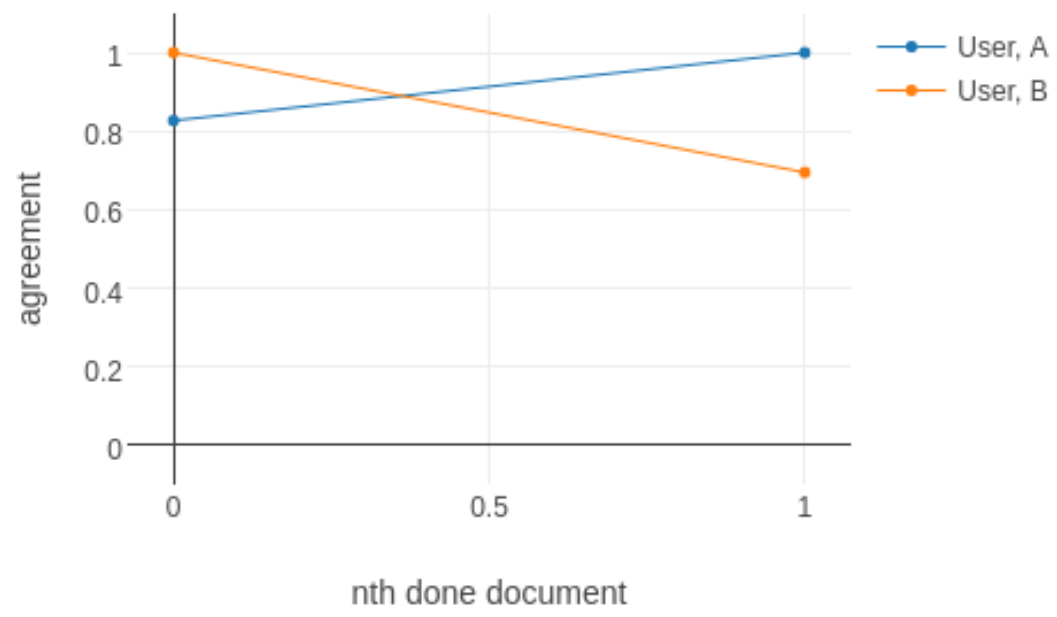

Figura 3.54: Curva de auto-concordância ao longo do tempo

Por fim, o curador tem uma visualização conjunta das estatísticas gerais de cada anotador, como ilustrado pela figura 3.55. 


Collaborations
\begin{tabular}{|l|l|l|l|l|l|l|}
\hline Collaborator & Time spent & Time spent AVG & Time spent SD & \# Views & \# Views AVG & \# Views SD \\
\hline User, B & $1 \mathrm{~m} 37 \mathrm{~s}$ & $48 \mathrm{~s}$ & $1 \mathrm{~s}$ & 2,00 & 1,00 & 0,00 \\
\hline User, A & $19 \mathrm{~m} \mathrm{32s}$ & $9 \mathrm{~m} \mathrm{46s}$ & $7 \mathrm{~m} \mathrm{50s}$ & 16,00 & 8,00 & 0,00 \\
\hline
\end{tabular}

Documents
\begin{tabular}{|l|l|l|l|l|l|l|l|l|}
\hline Name & \# Tokens & Time spent & Time spent AVG & Time spent SD & \# Views & \# Views AVG & \# Views SD \\
\hline 02.txt & 13 & $2 \mathrm{~m} \mathrm{46s}$ & $1 \mathrm{~m} \mathrm{23s}$ & $33 \mathrm{~s}$ & 9 & 4,50 & 3,50 & 土 \\
\hline $01 . t x t$ & 11 & $18 \mathrm{~m} \mathrm{23s}$ & $9 \mathrm{~m} 11 \mathrm{~s}$ & $8 \mathrm{~m} \mathrm{24s}$ & 9 & 4,50 & 3,50 & \\
\hline
\end{tabular}

Figura 3.55: Estatísticas básicas sobre colaboradores e documentos

\section{5}

\section{Aprendizado automático}

O módulo de aprendizado automático possibilita a criação de tarefas para o treinamento e o teste de classificadores para NER e RE. A figura 3.56 mostra o formulário principal de configuração da tarefa General, onde se define o seu nome, tipo e o projeto de onde consumir os dados GSA.

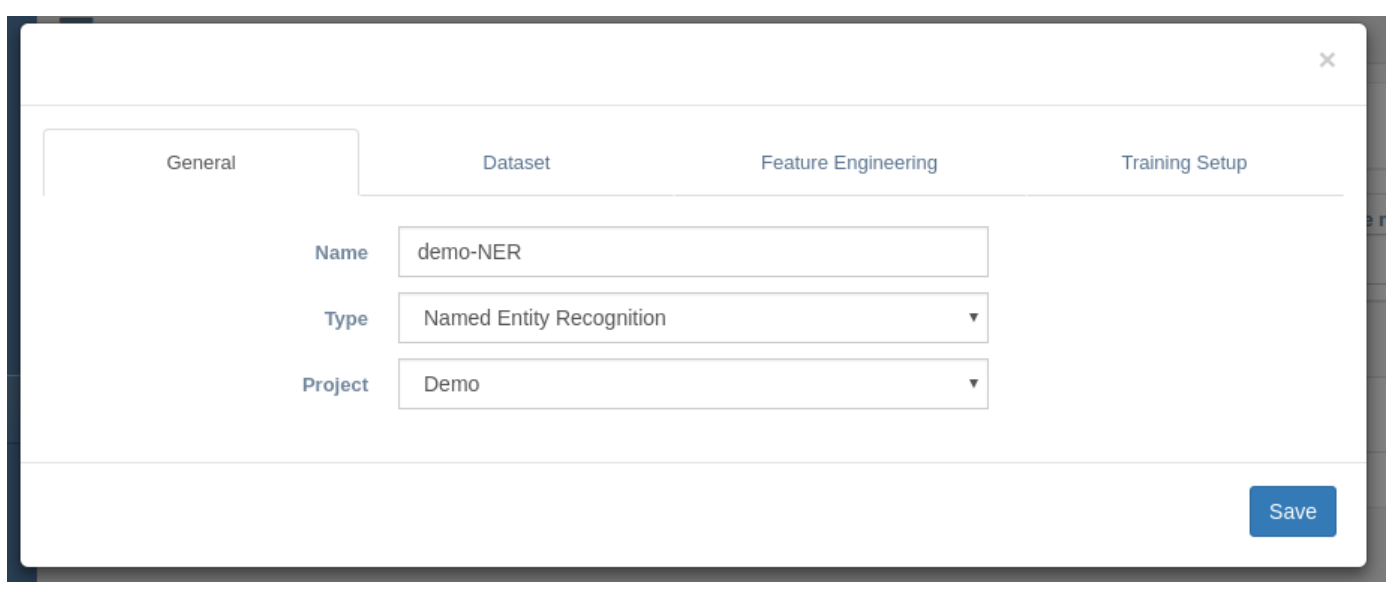

Figura 3.56: Configurações gerais das tarefas

A figura 3.57 mostra o formulário de configuração dos dados a serem ou não usados no treinamento e teste do classificador da tarefa. Uma barra superior indica a quantidade e o percentual de documentos para treino e teste. A parte inferior mostra uma árvore representativa da ontologia usada, onde se pode generalizar algumas classes pelas classes que as contêm ou mesmo excluir algumas entidades. 


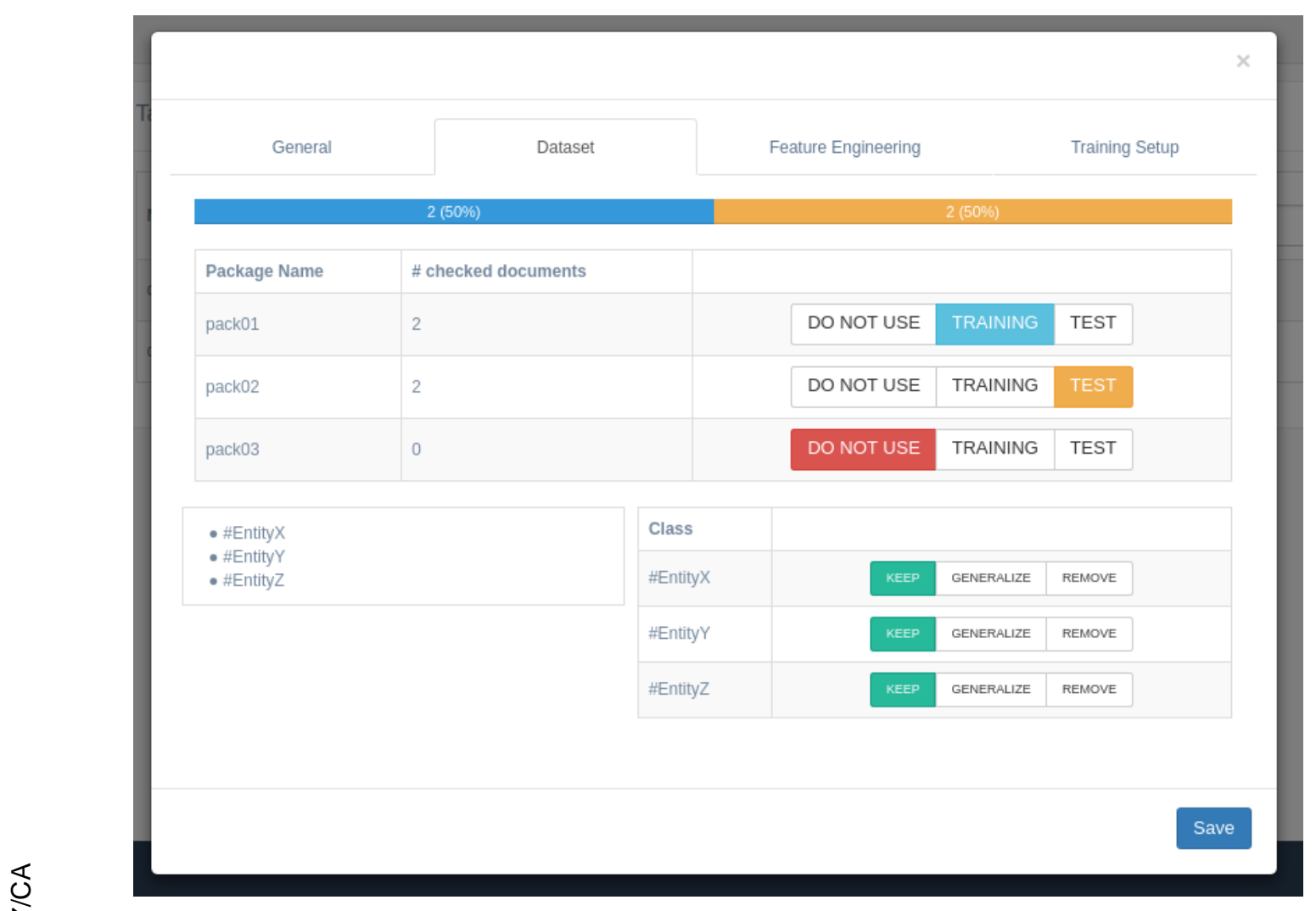

Figura 3.57: Configurações dos dados das tarefas

O formulário de atributos para o classificador, ilustrado pelas figuras 3.58 e 3.59, apresenta diversas opções para NER e RE. Estes atributos são baseados nos descritos por (6). Para NER, há 6 tipos disponíveis:

- FORM(X, step, regex): aplica uma expressão regular (regex) sobre o conteúdo completo do parâmetro FORM (conforme resultado do POS Tagger) do token localizado a um número de passos (step, com valor nulo, positivo ou negativo) do token X. (Note-se que, se step é nulo, o atributo representará a aplicação da regex sobre a representação FORM do próprio token $\mathrm{X}$.);

- LEMMA(X, step, regex): o mesmo conceito de $\operatorname{FORM}(\mathrm{X}$, step, regex), porém aplicado sobre a representação LEMMA;

- POS(X, step): o POS tag do token localizado a step passos do token X;

- PROB(X, step): o valor da probabilidade, segundo o POS Tagger, do conteúdo de POS do token localizado a step passos do token X;

- RANGE-FORM(X, step, regex): aplica uma expressão regular sobre o conteúdo da string formada pela concatenação - com espaços - dos parâmetros FORM dos tokens em um range de step a partir do token X;

- RANGE-LEMMA(X, step, regex): o mesmo conceito de RANGEFORM(X, step, regex), porém aplicado sobre a representação LEMMA. 
Há uma diferença entre NER e RE no tocante aos tipos de instância a serem avaliados. Em NER, avalia-se token a token. Em RE, avalia-se as relações entre "nós", isto é, entre entidades nomeadas segundo a ontologia, presentes no texto. São 12 os atributos disponíveis:

- RANGE-FORM(X, step, regex): o mesmo conceito usado no NER, considerando, porém, que o parâmetro step se baseia em um dos nós da relação $\mathrm{X}$, dependendo do sinal: se step é negativo, aplica-se à esquerda da relação; se positivo, à direita desta. Valores nulos de step não implementam esta feature;

- RANGE-LEMMA(X, step, regex): o mesmo conceito de RANGE-FORM, descrito no item anterior, aplicado sobre LEMMA;

- POSITIONAL-FORM(X, step, regex): o mesmo conceito usado no NER, considerando, porém, que o parâmetro step se baseia em um dos nós da relação $\mathrm{X}$, dependendo do sinal: se step é negativo, aplica-se à esquerda da relação; se positivo, à direita desta. Valores nulos de step não implementam esta feature;

- POSITIONAL-LEMMA(X, step, regex): o mesmo conceito de POSITIONAL-FORM, descrito no item anterior, aplicado sobre LEMMA;

- POS(X, step): o mesmo conceito usado no NER, considerando, porém, que o parâmetro step se baseia em um dos nós da relação X, dependendo do sinal: se step é negativo, aplica-se à esquerda da relação; se positivo, à direita desta. Valores nulos de step não implementam esta feature;

- INTERIOR-RANGE-FORM(X, regex): aplica uma expressão regular sobre o conteúdo da string formada pela concatenação, com espaços, dos parâmetros FORM dos tokens entre os nós da relação X;

- INTERIOR-RANGE-LEMMA(X, regex): o mesmo conceito de INTERIOR-RANGE-FORM, descrito no item anterior, aplicado sobre LEMMA;

- NODE-TO-NODE-DISTANCE(X): calcula a distância, em tokens, entre os nós da relação X. Para fins de redução da magnitude desse atributo a uma ordem de grandeza próxima dos outros, que são binários, o valor é dividido pela máxima quantidade de tokens encontrada nos documentos de treino do modelo;

- NODE-TO-NODE-DISTANCE-WITH-SIGNAL(X): mesmo conceito do atributo descrito acima, porém possibilitando valores negativos. A ideia é que este atributo, além de representar a distância entre nós, carregue também a informação do sentido da relação: números negativos traduzem relações da direita para a esquerda e, positivos, da esquerda para a direita;

- CLASS-NODE-FROM(X): classe de NER do nó de saída da relação X;

- CLASS-NODE-TO(X): classe de NER do nó de chegada da relação X;

- POSSIBLE-RELATION(X): indica se a relação é ou não possível, com base nos dados do conjunto de treinamento. 
Há também a opção de configurar a leitura das POS Tags em dimensões ou níveis específicos, como já comentado anteriormente. Uma das características mais importantes está no botão Auto generate, que, com base nos parâmetros da parte superior do formulário, gera atributos automaticamente. Essa geração automática cria expressões regulares pelo uso das tabelas de frequências acumuladas de palavras ligadas às entidades e às relações (conectores).

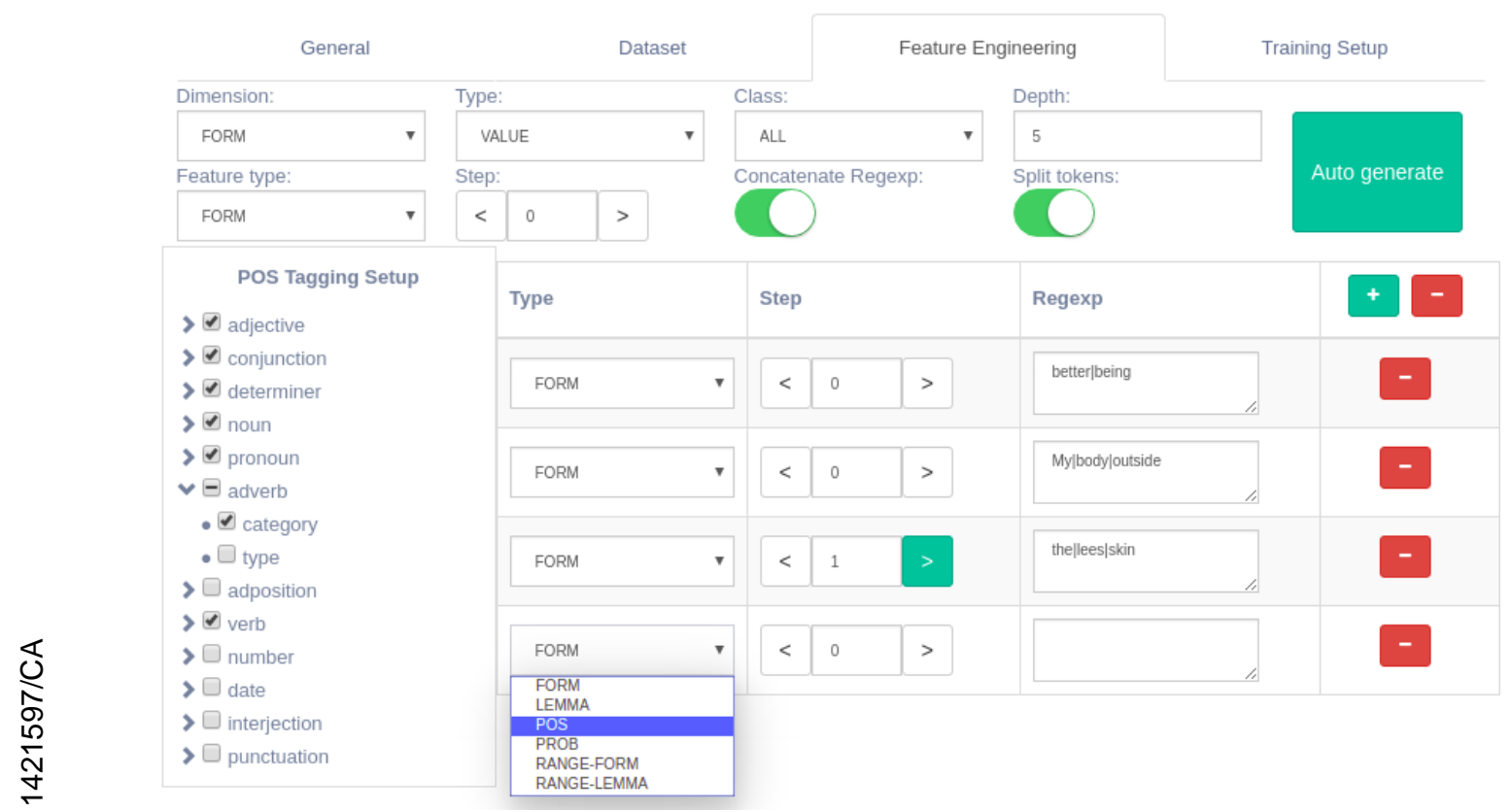

Figura 3.58: Engenharia de atributos da tarefas

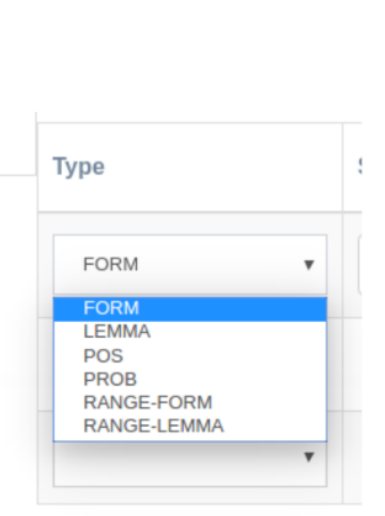

(a)

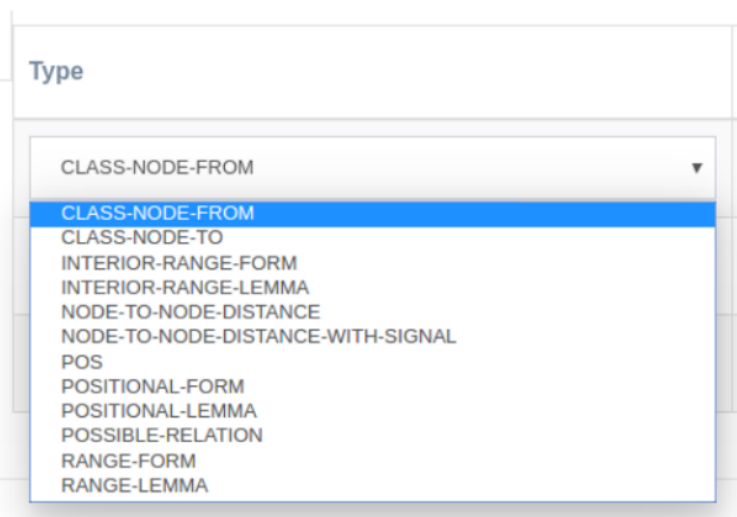

(b)

Figura 3.59: Atributos disponíveis: (a) NER; (b) RE

A partir dos atributos definidos para a tarefa, uma matriz numérica é criada com base nos dados de treino, um exemplo do formato desta matriz para a tarefa de NER pode ser vista na figura 3.60. Nota-se que cada amostra 
de aprendizado equivale a um token do documento. Outro ponto a se observar na figura é que a classificação do token (coluna Y) não equivale apenas ao que este representa no domínio, mas também se o mesmo participa da descrição no início do bloco anotado ou não. Deve-se observar também que a coluna $\mathrm{Y}$ da referida imagem não está no formato numérico com intuito de facilitar a explicação desta, já que as classes devem ser codificadas para valores numéricos antes de submetida aos algoritmos de aprendizado automático.

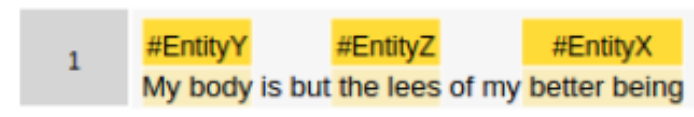

(a)

\begin{tabular}{|c|c|c|c|c|c|}
\hline & FORM $(x, 0, "$ "t") & FORM(X, -1, "of") & RANGE-FORM( $X,-3$, "is") & $\operatorname{POS}(X, 0)[$ verb] & $Y$ \\
\hline My & 0 & 0 & 0 & 0 & B-\#EntityY \\
\hline body & 0 & 0 & 0 & 0 & I-\#EntityY \\
\hline is & 0 & 0 & 0 & 1 & $\mathrm{o}$ \\
\hline but & 1 & 0 & 1 & 0 & $\mathrm{o}$ \\
\hline the & 1 & 0 & 1 & 0 & B-\#Entityz \\
\hline lees & 0 & 0 & 1 & 0 & I-\#Entityz \\
\hline of & 0 & 0 & 0 & 0 & $\mathrm{o}$ \\
\hline my & 0 & 1 & 0 & 0 & $\mathrm{o}$ \\
\hline better & 1 & 0 & 0 & 0 & B-\#EntityX \\
\hline being & 0 & 0 & 0 & 1 & I-\#Entity $x$ \\
\hline
\end{tabular}

(b)

Figura 3.60: Exemplo de atributos para a tarefa de NER: (a) documento de entrada; (b) exemplo de uma matriz criada utilizando o documento de entrada

Como na figura acima, a figura 3.61 apresenta um exemplo do formato da matriz de treino, só que desta vez para a tarefa de RE. É possível notar nesta figura uma diferença crucial entre as instâncias das tarefas, que é o fato de cada amostra não ser mais apenas um token, porém um documento inteiro, sendo este descrito na forma de um grafo completo, onde os nós são as entidades anotadas, e o que será classificado na tarefa é a existência de uma aresta e seu rótulo. Esta definição do rótulo de uma aresta pelo modelo é uma melhoria ao que foi feito por (6), onde apenas era feita a classificação da existência das arestas, ou seja, o problema era tratado como uma classificação binária, sendo a rotulação feita por meio de regras pré-definidas para o domínio. Outra melhoria feita foi o fato de a abordagem utilizada no LER poder retornar grafos desconexos e até mesmo aceitar ciclos nestes. Na proposta anterior apenas uma árvore era dada como saída do classificador. 


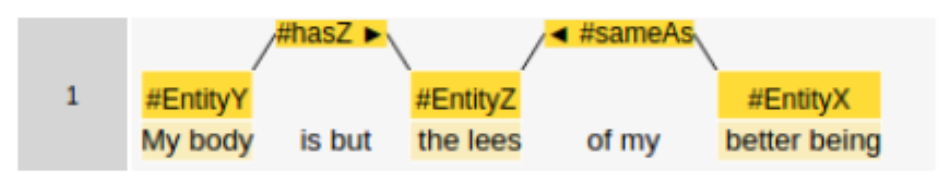

(a)

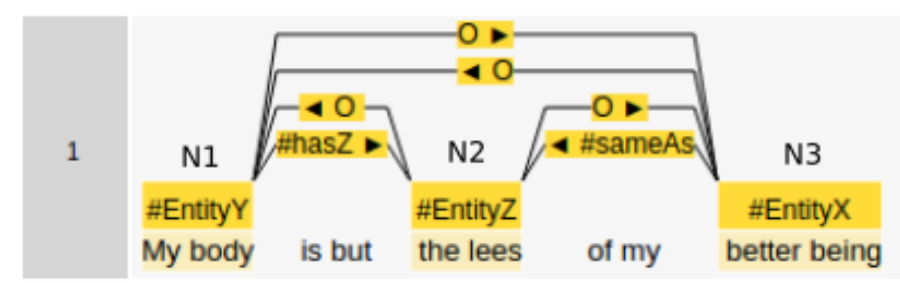

(b)

\begin{tabular}{|c|c|c|c|}
\hline & NODE-TO-NODE-DISTANCE(X) & INTERIOR-RANGE-FORM(X, "is") & $\mathrm{Y}$ \\
\hline $\mathrm{N} 1 \rightarrow \mathrm{N} 2$ & 4 & 1 & \#hasz \\
\hline N1 $\rightarrow$ N3 & 8 & 1 & $\mathrm{o}$ \\
\hline $\mathrm{N} 2 \rightarrow \mathrm{N} 1$ & 4 & 1 & $\mathrm{o}$ \\
\hline N2 $\rightarrow$ N3 & 4 & 0 & $\mathrm{o}$ \\
\hline $\mathrm{N} 3 \rightarrow \mathrm{N} 1$ & 8 & 1 & $\mathrm{o}$ \\
\hline N3 $\rightarrow$ N2 & 4 & 0 & \#sameAs \\
\hline
\end{tabular}

(c)

\begin{tabular}{l|c|r|}
\multicolumn{3}{c}{ FEATURES } \\
\cline { 2 - 3 } 01.txt \\
\cline { 2 - 3 } 02.txt $[4,1],[8,1],[4,1],[4,0],[8,1],[4,0]]$ & {$[\#$ \#hasZ, O, O, O, O, \#sameAs] } \\
\cline { 2 - 4 } & {$[\ldots]$} & {$[\ldots]$} \\
\cline { 2 - 4 }
\end{tabular}

(d)

Figura 3.61: Exemplo de atributos para a tarefa de RE: (a) documento de entrada; (b) perspectiva do documento de entrada criada para geração da matriz de atributos; (c) exemplo simplificado de uma matriz criada utilizando o documento de entrada; (d) exemplo de uma matriz criada utilizando o documento de entrada

O último menu da criação da tarefa, Training Setup, trata das configurações de gridsearch (33) a serem executadas na tarefa, para a busca dos melhores parâmetros em relação a 4 diferentes índices: Accuracy; Precision; Recall; F1. Os algoritmos de aprendizado automático disponíveis na plataforma são os mesmos utilizados por (6) com acréscimo de alguns outros. Para a tarefar de NER: Support Vector Classification (34); Random Forest (35); Linear Stochastic Gradient Descent (36). Para a tarefa de RE: Structured Perceptron (37); Frank-Wolfe SSVM (38). Tais algoritmos foram adicionados apenas com o intuito de demostrar que dada a forma como o LER fora implementando, é possível o uso de vários algoritmos para as tarefas de NER e RE. Espera-se que com a evolução da ferramente e o uso desta em diversos domínios diferentes, mais algoritmos sejam incluídos. 


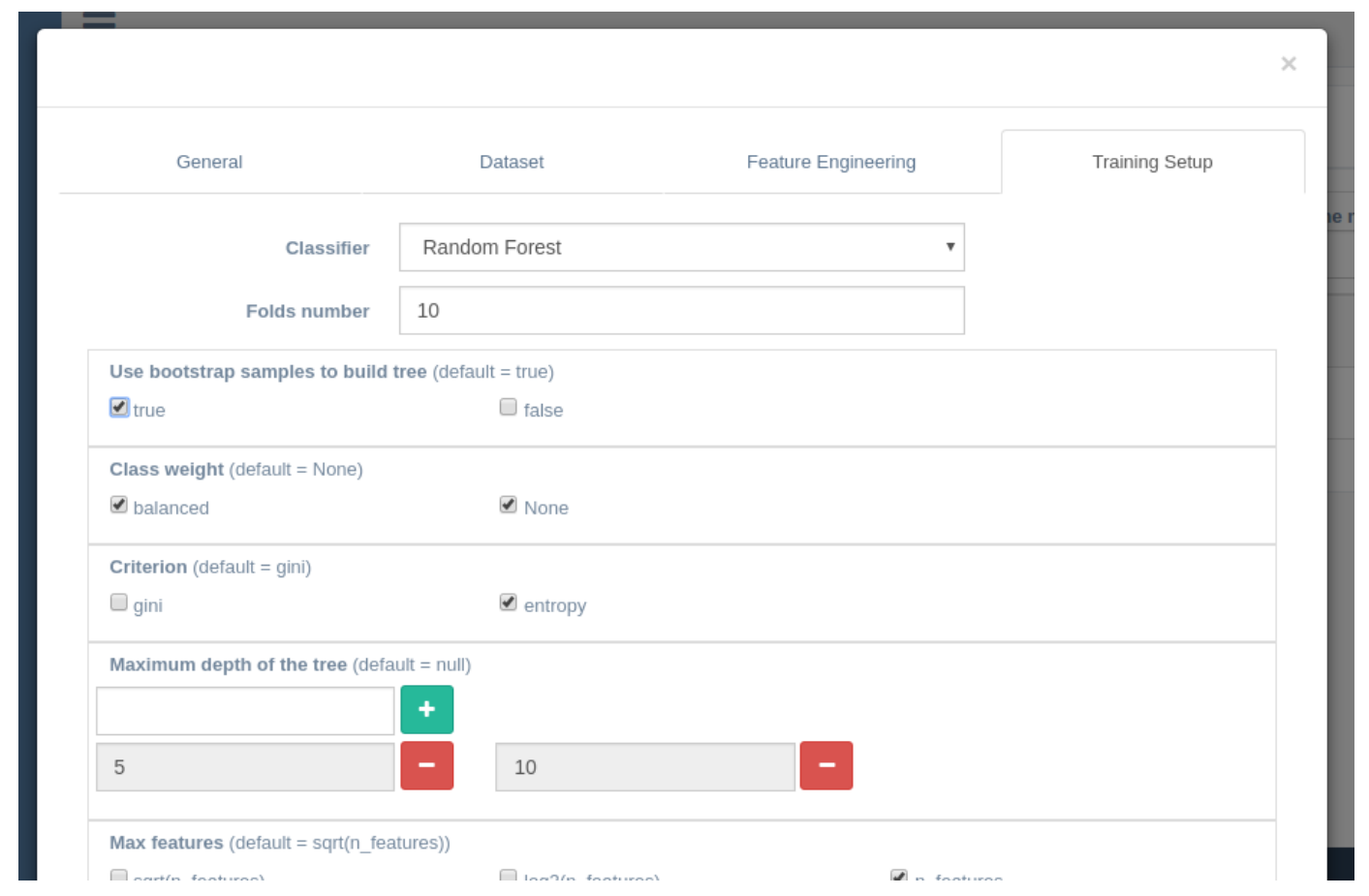

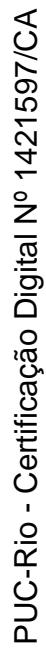

Figura 3.62: Configurações dos classificadores

Criadas as tarefas, elas podem ser iniciadas ou encerradas em modo paralelo e independente, como ilustrado pela figura 3.63. 


\begin{tabular}{|l|l|l|l|l|}
\hline Name & Type & Project & Status & \\
\hline demo-NER & NER & Demo & off & Task to c \\
\hline
\end{tabular}

(a)

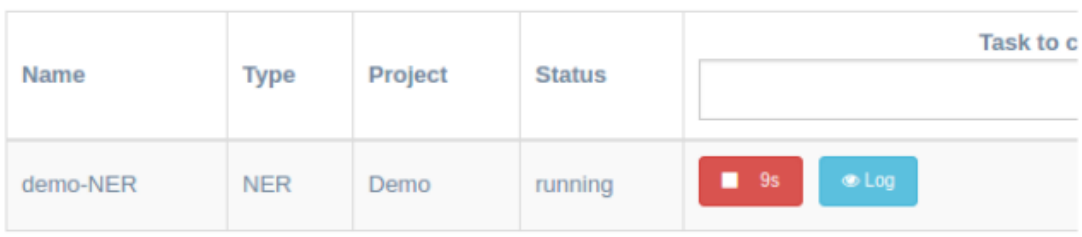

(b)

\begin{tabular}{|c|c|c|c|c|c|}
\hline & & & & & Task to \\
\hline demo-NER & NER & Demo & running & D $10 \mathrm{~s}$ & - Log \\
\hline demo-NER-clone & NER & Demo & running & D 7 & - Log \\
\hline
\end{tabular}

(c)

Figura 3.63: Execução de tarefas: (a) estado inicial da tarefa; (b) tarefa em execução; (c) tarefas executando em paralelo

Durante a execução, ou mesmo em caso de encerramento com sucesso ou erro, é possível visualizar o log de cada tarefa (ver figura 3.64), que apresenta em formato de texto as principais informações sobre seu processo de treinamento e teste.

INFO [2017-04-11 02:48:12,756]: Starting logger.

INFO [2017-04-11 02:48:12,879]: Master Thread configuration DONE.

INFO [2017-04-11 02:48:12,968]: Starting Master Thread.

INFO [2017-04-11 02:48:13,097]: Slave Process started.

INFO [2017-04-11 02:48:13,290]: Master sent data through PIPE conn to Slave.

INFO [2017-04-11 02:48:13,388]: Master sent msg to Slave to receive data.

INFO [2017-04-11 02:48:13,388]: Starting NER learning function.

INFO [2017-04-11 02:48:13.507]: Slave received data.

INFO [2017-04-11 02:48:13,507]: Collecting trainning documents

INFO [2017-04-11 02:48:14,117]: Collecting test documents

INFO [2017-04-11 02:48:14,532]: Building features

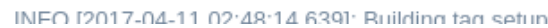

Figura 3.64: Log de execução da tarefa 
Por fim, em caso de rodada completa da tarefa e sem erros, é possível ler os resultados numéricos dos melhores parâmetros aplicados, em termos 4 índices alvo, como ilustrado pela figura 3.65 e 3.66 .

\begin{tabular}{|l|l|}
\hline Task elapsed time: 43 s \\
\hline model-recall-demo-NER \\
\hline model-precision-demo-NER \\
\hline model-fscore-demo-NER \\
\hline model-accuracy-demo-NER \\
\hline \begin{tabular}{l}
\hline Classifier: Random Forest \\
Grid search metric: accuracy \\
Training elapsed cPU time: 0.08897500000000047 seconds
\end{tabular} \\
\hline Best Parameters \\
\hline Parameter & Value \\
\hline Max features & n_features \\
\hline Class weight & None \\
\hline Training scores & \\
\hline Test scores & \\
\hline
\end{tabular}

Figura 3.65: Resultados da tarefa

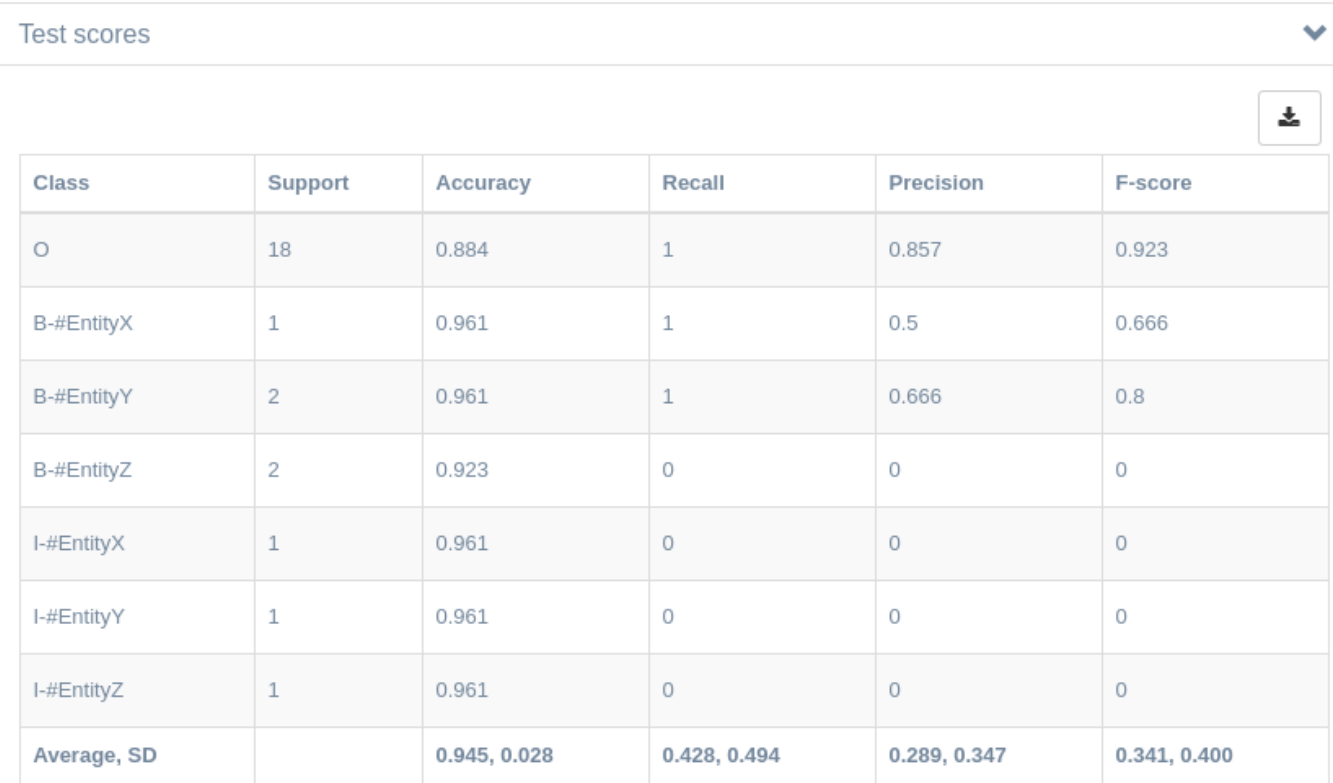

Figura 3.66: Scores do modelo treinado 
O sistema LER avalia os resultados de todos os modelos - de NER e RE e escolhe os melhores parâmetros para cada um dos clássicos índices Accuracy, Precision, Recall e F1 (39):

$$
\begin{gathered}
\text { Accuracy }=\frac{t p+t n}{t p+t n+f p+f n} \\
\text { Precision }=\frac{t p}{t p+f p} \\
\text { Recall }=\frac{t p}{t p+f n} \\
F 1=2 \cdot \frac{\text { Precision } \cdot \text { Recall }}{\text { Precision }+ \text { Recall }}
\end{gathered}
$$

Sendo:

$$
\begin{aligned}
& \text { tp — "true positive" } \\
& \mathrm{fp} \text { — "false positive" } \\
& \text { tn — "true negative" } \\
& \mathrm{fn} \text { — "false negative" }
\end{aligned}
$$

\section{6}

\section{Publicação de serviços}

Após todo o processo de curadoria e treinamento dos modelos, estes podem ser finalmente implantados para o uso na tarefa de estruturação dos dados textuais. No LER isso é feito por meio de serviços que disponibilizarão uma interface utilizando o protocolo HTTP. A figura 3.67 mostra a tela de criação de tais serviços, onde o usuário escolhe dentre todos os modelos treinados para determinado projeto, qual modelo ficará encarregado para o reconhecimento de entidades e qual será o modelo responsável pela extração de relações, bem como a definição de mapeamentos do texto classificado para propriedades das entidades. 


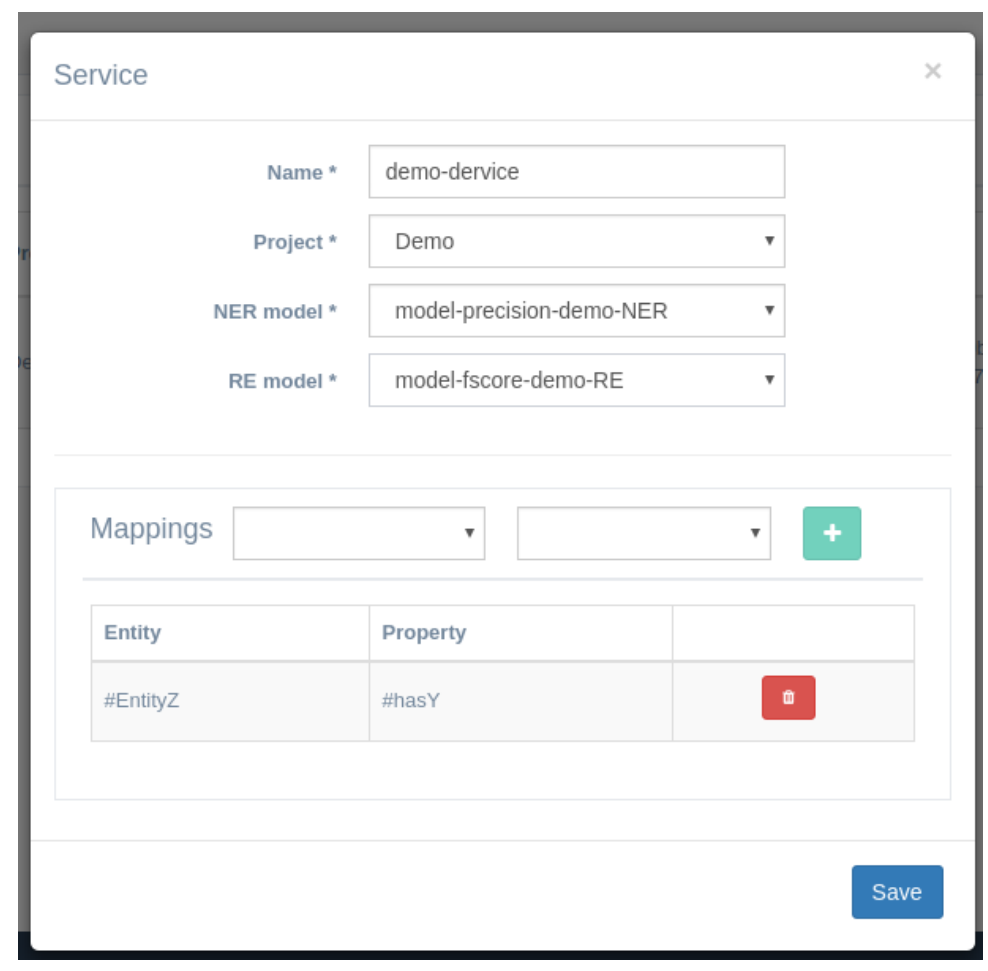

Figura 3.67: Criação do serviço

Assim que o serviço é criado, ficará ativo e esperando requisições. A figura 3.68 mostra a tela que lista os serviços ativos na plataforma, nesta mesma imagem é possível notar a presença de um token de autenticação associado ao serviço, esta é a forma como as requisições a este serão controladas, apenas quem estiver de posse desse token poderá ter suas requisições aceitas.

\begin{tabular}{|c|c|c|c|c|c|c|c|}
\hline Name & Project & NER model & RE model & Token & URL & & \\
\hline $\begin{array}{l}\text { demo- } \\
\text { dervice }\end{array}$ & Demo & $\begin{array}{l}\text { model- } \\
\text { precision- }\end{array}$ & $\begin{array}{l}\text { model- } \\
\text { fscore- }\end{array}$ & $\begin{array}{l}\text { 013b8764-1e9c-4f9e- } \\
\text { a31b-ca59a3b287d5 }\end{array}$ & $\begin{array}{l}\text { http://127.0.0.1:50003/services/58e572ct3249b0480fef1301/predict? } \\
\text { token }=013 \mathrm{~b} 8764-1 \mathrm{e} 9 \mathrm{c}-499 \mathrm{e}-\mathrm{a} 31 \mathrm{~b}-\mathrm{c} \text { a59a3b287d5 }\end{array}$ & 1 & 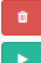 \\
\hline
\end{tabular}

Figura 3.68: Serviços disponíveis

A resposta dada pelo serviço é estruturada em dois formatos, JSON (40) e triplas RDF (41), as figuras 3.69 e 3.70 mostram exemplos de retornos dados pelos serviços, onde a primeira mostra o resultado do teste que o próprio LER disponibiliza em sua interface, e a segunda o resultado do acesso aos serviços utilizando uma aplicação externa. 
Service test

My body is but the lees of my better being

1 \#Entityz \#Entityz \#EntityX\#EntityX

My body is but the lees of my better being

<http://www.semanticweb.org/fake-ontology/Entityz/1><http://www.w3.org/1999/02/22-rdf-syntax-ns\#ttype> <http://www.semanticweb.org/fake-ontology/Entityz> . <http://www. semanticweb.org/fake-ontology/EntityZ/1><http://www.semanticweb.org/fake-ontology/has $Y>$ "the lees of my" .

<http://www. semanticweb.org/fake-ontology/EntityX/0><http://www.w3.org/1999/02/22-rdf-syntax-ns"ttype> <http:///www.semanticweb.org/fake-ontology/EntityX> .

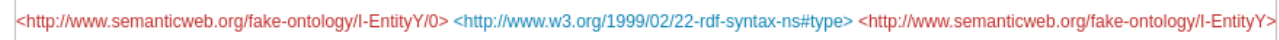
<http://www. semanticweb.org/fake-ontology/Entityz/0><http://www.semanticweb.org/fake-ontology/has $Y>$ "but"

<http://www.semanticweb.org/fake-ontology/EntityX/1><http://www.w3.org/1999/02/22-rdf-syntax-ns\#ttype> <http://www.semanticweb.org/fake-ontology/EntityX> . <http://www. semanticweb.org/fake-ontology/Entityz/0><http://www.w3.org/1999/02/22-rdf-syntax-ns \#type><http://www.semanticweb.org/fake-ontology/Entityz> .

Figura 3.69: Teste do serviço

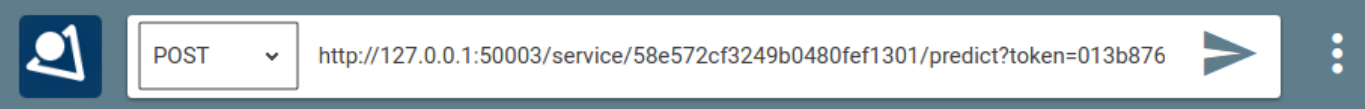

Response

BODY HEADERS

"rdfTriples": [

"<http: //Www. semanticweb.org/fake-ontology/Entityz/0><http://w "<http://WWW. semanticweb.org/fake-ontology/EntityX/O><http://W

"<http://WWW. semanticweb.org/fake-ontology/EntityX/1><http://w

"<http://WWW. semanticweb.org/fake-ontology/Entityz/0><http://w

"<http://WWW. semanticweb.org/fake-ontology/I - EntityY/O>< <ttp:/.

"<http://WWw. semanticweb.org/fake-ontology/Entityz/1><http://W

]$_{n}$

"<http://WWW. semanticweb.org/fake-ontology/Entityz/1> <http://w json" :

"sentences": [

"tnkanc". I

Figura 3.70: Teste externo do serviço 
I try all things, I achieve what I can.

Herman Melville, Moby-Dick; or, The Whale. 


\section{4 \\ Experimentos}

Este capítulo apresenta as descrições e os resultados de dois tipos de experimentos, o primeiro relativo a uma avaliação do ERAS com a participação de um grupo de anotadores recrutados e o segundo relativo ao funcionamento do LER sobre dados de tweets de trânsito anotados de forma especializada, tendo uma versão modificada da TEDO como base.

\section{1}

\section{Experimento de anotação}

Um experimento de anotação foi conduzido com o intuito de avaliar o comportamento da plataforma para a tarefa de curadoria de dados, tarefa esta de domínio do subsistema ERAS. Optou-se por executar a tarefa de curadoria de anotações sobre o mesmo domínio de dados avaliados por (6), que é o de tweets de eventos de trânsito.

As próximas seções descrevem a metodologia empregada no experimento, seguida pelos resultados acompanhados de uma análise.

\subsection{1 \\ Metodologia}

Foram coletados 100 tweets de eventos de trânsito, 50 da conta @operacoesRio e 50 da conta @odia24horas. Em seguida, foram separados 25 tweets de cada conta com o objetivo de criar o guia de anotação (o resultado pode ser visto no Apêndice A) e, também, realizar adaptações na ontologia TEDO com base nas dificuldades encontradas ao utilizar a mesma para anotar os textos. A Figura 4.1 mostra a ontologia resultante. 


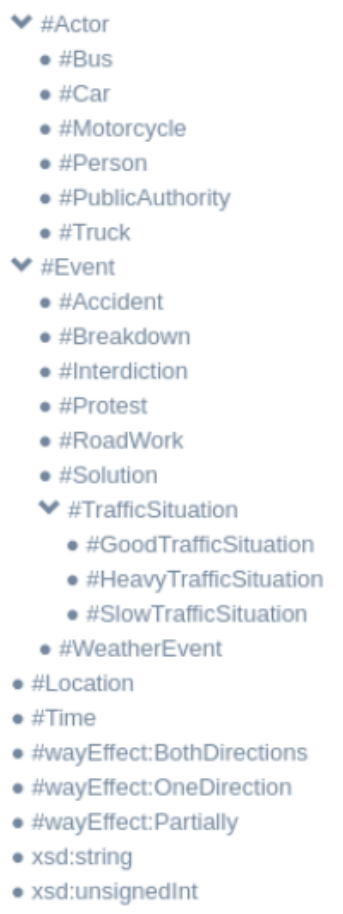

(a)

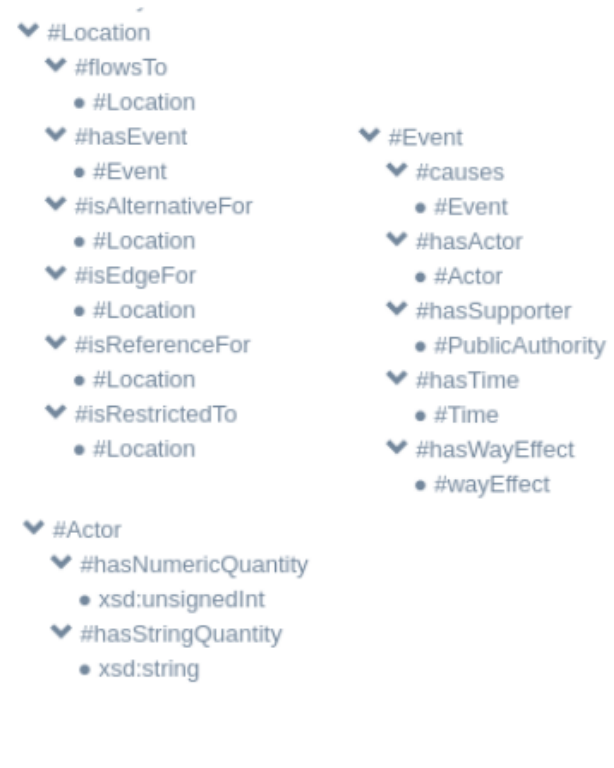

(b)

Figura 4.1: Visões da ontologia usada na anotação dos dados: (a) entidades; (b) relações

O restante dos tweets foi anotado por 20 participantes de forma a validar a efetividade do guia de anotação e a consistência da ontologia, com base nas anotações realizadas, concordâncias obtidas, comentários feitos nos documentos (ver Apêndice B) e respostas dadas ao questionário distribuído no final do experimento (ver Apêndice C). Os participantes foram separados em seis grupos com configurações distintas de aquecimento e passo de re-anotação. Além disso, os participantes foram separados em dois tipos. Uma parte deles anotou baseando-se apenas no guia de anotação - tipo A. A outra parte - tipo B - teve acesso ao guia de anotação e, também, receberam uma explicação presencial sobre a tarefa e tiraram dúvidas ao longo da anotação.

\subsection{2 \\ Resultados}

A análise sobre a concordância dos participantes foi separada em duas etapas. Primeiramente avaliou-se a diferença de concordância entre os grupos. Num segundo momento, avaliou-se a diferença de concordância entre os diferentes tipos de participantes. A concordância foi medida de duas formas, primeiramente tomando como referência o GSA (que foi criado pelo autor deste trabalho) e depois comparando as anotações dos participantes de cada grupo entre eles mesmos que é a auto-concordância. Para cada agrupamento, foi calculado o valor médio de concordância acompanhado do seu desvio-padrão.

Os resultados da concordância entre grupos são apresentados nas Tabelas 4.1,4.2, 4.3 e 4.4. Notou-se que a tarefa de identificação de relações parece mais 
complexa, pois a média de concordância de todos os grupos é consideravelmente inferior quando comparada a tarefa de identificação de entidades. A tarefa de identificação de conectores também teve média de concordância baixa, o que já era esperado, pois os conectores têm dependência direta com as relações. Com os resultados obtidos, não é possível afirmar que a configuração de aquecimento e passo de re-anotação tenham alguma influência na melhoria da concordância, seja com o GSA, como também a própria auto-concordância.

Tabela 4.1: Concordância com entidades, relações e conectores nos grupos

\begin{tabular}{rrr}
\hline Grupo (aquecimento, passo de re-anotação) & Concordância com o GSA & Auto-concordância \\
\hline$(0,5)$ & $0.572(\sigma 0.135)$ & $0.767(\sigma 0.116)$ \\
$(2,5)$ & $0.530(\sigma 0.036)$ & $0.800(\sigma 0.125)$ \\
$(4,5)$ & $0.497(\sigma 0.166)$ & $0.777(\sigma 0.133)$ \\
$(0,10)$ & $0.417(\sigma 0.189)$ & $0.480(\sigma 0.228)$ \\
$(2,10)$ & $0.543(\sigma 0.107)$ & $0.773(\sigma 0.023)$ \\
$(4,10)$ & $0.520(\sigma 0.087)$ & $0.720(\sigma 0.066)$ \\
\hline
\end{tabular}

Tabela 4.2: Concordância com entidades nos grupos

\begin{tabular}{rrr}
\hline Grupo (aquecimento, passo de re-anotação) & Concordância com o GSA & Auto-concordância \\
\hline$(0,5)$ & $0.835(\sigma 0.077)$ & $0.918(\sigma 0.066)$ \\
$(2,5)$ & $0.820(\sigma 0.070)$ & $0.887(\sigma 0.055)$ \\
$(4,5)$ & $0.713(\sigma 0.204)$ & $0.847(\sigma 0.110)$ \\
$(0,10)$ & $0.628(\sigma 0.247)$ & $0.643(\sigma 0.321)$ \\
$(2,10)$ & $0.817(\sigma 0.058)$ & $0.900(\sigma 0.020)$ \\
$(4,10)$ & $0.760(\sigma 0.092)$ & $0.790(\sigma 0.085)$ \\
\hline
\end{tabular}

Tabela 4.3: Concordância com relações nos grupos

\begin{tabular}{rrr}
\hline Grupo (aquecimento, passo de re-anotação) & Concordância com o GSA & Auto-concordância \\
\hline$(0,5)$ & $0.273(\sigma 0.278)$ & $0.438(\sigma 0.293)$ \\
$(2,5)$ & $0.243(\sigma 0.137)$ & $0.623(\sigma 0.200)$ \\
$(4,5)$ & $0.143(\sigma 0.315)$ & $0.413(\sigma 0.412)$ \\
$(0,10)$ & $0.040(\sigma 0.268)$ & $0.007(\sigma 0.439)$ \\
$(2,10)$ & $0.170(\sigma 0.243)$ & $0.473(\sigma 0.367)$ \\
$(4,10)$ & $0.150(\sigma 0.185)$ & $0.493(\sigma 0.190)$ \\
\hline
\end{tabular}

Tabela 4.4: Concordância com conectores nos grupos

\begin{tabular}{|c|c|c|}
\hline Grupo (aquecimento, passo de re-anotação) & Concordância com o GSA & Auto-concordância \\
\hline$(0,5)$ & $0.088(\sigma 0.260)$ & $0.525(\sigma 0.205)$ \\
\hline$(2,5)$ & $0.020(\sigma 0.026)$ & $0.673(\sigma 0.320)$ \\
\hline$(4,5)$ & $0.097(\sigma 0.167)$ & $0.920(\sigma 0.139)$ \\
\hline$(0,10)$ & $0.060(\sigma 0.081)$ & $0.415(\sigma 0.582)$ \\
\hline$(2,10)$ & $0.123(\sigma 0.150)$ & $0.590(\sigma 0.373)$ \\
\hline$(4,10)$ & $0.093(\sigma 0.075)$ & $0.363(\sigma 0.335)$ \\
\hline
\end{tabular}

Os resultados da concordância entre tipos de participantes são apresentados nas Tabelas 4.5,4.6, 4.7 e 4.8. Como na concordância entre grupos, notou-se que as tarefas de identificação de relações e de conectores parecem mais complexas que a de identificação de entidades. Observou-se, porém, que há uma diferença significativa na concordância dos grupos. O tipo B, que recebeu uma 
explicação presencial sobre a tarefa e teve dúvidas sanadas ao longo da anotação, teve uma média de concordância bem superior quando comparado com o tipo A, que apenas teve acesso ao guia de anotação. Assim pode-se supor que o guia de anotação pode ser importante, mas a presença de um especialista do domínio da tarefa de anotação foi determinante para um melhor desempenho dos participantes do experimento.

Tabela 4.5: Concordância com entidades, relações e conectores nos tipos de anotador

\begin{tabular}{|c|c|c|}
\hline Tipo anotador & Concordância com o GSA & Auto-concordância \\
\hline A & $0.452\left(\begin{array}{ll}\sigma & 0.132\end{array}\right)$ & $0.681(\sigma 0.190)$ \\
\hline B & $0.600(\sigma 0.049)$ & $0.752(\sigma 0.134)$ \\
\hline
\end{tabular}

Tabela 4.6: Concordância com entidades nos tipos de anotador

\begin{tabular}{rrr}
\hline Tipo anotador & Concordância com o GSA & Auto-concordância \\
\hline A & $0.700(\sigma 0.172)$ & $0.765(\sigma 0.201)$ \\
B & $0.848(\sigma 0.033)$ & $0.916(\sigma 0.045)$ \\
\hline
\end{tabular}

Tabela 4.7: Concordância com relações nos tipos de anotador

\begin{tabular}{|c|c|c|}
\hline Tipo anotador & Concordância com o GSA & Auto-concordância \\
\hline A & $0.069\left(\begin{array}{lll}\sigma & 0.239)\end{array}\right.$ & $0.315(\sigma 0.362)$ \\
\hline B & $0.318(\sigma 0.102)$ & $0.501(\sigma 0.338)$ \\
\hline
\end{tabular}

Tabela 4.8: Concordância com conectores nos tipos de anotador

\begin{tabular}{rrr}
\hline Tipo anotador & Concordância com o GSA & Auto-concordância \\
\hline A & $0.022(\sigma 0.134)$ & $0.681(\sigma 0.345)$ \\
B & $0.166(\sigma 0.090)$ & $0.404(\sigma 0.347)$ \\
\hline
\end{tabular}

Os questionários respondidos ao final do experimento, que podem ser encontrados no Apêndice $\mathrm{C}$, mostram que os participantes tiveram uma impressão positiva da ferramenta, destacando a sua facilidade de uso. Nos questionários, também foi possível ver que grande parte dos participantes do tipo B, que receberam treinamento presencial, não sentiram necessidade de ler o guia de anotação de forma detalhada. Notou-se também que um guia muito extenso não agradou aos participantes.

Com base nos resultados obtidos no experimento, que podem ser vistos de forma mais detalhada no Apêndice $\mathrm{D}$, percebe-se que a concordância média obtida na tarefa de identificação de relações e de conectores foi insatisfatória. Para sanar este problema, um caminho possível seria o de modificar a ontologia de forma a facilitar o entendimento das relações. 


\section{2}

\section{Experimento de aprendizado automático}

Os resultados obtidos no experimento de anotação indicaram a necessidade de algumas pequenas mudanças para a melhoria da ontologia. Em primeiro lugar, as classes HeavyTrafficSituation e SlowTrafficSituation causaram dúvidas em alguns anotadores, incluindo o autor desta dissertação. Qual seria a diferença entre um tráfego pesado e um tráfego lento? Destarte, as duas classes se transformaram em BadTrafficSituation, o exato oposto de GoodTrafficSituation. Foram também retiradas as relações hasNumericQuantity e hasStringQuantity, pois entendeu-se que apenas a informação sobre o tipo de Actor era realmente importante e não as quantidades, pelo que, doravante, "2 Carros" seria classificado simplesmente como Car. Outrossim, a classe WeatherEvent foi retirada, uma vez que em nenhum momento apareceu no conjunto de dados usado. A mudança mais importante diz respeito às relações com radical "is", como isReferenceFor, ou isEdgeFor, posto que geraram muitas dúvidas quanto à direção de relação: uma Location $A$ era algo em relação a outra $L o$ cation $B$ ou esta Location $B$ tinha a Location $A$ como alvo de uma relação? Para simplificar, todas as relações "is..." se tornaram "has...", de modo que a Location principal do evento sempre tem ("has") alguma relação que sai dela para Locations secundários, o que também torna os diagramas finais da anotação mais claros. A única exceção foi a relação isRestrictedTo, que foi retirada, pois diversas vezes confundia-se com isReferenceTo. Todas as mudanças descritas podem ser vistas quando as figuras 4.1 e 4.2 são comparadas, onde a primeira mostra a versão da ontologia utilizada no experimento de anotação e a segunda a versão utilizada para anotar os documentos para o experimento de aprendizado automático.

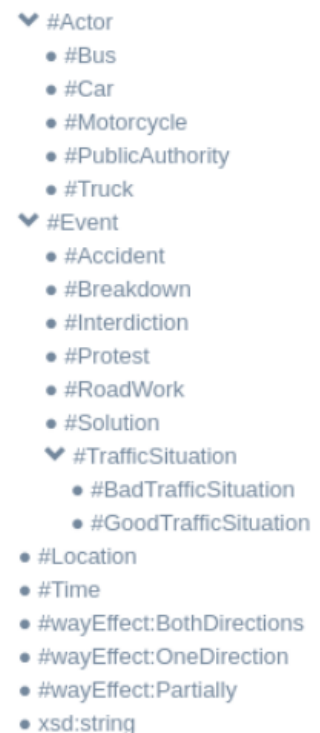

(a)

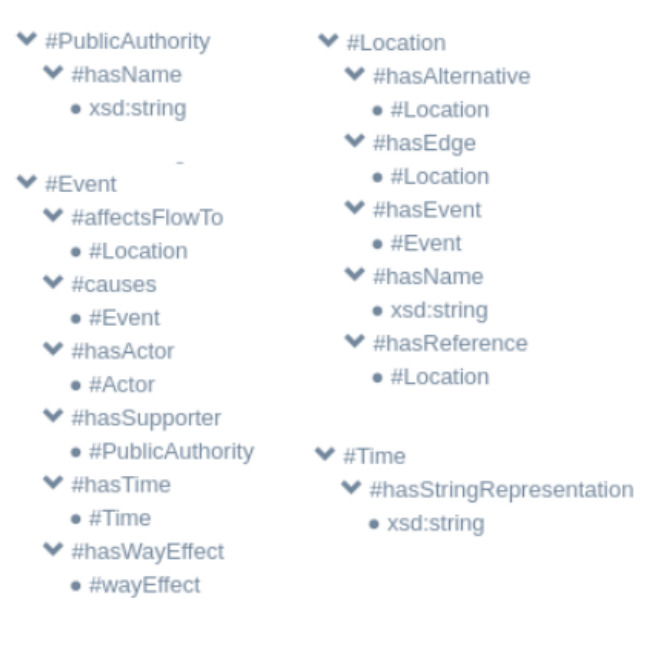

(b)

Figura 4.2: Visões da ontologia usada na anotação dos dados para o experimento de aprendizado automático: (a) entidades; (b) relações 


\subsection{1}

\section{Dados}

Para os experimentos de aprendizado de máquina, 600 novos tweets foram coletados (metade pertence à conta @operacoesRio e a outra metade à conta @odia24horas) e anotados exclusivamente pelo autor deste trabalho. Usouse uma re-anotação ativada por passo 10, ou seja, as anotações de 60 tweets foram repetidas para medições de auto-concordância. A tabela 4.9 apresenta os resultados de tempos de anotação.

Tabela 4.9: Estatísticas de tempo do conjunto de dados usado no experimento de aprendizado automático

\begin{tabular}{rr}
\hline Tempo gasto anotando & Tempo médio por documento \\
\hline $15 \mathrm{~h} 52 \mathrm{~m}$ & $1 \mathrm{~m} 35 \mathrm{~s}(\sigma 1 \mathrm{~m} 44 \mathrm{~s})$ \\
\hline
\end{tabular}

A figura 4.3(a) mostra, para o total de tokens em todo o conjunto de dados, a divisão entre não marcados, marcados como Tag ou marcados como Connector. Percebe-se a proximidade entre as quantidades de tokens participando como Tag e como Connector, e menos tokens não anotados, o que indica que boa parte do conteúdo dos documentos tinha informação relevante. Percebe-se também que um elevado percentual dos tokens oferece alguma informação importante para o aprendizado de máquinas. A parte (b) da figura mostra a distribuição do número de tokens entre os documentos, que segue um padrão normal com média próxima a 20. Em se tratando de tweets, o número máximo de tokens estará sempre limitado. 


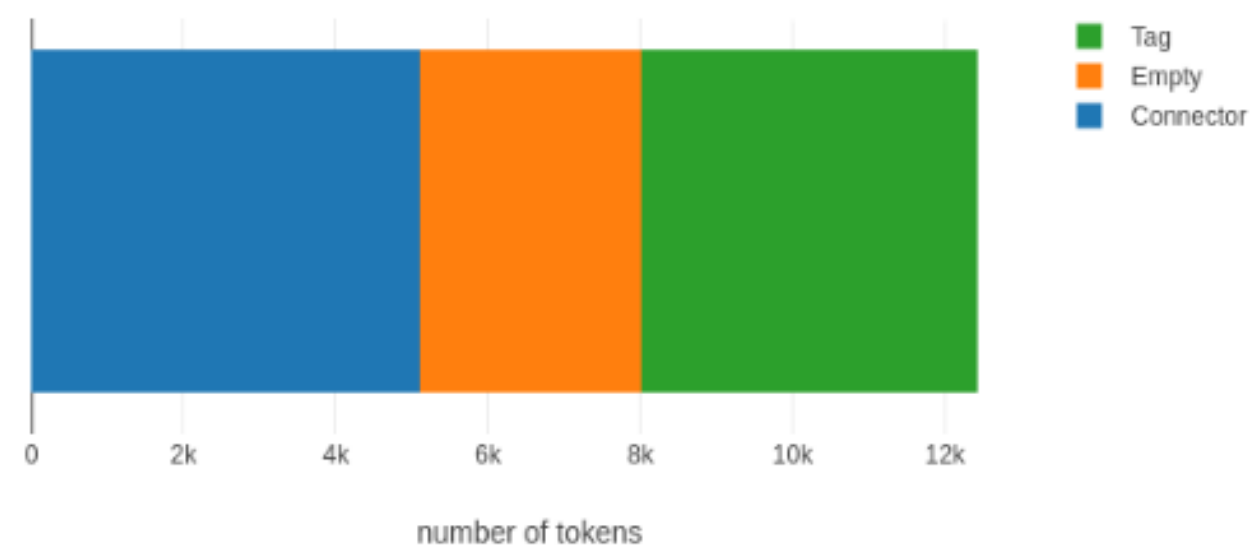

(a)

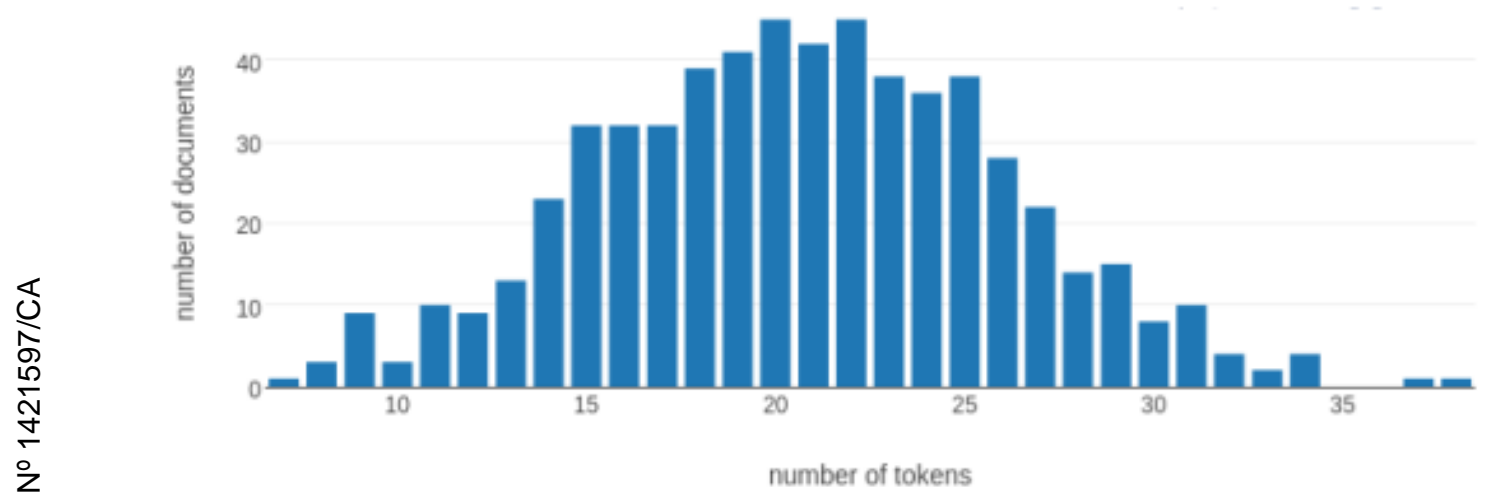

(b)

Figura 4.3: Estatísticas de tokens nos dados utilizados no experimento: (a) Cobertura dos tokens; (b) Histograma de distribuição de documentos por quantidade de tokens

A figura 4.4 apresenta os dados para Tags. A parte (a) da figura deixa evidente o desbalanceio entre as classes, com uma maioria de Location e algumas classes aparecendo muito raramente. A parte (b) apresenta a distribuição do número de Tags ou entidades identificadas nos documentos. 


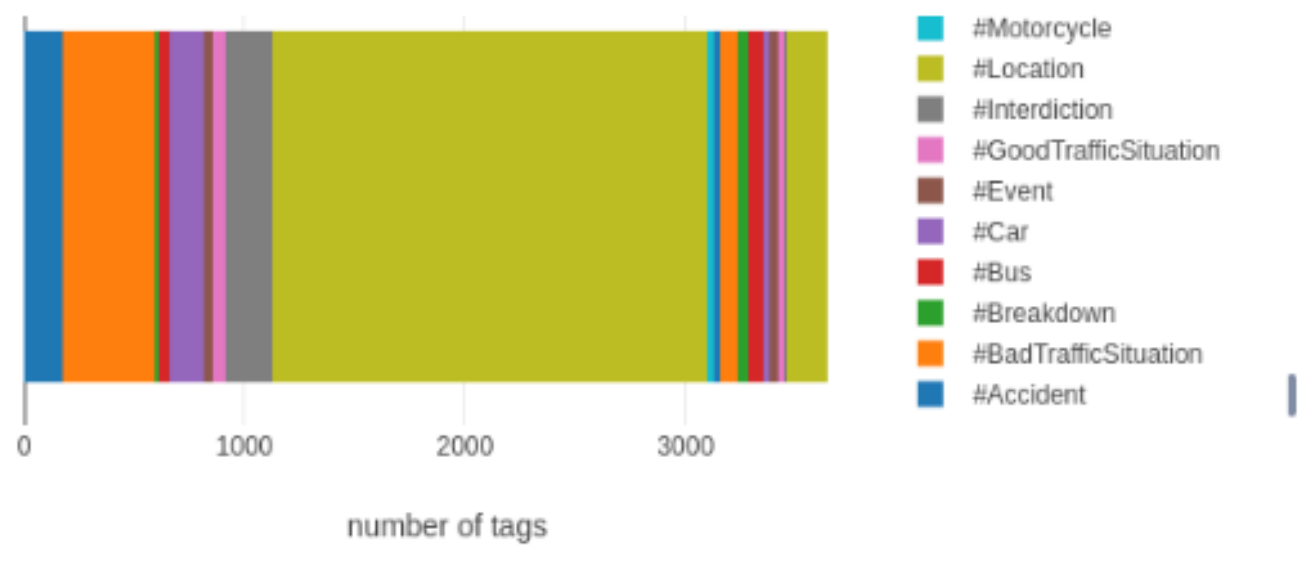

(a)

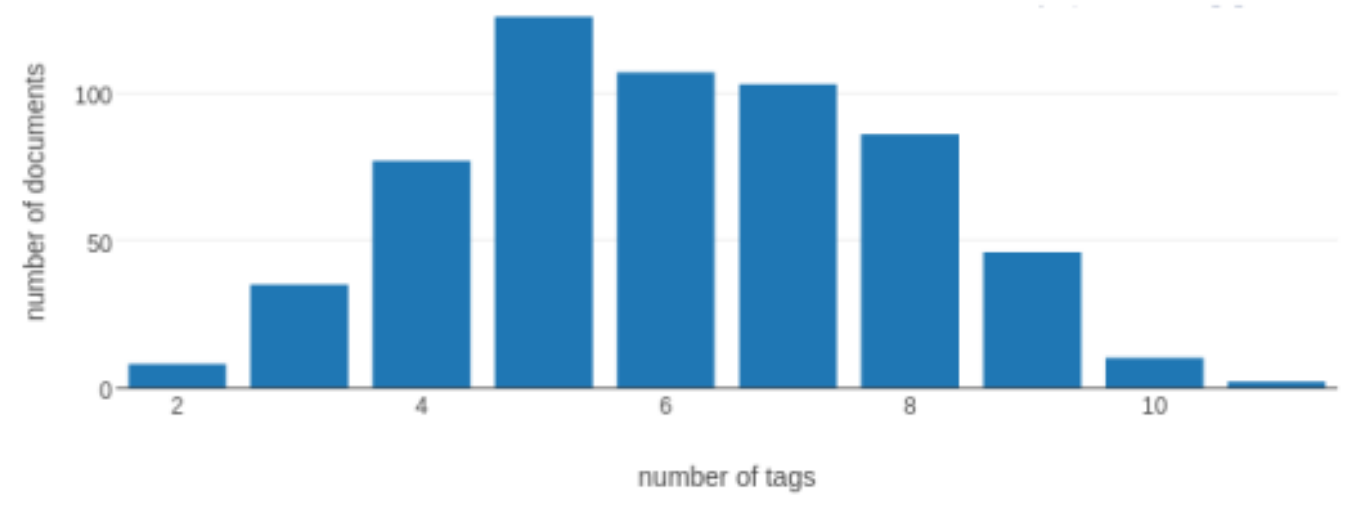

(b)

Figura 4.4: Estatísticas de entidades nos dados utilizados no experimento: (a) Distribuição de entidades nos dados; (b) Histograma de distribuição de documentos por quantidade de entidades

A figura 4.5 mostra a distribuição entre relations, onde também ocorre um desbalanço, com as relações envolvendo classes mais frequentes aparecendo, logicamente, mais vezes. O desbalanço, neste caso, é menor do que o observado para as entidades. 


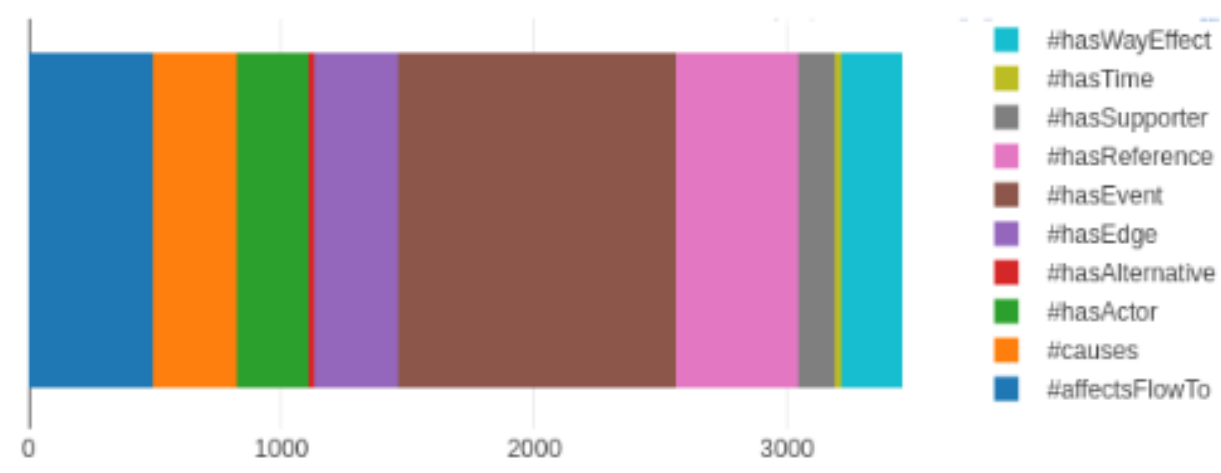

number of relations

(a)

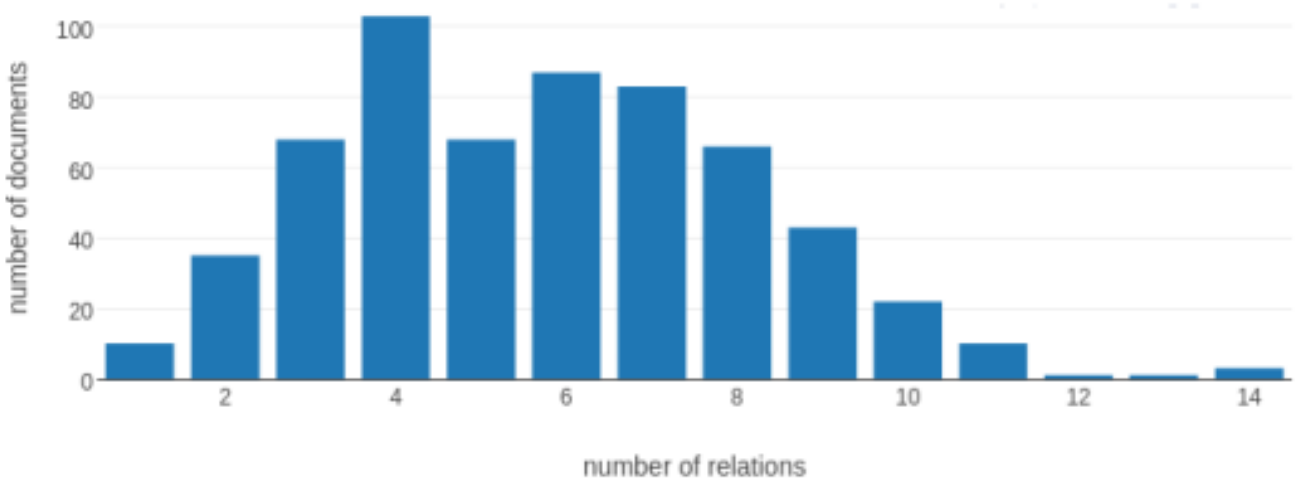

(b)

Figura 4.5: Estatísticas de relações nos dados utilizados no experimento: (a) Distribuição de relações nos dados; (b) Histograma de distribuição de documentos por quantidade de relações

A figura 4.6 apresenta a estatística quanto às participações dos connectors em cada relação, que tende a seguir a mesma distribuição verificada para as relações. 


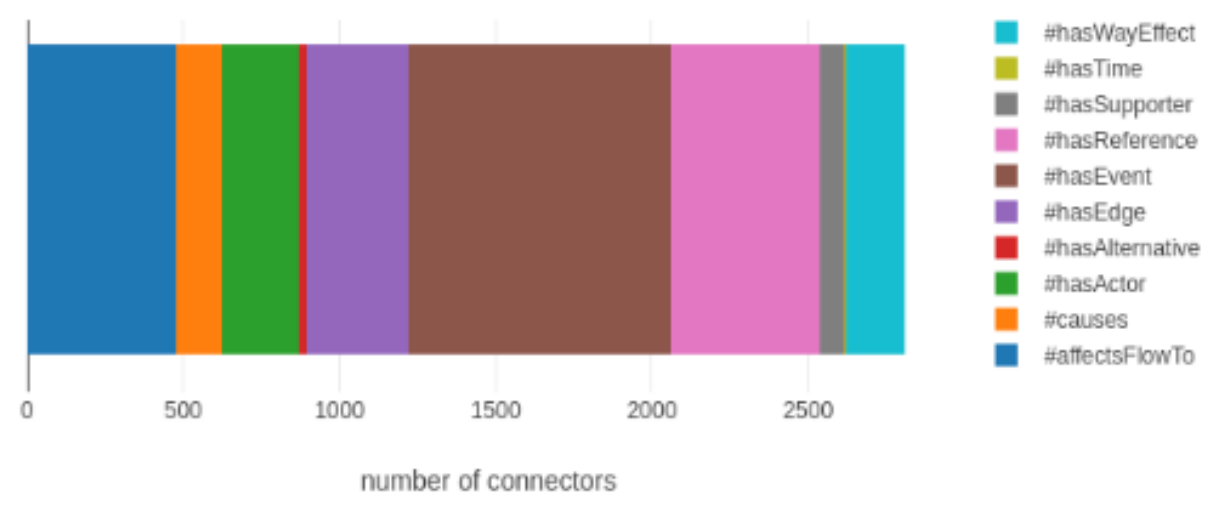

(a)

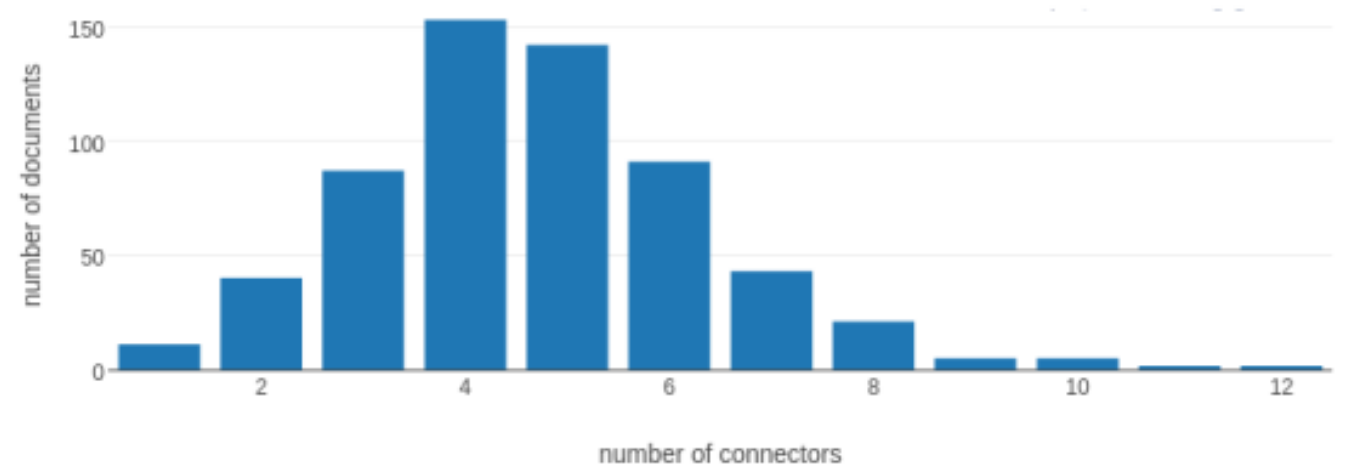

(b)

Figura 4.6: Estatísticas de conectores nos dados utilizados no experimento: (a) Distribuição de conectores nos dados; (b) Histograma de distribuição de documentos por quantidade de conectores

A figura 4.7, uma das mais importantes para o entendimento dos resultados posteriores, apresenta as estatísticas de auto-concordância, uma em relação a cada item da anotação. A parte (a), referente à concordância de todos os itens, mostra que em alguns documentos houve forte variação na re-anotação. A parte (b), referente à concordância apenas entre entidades (Tags), mostra que pouco da discordância geral se deve a este item. A parte (c), referente exclusivamente às relações, explica a maior parte da discordância geral. A parte (d), referente exclusivamente aos connectors, mostra as maiores discordâncias, mas é apenas uma consequência direta da discordância nas relações. Assim, a anotação das relações foi menos precisa que a das entidades, o que influenciará, de certa forma, na diferença entre os resultados de NER e RE posteriores. 


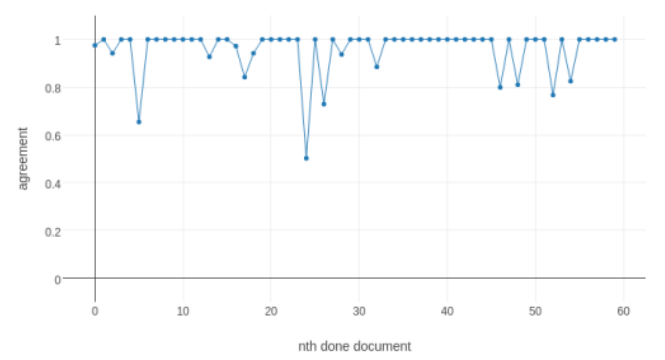

(a)

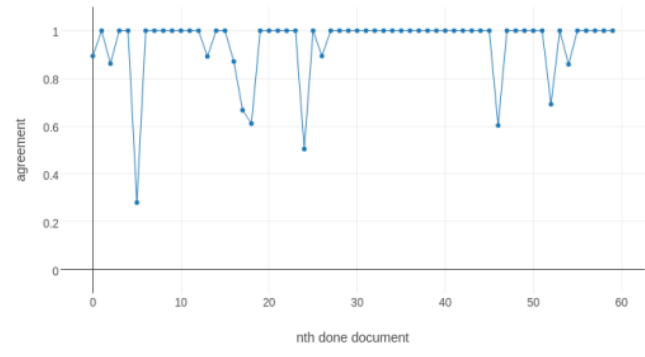

(c)

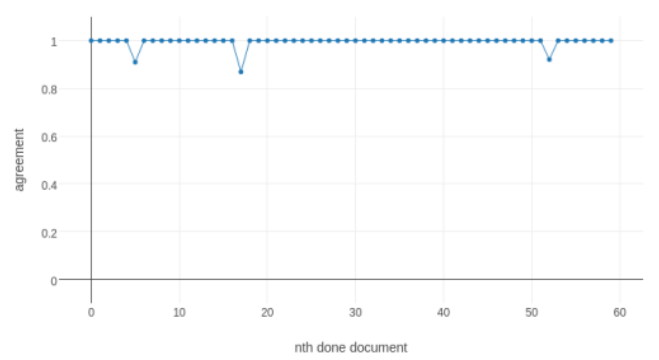

(b)

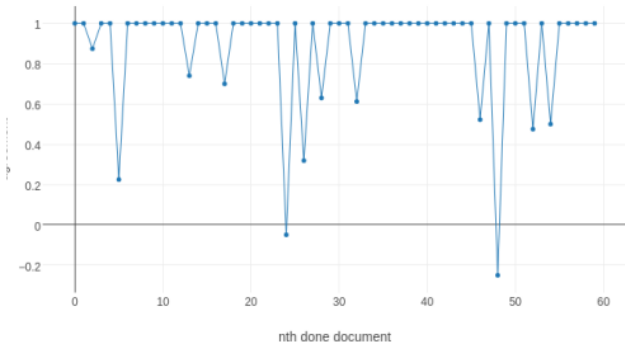

(d)

Figura 4.7: Estatísticas de auto-concordância ano longo do tempo nos dados utilizados no experimento: (a) auto-concordância com entidades, relações e conectores; (b) auto-concordância com entidades; (c) auto-concordância com relações; (d) auto-concordância com conectores

A figura 4.8 mostra a nuvem de palavras gerada pelo sistema relativa às entidades, caracterizando os principais termos ligados à identificação das classes.

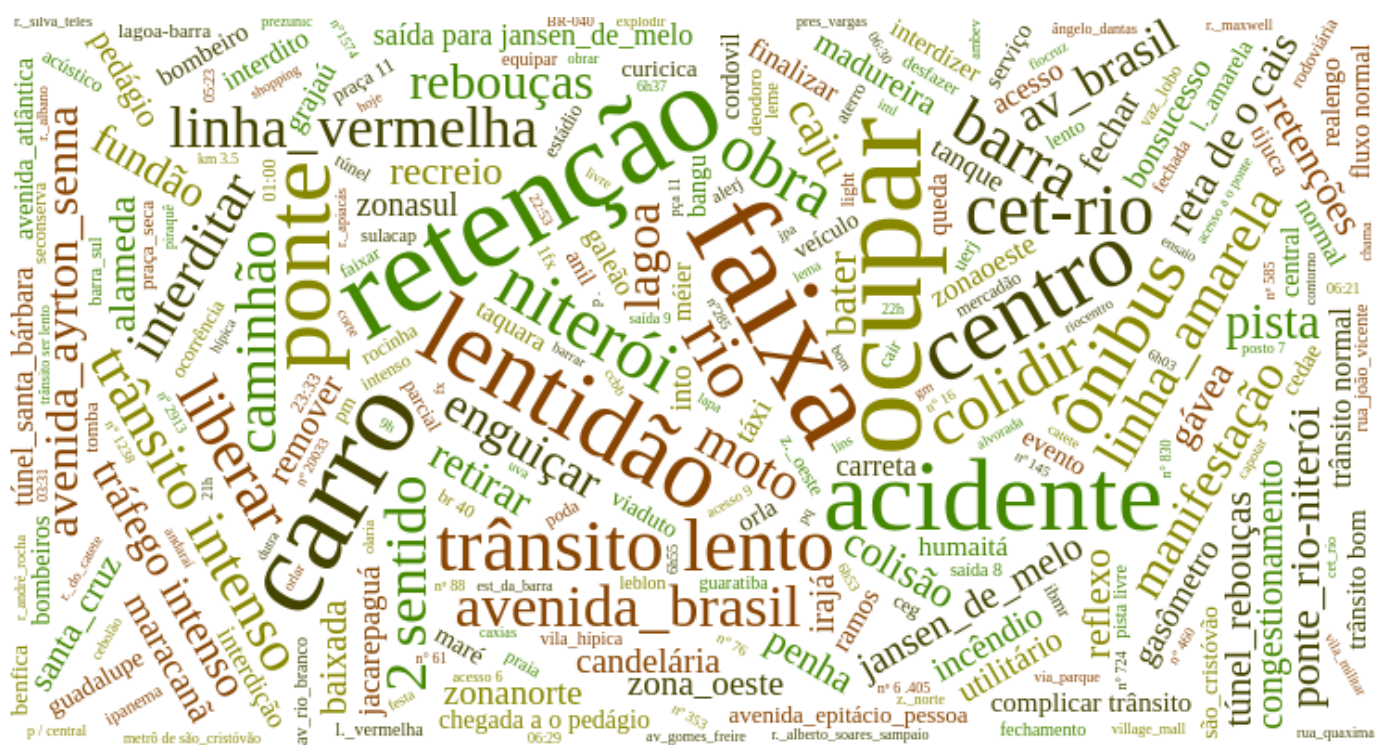

Figura 4.8: Nuvem de palavras associadas às entidades nos dados utilizados no experimento

A figura 4.9 apresenta as curvas de frequências acumuladas das palavras 
associadas a cada entidade. A parte (b) se diferencia da (a) por eliminar o caso Location, que muda a escala e dificulta a visualização das outras classes. A parte linear da curva, quando acontece, representa uma taxa de aumento constante na frequência acumulada quando da adição de uma nova palavra, mostrando que a generalização automática das expressões para a identificação de determinada classe se faz mais difícil. A parte (a) tem um exemplo claro dessa situação nos caso de Location, onde a parte não linear diz respeito a palavras que indicam locais que aparecem mais frequentemente, como "Ponte Rio-Niterói" e "Centro", enquanto a parte linear se refere a palavras menos frequentes. Nesses casos, apenas a parte não linear com a maior taxa de crescimento deve ser usada para uma geração automática de atributos que não implique em um aumento exagerado da quantidade total de atributos. A parte (b) tem outro exemplo na classe Time, onde a taxa de aumento constante acontece em quase toda a curva, o que é de se esperar, uma vez que cada evento terá um tempo diferente dos outros, com raros casos de repetição. Nesses casos, com tempos e outros tipos semelhantes, recomenda-se o uso de expressões regulares que generalizem a referida informação. A geração automática dos atributos usa como parâmetro principal um valor de profundidade (depth), que representa o valor da abscissa destes gráficos. O valor exato a ser considerado é algo subjetivo, variando de acordo com a quantidade máxima de atributos que cada um tolere. Para o presente trabalho, no caso da tarefa NER e tendo como base a parte (b) da figura, considerou-se 20 um valor razoável. 


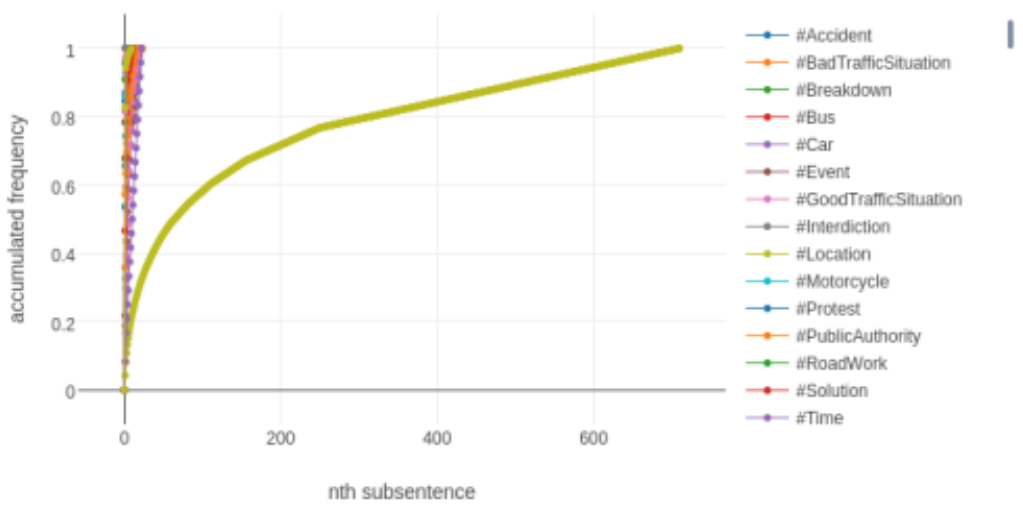

(a)

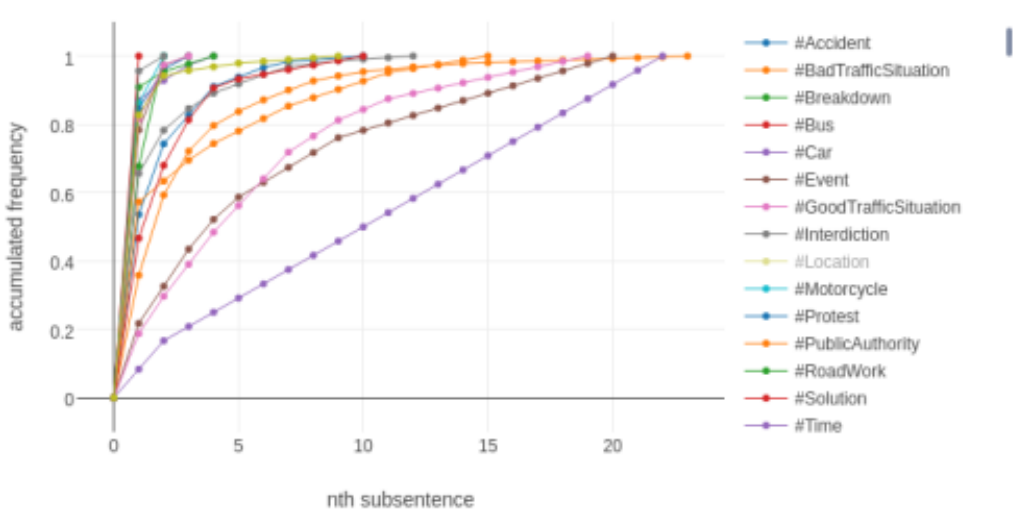

(b)

Figura 4.9: Curva de frequência acumulada de palavras associadas às entidades: (a) todas entidades; (b) excluindo a entidade com mais ocorrências, neste caso Location

A figura 4.10 apresenta a nuvem de palavras referente aos conectores, elucidando alguns casos típicos de indicação de sentido de fluxo, de locais, entre outros. 


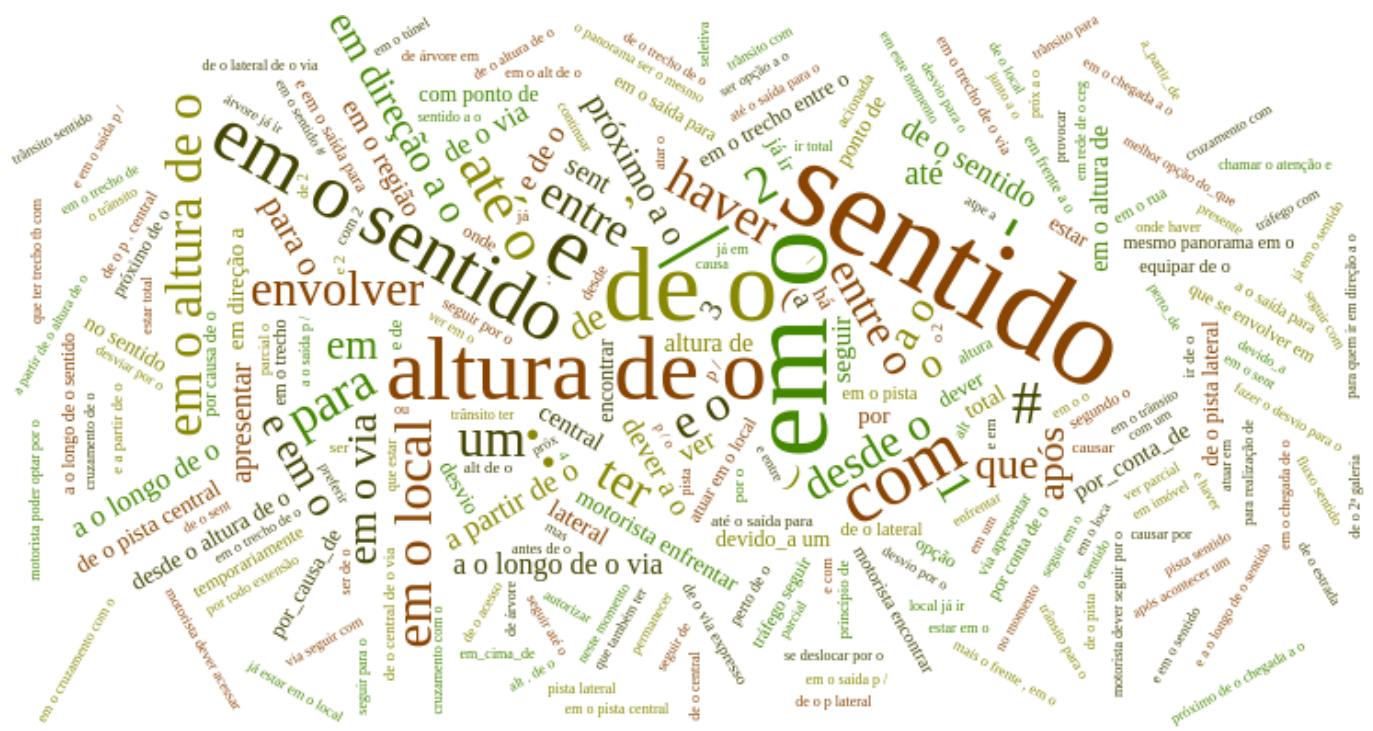

Figura 4.10: Nuvem de palavras associadas aos conectores nos dados utilizados no experimento

As curvas da figura 4.11, semelhantes às da figura 4.9, se referem às frequências dos conectores para cada relação. Seguindo a mesma ideia descrita para as entidades, definiu-se 20 como um valor de depth suficiente para a geração automática de bons atributos para a etapa de RE. 


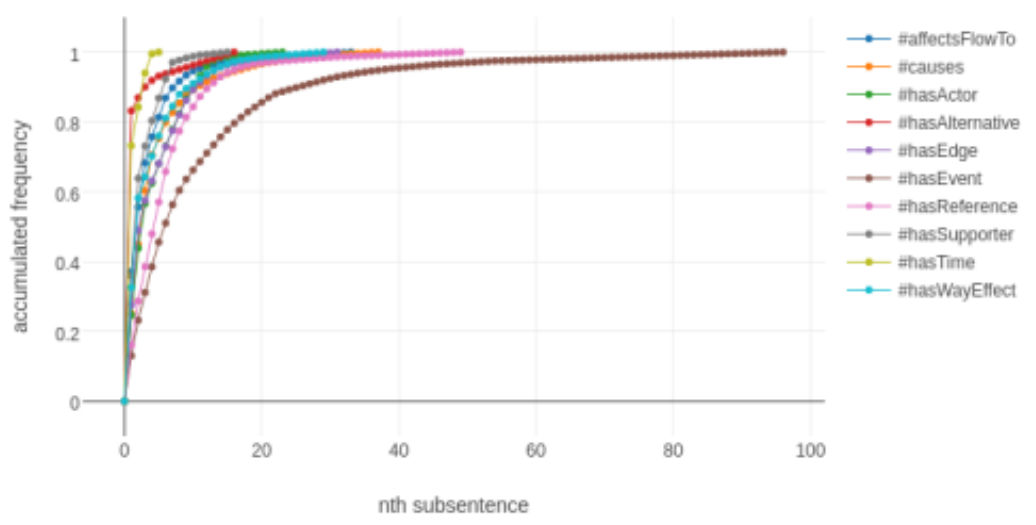

(a)

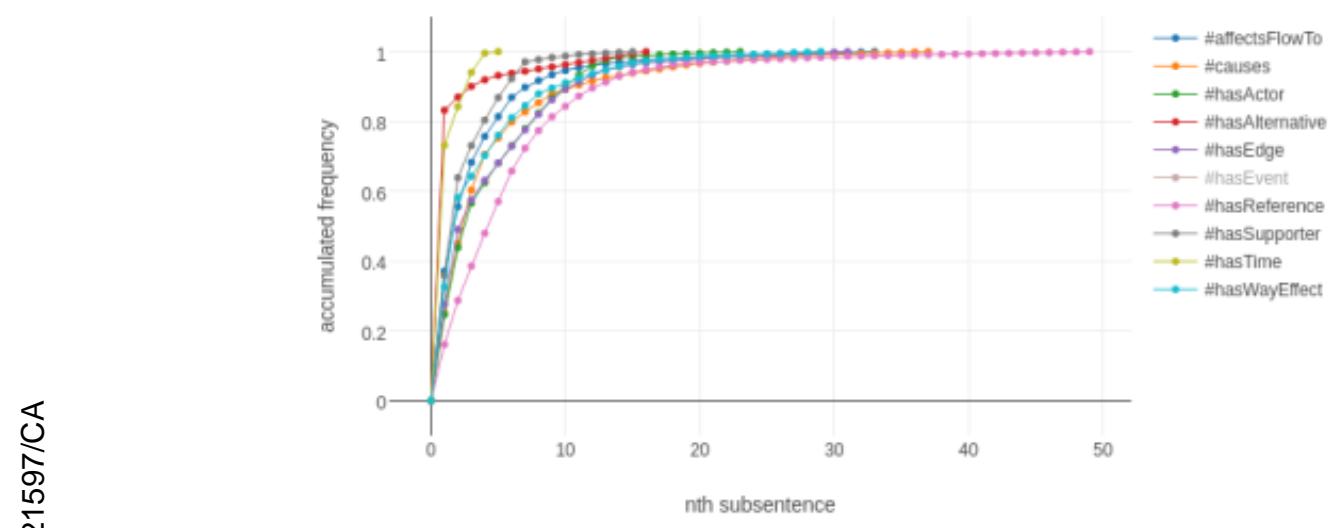

(b)

Figura 4.11: Curva de frequência acumulada de palavras associadas aos conectores: (a) todos conectores; (b) excluindo conector com mais ocorrências, neste caso hasEvent

\subsection{2}

\section{Metodologia}

Os experimentos de NER e RE, ambos adotando uma estratégia de crossvalidation de 10-fold, foram conduzidos em alguns passos semelhantes:

1. Separação randômica de $20 \%$ dos dados de cada conta de tweets de trânsito para serem utilizados como conjunto de teste, isto é, destacados do fluxo do experimento para serem utilizados apenas na etapa final, sem iterações sobre eles para melhoria dos modelos;

2. Execução do mesmo procedimento do item anterior nos $80 \%$ restantes, para criação dos conjuntos de treino e revalidação;

3. Uso do gerador automático de atributos com base nos dados;

4. Adição de alguns atributos que não foram contemplados no item anterior;

5. Treinamento dos modelos utilizando todos os classificadores disponíveis com suas configurações padrão; 
6. Apenas nas tarefas de NER, execução da mesma ação do item anterior com acréscimo de atributos;

7. Avaliação e seleção, com base no F1 médio, dos classificadores com resultados minimamente razoáveis e, apenas no caso do NER, verificação da melhoria ou não do resultado pelo acréscimo de atributos do item anterior;

8. Execução do gridsearch em todos os classificadores selecionados no item anterior;

9. Treino do modelo final com os melhores parâmetros encontrados no item anterior, usando para treino o conjunto de treino completo (treino e validação) e para o teste único e definitivo o conjunto de teste separado no primeiro item;

10. Execução do item anterior utilizando agrupamentos e remoções de entidades, para mero teste desta estratégia, sem objetivar qualquer melhoria de modelo.

Os atributos para NER foram os seguintes:

- LEMMA\{0\} automático do tipo VALUE com separação das palavras e sem concatenação das expressões regulares;

- RANGE-LEMMA $\{-4,4\}$ automático do tipo FROM-CONNECTOR, com separação das palavras e sem concatenação das expressões regulares;

- RANGE-LEMMA $\{-4,4\}$ automático do tipo TO-CONNECTOR, com separação das palavras e sem concatenação das expressões regulares;

- POS $\{-3,-2,-1,0,1,2,3\}$ apenas com as categorias da árvore de POS Tagging

Os atributos para RE foram os seguintes:

- NODE-TO-NODE-DISTANCE;

- NODE-TO-NODE-DISTANCE-WITH-SIGNAL;

- CLASS-NODE-FROM;

- CLASS-NODE-TO;

- POSSIBLE-RELATION;

- INTERIOR-RANGE-LEMMA\{-4, 4\} automático do tipo CONNECTOR, com separação das palavras e sem concatenação das expressões regulares; 


\subsection{3 \\ Resultados}

Esta seção apresenta os resultados dos experimentos descritos, executados no ambiente LER, que funciona em um servidor Intel ${ }^{\circledR}$ Core $^{\mathrm{TM}} \mathrm{i} 5$, com CPU $650 @ 3.20 \mathrm{GHz}$ e 12GB de RAM. Esses resultados estão descritos de forma mais detalhada no Apêndice E. As próximas seções estão dividas entre os experimentos executados para a tarefa de NER e RE respectivamente.

\subsubsection{1}

NER

O passo 5 da metodologia, cujos resultados podem ser vistos na tabela 4.10, indica que, com parâmetros default, o algoritmo Random Forest se mostra o mais rápido. Entretanto, o SGD apresenta o melhor resultado de F1. Percebese claramente o estranho comportamento do classificador SVC, que resultou em um F1 extremamente baixo. Isso provavelmente se deve ao fato do kernel default para o SVC ser do tipo RBF, que tende a piores resultados quando os valores dos atributos não são normalmente distribuídos (42), como é o caso aqui tratado, cuja distribuição é binomial.

Tabela 4.10: Resultado NER passo 5

\begin{tabular}{rrrrr}
\hline Classificador & Tempo tarefa & Tempo CPU treino & F1 validação & F1 revalidação \\
\hline Random Forest & $4 \mathrm{~m} \mathrm{31s}$ & $0.514 \mathrm{~s}$ & $0.554(\sigma 0.281)$ & $0.682(\sigma 0.353)$ \\
Stochastic Gradient Descent & $4 \mathrm{~m} 52 \mathrm{~s}$ & $1.672 \mathrm{~s}$ & $0.574(\sigma 0.293)$ & $0.752(\sigma 0.310)$ \\
SVC & $11 \mathrm{~m} \mathrm{47s}$ & $50.304 \mathrm{~s}$ & $0.055(\sigma 0.205)$ & $0.067(\sigma 0.224)$ \\
\hline
\end{tabular}

Uma vez que os parâmetros default do SVC apresentaram tal problema, um gridsearch especial foi feito para este classificador ainda no passo 5, para uma avaliação sobre a possibilidade ou não de deixá-lo entre os avaliados nos passos seguintes. Os resultados podem ser vistos na tabela 4.11, onde o kernel linear se mostrou o mais adequado.

Tabela 4.11: Gridsearch no NER para o SVC no passo 5

\begin{tabular}{rrr}
\hline Parâmetro & Valores testados & Melhor valor \\
\hline Kernel & Radial Basis Function, Linear, Polynomial, Sigmoidal & Linear \\
\hline
\end{tabular}

Passando ao passo 6, onde a mudança de atributos ocorre apenas pelo aumento da quantidade de níveis do POS Tagging consideradas, agora com todos, nova rodada é realizada mantendo-se os parâmetros default, exceto pela mudança pontual do kernel do SVC de RBF para Linear. Os resultados podem ser vistos na tabela 4.12. Percebe-se que, como era esperado, os tempos de treinamento aumentaram, mas mantendo a mesma proporção relativa entre os classificadores, onde se vê que o SVC é muitíssimo mais lento que os demais. Não obstante, pelo uso de um kernel linear, também apresenta o melhor resultado de todos. Em termos de atributos, percebe-se que os resultados melhoraram em todos os classificadores, o que leva à conclusão de que o uso de mais níveis de POS tende a melhorar a qualidade da classificação no caso aqui estudado. 
Tabela 4.12: Resultado NER passo 6

\begin{tabular}{rrrrr}
\hline Classificador & Tempo tarefa & Tempo CPU treino & F1 validação & F1 revalidação \\
\hline Random Forest & $6 \mathrm{~m} \mathrm{19s}$ & $0.712 \mathrm{~s}$ & $0.567(\sigma 0.243)$ & $0.777(\sigma 0.296)$ \\
Stochastic Gradient Descent & $6 \mathrm{~m} \mathrm{54s}$ & $2.959 \mathrm{~s}$ & $0.609(\sigma 0.284)$ & $0.776(\sigma 0.260)$ \\
SVC & $1 \mathrm{~h} 11 \mathrm{~m} \mathrm{43s}$ & $64.763 \mathrm{~s}$ & $0.731(\sigma 0.226)$ & $0.879(\sigma 0.221)$ \\
\hline
\end{tabular}

Os passos 7 e 8, isto é, a seleção dos classificadores minimamente viáveis (neste caso, todos) e execução de gridsearch em todos estes para a escolha da melhor combinação classificador-parâmetros, têm seus resultados apresentados nas tabelas 4.13, 4.14, 4.15 e 4.16. O SVC apresenta o melhor desempenho no conjunto de treino, com um maior F1 médio e menor desvio padrão, sendo, de outra sorte, vencido pelo Random Forest no conjunto de revalidação, que por sua vez apresentou um valor de F1 médio próximo ao do SVC no conjunto de treino, mas com um desvio padrão um pouco maior. Por fim, escolheu-se o Random Forest e seus melhores parâmetros como a estratégia final para NER em razão do maior valor de F1 para a revalidação. É de se notar que o seu tempo de treino foi o dobro do observado no SVC, o que se deve ao elevado número de árvores adotado. Todavia, sabe-se que a complexidade do SVC na presente implementação cresce mais que quadraticamente com o número de instâncias (34), enquanto a do Random Forest depende mais do número de árvores - já fixado - e suas profundidades, do que da quantidade de dados de treino $(35,43)$, de onde se conclui que essa diferença de tempos deverá diminuir, ou mesmo se inverter, com o aumento da quantidade de dados.

Tabela 4.13: Gridsearch no NER para o Random Forest no passo 8

\begin{tabular}{rrr}
\hline Parâmetro & Valores testados & Melhor valor \\
\hline Class weight & balanced, None & None \\
Criterion & gini, entropy & gini \\
Max features & sqrt(n_features), log2(n_features), n_features & $\mathrm{n}$ _features \\
Number of trees in the forest & $10,50,100$ & 50 \\
Use out-of-bag samples to estimate accuracy & true, false & true \\
One vs Rest & true, false & true \\
\hline
\end{tabular}

Tabela 4.14: Gridsearch no NER para o Stochastic Gradient Descent no passo $\underline{8}$

\begin{tabular}{rrr}
\hline Parâmetro & Valores testados & Melhor valor \\
\hline Class weight & balanced, None & None \\
Learning rate & constant, optimal, invscaling & \\
Loss function & Hinge, Log, Modified huber, Epsilon insensitive, & \\
& Squared epsilon insensitive, Squared hinge, Perceptron, Huber, & Hinge \\
& Epsilon insensitive, Squared epsilon insensitive & true, false \\
One vs Rest & None, 11, 12, elasticnet & elasticnet \\
Penalty & &
\end{tabular}


Tabela 4.15: Gridsearch no NER para o SVC no passo 8

\begin{tabular}{rrr}
\hline Parâmetro & Valores testados & Melhor valor \\
\hline Penalty parameter C & $0.1,1,10,100$ & 1 \\
Class weight & balanced, None & None \\
One vs Rest & true, false & true \\
Use Shrinking heuristic & true, false & true \\
\hline
\end{tabular}

Tabela 4.16: Resultado NER passo 8

\begin{tabular}{|c|c|c|c|c|}
\hline Classificador & Tempo tarefa & Tempo CPU treino & F1 validação & F1 revalidação \\
\hline $\operatorname{Re}$ & $1 \mathrm{~d} 14$ & 218 & 0.7 & 13) \\
\hline Stochastic Gradient Descent & $11 \mathrm{~h} 30 \mathrm{~m} 37 \mathrm{~s}$ & $12.315 \mathrm{~s}$ & $0.676(\sigma 0.233)$ & $0.833(\sigma 0.229)$ \\
\hline SVC & $13 \mathrm{~h} 29 \mathrm{~m} 28 \mathrm{~s}$ & $108.015 \mathrm{~s}$ & $0.751(\sigma 0.192)$ & $0.881(\sigma 0.216)$ \\
\hline
\end{tabular}

As tabelas 4.17 e 4.18 apresentam os valores de F1 por classe para NER referentes à validação e teste final, respectivamente. Obteve-se, portanto, um classificador com F1-score médio de 0.821, com desvio padrão entre classes de 0.287 , com valores de Precision e Recall razoavelmente próximos ao valor de F1. Nota-se que a maioria dos valores individuais de F1 foi 1 ou muito próxima de 1, restando algumas classes com valores de F1 nulos, todas ligadas ao Enumerator wayEffect.

Tabela 4.17: Resultado final detalhado: Random Forest (validação)

\begin{tabular}{|c|c|c|c|c|c|}
\hline Class & Support & Accuracy, $\sigma \mathbf{C V}$ & Recall, $\sigma \mathbf{C V}$ & Precision, $\sigma \mathbf{C V}$ & $\mathbf{F} 1, \sigma \mathbf{C V}$ \\
\hline $\mathrm{O}$ & 6457 & $0.964,0.016$ & $0.980,0.010$ & $0.964,0.019$ & $0.972,0.012$ \\
\hline B-\#Accident & 141 & $0.999,0.000$ & $0.962,0.053$ & $0.991,0.025$ & $0.975,0.028$ \\
\hline B-\#BadTrafficSituation & 339 & $0.996,0.002$ & $0.948,0.046$ & $0.944,0.044$ & $0.945,0.032$ \\
\hline B-\#Breakdown & 17 & $0.999,0.000$ & $0.962,0.104$ & $0.944,0.157$ & $0.940,0.115$ \\
\hline B-\#Bus & 39 & $1.000,0.000$ & $1.000,0.000$ & $1.000,0.000$ & $1.000,0.000$ \\
\hline B-\#Car & 126 & $0.999,0.000$ & $0.983,0.049$ & $1.000,0.000$ & $0.990,0.027$ \\
\hline B-\#Event & 37 & $0.998,0.000$ & $0.667,0.204$ & $0.925,0.114$ & $0.749,0.131$ \\
\hline B-\#GoodTrafficSituation & 45 & $0.997,0.002$ & $0.546,0.307$ & $0.625,0.370$ & $0.560,0.315$ \\
\hline B-\#Interdiction & 165 & $0.999,0.001$ & $0.974,0.043$ & $0.995,0.014$ & $0.984,0.026$ \\
\hline B-\#Location & 1586 & $0.980,0.007$ & $0.960,0.017$ & $0.920,0.036$ & $0.939,0.024$ \\
\hline B-\#Motorcycle & 22 & $0.999,0.000$ & $0.944,0.157$ & $1.000,0.000$ & $0.962,0.104$ \\
\hline B-\#Protest & 17 & $0.999,0.000$ & $0.802,0.275$ & $1.000,0.000$ & $0.858,0.208$ \\
\hline B-\#PublicAuthority & 63 & $0.998,0.001$ & $0.854,0.212$ & $0.870,0.204$ & $0.839,0.183$ \\
\hline B-\#RoadWork & 32 & $0.999,0.000$ & $0.925,0.138$ & $1.000,0.000$ & $0.955,0.083$ \\
\hline B-\#Solution & 55 & $0.999,0.000$ & $0.916,0.220$ & $1.000,0.000$ & $0.937,0.165$ \\
\hline B-\#Time & 20 & $0.998,0.001$ & $0.60,0.447$ & $0.604,0.447$ & $0.586,0.426$ \\
\hline B-\#Truck & 30 & $1.000,0.000$ & $1.000,0.000$ & $1.000,0.000$ & $1.000,0.000$ \\
\hline B-\#wayEffect:BothDirections & 30 & $0.999,0.000$ & $0.980,0.059$ & $0.901,0.153$ & $0.929,0.092$ \\
\hline B-\#wayEffect:OneDirection & 4 & $0.998,0.000$ & $0.000,0.000$ & $0.000,0.000$ & $0.000,0.000$ \\
\hline B-\#wayEffect:Partially & 146 & $0.998,0.001$ & $0.840,0.285$ & $0.846,0.299$ & $0.838,0.284$ \\
\hline I-\#BadTrafficSituation & 105 & $0.997,0.002$ & $0.872,0.167$ & $0.904,0.109$ & $0.878,0.124$ \\
\hline I-\#Event & 8 & $0.998,0.000$ & $0.200,0.400$ & $0.200,0.400$ & $0.200,0.400$ \\
\hline I-\#GoodTrafficSituation & 43 & $0.997,0.002$ & $0.732,0.329$ & $0.825,0.290$ & $0.750,0.288$ \\
\hline I-\#Location & 396 & $0.976,0.013$ & $0.617,0.206$ & $0.754,0.161$ & $0.657,0.141$ \\
\hline I-\#Protest & 2 & $0.997,0.000$ & $0.500,0.000$ & $0.500,0.000$ & $0.500,0.000$ \\
\hline I-\#PublicAuthority & 9 & $0.998,0.001$ & $0.500,0.408$ & $0.666,0.471$ & $0.555,0.415$ \\
\hline I-\#Time & 8 & $0.995,0.001$ & $0.270,0.270$ & $0.450,0.450$ & $0.338,0.338$ \\
\hline I-\#wayEffect:BothDirections & 34 & $0.999,0.000$ & $0.800,0.400$ & $0.713,0.379$ & $0.748,0.382$ \\
\hline I-\#wayEffect:Partially & 2 & $0.998,0.000$ & $0.500,0.000$ & $1.000,0.000$ & $0.666,0.000$ \\
\hline $\bar{e}, \sigma$ & & $0.996,0.007$ & $0.753,0.263$ & $.812,0.250$ & $.767,0.252$ \\
\hline
\end{tabular}


Tabela 4.18: Resultado final detalhado: Random Forest (teste)

\begin{tabular}{rrrrrr}
\hline Class & Support & Accuracy & Recall & Precision & F1 \\
\hline O & 1553 & 0.962 & 0.981 & 0.960 & 0.971 \\
B-\#Accident & 36 & 0.999 & 0.972 & 1.000 & 0.985 \\
B-\#BadTrafficSituation & 72 & 0.997 & 0.986 & 0.946 & 0.965 \\
B-\#Breakdown & 5 & 1.000 & 1.000 & 1.000 & 1.000 \\
B-\#Bus & 11 & 1.000 & 1.000 & 1.000 & 1.000 \\
B-\#Car & 28 & 0.999 & 0.964 & 1.000 & 0.981 \\
B-\#Event & 5 & 0.999 & 0.800 & 0.800 & 0.800 \\
B-\#Interdiction & 15 & 0.998 & 0.800 & 0.923 & 0.857 \\
B-\#Location & 33 & 0.999 & 0.976 & 1.000 & 0.988 \\
B-\#Motorcycle & 790 & 0.976 & 0.938 & 0.917 & 0.927 \\
B-\#Protest & 9 & 1.000 & 1.000 & 1.000 & 1.000 \\
B-\#GoodTrafficSituation & 1.000 & 1.000 & 1.000 & 1.000 \\
B-\#PublicAuthority & 18 & 0.997 & 0.777 & 0.933 & 0.848 \\
B-\#RoadWork & 12 & 0.999 & 0.916 & 1.000 & 0.956 \\
B-\#Solution & 20 & 0.997 & 0.800 & 0.941 & 0.864 \\
B-\#Time & 4 & 0.999 & 0.750 & 1.000 & 0.857 \\
B-\#Truck & 7 & 0.999 & 0.857 & 1.000 & 0.923 \\
B-\#wayEffect:BothDirections & 8 & 0.999 & 1.000 & 0.888 & 0.941 \\
B-\#wayEffect:Partially & 42 & 0.996 & 0.000 & 0.000 & 0.000 \\
I-\#BadTrafficSituation & 24 & 0.999 & 0.857 & 0.947 & 0.900 \\
I-\#GoodTrafficSituation & 13 & 0.998 & 0.958 & 0.958 & 0.958 \\
I-\#Location & 115 & 0.976 & 0.846 & 0.916 & 0.879 \\
I-\#Time & 5 & 0.997 & 0.626 & 0.827 & 0.712 \\
I-\#wayEffect:BothDirections & 10 & 1.000 & 0.000 & 0.000 & 0.000 \\
I-\#wayEffect:Partially & 2 & 0.998 & 0.200 & 0.250 & 0.222 \\
\hline Average, $\sigma$ & & $\mathbf{0 . 9 9 5 ,} \mathbf{0 . 0 0 9}$ & $\mathbf{0 . 8 0 0 , 0 . 2 8 9}$ & $\mathbf{0 . 8 4 8 , 0 . 2 9 0}$ & $\mathbf{0 . 8 2 1 , 0 . 2 8 7}$
\end{tabular}

Após a escolha do melhor classificador e teste final, estudou-se também o mesmo conjunto de parâmetros sobre um conjunto de dados com generalização das classes pertencentes à Actor e exclusão da classe wayEffect:Partially, que foi a mais problemática no teste já discutido. O estado final da árvore pode ser visto na figura 4.12 . 


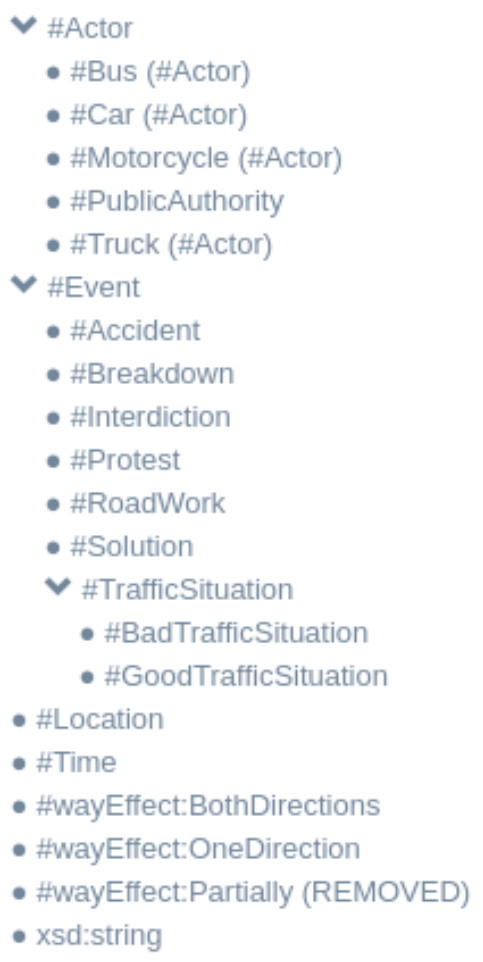

Figura 4.12: Generalização e remoções usadas para redução das classes

A tabela 4.19 mostra o resultado global com redução de classes comparado ao resultado original sem redução. Conclui-se que, neste caso específico, a redução do número de classes piorou o valor de F1, diminuindo, porém, o tempo de treinamento. Isso não significa que a estratégia de generalização não possa melhorar o desempenho de NER em outros casos. Detalhes dos resultados deste teste de generalizações são apresentados nas tabelas 4.20 e 4.21.

Tabela 4.19: Resultado NER final

\begin{tabular}{rrrrr}
\hline Classificador & Tempo tarefa & Tempo CPU treino & F1 validação & F1 teste \\
\hline Random Forest & $3 \mathrm{~h} 20 \mathrm{~m} 7 \mathrm{~s}$ & $387.326 \mathrm{~s}$ & $0.767(\sigma 0.252)$ & $0.821(\sigma 0.287)$ \\
Random Forest (com redução de classes) & $1 \mathrm{~h} 44 \mathrm{~m} 22 \mathrm{~s}$ & $252.572 \mathrm{~s}$ & $0.734(\sigma 0.273)$ & $0.818(\sigma 0.287)$ \\
\hline
\end{tabular}


Tabela 4.20: Resultado final detalhado: Random Forest (validação com redução de classes)

\begin{tabular}{|c|c|c|c|c|c|}
\hline Class & s Support & Accuracy, $\sigma \mathbf{C V}$ & Recall, $\sigma$ CV & Precision, $\sigma \mathbf{C V}$ & $\mathbf{F} 1, \sigma \mathbf{C V}$ \\
\hline $\mathrm{O}$ & 6605 & $0.965,0.016$ & $0.981,0.009$ & $0.966,0.019$ & $0.973,0.012$ \\
\hline B-\#Accident & 141 & $0.999,0.000$ & $0.962,0.053$ & $0.984,0.046$ & $0.972,0.033$ \\
\hline B-\#BadTrafficSituation & 339 & $0.995,0.002$ & $0.942,0.053$ & $0.937,0.039$ & $0.938,0.031$ \\
\hline B-\#Breakdown & 17 & $0.999,0.000$ & $0.962,0.104$ & $1.000,0.000$ & $0.977,0.062$ \\
\hline B-\#Event & 37 & $0.998,0.001$ & $0.636,0.161$ & $0.925,0.114$ & $0.733,0.086$ \\
\hline B-\#Location & 1586 & $0.980,0.007$ & $0.957,0.019$ & $0.922,0.033$ & $0.939,0.024$ \\
\hline B-\#Protest & 17 & $0.999,0.000$ & $0.833,0.288$ & $1.000,0.000$ & $0.875,0.216$ \\
\hline B-\#PublicAuthority & 63 & $0.998,0.001$ & $0.854,0.212$ & $0.925,0.159$ & $0.857,0.154$ \\
\hline B-\#RoadWork & 32 & $0.999,0.000$ & $0.925,0.138$ & $1.000,0.000$ & $0.955,0.083$ \\
\hline B-\#Solution & 55 & $0.999,0.000$ & $0.916,0.220$ & $0.987,0.033$ & $0.930,0.163$ \\
\hline I-\#Event & 8 & $0.998,0.000$ & $0.200,0.400$ & $0.133,0.266$ & $0.160,0.320$ \\
\hline I-\#GoodTrafficSituation & 43 & $0.997,0.002$ & $0.757,0.339$ & $0.851,0.300$ & $0.774,0.299$ \\
\hline I-\#Location & 396 & $0.976,0.013$ & $0.618,0.202$ & $0.777,0.168$ & $0.665,0.138$ \\
\hline I-\#Protest & 2 & $0.997,0.000$ & $0.500,0.000$ & $0.500,0.000$ & $0.500,0.000$ \\
\hline I-\#PublicAuthority & 9 & $0.998,0.001$ & $0.575,0.422$ & $0.538,0.411$ & $0.555,0.415$ \\
\hline I-\#Time & 8 & $0.995,0.001$ & $0.270,0.270$ & $0.460,0.460$ & $0.340,0.340$ \\
\hline I-\#wayEffect:BothDirections & 34 & $0.999,0.000$ & $0.900,0.300$ & $0.747,0.295$ & $0.808,0.286$ \\
\hline \multicolumn{2}{|l|}{ Average, $\sigma$} & $0.995,0.008$ & $0.728,0.276$ & $0.767,0.278$ & $0.734,0.273$ \\
\hline B-\#Actor & 53 & 0.999 & 0.981 & 1.000 & 0.990 \\
\hline B-\#BadTrafficSituation & 72 & 0.997 & 0.986 & 0.946 & 0.965 \\
\hline B-\#Breakdown & 5 & 1.000 & 1.000 & 1.000 & 1.000 \\
\hline B-\#Event & 5 & 0.999 & 0.800 & 1.000 & 0.888 \\
\hline B-\#GoodTrafficSituation & 15 & 0.997 & 0.800 & 0.857 & 0.827 \\
\hline B-\#Interdiction & 43 & 0.999 & 0.976 & 1.000 & 0.988 \\
\hline B-\#Location & 390 & 0.978 & 0.946 & 0.922 & 0.934 \\
\hline B-\#Protest & 9 & 1.000 & 1.000 & 1.000 & 1.000 \\
\hline B-\#PublicAuthority & 18 & 0.997 & 0.777 & 0.875 & 0.823 \\
\hline B-\#RoadWork & 12 & 0.999 & 0.916 & 1.000 & 0.956 \\
\hline B-\#Solution & 20 & 0.997 & 0.800 & 0.941 & 0.864 \\
\hline B-\#Time & 4 & 0.998 & 0.750 & 0.600 & 0.666 \\
\hline B-\#wayEffect:BothDirections & 8 & 0.999 & 1.000 & 0.888 & 0.941 \\
\hline I-\#BadTrafficSituation & 24 & 0.999 & 0.000 & 0.000 & 0.000 \\
\hline I-\#GoodTrafficSituation & 13 & 0.998 & 0.958 & 0.958 & 0.958 \\
\hline I-\#Location & 115 & 0.975 & 0.846 & 0.916 & 0.879 \\
\hline I-\#Time & 5 & 0.996 & 0.608 & 0.833 & 0.703 \\
\hline I-\#wayEffect:BothDirections & 10 & 1.000 & 0.000 & 0.000 & 0.000 \\
\hline Average & & $995(\sigma 0.009)$ & $6\left(\begin{array}{lll}\sigma & 0.289\end{array}\right)$ & $0.292)$ & $.287)$ \\
\hline
\end{tabular}

\subsubsection{2 \\ RE}

Seguindo em RE o que foi feito para NER, os resultados do passo 5 podem ser vistos na tabela 4.22. O algoritmo Frank Wolfe SSVM apresentou, com seus parâmetros default, o melhor resultado de F1 para validação e revalidação, porém com um tempo de treinamento mais que 20 vezes maior que o Structured Perceptron. 
Tabela 4.22: Resultado RE passo 5

\begin{tabular}{|c|c|c|c|c|}
\hline Classificador & Tempo tarefa & Tempo CPU treino & F1 validação & F1 revalidação \\
\hline Frank Wc & $34 \mathrm{~s}$ & $335.189 \mathrm{~s}$ & $0.617\left(\begin{array}{lll}\sigma & 0.340)\end{array}\right.$ & $0.674(\sigma 0.356)$ \\
\hline Structured Perceptron & $2 \mathrm{~h} 55 \mathrm{~m} \mathrm{23s}$ & $14.983 \mathrm{~s}$ & $0.552(\sigma 0.294)$ & $0.635(\sigma 0.293)$ \\
\hline
\end{tabular}

Passando direto ao passo 8, execução de gridsearch, definiu-se os melhores parâmetros para cada algoritmo dentro dos critérios de busca de cada caso, conforme pode ser visto nas tabelas 4.23 e 4.24 .

Tabela 4.23: Gridsearch no RE para o Frank Wolfe SSVM no passo 8

\begin{tabular}{rrr}
\hline Parâmetro & Valores testados & Melhor valor \\
\hline Penalty parameter C & $0.1,1,10,100$ & 100 \\
Use weight averaging & true, false & false \\
\hline
\end{tabular}

Tabela 4.24: Gridsearch no RE para o Structured Perceptron no passo 8

\begin{tabular}{rrr}
\hline Parâmetro & Valores testados & Melhor valor \\
\hline Average & true, false & true \\
Batch learning & true, false & false \\
\hline
\end{tabular}

Os algoritmos foram reavaliados, ainda sobre o conjunto de revalidação. Os resultados apresentados na tabela 4.25 indicam que, mais uma vez, o algoritmo Frank Wolfe SSVM alcança o melhor desempenho em termos de F1, novamente apresentando o maior tempo de treinamento. Seguindo o critério de maior F1 na revalidação, escolheu-se o Frank Wolfe SSVM, com seus melhores parâmetro, como estratégia final para teste.

Tabela 4.25: Resultado RE passo 8

\begin{tabular}{rrrrr}
\hline Classificador & Tempo tarefa & Tempo CPU treino & F1 validação & F1 revalidação \\
\hline Frank Wolfe SSVM & $7 \mathrm{~h} 42 \mathrm{~m} 12 \mathrm{~s}$ & $212.895 \mathrm{~s}$ & $0.658(\sigma 0.269)$ & $0.725(\sigma 0.223)$ \\
Structured Perceptron & $3 \mathrm{~h} 5 \mathrm{~m} 47 \mathrm{~s}$ & $16.456 \mathrm{~s}$ & $0.634(\sigma 0.291)$ & $0.665(\sigma 0.342)$ \\
\hline
\end{tabular}

Os resultados finais, apresentados nas tabelas 4.26 e 4.27 , mostram que foi obtido um classificador com F1 médio de 0.701 sobre o conjunto de teste, com valores de Precision e Recall próximos a F1.

Tabela 4.26: Resultado final detalhado: Frank Wolfe SSVM (validação)

\begin{tabular}{rrrrrr}
\hline Class & Support & Accuracy, $\sigma$ CV & Recall, $\sigma$ CV & Precision, $\sigma$ CV & F1, $\sigma$ CV \\
\hline O & 13797 & $0.885,0.019$ & $0.917,0.033$ & $0.944,0.017$ & $0.930,0.013$ \\
\#affectsFlowTo & 390 & $0.987,0.003$ & $0.826,0.068$ & $0.714,0.069$ & $0.763,0.051$ \\
\#causes & 261 & $0.992,0.003$ & $0.804,0.144$ & $0.778,0.072$ & $0.782,0.086$ \\
\#hasActor & 230 & $0.998,0.001$ & $0.965,0.043$ & $0.956,0.078$ & $0.958,0.044$ \\
\#hasAlternative & 18 & $0.998,0.001$ & $0.166,0.267$ & $0.214,0.364$ & $0.185,0.304$ \\
\#hasEdge & 279 & $0.979,0.012$ & $0.522,0.325$ & $0.438,0.290$ & $0.420,0.240$ \\
\#hasEvent & 864 & $0.957,0.008$ & $0.707,0.186$ & $0.598,0.104$ & $0.626,0.080$ \\
\#hasReference & 390 & $0.966,0.012$ & $0.314,0.175$ & $0.289,0.198$ & $0.292,0.174$ \\
\#hasSupporter & 112 & $0.998,0.001$ & $0.923,0.136$ & $0.934,0.074$ & $0.919,0.079$ \\
\#hasTime & 21 & $0.999,0.000$ & $0.900,0.223$ & $0.958,0.093$ & $0.904,0.157$ \\
\hline Average, $\sigma$ & & $\mathbf{0 . 9 7 6 , 0 . 0 3 3}$ & $\mathbf{0 . 7 0 4 , 0 . 2 6 4}$ & $\mathbf{0 . 6 8 2 , 0 . 2 7 1}$ & $\mathbf{0 . 6 7 8 , 0 . 2 7 0}$
\end{tabular}


Tabela 4.27: Resultado final detalhado: Frank Wolfe SSVM (teste)

\begin{tabular}{|c|c|c|c|c|c|}
\hline Class & Support & Accuracy & Recall & Precision & F1 \\
\hline $\mathrm{O}$ & 3442 & 0.913 & 0.966 & 0.932 & 0.949 \\
\hline \#affectsFlowTo & 99 & 0.990 & 0.747 & 0.860 & 0.799 \\
\hline \#causes & 71 & 0.992 & 0.690 & 0.830 & 0.753 \\
\hline \#hasActor & 57 & 0.997 & 0.859 & 0.942 & 0.899 \\
\hline \#hasAlternative & 8 & 0.997 & 0.125 & 0.200 & 0.153 \\
\hline \#hasEdge & 52 & 0.990 & 0.615 & 0.640 & 0.627 \\
\hline \#hasEvent & 226 & 0.966 & 0.623 & 0.726 & 0.671 \\
\hline \#hasReference & 100 & 0.976 & 0.240 & 0.558 & 0.335 \\
\hline \#hasSupporter & 33 & 0.999 & 0.939 & 1.000 & 0.968 \\
\hline \#hasTime & 4 & 0.999 & 0.750 & 1.000 & 0.857 \\
\hline
\end{tabular}

O teste da árvore da figura 4.12 foi realizado também para este classificador e os resultados comparativos para RE são apresentados na tabela 4.28, onde mais uma vez se vê que o resultado piorou com a redução de classes, com correspondente redução do tempo de treinamento, exatamente como o comportamento para NER. As tabelas 4.29 e 4.30 detalham os resultados da redução para cada classe de relação.

Tabela 4.28: Resultado RE final

\begin{tabular}{rrrrr}
\hline Classificador & Tempo tarefa & Tempo CPU treino & F1 validação & F1 teste \\
\hline Frank Wolfe SSVM & $4 \mathrm{~h} 24 \mathrm{~m} 58 \mathrm{~s}$ & $322.663 \mathrm{~s}$ & $0.678(\sigma 0.270)$ & $0.701(\sigma 0.254)$ \\
Frank Wolfe SSVM (com redução de classes) & $2 \mathrm{~h} 30 \mathrm{~m} 42 \mathrm{~s}$ & $205.059 \mathrm{~s}$ & $0.647(\sigma 0.304)$ & $0.662(\sigma 0.282)$ \\
\hline
\end{tabular}

Tabela 4.29: Resultado final detalhado: Frank Wolfe SSVM (validação com redução de classes)

\begin{tabular}{rrrrrr}
\hline Class & Support & Accuracy, $\sigma$ CV & Recall, $\sigma$ CV & Precision, $\sigma$ CV & F1, $\sigma$ CV \\
\hline O & 11817 & $0.863,0.048$ & $0.906,0.081$ & $0.927,0.022$ & $0.913,0.037$ \\
\#affectsFlowTo & 390 & $0.986,0.005$ & $0.745,0.107$ & $0.790,0.113$ & $0.755,0.062$ \\
\#causes & 261 & $0.990,0.004$ & $0.784,0.146$ & $0.771,0.083$ & $0.766,0.084$ \\
\#hasActor & 230 & $0.998,0.001$ & $0.960,0.051$ & $0.965,0.064$ & $0.960,0.043$ \\
\#hasAlternative & 18 & $0.997,0.001$ & $0.095,0.233$ & $0.071,0.174$ & $0.081,0.199$ \\
\#hasEdge & 279 & $0.975,0.011$ & $0.446,0.300$ & $0.407,0.269$ & $0.358,0.196$ \\
\#hasEvent & 864 & $0.946,0.019$ & $0.691,0.180$ & $0.614,0.146$ & $0.615,0.078$ \\
\#hasReference & 390 & $0.961,0.026$ & $0.226,0.198$ & $0.305,0.238$ & $0.210,0.170$ \\
\#hasSupporter & 112 & $0.999,0.000$ & $0.971,0.057$ & $0.908,0.101$ & $0.933,0.059$ \\
\#hasTime & 21 & $0.999,0.000$ & $0.858,0.224$ & $0.958,0.093$ & $0.880,0.152$ \\
\hline Average, $\sigma$ & & $\mathbf{0 . 9 7 1 , 0 . 0 3 9}$ & $\mathbf{0 . 6 6 8 , 0 . 2 9 3}$ & $\mathbf{0 . 6 7 2 , 0 . 2 9 6}$ & $\mathbf{0 . 6 4 7 , 0 . 3 0 4}$
\end{tabular}


Tabela 4.30: Resultado final detalhado: Frank Wolfe SSVM (teste com redução de classes)

\begin{tabular}{rrrrrr}
\hline Class & Support & Accuracy & Recall & Precision & F1 \\
\hline O & 2884 & 0.889 & 0.963 & 0.906 & 0.934 \\
\#affectsFlowTo & 99 & 0.988 & 0.666 & 0.891 & 0.763 \\
\#causes & 71 & 0.991 & 0.661 & 0.870 & 0.752 \\
\#hasActor & 57 & 0.997 & 0.912 & 0.945 & 0.928 \\
\#hasAlternative & 8 & 0.996 & 0.125 & 0.125 & 0.125 \\
\#hasEdge & 52 & 0.983 & 0.673 & 0.454 & 0.542 \\
\#hasEvent & 226 & 0.957 & 0.473 & 0.781 & 0.589 \\
\#hasReference & 100 & 0.970 & 0.130 & 0.448 & 0.201 \\
\#hasSupporter & 33 & 0.998 & 0.878 & 1.000 & 0.935 \\
\#hasTime & 4 & 0.999 & 0.750 & 1.000 & 0.857 \\
\hline Average, $\sigma$ & & $\mathbf{0 . 9 7 7 ,} \mathbf{0 . 0 3 2}$ & $\mathbf{0 . 6 2 3 , 0 . 2 8 2}$ & $\mathbf{0 . 7 4 2 , 0 . 2 8 1}$ & $\mathbf{0 . 6 6 2 , 0 . 2 8 2}$
\end{tabular}

\subsubsection{3}

\section{Uso dos modelos finais}

Uma vez escolhidos os classificadores de NER e RE, estes foram estabelecidos para um serviço de exemplo, onde foram executados testes com dados totalmente novos e mais recentes retirados diretamente dos canais de twitter, isto é, dados que não participaram do conjunto de treinamento e tampouco do conjunto de teste.

A figura 4.13 mostra um exemplo de resposta razoável, com triplas RDF correspondentes apresentadas na figura 4.14. Percebe-se claramente que as falhas se devem, neste caso, somente ao classificador de RE, pois as entidades de NER foram correta e totalmente identificadas. Isso provavelmente se deve ao que foi diagnosticado na figura 4.7, onde as quedas na autoconcordância nas anotações das relações implicaram quedas ainda maiores nas auto-concordâncias de conectores, o que provavelmente atrapalhou o processo posterior de geração automática de atributos, gerando expressões regulares ambíguas e reduzindo o desempenho de RE como um todo. Esse resultado mostra a importância da busca por um processo cada vez melhor e mais aperfeiçoado de anotação. 


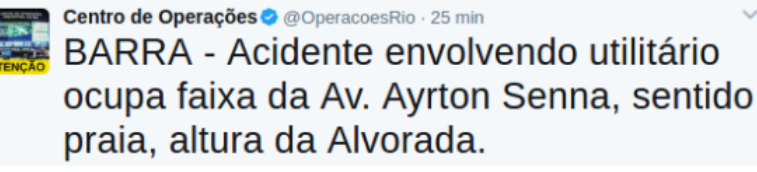

(a)

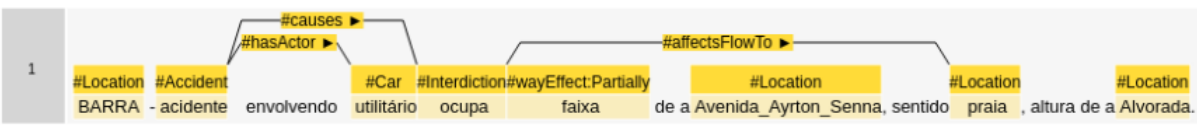

(b)

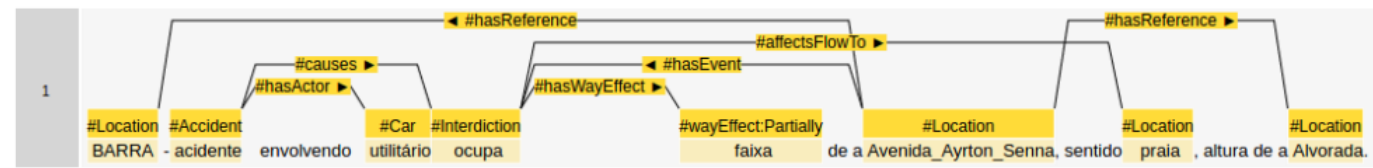

(c)

Figura 4.13: Teste com resposta razoável: (a) tweet original; (b) anotação predita; (c) anotação esperada

<http://inf.puc-rio.br/ontologies/TEDO/Car/0> <http://www.w3.org/1999/02/22-rdfsyntax-ns\#type><http://inf.puc-rio.br/ontologies/TEDO/Car> .

<http://inf .puc-rio.br/ontologies/TEDO/Accident/0〉<http://www.w3.org/1999/02/22-rdf -syntax-ns\#type><http://inf.puc-rio.br/ontologies/TEDO/Accident> .

3 〈http://inf.puc-rio.br/ontologies/TEDO/Accident/0><http://inf.puc-rio.br/ontologies /TEDO/hasActor > 〈http://inf .puc-rio.br/ontologies/TEDO/Car/0> .

<http://inf.puc-rio.br/ontologies/TEDO/Location/2> <http://inf.puc-rio.br/ontologies /TEDO/hasName> "Avenida_Ayrton_Senna" .

$5<$ http://inf.puc-rio.br/ontologies/TEDO/Accident/0〉<http://inf.puc-rio.br/ontologies /TEDO/causes><http://inf.puc-rio.br/ontologies/TEDO/Interdiction/0> .

<http://inf.puc-rio.br/ontologies/TEDO/Interdiction/0〉<http://inf.puc-rio.br/ ontologies/TEDO/affectsFlowTo> <http://inf .puc-rio.br/ontologies/TEDO/Location /0>.

<http://inf .puc-rio.br/ontologies/TEDO/Location/1> <http://inf.puc-rio.br/ontologies /TEDO/hasName> "BARRA" .

<http://inf.puc-rio.br/ontologies/TEDO/Location/3><http://inf.puc-rio.br/ontologies /TEDO/hasName> "Alvorada" .

<http://inf .puc-rio.br/ontologies/TEDO/Location/0> <http://www.w3.org/1999/02/22-rdf -syntax-ns\#type><http://inf.puc-rio.br/ontologies/TEDO/Location> .

<http://inf .puc-rio.br/ontologies/TEDO/Location/0> <http://inf .puc-rio.br/ontologies /TEDO/hasName> "praia" .

<http://inf .puc-rio.br/ontologies/TEDO/Interdiction/0><http://www.w3.org /1999/02/22-rdf-syntax-ns\#type><http://inf .puc-rio.br/ontologies/TEDo/ Interdiction $>$.

<http://inf .puc-rio.br/ontologies/TEDO/Location/3><http://www.w3.org/1999/02/22-rdf -syntax-ns\#type><http://inf.puc-rio.br/ontologies/TEDO/Location> . -syntax-ns\#type><http://inf.puc-rio.br/ontologies/TEDO/Location> . -syntax-ns\#type><http://inf.puc-rio.br/ontologies/TEDO/Location> .

Figura 4.14: Teste com resposta razoável: triplas RDF retornadas

Já a figura 4.15, com triplas correspondentes na figura 4.16, mostra um exemplo de resposta melhor, os únicos equívocos da anotação foram a ausência 
da relação hasWayEffect entre a entidade Interdiction e wayEffect:Partially, e a presença de algumas relações do tipo hasReference que não deveriam existir.

LINHA VERMELHA | dois carros bateram no sentido Baixada,

na altura do aeroporto. 1 faixa ocupada. CET-Rio no local.

\#ViasExpressas

(a)

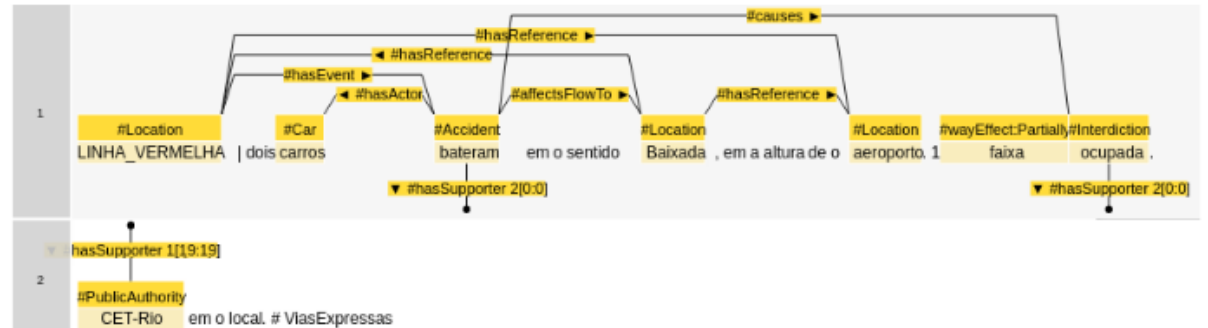

(b)

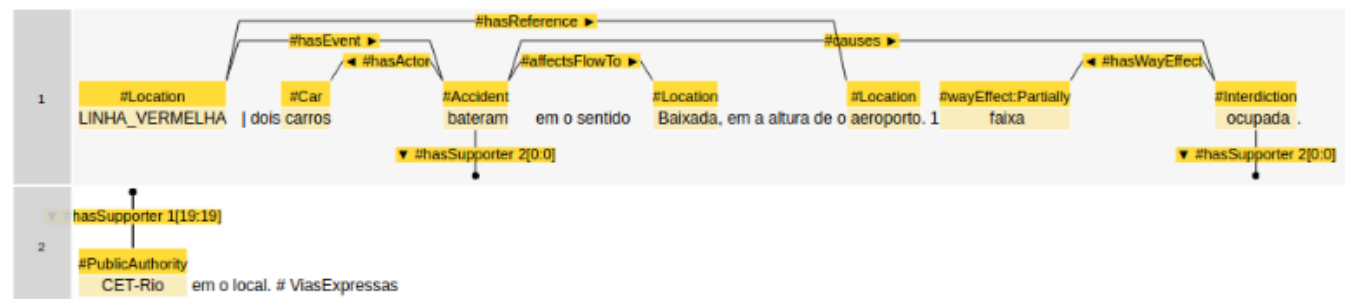

(c)

Figura 4.15: Teste com boa resposta: (a) tweet original; (b) anotação predita; (c) anotação esperada 
1

<http://inf.puc-rio.br/ontologies/TEDO/Car/0><http://www.w3.org/1999/02/22-rdfsyntax-ns\#type><http://inf.puc-rio.br/ontologies/TEDO/Car> .

$<$ http://inf.puc-rio.br/ontologies/TEDO/Location/2><http://inf.puc-rio.br/ontologies /TEDO/hasName> "Baixada" .

<http://inf.puc-rio.br/ontologies/TEDO/Interdiction/0><http://inf.puc-rio.br/ ontologies/TEDO/hasSupporter> <http://inf .puc-rio.br/ontologies/TEDO/ PublicAuthority/0>.

<http://inf.puc-rio.br/ontologies/TEDO/PublicAuthority/0> <http://www.w3.org /1999/02/22-rdf-syntax-ns\#type><http://inf .puc-rio.br/ontologies/TEDO/ PublicAuthority> .

<http://inf .puc-rio.br/ontologies/TEDO/Location/0> <http://inf.puc-rio.br/ontologies /TEDO/hasEvent> 〈http://inf.puc-rio.br/ontologies/TEDO/Accident/0 .

<http://inf.puc-rio.br/ontologies/TEDO/Interdiction/0><http://www.w3.org /1999/02/22-rdf-syntax-ns\#type><http://inf .puc-rio.br/ontologies/TEDo/ Interdiction> .

<http://inf.puc-rio.br/ontologies/TEDO/Location/0> <http://www.w3.org/1999/02/22-rdf -syntax-ns\#type><http://inf.puc-rio.br/ontologies/TEDO/Location> .

<http://inf .puc-rio.br/ontologies/TEDO/Location/2> <http://www.w3.org/1999/02/22-rdf -syntax-ns\#type><http://inf.puc-rio.br/ontologies/TEDO/Location> .

$\langle$ http://inf .puc-rio.br/ontologies/TEDO/Accident/0><http://inf.puc-rio.br/ontologies /TEDO/hasSupporter> 〈http://inf.puc-rio.br/ontologies/TEDO/PublicAuthority/0〉 .

<http://inf .puc-rio.br/ontologies/TEDO/Location/1> <http://www.w3.org/1999/02/22-rdf -syntax-ns\#type><http://inf.puc-rio.br/ontologies/TEDO/Location> .

<http://inf .puc-rio.br/ontologies/TEDO/Location/2〉<http://inf.puc-rio.br/ontologies /TEDO/hasReference><http://inf.puc-rio.br/ontologies/TEDO/Location/0> .

$\langle$ http://inf.puc-rio.br/ontologies/TEDO/Location/0> <http://inf.puc-rio.br/ontologies /TEDO/hasName> "LINHA_VERMELHA" .

<http://inf .puc-rio.br/ontologies/TEDO/Location/0> <http://inf .puc-rio.br/ontologies /TEDO/hasReference> <http://inf.puc-rio.br/ontologies/TEDO/Location/1> .

<http://inf .puc-rio.br/ontologies/TEDO/Location/2><http://inf.puc-rio.br/ontologies /TEDO/hasReference> <http://inf.puc-rio.br/ontologies/TEDO/Location/1> .

$\langle$ http://inf.puc-rio.br/ontologies/TEDO/Accident/0〉<http://inf.puc-rio.br/ontologies /TEDO/causes><http://inf.puc-rio.br/ontologies/TEDO/Interdiction/0> .

<http://inf .puc-rio.br/ontologies/TEDO/Accident/0> <http://www.w3.org/1999/02/22-rdf -syntax-ns\#type><http://inf.puc-rio.br/ontologies/TEDO/Accident> .

<http://inf.puc-rio.br/ontologies/TEDO/Accident/0><http://inf.puc-rio.br/ontologies /TEDO/hasActor> <http://inf .puc-rio.br/ontologies/TEDO/Car/0〉 .

<http://inf .puc-rio.br/ontologies/TEDO/Accident/0><http://inf.puc-rio.br/ontologies /TEDO/affectsFlowTo> <http://inf .puc-rio.br/ontologies/TEDO/Location/2> .

<http://inf .puc-rio.br/ontologies/TEDO/Location/1> <http://inf.puc-rio.br/ontologies /TEDO/hasName> "aeroporto" .

Figura 4.16: Teste com boa resposta: triplas RDF retornadas

O terceiro e último exemplo, ilustrado na figura 4.17 e com triplas na figura 4.18, mostra um caso de extração perfeita das informações, combinando exatamente com o resultado de uma anotação manual em termos de NER e RE. 
Centro de Operações @ @operacoesRio · $20 \mathrm{~h}$

AV ATLÂNTICA | há retenções no

sentido Leme, desde a altura do Othon

Palace até a Av Princesa Isabel.

(a)

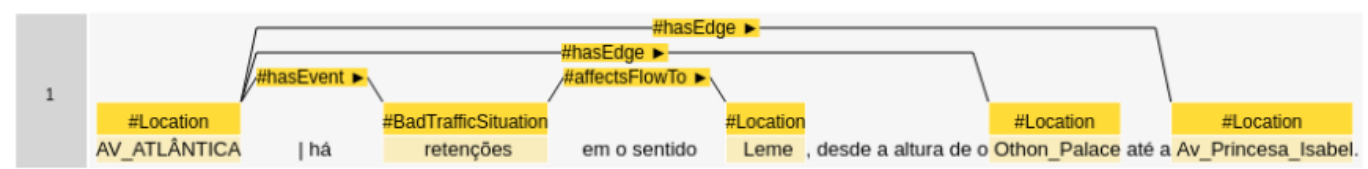

(b)

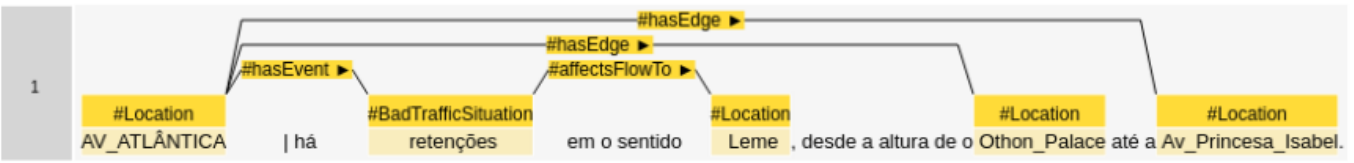

(c)

Figura 4.17: Teste com resposta perfeita: (a) tweet original; (b) anotação predita; (c) anotação esperada

<http://inf .puc-rio.br/ontologies/TEDO/Location/1> <http://www.w3.org/1999/02/22-rdf -syntax-ns\#type><http://inf.puc-rio.br/ontologies/TEDO/Location> . <http://inf .puc-rio.br/ontologies/TEDO/Location/2> <http://www.w3.org/1999/02/22-rdf -syntax-ns\#type><http://inf.puc-rio.br/ontologies/TEDO/Location> . <http://inf.puc-rio.br/ontologies/TEDO/BadTrafficSituation/0><http://www.w3.org /1999/02/22-rdf-syntax-ns\#type><http://inf .puc-rio.br/ontologies/TEDO/ BadTrafficSituation> .

<http://inf .puc-rio.br/ontologies/TEDO/Location/0> <http://inf.puc-rio.br/ontologies /TEDO/hasEdge> <http://inf.puc-rio.br/ontologies/TEDO/Location/1> .

<http://inf .puc-rio.br/ontologies/TEDO/Location/2> <http://inf.puc-rio.br/ontologies /TEDO/hasName> "Av_Princesa_Isabel" .

$\langle$ http://inf.puc-rio.br/ontologies/TEDO/Location/0><http://inf.puc-rio.br/ontologies /TEDO/hasName> "AV_ATLÂNTICA" .

<http://inf .puc-rio.br/ontologies/TEDO/Location/1> <http://inf .puc-rio.br/ontologies /TEDO/hasName> "Othon_Palace" .

<http://inf.puc-rio.br/ontologies/TEDO/BadTrafficSituation/0> <http://inf.puc-rio.br /ontologies/TEDO/affectsFlowTo><http://inf.puc-rio.br/ontologies/TEDO/Location /3> .

<http://inf .puc-rio.br/ontologies/TEDO/Location/3> <http://inf .puc-rio.br/ontologies /TEDO/hasName> "Leme" .

<http://inf .puc-rio.br/ontologies/TEDO/Location/0> <http://www.w3.org/1999/02/22-rdf -syntax-ns\#type><http://inf.puc-rio.br/ontologies/TEDO/Location> .

〈http://inf.puc-rio.br/ontologies/TEDO/Location/0> <http://inf .puc-rio.br/ontologies /TEDO/hasEdge> <http://inf.puc-rio.br/ontologies/TEDO/Location/2> .

<http://inf .puc-rio.br/ontologies/TEDO/Location/3><http://www.w3.org/1999/02/22-rdf -syntax-ns\#type><http://inf.puc-rio.br/ontologies/TEDO/Location> .

$\langle$ http://inf.puc-rio.br/ontologies/TEDO/Location/0〉<http://inf.puc-rio.br/ontologies /TEDO/hasEvent> 〈http://inf.puc-rio.br/ontologies/TEDO/BadTrafficSituation/0> .

Figura 4.18: Teste com resposta perfeita: triplas RDF retornadas 


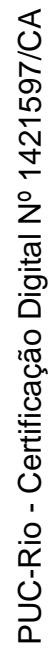

I know not all that may be coming, but be it what it will, I'll go to it laughing.

Herman Melville, Moby-Dick; or, The Whale. 


\section{5}

\section{Conclusão}

Este trabalho propôs a implementação de um sistema web, o LER, para a execução das atividades de curadoria de dados, aprendizado de máquina e construção de serviços. A etapa de curadoria é de tal modo importante e complexa que inspirou a implementação de um subsistema especial, o ERAS, como subsistema do LER. A etapa de aprendizado de máquina realiza o treinamento de modelos para as tarefas de identificação de entidades (NER) e de extração de relações entre as entidades identificadas (RE). A última etapa, a de construção de serviços, combina classificadores de NER e RE previamente treinados com dados gerados na etapa de curadoria, disponibilizando serviços preparados para receberem dados textuais puros e exportarem a informação estruturada extraída do texto.

O ERAS foi implementado com o objetivo de ser uma ferramenta robusta e de simples uso por pessoal não especializado na tarefa de anotação. Para fins de avaliação do estado atual deste sistema, um grupo de anotadores de diferentes origens e perfis foi recrutado para uma tarefa de anotação de tweets de trânsito, tendo como referência uma versão levemente modificada da ontologia TEDO, proposta em (6). Diversas questões relacionadas ao processo de anotação foram analisadas e questionários foram preenchidos. Os resultados do experimento mostraram que a ferramenta atendeu satisfatoriamente o que fora proposto neste trabalho, pois ela se mostrou muito adequada à tarefa de anotação e recebeu muitos elogios por parte dos participantes do experimento. Durante a condução dos experimento tornou-se claro o fato de que a construção de uma ontologia não é um processo estático, e que a definição de uma que se adéque bem a dados textuais, é uma tarefa muito difícil e trabalhosa, porém essa etapa do processo é de suma importância e deve ser executada com atenção, já que afeta diretamente a qualidade dos dados anotados. Outro ponto que pôde-se notar nestes resultados foi que a tarefa de identificação de relações entre entidades no domínio de tweets de trânsito é complexa e por vezes ambígua, o que acaba gerando anotações finais com qualidade abaixo do esperado, porém notou-se também que ter um especialista da tarefa dando suporte aos anotadores é de suma importância.

O restante do sistema LER, isto é, as etapas de aprendizado automático e criação de serviços, foi testado pelo uso de um conjunto de 600 tweets de trânsito anotados exclusivamente pelo autor deste trabalho, tendo como base ontológica uma versão da TEDO otimizada a partir das experiências de anotação citadas acima. Para as tarefas de NER e RE, diferentes conjuntos de atributos, classificadores, algoritmos e parâmetros foram avaliados, selecionando os mais adequados usando os valores de F1 e tempos de treinamento, nesta ordem, como principais critérios. Para a tarefa NER, obteve-se um melhor resultado no conjunto de teste $(\mathrm{F} 1=0.821$, Precision $=0.848$ e Recall $=$ 
0.800) pelo uso do classificador Random Forest com 50 árvores (entre outros parâmetro ótimos), atributos de contexto gerados automaticamente pela ferramenta e informações completas de POS Tagging. Para a tarefa RE, obteve-se um melhor resultado no conjunto de teste $(\mathrm{F} 1=0.701$, Precision $=0.769 \mathrm{e}$ Recall $=0.655)$ utilizando o algoritmo Frank Wolfe SSVM, atributos relativos às entidades identificadas e atributos de contexto gerados automaticamente pela ferramenta (fazendo intenso uso dos conectores registrados na etapa de anotação). Alguns testes acerca da redução de classes por generalização baseada na ontologia foram feitos e não melhoraram os resultados de NER e RE, exceto em relação ao tempo de treinamento.

Os melhores modelos foram selecionados e alocados em série como um serviço, para a demonstração da automação complexa do fluxo de extração das informações em novos tweets de trânsito nunca "vistos" pelos classificadores. Os resultados são interessantes, mas melhorias podem ser feitas. Neste caso específico, a perda da eficiência do serviço reside no modelo para RE, que teve um pior F1 comparado ao obtido para NER. Contudo, novos trabalhos deverão visar a melhoria de ambos os classificadores.

Recomenda-se que trabalhos futuros atuem em diversas linhas:

- Realização de novos experimentos de anotação com um número maior de anotadores, por mais tempo e com mais documentos. A ferramenta ERAS está preparada para registrar diversos dados relativos ao comportamento dos anotadores, mesmo relativos à dinâmica das concordâncias. Os resultados do aprendizado de máquina deixam claro, como infere-se por pura lógica, que o processo de anotação, se otimizado, produz melhores classificadores.

- Uso de técnicas de process mining (44) nos logs de anotação, isto é, uma atividade derivada do que se diz no item acima. Este tipo de análise seria interessante, por exemplo, para descobrir quais fluxos de uso levam a maiores concordâncias, o que seria uma informação muito útil já que afeta diretamente a qualidade dos modelos treinados;

- Melhoria no feedback dado nas anotações. Atualmente o único tipo de retorno que o anotador pode dar via sistema se resume a uma caixa de texto livre em cada documento anotado. Abordagens onde o usuário também desse o feedback no nível das entidades, relações e conectores poderiam trazer mais informações úteis ao processo de curadoria. Outra função interessante seria a possibilidade do anotador atribuir um índice de incerteza após efetuar determinada anotação, o que facilitaria a separação dos documentos entre níveis de dificuldade e identificação de melhorias na ontologia definida para o domínio;

- Criar mecanismos que auxiliem o curador na construção da ontologia. Um curador poderia definir apenas algumas entidades e relações genéricas e o LER o ajudaria, por exemplo, a identificar quais classes devessem ser especializadas ou generalizadas. Isso tornaria o sistema mais proativo e amigável para pessoas que não estão familiarizadas com a construção de ontologias;

- Teste do sistema LER em outros domínios, diferentes de tweets de trânsito. Um trabalho relativo a relatórios operacionais da área de 
petróleo e gás (45) já demonstrou, com bons resultados, a viabilidade do uso do LER em um caso demasiadamente complexo e desafiador.

- Aplicação de técnicas de seleção automática ou indução de atributos (46), para melhoria da capacidade de classificação dos algoritmos atualmente usados.

- Aplicação de outros métodos para NER e RE, inclusive considerando-as como uma única tarefa (metodologia "end-to-end") (47). Recomendase também testes do uso de Deep Learning para NER e RE, conforme avaliado por outros autores (48). 


\section{Referências bibliográficas}

[1] FILIPPOV, S.. Mapping text and data mining in academic and research communities in Europe. Lisbon Council, 2014.

[2] ITTOO, A.; NGUYEN, L. M. ; VAN DEN BOSCH, A.. Text analytics in industry: Challenges, desiderata and trends. Computers in Industry, 78:96-107, 2016.

[3] HE, W.; ZHA, S. ; LI, L.. Social media competitive analysis and text mining: A case study in the pizza industry. International Journal of Information Management, 33(3):464-472, 2013.

[4] ATSERIAS, J.; CODINA, J.. What is the text of a tweet? In: WORKSHOP PROGRAMME, p. 29.

[5] REDLICH, L. R.. Modelagem de eventos de trânsito com base em clipping de grandes massas de dados da web. Master's thesis, PUCRio, 2013.

[6] AlBUqUeRQUE, F. C.; CASANOVA, M. A.; LOPES, H.; REDLICH, L. R.; DE MACEDO, J. A. F.; LEMOS, M.; DE CARVALHO, M. T. M. ; RENSO, C.. A methodology for traffic-related twitter messages interpretation. Computers in Industry, 78:57-69, 2016.

[7] DA COSTA AlBuquerque, F.; CASANOVA, M. A.; DE MACEDO, J. A. F.; DE CARVALHO, M. T. M. ; RENSO, C.. A proactive application to monitor truck fleets. In: MOBILE DATA MANAGEMENT (MDM), 2013 IEEE 14TH INTERNATIONAL CONFERENCE ON, volumen 1, p. 301304. IEEE, 2013.

[8] SOWA, J. F.; OTHERS. Knowledge representation: logical, philosophical, and computational foundations, volumen 13. MIT Press, 2000.

[9] KANEIWA, K.; IWAZUME, M. ; FUKUDA, K.. An upper ontology for event classifications and relations. In: AUSTRALASIAN JOINT CONFERENCE ON ARTIFICIAL INTELLIGENCE, p. 394-403. Springer, 2007.

[10] WORBOYS, M.; HORNSBY, K.. From objects to events: Gem, the geospatial event model. In: INTERNATIONAL CONFERENCE ON GEOGRAPHIC INFORMATION SCIENCE, p. 327-343. Springer, 2004.

[11] MOTTA, E. N.; FERNANDES, E. R. ; MILIDIÚ, R. L.. F-ext-ws-2.0: A web service for natural language processing. 2010. 
[12] PLATT, J. C.. 12 fast training of support vector machines using sequential minimal optimization. Advances in kernel methods, p. 185208, 1999.

[13] HALL, M.; FRANK, E.; HOLMES, G.; PFAHRINGER, B.; REUTEMANN, P. ; WITTEN, I. H.. The weka data mining software: an update. ACM SIGKDD explorations newsletter, 11(1):10-18, 2009.

[14] FERNANDES, E. R.; DOS SANTOS, C. N. ; MILIDIÚ, R. L.. Latent structure perceptron with feature induction for unrestricted coreference resolution. In: JOINT CONFERENCE ON EMNLP AND CONLLSHARED TASK, p. 41-48. Association for Computational Linguistics, 2012.

[15] CHU, T. C.; HUANG, R.. Sourcing the crowd for a few good ones: Event type detection. In: 24TH INTERNATIONAL CONFERENCE ON COMPUTATIONAL LINGUISTICS, p. 1239, 2012.

[16] MADLBERGER, L.; ROMADHONY, A. ; PURWARIANTI, A.. Gotong royong in nlp research a mobile tool for collaborative text annotation in indonesia. In: ASIAN LANGUAGE PROCESSING (IALP), 2016 INTERNATIONAL CONFERENCE ON, p. 99-102. IEEE, 2016.

[17] HOVY, E.; LAVID, J.. Towards a 'science'of corpus annotation: a new methodological challenge for corpus linguistics. International journal of translation, 22(1):13-36, 2010.

[18] OF SHEFFIELD, T. U.. Gate home. https://gate.ac.uk/, 2017. Accesso em 07 de abril de 2017.

[19] CUNNINGHAM, H.; MAYNARD, D.; BONTCHEVA, K. ; TABLAN, V.. Gate: an architecture for development of robust hlt applications. In: PROCEEDINGS OF THE 40TH ANNUAL MEETING ON ASSOCIATION FOR COMPUTATIONAL LINGUISTICS, p. 168-175. Association for Computational Linguistics, 2002.

[20] CUnNINGHAM, H.; MAYNARD, D. ; BONTCHEVA, K.. Text processing with gate. Gateway Press CA, 2011.

[21] STENETORP, P.; PYYSALO, S.; TOPIĆ, G.; OHTA, T.; ANANIADOU, S. ; TSUJII, J.. Brat: a web-based tool for nlp-assisted text annotation. In: PROCEEDINGS OF THE DEMONSTRATIONS AT THE 13TH CONFERENCE OF THE EUROPEAN CHAPTER OF THE ASSOCIATION FOR COMPUTATIONAL LINGUISTICS, p. 102-107. Association for Computational Linguistics, 2012.

[22] BONTCHEVA, K.; DERCZYNSKI, L.; FUNK, A.; GREENWOOD, M. A.; MAYNARD, D. ; ASWANI, N.. Twitie: An open-source information extraction pipeline for microblog text. In: RANLP, p. 83-90, 2013.

[23] YIMAM, S. M.; GUREVYCH, I.; DE CASTILHO, R. E. ; BIEMANN, C.. Webanno: A flexible, web-based and visually supported system for distributed annotations. In: ACL (CONFERENCE SYSTEM DEMONSTRATIONS), p. 1-6, 2013. 
[24] MÜLLER, C.; STRUBE, M.. Multi-level annotation of linguistic data with mmax2. Corpus technology and language pedagogy: New resources, new tools, new methods, 3:197-214, 2006.

[25] MORTON, T.; LACIVITA, J.. Wordfreak: an open tool for linguistic annotation. In: PROCEEDINGS OF THE 2003 CONFERENCE OF THE NORTH AMERICAN CHAPTER OF THE ASSOCIATION FOR COMPUTATIONAL LINGUISTICS ON HUMAN LANGUAGE TECHNOLOGY: DEMONSTRATIONS-VOLUME 4, p. 17-18. Association for Computational Linguistics, 2003.

[26] WISSLER, L.; ALMASHRAEE, M.; DÍAZ, D. M. ; PASCHKE, A.. The gold standard in corpus annotation. In: IEEE GSC, 2014.

[27] CAMPBELL, B.; JONES, M. ; MORTIMORE, C.. Json web token (jwt) profile for oauth 2.0 client authentication and authorization grants. 2015.

[28] CENTER, T. R.. Welcome | Freeling Homepage. http://nlp.cs.upc.edu/freeling/node/1, 2017. [Acesso em 20 de Março de 2017].

[29] PADRÓ, L.; STANILOVSKY, E.. Freeling 3.0: Towards wider multilinguality. In: PROCEEDINGS OF THE LANGUAGE RESOURCES AND EVALUATION CONFERENCE (LREC 2012), Istanbul, Turkey, May 2012. ELRA.

[30] MELVILLE, H.. Moby-dick; or, the whale. 1851. Ed. Harrison Hayford et al. Evanston: Northwestern UP and the Newberry Library, 1988.

[31] UNIVERSALDEPENDENCIES. Conll-u format. http: //universaldependencies.org/format.html, 2017. [Online; accessed 9-april-2017].

[32] CARLETTA, J.. Assessing agreement on classification tasks: the kappa statistic. Computational linguistics, 22(2):249-254, 1996.

[33] WIKIPEDIA. Hyperparameter optimization. https://en.wikipedia.org/w/index.php?title=Hyperparameter_optimization, 2017. [Acesso em 26 de Março de 2017].

[34] CHANG, C.-C.; LIN, C.-J.. Libsvm: a library for support vector machines. ACM Transactions on Intelligent Systems and Technology (TIST), 2(3):27, 2011.

[35] BREIMAN, L.. Random forests. Machine learning, 45(1):5-32, 2001.

[36] BOTTOU, L.. Large-scale machine learning with stochastic gradient descent. In: PROCEEDINGS OF COMPSTAT'2010, p. 177-186. Springer, 2010. 
[37] HUANG, L.; FAYONG, S. ; GUO, Y.. Structured perceptron with inexact search. In: PROCEEDINGS OF THE 2012 CONFERENCE OF THE NORTH AMERICAN CHAPTER OF THE ASSOCIATION FOR COMPUTATIONAL LINGUISTICS: HUMAN LANGUAGE TECHNOLOGIES, p. 142151. Association for Computational Linguistics, 2012.

[38] LACOSTE-JULIEN, S.; JAGGI, M.; SCHMIDT, M. ; PLETSCHER, P.. Block-coordinate frank-wolfe optimization for structural svms. arXiv preprint arXiv:1207.4747, 2012.

[39] POWERS, D. M.. Evaluation: from precision, recall and f-measure to roc, informedness, markedness and correlation. 2011.

[40] CROCKFORD, D.. The application/json media type for javascript object notation (json). 2006.

[41] BECKETT, D.. Rdf 1.1 n-triples. W3C Recommendation, 2014.

[42] SCIKIT LEARN. Preprocessing data. http://scikit-learn.org/ stable/modules/preprocessing.html, 2017. [Online; accessed 9-april2017].

[43] SOLÉ, X.; RAMISA, A. ; TORRAS, C.. Evaluation of random forests on large-scale classification problems using a bag-of-visual-words representation. In: CCIA, p. 273-276, 2014.

[44] AALST, W.; ADRIANSYAH, A.; MEDEIROS, A. K. A.; ARCIERI, F.; BAIER, T.; BLICKLE, T.; BOSE, J. C.; BRAND, P.; BRANDTJEN, R.; BUIJS, J. ; OTHERS. Process mining manifesto. In: BUSINESS PROCESS MANAGEMENT WORKSHOPS, p. 169-194. Springer, 2012.

[45] FURTADO, T.. Interpretação automática de relatórios de operação de equipamentos. Master's thesis, PUC-Rio, 2017.

[46] MOTTA, E. N.. Induçao e Seleçao Incrementais de Atributos no Aprendizado Supervisionado. PhD thesis, PUC-Rio, 2014.

[47] MIWA, M.; BANSAL, M.. End-to-end relation extraction using lstms on sequences and tree structures. arXiv preprint arXiv:1601.00770, 2016.

[48] CHIU, J. P.; NICHOLS, E.. Named entity recognition with bidirectional lstm-cnns. arXiv preprint arXiv:1511.08308, 2015. 
A

\section{Experimento de anotação: Guia de anotação}

O documento contido nas seções seguintes é o guia de anotação que foi dado aos participantes do experimento de anotação descrito no capítulo 4 desta dissertação.

\section{A.1}

\section{FERRAMENTA DE ANOTAÇÃO}

Para a tarefa de anotação que será explicada na seção A.2 deste documento, o anotador utilizará uma ferramenta online implementada para tal fim. Esta ferramenta fará uso de uma ontologia para a tarefa de anotação, esta ontologia é basicamente uma série de regras que definem a estrutura de um domínio, ou seja, quais entidades fazem parte deste domínio, quais são as relações possíveis entre estas entidades e quais as restrições associadas à estas relações. A ferramenta que será utilizada no processo de anotação (Figura A.1) tem basicamente as seguintes características:

Document package

proj - TEDO

Figura A.1: Ferramenta de anotação

- Seletor de pacotes de documentos disponíveis para anotação;

- Indicador de progresso, mostrando quantos documentos estão disponíveis para anotação e quanto já foram finalizados;

- Apresentação de um resumo da ontologia que descreve o domínio da anotação (é mostrado quando se clica no botão "Ontology", como pode ser visto na Figura A.2, este resumo está descrito no formato de árvore: no $1^{\mathrm{O}}$ nível estão todas as entidades disponíveis para rotulação, no $2^{\mathrm{O}}$ as relações possíveis que podem partir da entidade em questão e no $3^{\circ}$ as entidades que podem ser atingidas pela relação); 
- Guia de anotação (este documento), que é apresentado quando o botão "Guidelines" é acionado;

- Função de ir para o próximo documento (os documentos são apresentados aleatoriamente para anotação, porém não há obrigação de finalizar os documentos na ordem apresentada, é possível anotar parte de um documento e ir para outro caso queira, que em algum momento no futuro o documento não finalizado será reapresentado);

- Capacidade de adicionar comentários ao documento (acionando o botão "Comments"), como pode ser visto na Figura A.3;

- Desfazer (acionando o botão undo) ou refazer (acionando o botão redo) ações;

- Finalizar a anotação de um documento (acionando o botão "DONE", uma vez finalizado o documento não será mais apresentado para o anotador);

- Possibilidade de rotulação das palavras, criação de relações entre os rótulos e associação de palavras às relações;

- Todas as ações que afetam o documento anotado são salvas automaticamente.

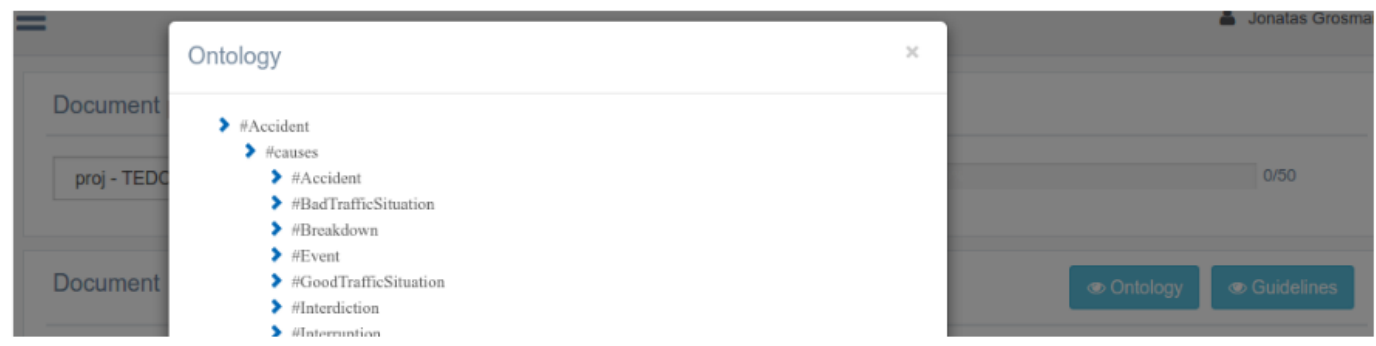

Figura A.2: Resumo da ontologia de anotação

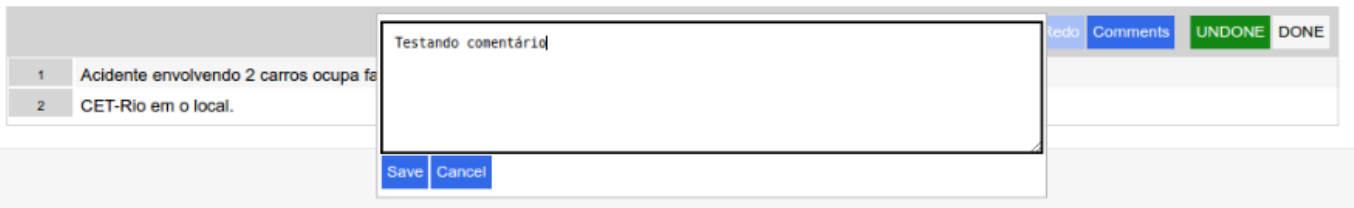

Figura A.3: Adicionando comentários 


\section{A.1.1}

\section{PROCESSO DE ANOTAÇÃO}

O processo de anotação pode ser dividido basicamente em 3 partes, rotulação de palavras, criação de relacionamento entre rótulos e criação de conectores. O processo de rotulação é a associação de um bloco de texto a uma determinada entidade descrita na ontologia que modela o domínio do documento. Este processo segue os seguintes passos:

- Selecionar a palavra ou conjunto de palavras que serão rotuladas (Figura A.4). Não é necessário selecionar toda a palavra que será rotulada apenas parte dela já é o suficiente;

- Abrir o menu de contexto (clicando com o botão direito do mouse) e selecionar o rótulo desejado (Figura A.5), logo após isso o rótulo estará associado à(s) palavra(s) selecionada(s) (Figura A.6).

Figura A.4: Rotulação, passo 1 


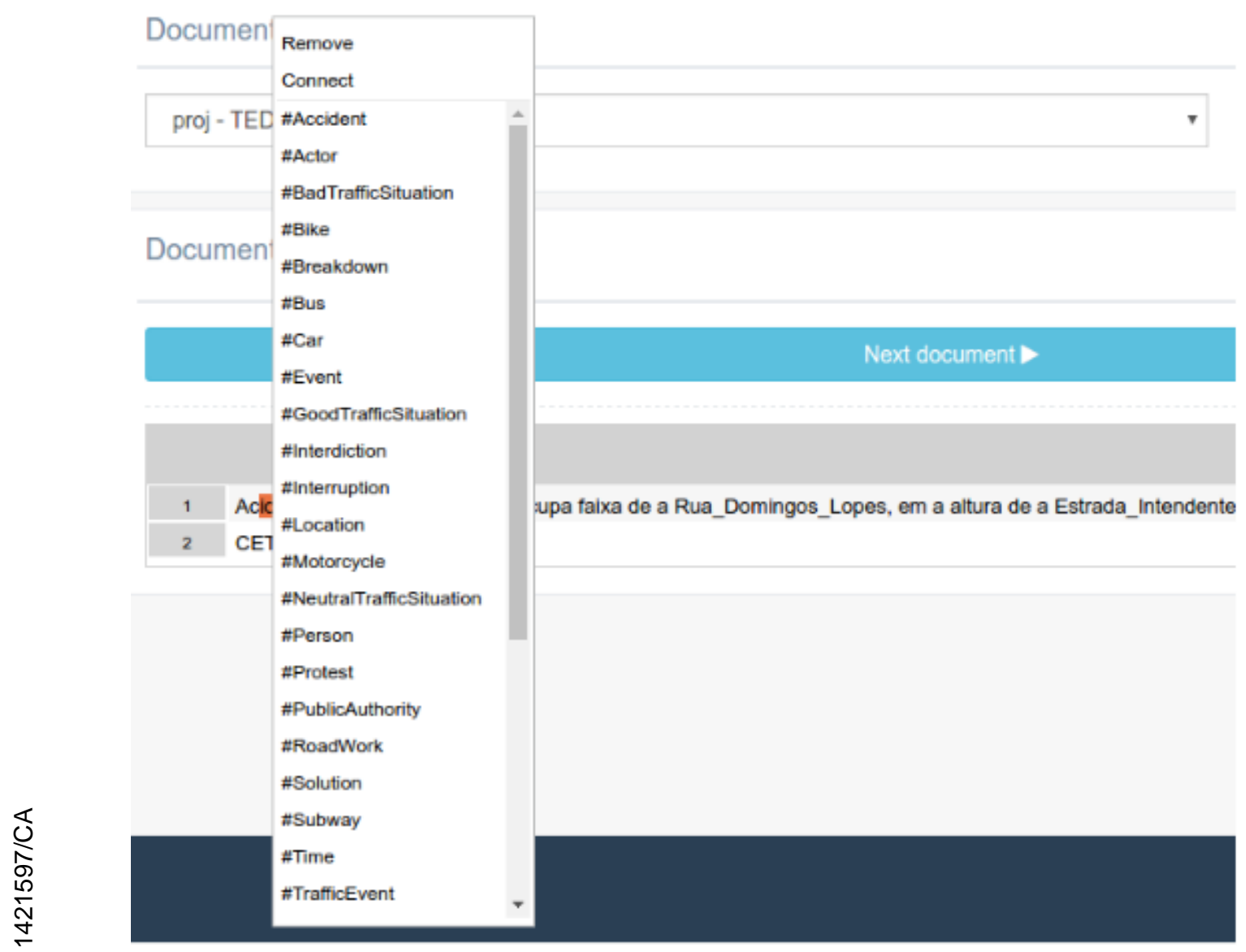

Figura A.5: Rotulação, passo 2

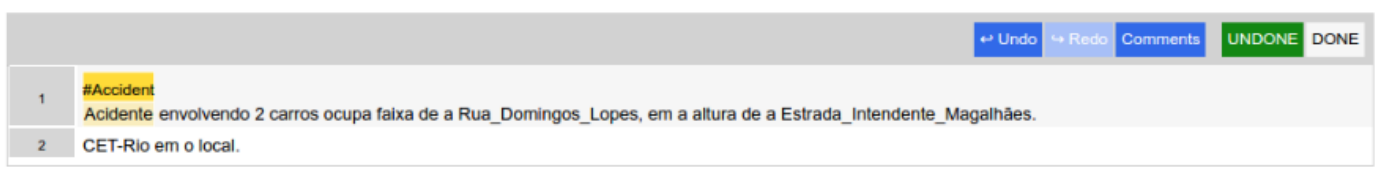

Figura A.6: Rotulação, resultado final

O processo de criação de relacionamento entre rótulos é a conexão de um bloco de texto rotulado à outro, de tal forma que descreva uma relação prevista na ontologia, esse processo segue os seguintes passos:

- Clicar com o botão esquerdo do mouse sobre o rótulo que será a origem da relação, após isso um arco será criado, ir em direção ao rótulo que será o destino da relação, caso a relação seja inválida o arco ficará vermelho (Figura A.7) e a relação não poderá ser criada (Isso ocorre por restrições definidas na ontologia, como é possível ver na Figura A.8, não existe relação possível partindo de \#Car para a \#Accident, porém o inverso existe), caso contrário ficará verde (Figura A.9) e para finalizar o processo 
basta clicar sobre o rótulo destino que a relação estará feita (Figura A.10).

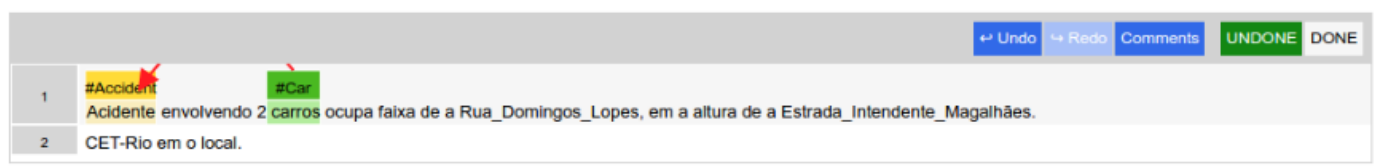

Figura A.7: Relacionamento entre os rótulos (relação inválida)

\begin{tabular}{|c|c|}
\hline $\begin{array}{l}\text { > \#Accident } \\
\text { > \#causes } \\
\text { > \#hasActor } \\
\text { > \#Actor } \\
\text { > \#Bike } \\
\text { > \#Bus } \\
\text { > \#Car } \\
\text { > \#Mntorvvolo }\end{array}$ & $\begin{array}{l}\text { > \#Cus } \\
\text { > \#hasNumericQuantity } \\
\text { > xsd:unsignedInt } \\
\text { > \#hasStringQuantity } \\
\text { > xsd:string } \\
\text { > EFvant }\end{array}$ \\
\hline
\end{tabular}

Figura A.8: Relação inválida de \#Car para \#Accident, porém válida de \#Accident para \#Car

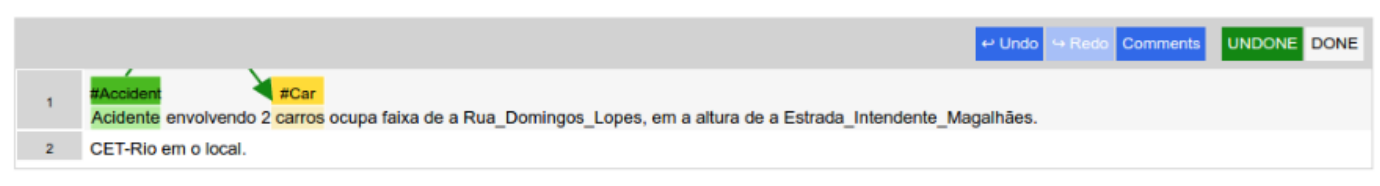

Figura A.9: Relacionamento entre os rótulos (relação válida)

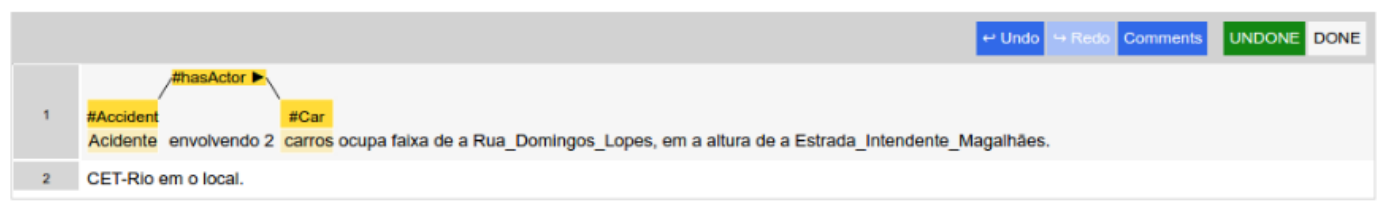

Figura A.10: Relacionamento entre os rótulos, resultado final

No processo de relacionamento não é necessário que os rótulos estejam na mesma sentença, como pode ser visto na Figura A.11, a descrição desse tipo 
de relação contém a informação da sentença e palavras que estão na ponta oposta da relação. Tal informação está no formato SENTENCA[PALAVRA INICIAL : PALAVRA FINAL], ou seja, a descrição 1[2:3] pode ser lida como "a ponta oposta da relação está ligada ao conjunto de palavras na sentença 1 do intervalo de 2 a 3 ".

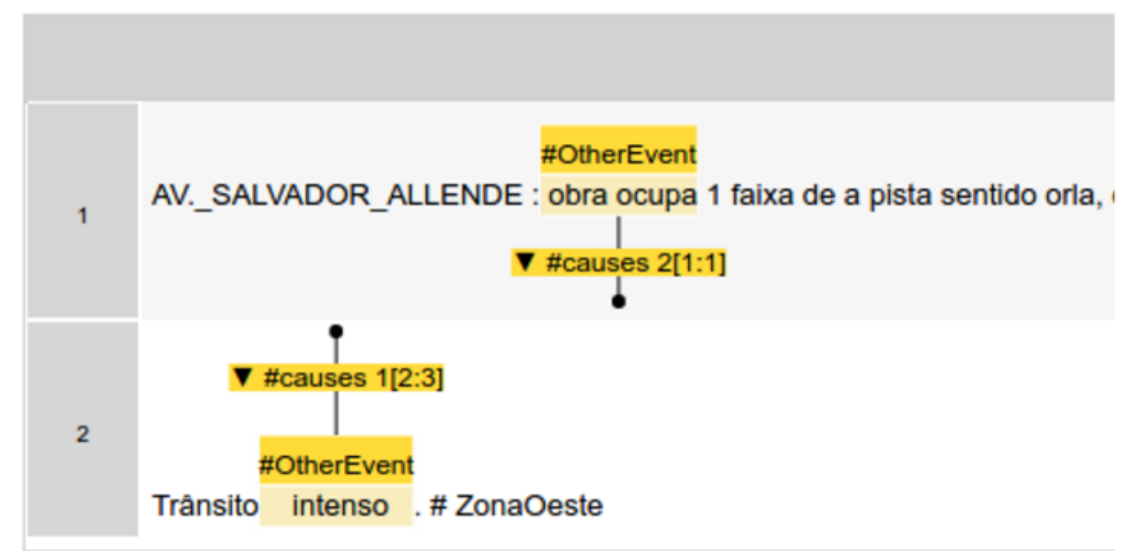

Figura A.11: Relações entre sentenças

O processo de criação de conectores é a conexão de um bloco de texto a uma relação, de tal forma que as palavras que compõem tal bloco descrevam a relação em questão. Esse processo segue os seguintes passos:

- Selecionar a palavra ou conjunto de palavras que serão associadas à relação (Figura A.12), não é necessário selecionar toda a palavra apenas parte dela já é o suficiente;

- Abrir o menu de contexto (clicando com o botão direito do mouse) e selecionar o item "Connect" (Figura A.13);

- Após aparecer o arco de conexão (Figura A.14), mova o mouse até a relação desejada e clique com o botão esquerdo, feito isso o bloco estará associado à relação (Figura A.15).

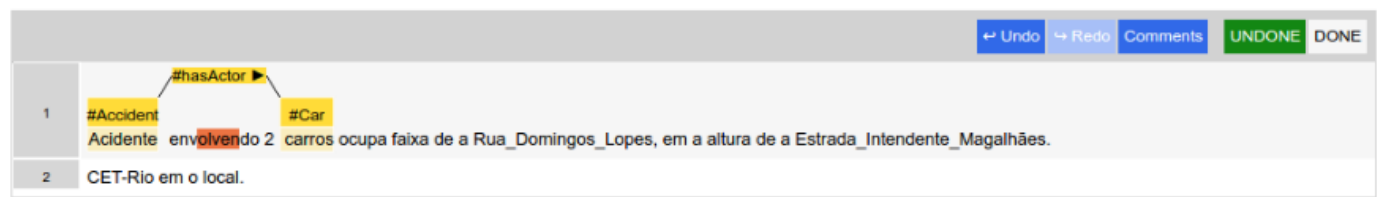

Figura A.12: Criação de conectores, passo 1 


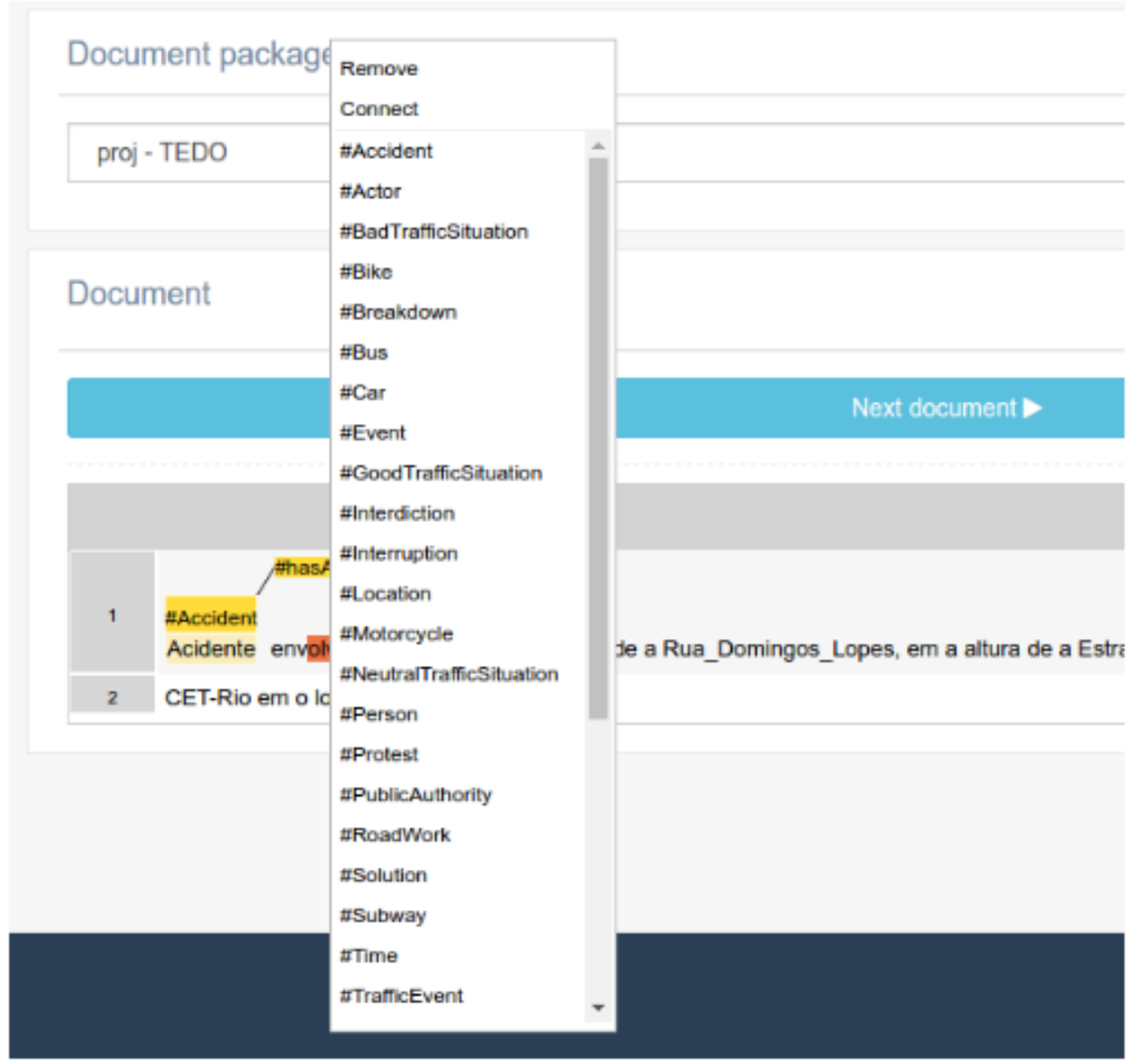

Figura A.13: Criação de conectores, passo 2

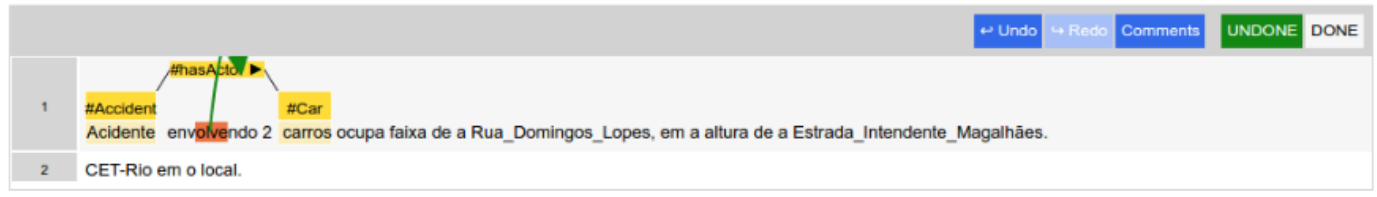

Figura A.14: Criação de conectores, passo 3

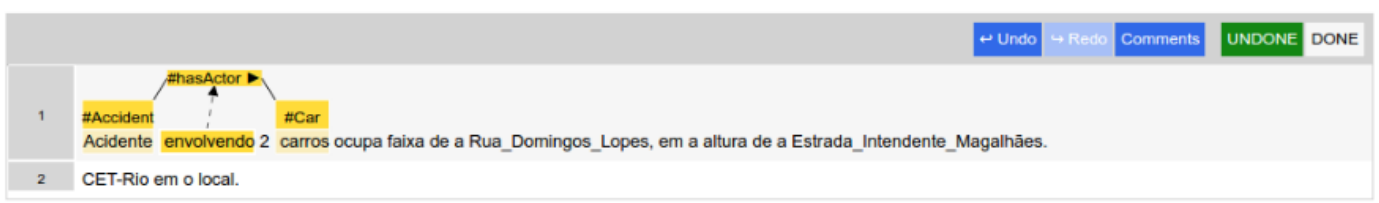

Figura A.15: Criação de conectores, resultado final 
A remoção de rótulos, relações e conectores, pode ser feita clicando com o botão direito do mouse sobre o item em questão (Figura A.16) e clicando em "Remove" ou pode ser feita removendo os itens presentes em uma área do texto selecionada, basta apenas selecionar a área desejada (Figura A.17), abrir o menu de contexto com o botão direito do mouse (Figura A.18), e clicar na opção "Remove" que então toda a área selecionada será limpa (Figura A.19).

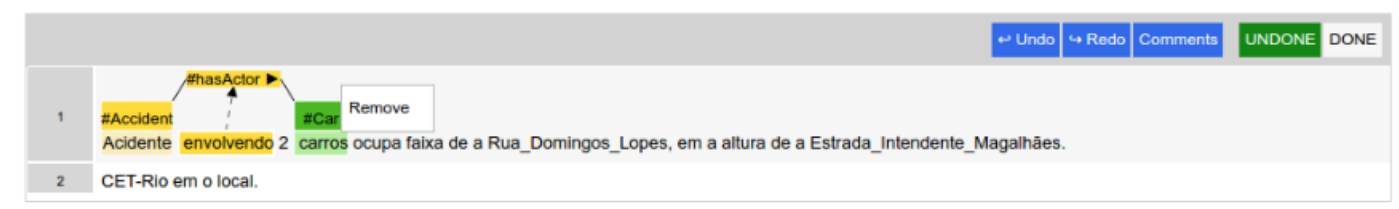

Figura A.16: Remoção de rótulos, relações e conectores

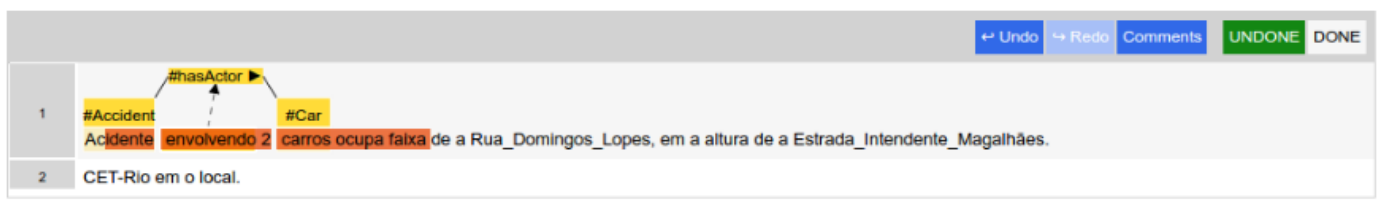

Figura A.17: Remoção por área de de rótulos, relações e conectores, passo 1 


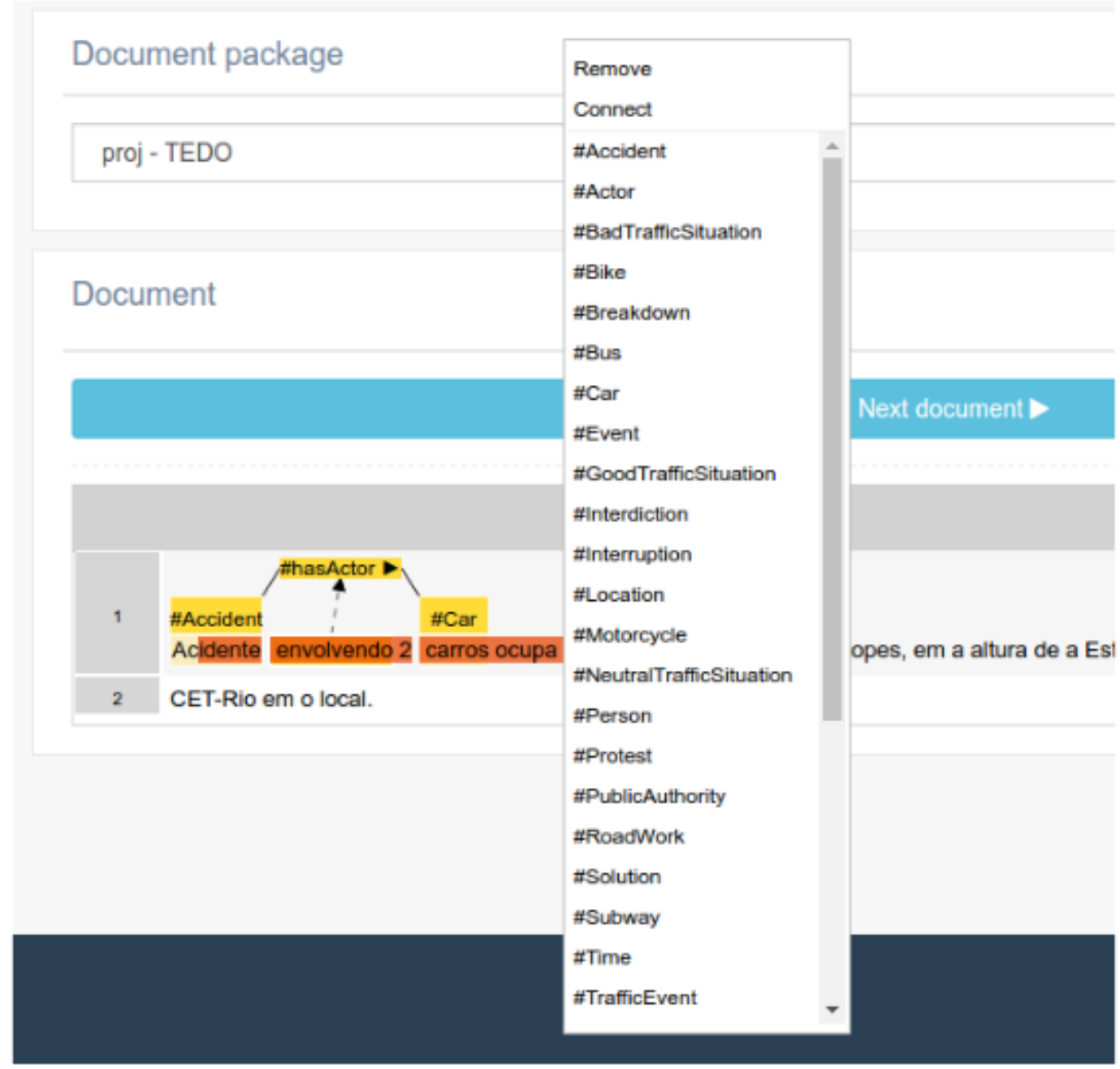

Figura A.18: Remoção por área de de rótulos, relações e conectores, passo 2

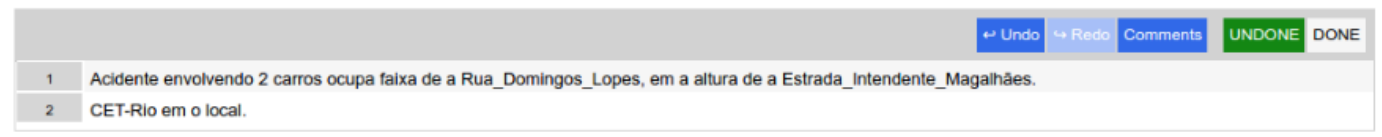

Figura A.19: Remoção por área de de rótulos, relações e conectores, resultado final

Assim que o processo de anotação estiver finalizado basta clicar no botão "DONE" que o documento será fechado para edição e não aparecerá mais para ser anotado, caso existam mais documentos para serem anotados, após finalizado o documento corrente, um novo documento será apresentado aleatoriamente (o mesmo que aconteceria se clicar no botão "Next document"), caso contrário a barra de status ficará em $100 \%$ e não aparecerão mais documentos para serem anotados. 


\section{A.1.2}

\section{ATALHOS}

Com intuito de tornar o processo de anotação mais prático e ágil alguns atalhos estão disponíveis na ferramenta:

- Tecla T (Rotulação): Após selecionar um bloco de texto e acionar a tecla, o último rótulo utilizado (em qualquer parte do documento) será associado ao bloco selecionado. Este atalho é bastante útil quando há $\mathrm{N}$ ocorrências de uma mesma entidade da ontologia em um mesmo documento, neste cenário, basta apenas que se atribua um rótulo seguindo o fluxo padrão descrito na seção A.1.1 e então os demais podem ser atribuídos utilizando a tecla T;

- Tecla C (criação de conectores): Basta apenas selecionar a área desejada e acionar o atalho que o arco de conexão será criado e poderá associar o bloco de texto à relação desejada.

- Tecla R (remoção de uma área do texto): Basta apenas selecionar a área desejada e acionar o atalho que todos os itens associados a área selecionada serão removidos.

- Tecla Z (desfazer): Basta apenas acionar o atalho que a última ação executada será desfeita.

- Tecla Y (refazer): Basta apenas acionar o atalho que a última ação desfeita será refeita.

\section{A.2}

\section{TAREFA DE ANOTAÇÃO}

Como já foi dito na seção anterior, a tarefa de anotação está associada a uma ontologia que descreve o domínio dos dados a serem anotados, na tarefa em particular descrita por este documento o domínio são tweets que descrevem eventos de trânsito na cidade do Rio de Janeiro, esta seção tem como objetivo descrever especificamente como tais dados devem ser anotados, mostrando sempre que possível exemplos destas anotações.

\section{A.2.1}

\section{RÓTULOS}

Na Figura A.20 é possível ver todas as classes da ontologia que será utilizada na tarefa de anotação. Todas estas classes estão disponíveis para serem rótulos de partes dos tweets de trânsito que deverão ser anotados. Nas próximas seções serão apresentadas descrições de cada uma das classes que compõem a ontologia, bem como exemplos de uso destas nos tweets. 


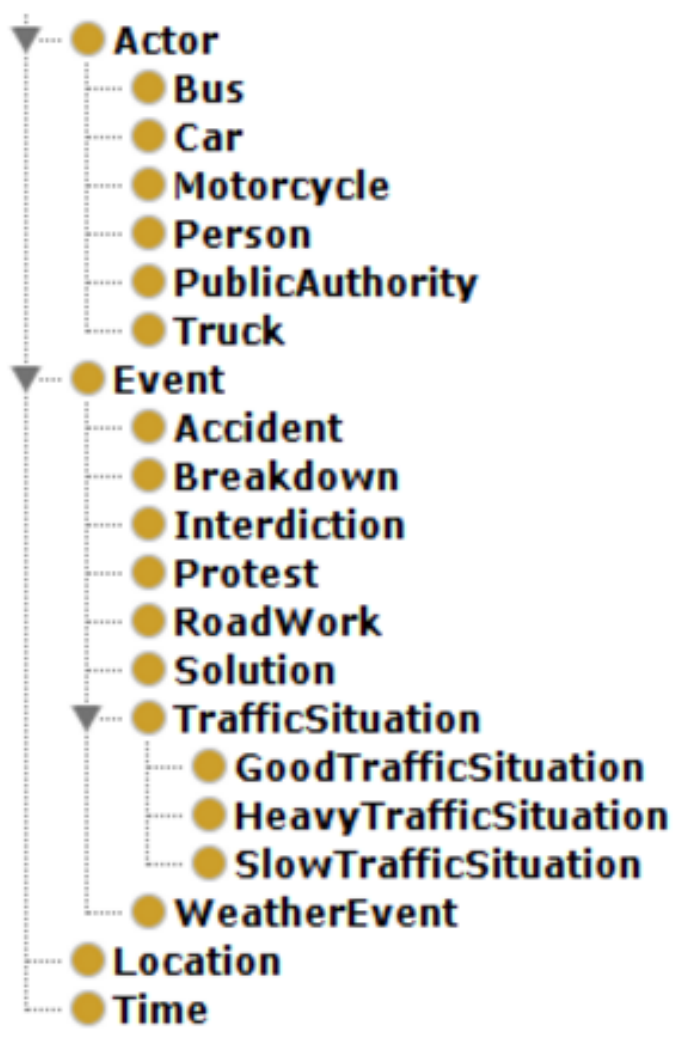

Figura A.20: Hierarquia de classes da ontologia de eventos de trânsito

\section{A.2.1.1 \\ Actor}

Esta classe descreve os atores envolvidos nos eventos de trânsito, tal classe deve ser utilizada apenas quando não há especialização desta (Bus. Car, Motorcycle, Person, PublicAuthority e Truck) que consiga descrever o ator em questão, um exemplo (hipotético) dessa situação pode ser visto na Figura A.21, outro exemplo do uso da classe (no caso uma especialização desta) pode ser visto na Figura A.22.

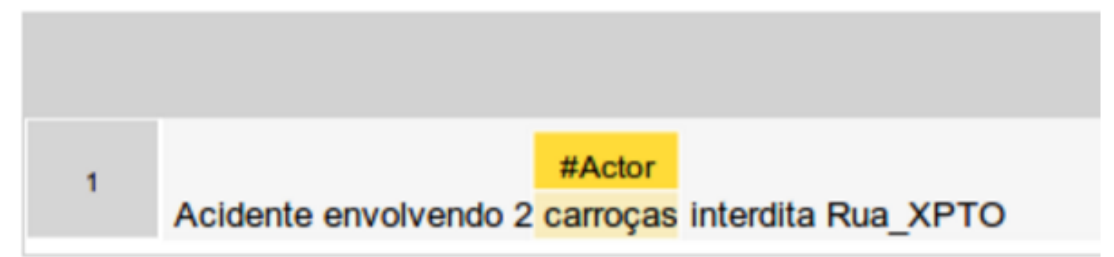

Figura A.21: Exemplo de rotulação, Actor 


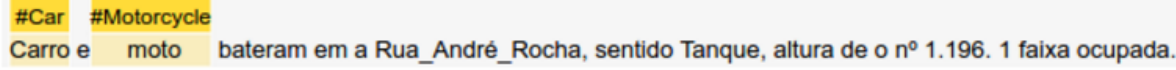

Figura A.22: Exemplo de rotulação, Car e Motorcycle

\section{A.2.1.2}

\section{Event}

Esta classe descreve os eventos descritos no tweet, e deve ser apenas utilizada para rotulação quando não há especialização desta que descreve o evento em questão, como pode ser visto na Figura A.23. As especializações da classe Event são Accident (a ocorrência de um acidente qualquer, no nosso caso, de um acidente de trânsito), Breakdown (uma falha qualquer, no nosso caso pode ser a falha de um carro por exemplo), Interdiction (a interdição de algo, no nosso caso de uma via), Protest (eventos como manifestações públicas, protestos e etc), RoadWork (uma obra acontecendo em uma via), Solution (Soluções para problemas causados por outros eventos, como remoção de carros acidentados, conserto de semáforos e etc), TrafficSituation (condições de trânsito, que podem ser especializadas em GoodTrafficSituation, HeavyTrafficSituation ou SlowTrafficSituation) e WeatherEvent (eventos climáticos, como chuva, ventanias e etc). As Figuras A.24, A.25, A.26, A.27, A.28, A.29, A.30 e A.31 mostram exemplos de uso das especializações da classe Event.

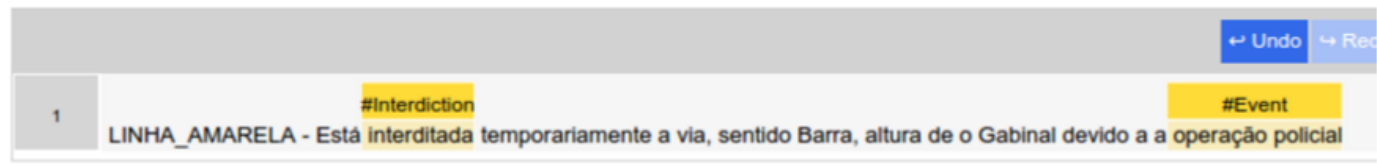

Figura A.23: Exemplo de rotulação, Interdiction e Event

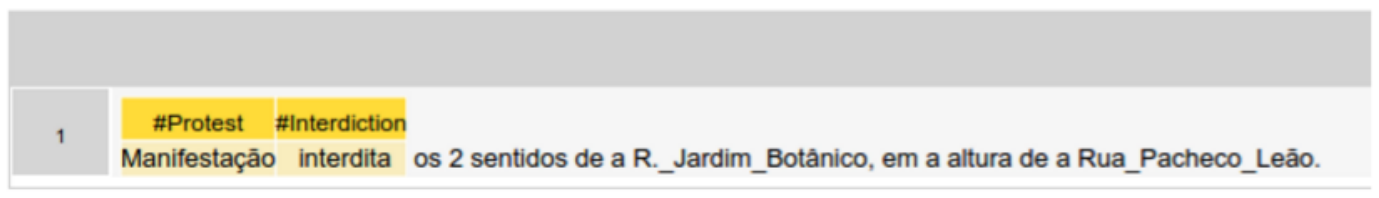

Figura A.24: Exemplo de rotulação, Protest e Interdiction 


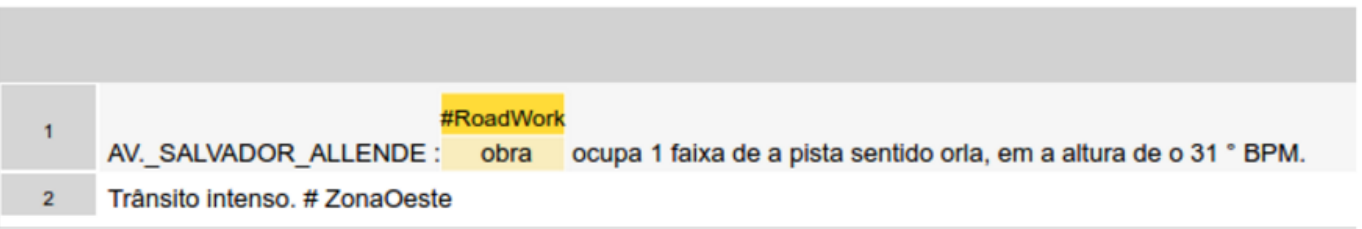

Figura A.25: Exemplo de rotulação, RoadWork

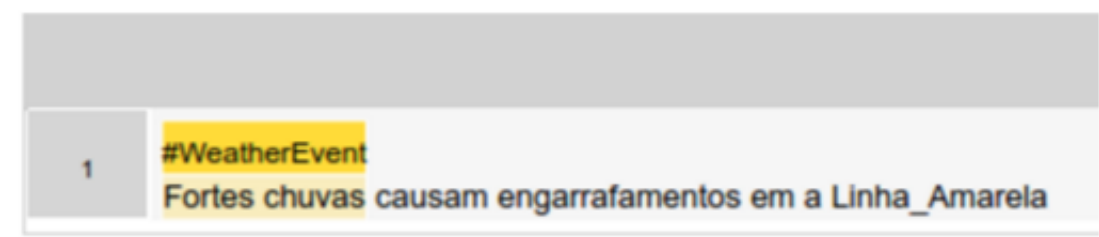

Figura A.26: Exemplo de rotulação, WeatherEvent

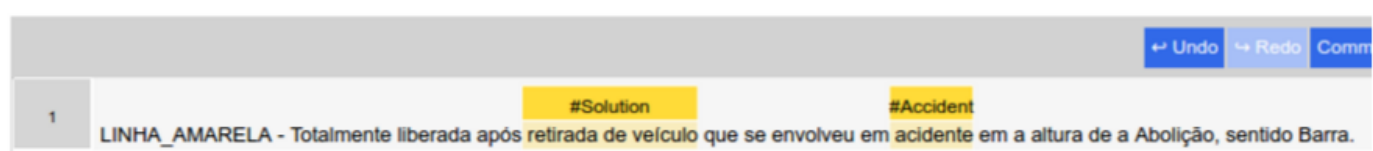

Figura A.27: Exemplo de rotulação, Solution e Accident

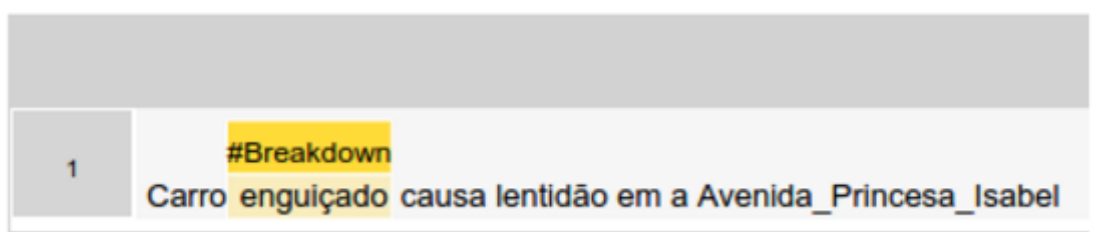

Figura A.28: Exemplo de rotulação, Breakdown

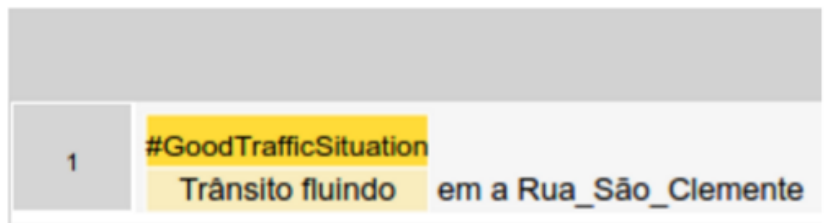

Figura A.29: GoodTrafficSituation 


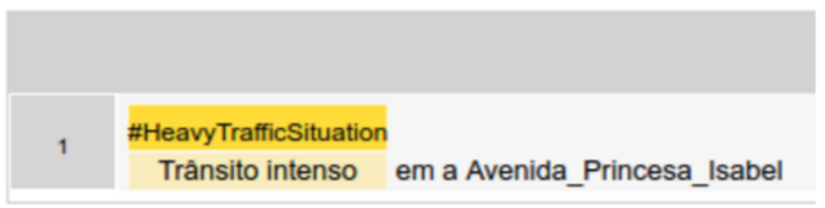

Figura A.30: HeavyTrafficSituation

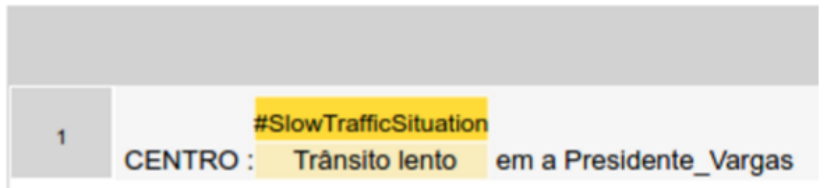

Figura A.31: SlowTrafficSituation

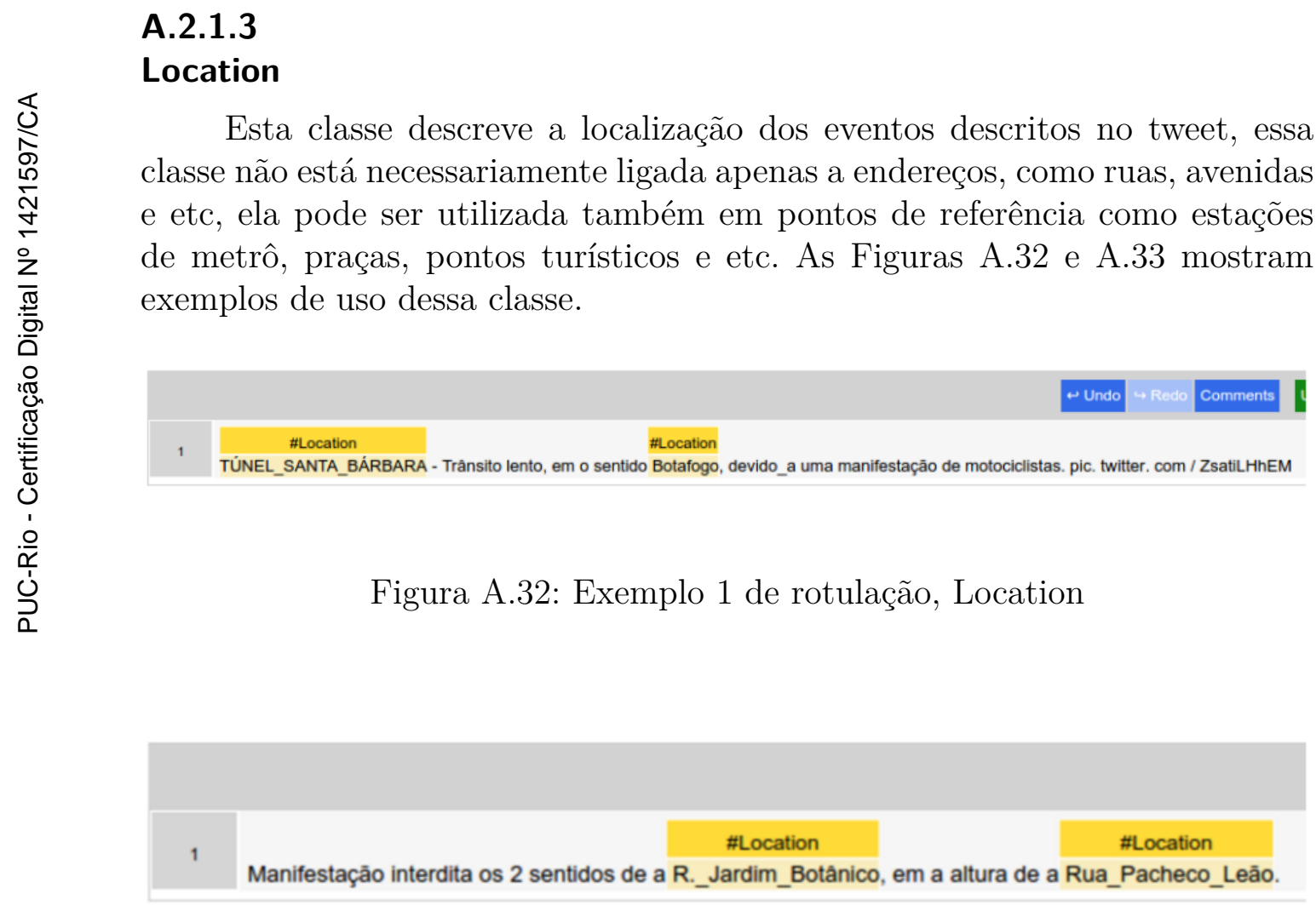

Figura A.33: Exemplo 2 de rotulação, Location 


\section{A.2.1.4}

\section{Time}

Esta classe descreve o tempo em que os eventos descritos ocorreram ou ocorrerão. As Figuras A.34 e A.35 mostram exemplos de uso dessa classe.

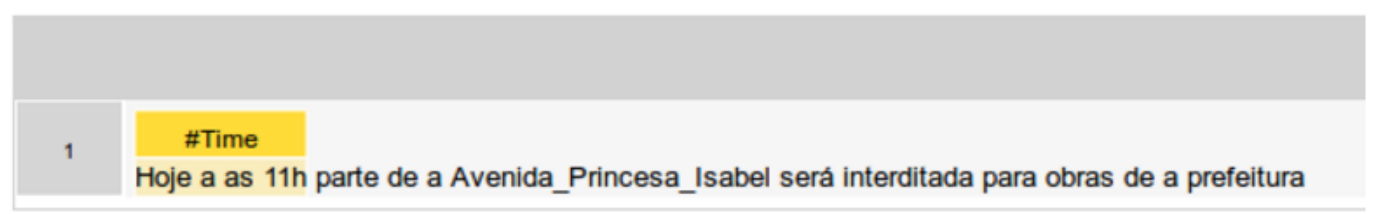

Figura A.34: Exemplo 1 de rotulação, Time

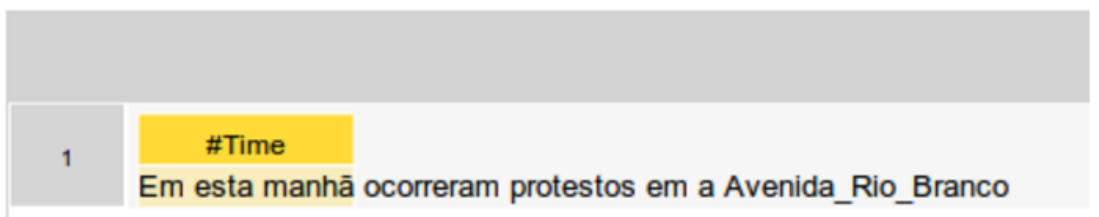

Figura A.35: Exemplo 2 de rotulação, Time

\section{A.2.1.5 \\ Tipos primitivos}

Além das classes já citadas nas seções anteriores, como pode ser visto na Figura A.36, há tipos primitivos na ontologia que também estão disponíveis para serem utilizados como rótulos.

\section{\#wayEffect:BothDirections \\ \#wayEffect:OneDirection \\ \#wayEffect:Partially \\ > xsd:string \\ xsd:unsignedInt}

Figura A.36: Tipos primitivos

O tipo wayEffect:BothDirections (Figura A.37), descreve o estado da via em que ambos os sentidos desta estão afetados por determinado evento, a mesma lógica se aplica aos tipos wayEffect:OneDirection (Figura A.38) e wayEffect:Partially (Figura A.39), onde o primeiro relata que um dos sentidos da via está comprometido e o último passa a ideia de que apenas parte da via foi afetada, porém mesmo assim o fluxo para ambos os sentidos continua acessível. 


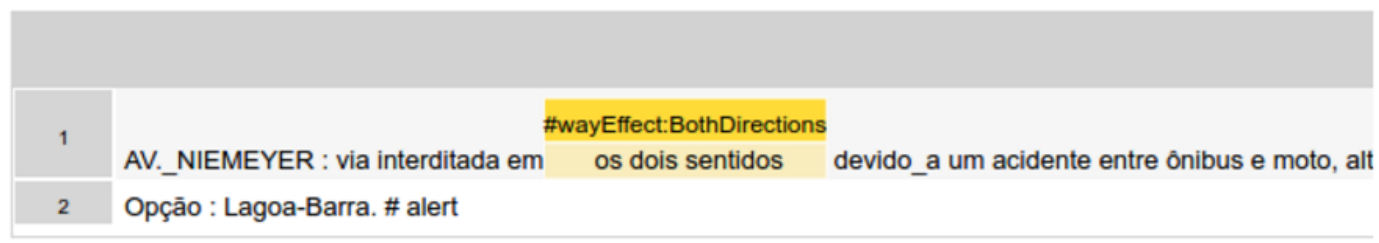

Figura A.37: wayEffect:BothDirections

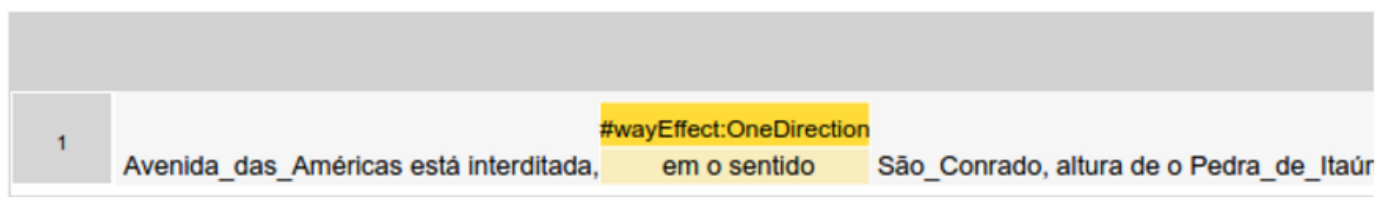

Figura A.38: wayEffect:OneDirection

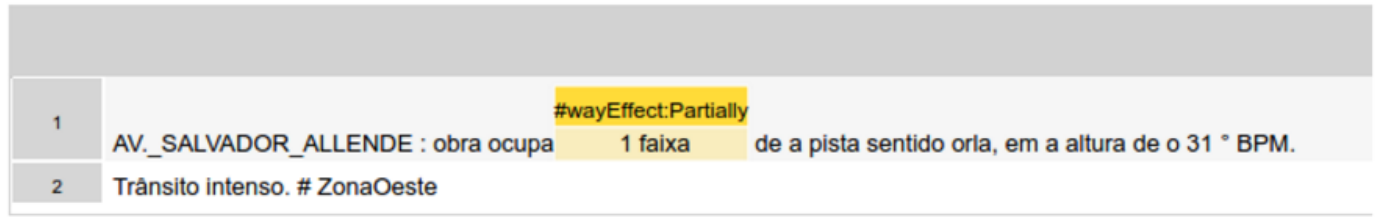

Figura A.39: wayEffect:Partially

Os tipos xsd:unsignedInt (Figura A.40) e xsd:string (Figura A.41) são utilizados apenas em uma situação específica, que é quando a quantidade de atores envolvidos no evento está presente, onde o primeiro tipo será utilizado quando esta quantidade é dada em formato numérico, e o segundo quando esta é dada em formato não numérico.

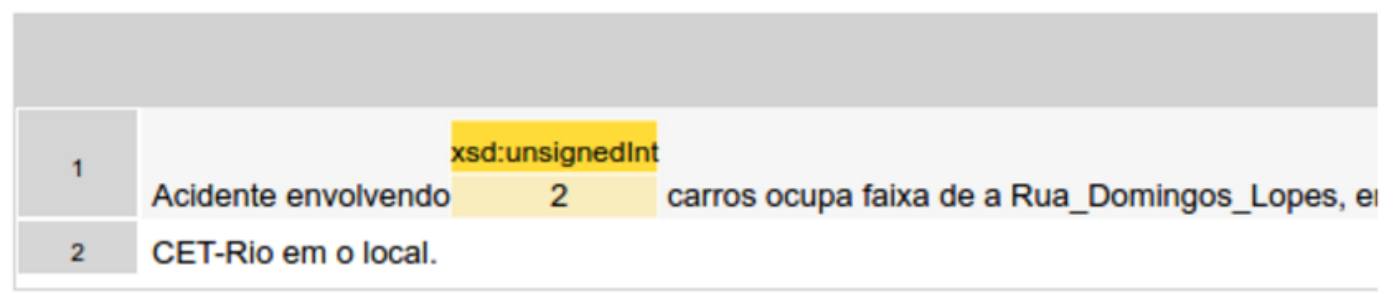

Figura A.40: xsd:unsignedInt 
Figura A.41: xsd:string

\section{A.2.2}

\section{RELAÇÕES}

Além de classes e tipos primitivos, a ontologia de trânsito utilizada na anotação dos tweets fornece também a descrição das seguintes relações:

- causes: Indica que um determinado evento causa outro (Figura A.42);

- flowsTo: Relaciona duas localizações onde a fonte da relação descreve uma via e o alvo a direção do fluxo desta (Figura A.43). Os termos "sentido", "direção" e "que vai para" são indicadores da presença desse tipo de relação;

- hasActor: Relaciona um evento qualquer aos atores envolvidos no mesmo (Figura A.44);

- hasEvent: Relaciona uma localização a eventos ocorridos nesta (Figura A.45);

- hasSupporter: Relaciona um evento qualquer a uma autoridade pública que está dando suporte ao mesmo (Figura A.46);

- hasTime: Relaciona um evento qualquer ao período em que este ocorreu (Figura A.47);

- isAlternativeFor: Relaciona 2 locais, onde um é uma via alternativa para o outro, geralmente esta relação ocorre quando há um evento de interdição (Figura A.48). Os termos "prefira a", "siga pela" e "vá pela" são indicadores da presença desse tipo de relação;

- isEdgeFor: Trata a relação entre dois locais, onde a fonte de relação descreve um limite para o alvo, geralmente esta relação está presente quando se reporta um evento de tráfego em uma via e os limites desta afetados (Figura A.49). Os termos "a partir", "até" e "entre" são indicadores da presença desse tipo de relação;

- isReferenceFor: Descreve a relação entre dois locais, onde a fonte da relação é uma referência que ajuda a definir com mais precisão a localização do alvo. Os termos "na altura", "próximo" e "perto" são indicadores da presença desse tipo de relação (Figura A.50);

- isRestrictedTo: Descreve a relação entre dois locais, onde a fonte da relação é uma referência que define com exatidão a localização do alvo (Figura A.51); 
- hasNumericQuantity: Relação que liga o tipo de ator envolvido em determinado evento e sua quantidade, quando descrita de forma numérica (Figura A.52);

- hasStringQuantity: Relação que liga o tipo de ator envolvido em determinado evento e sua quantidade, quando descrita de forma não numérica (Figura A.53);

- hasWayEffect: Esta relação liga um evento qualquer ao modo como a via foi afetada por ele (Figura A.54);

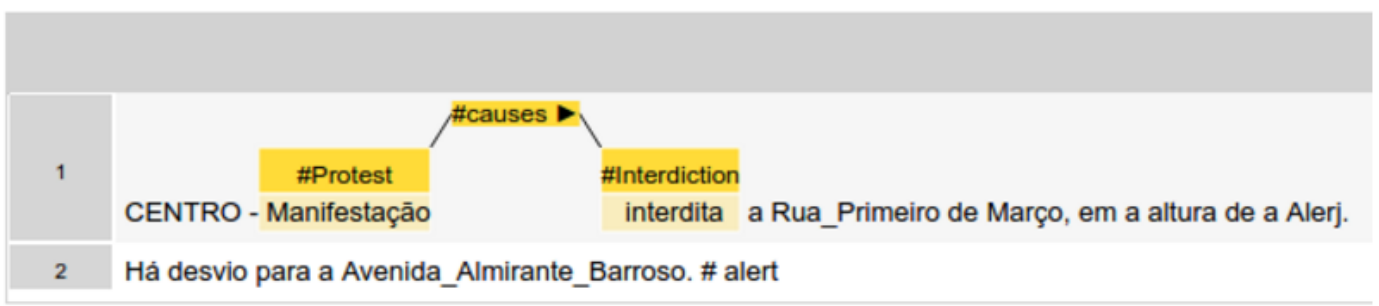

Figura A.42: causes

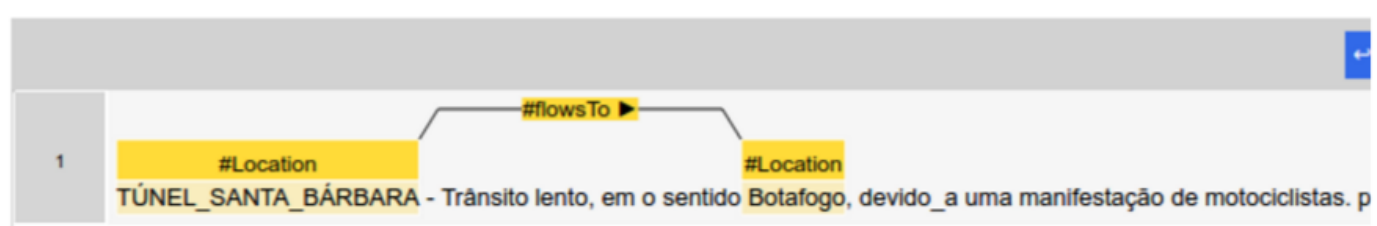

Figura A.43: flowsTo

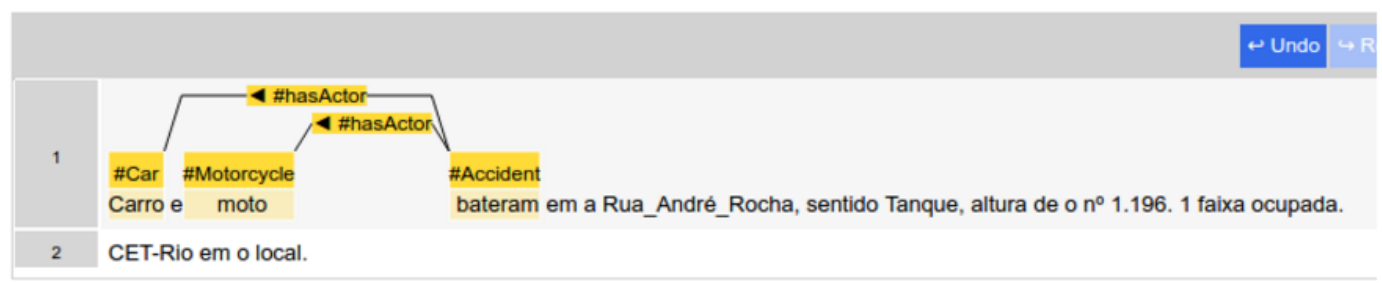

Figura A.44: hasActor 


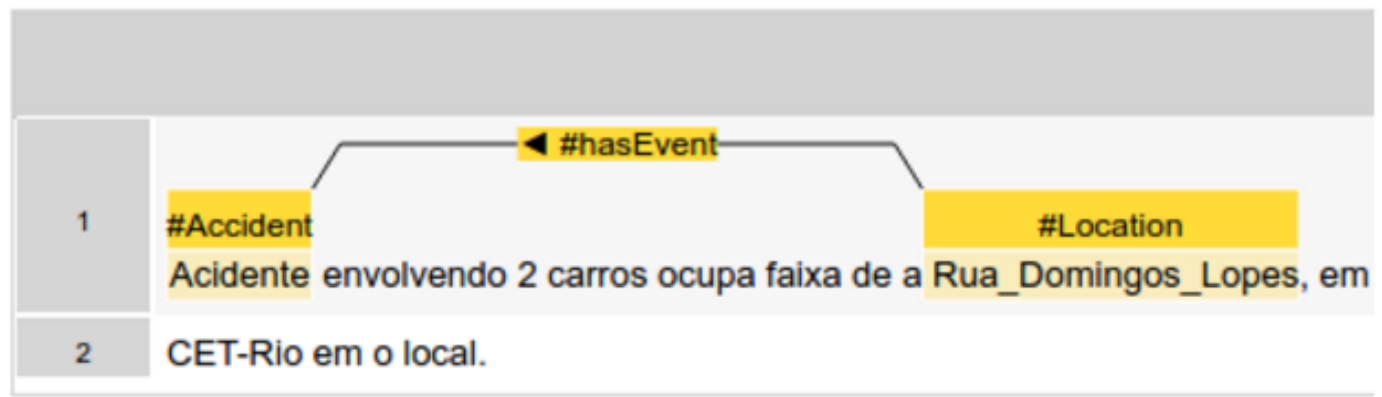

Figura A.45: hasEvent

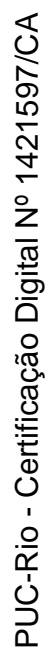

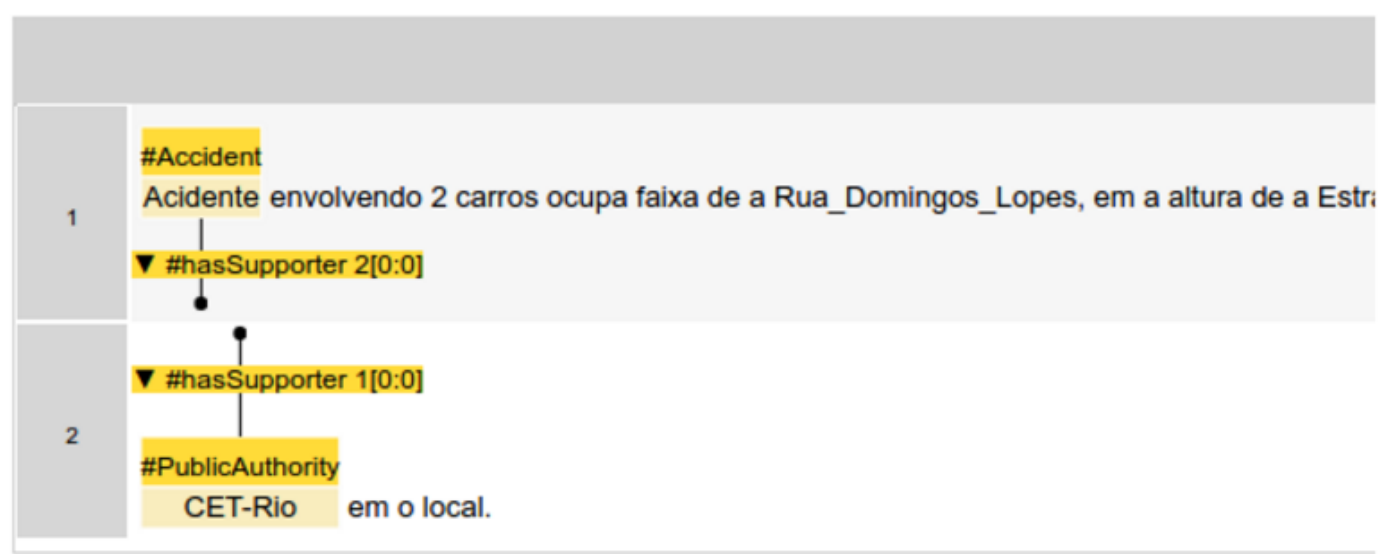

Figura A.46: hasSupporter

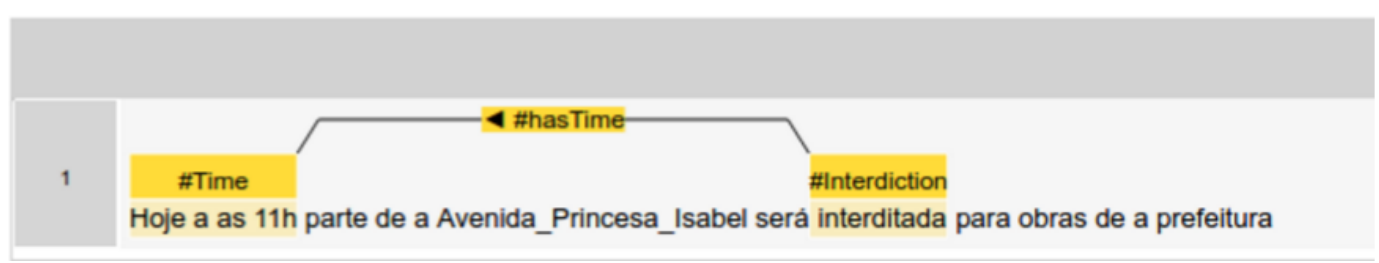

Figura A.47: hasTime 


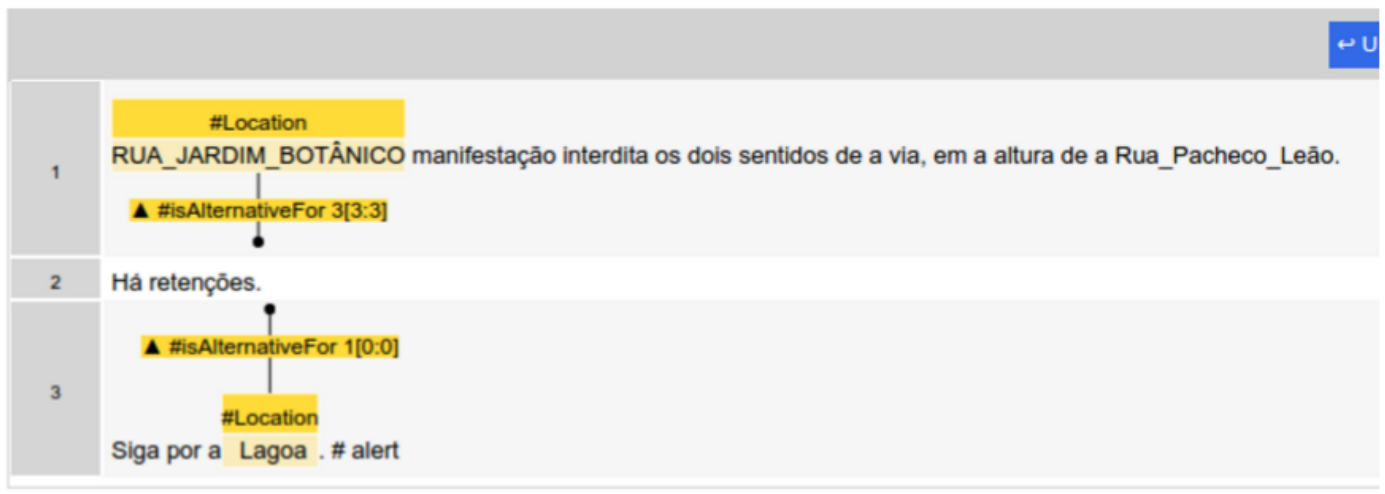

Figura A.48: isAlternativeFor

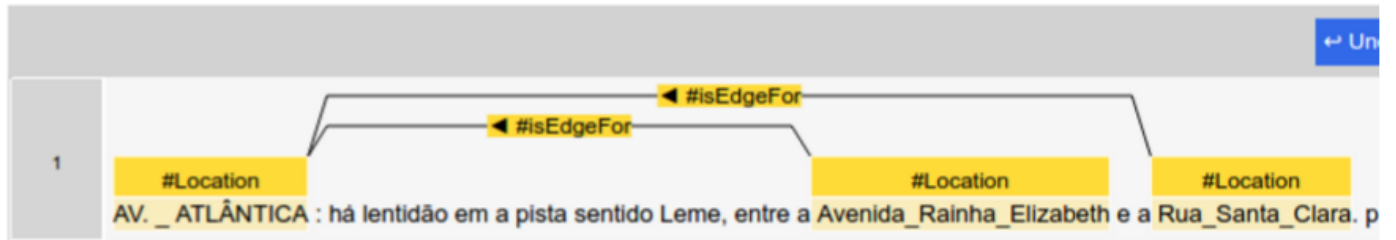

Figura A.49: isEdgeFor

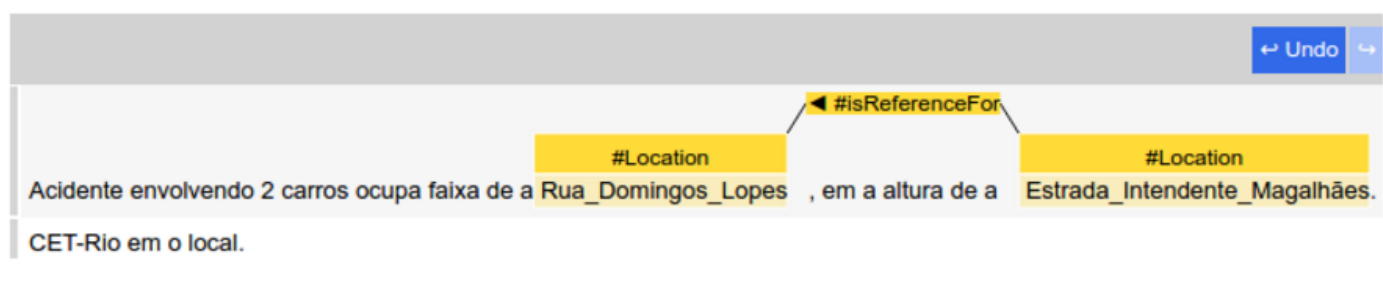

Figura A.50: isReferenceFor

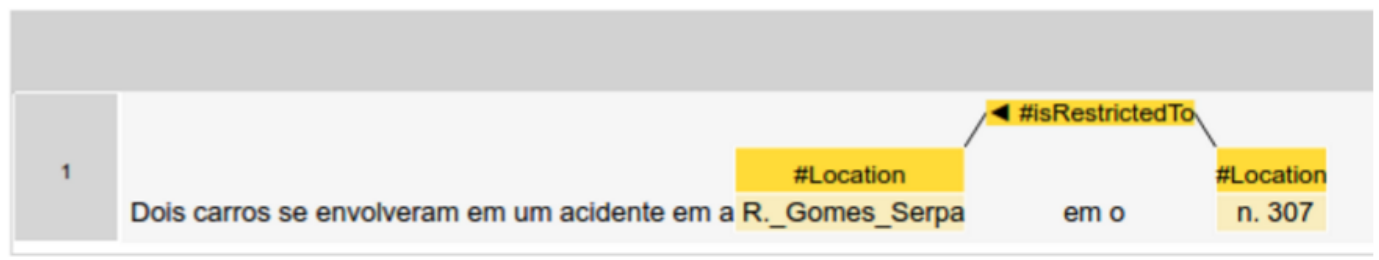

Figura A.51: isRestrictedTo 


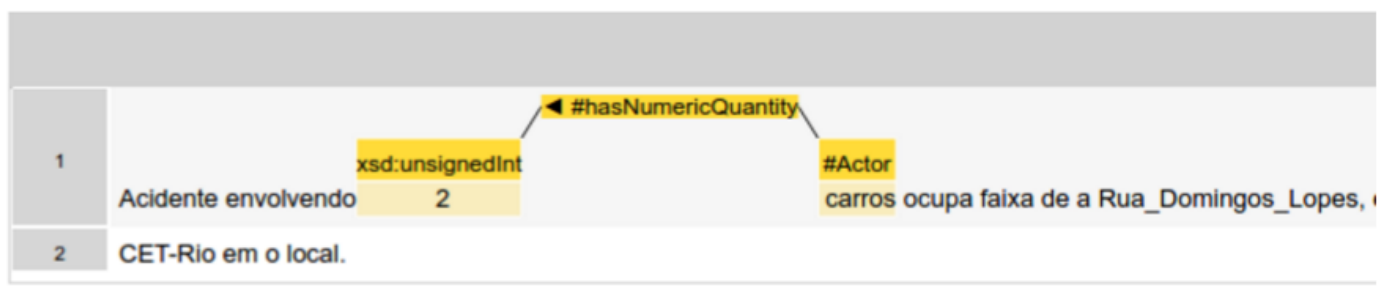

Figura A.52: hasNumericQuantity

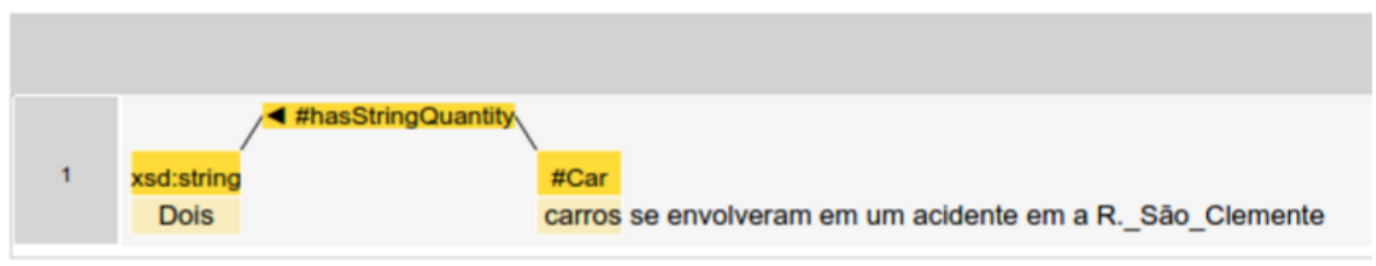

Figura A.53: hasStringQuantity

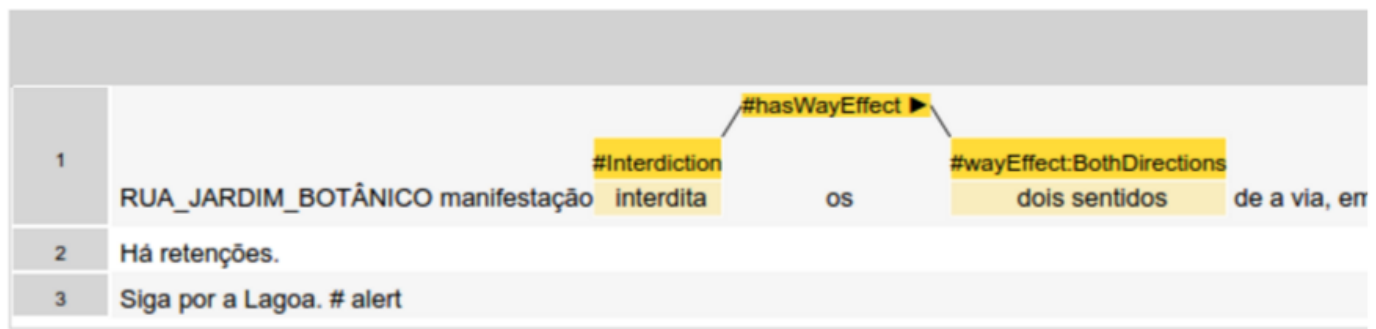

Figura A.54: hasWayEffect

\section{A.2.3}

\section{CONECTORES}

Como já foi dito na seção A.1.1, na ferramenta de anotação há a possibilidade de associação de blocos de texto a uma relação, neste caso, o anotador deve buscar associar partes do texto (que não estão rotulados) a relações que foram deduzidas justamente pela presença desta parte do texto, como pode ser visto na Figura A.55. 


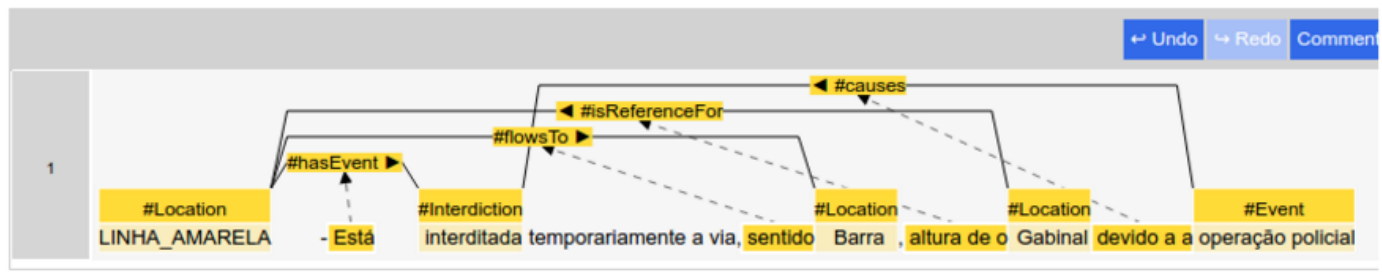

Figura A.55: conectores

\section{A.2.4 \\ EXEMPLOS}

As Figuras A.56, A.57, A.58, A.59, A.60, A.61, A.62 e A.63 são exemplos de tweets completamente anotados.

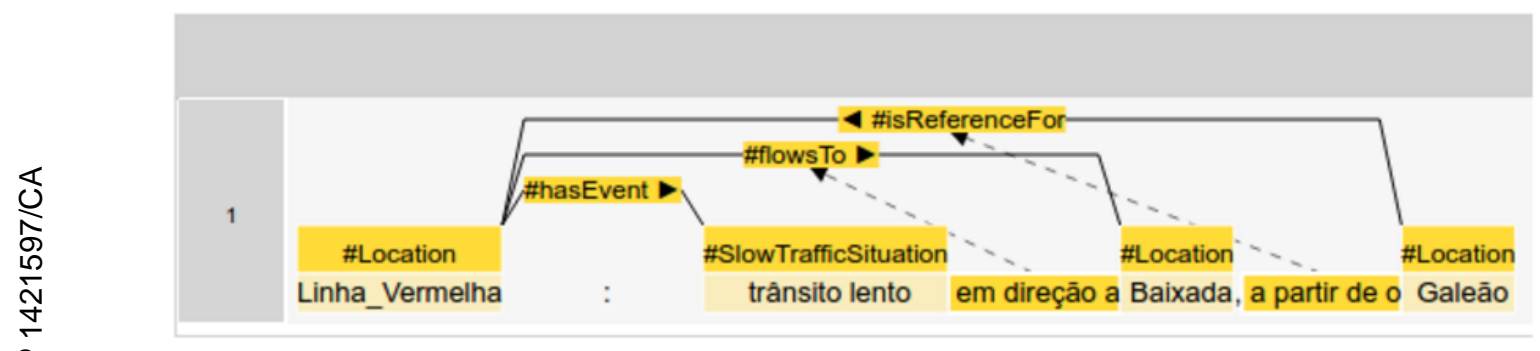

Figura A.56: exemplo 1

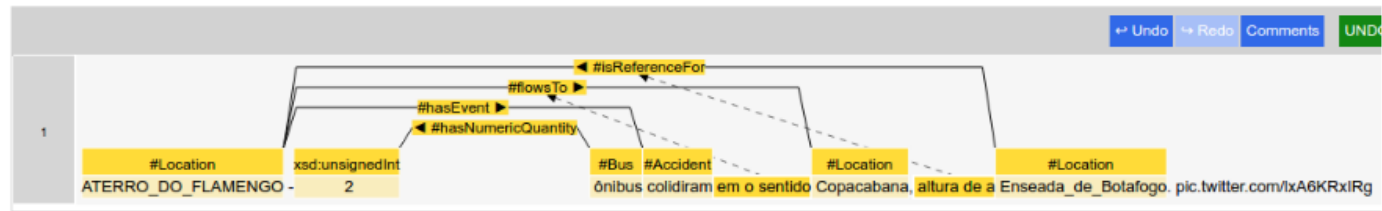

Figura A.57: exemplo 2 


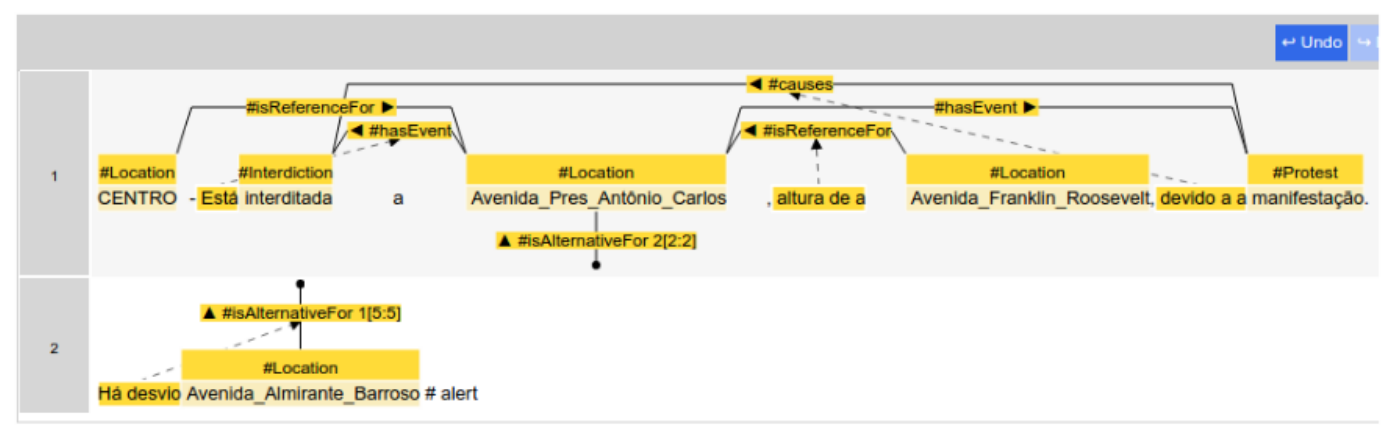

Figura A.58: exemplo 3

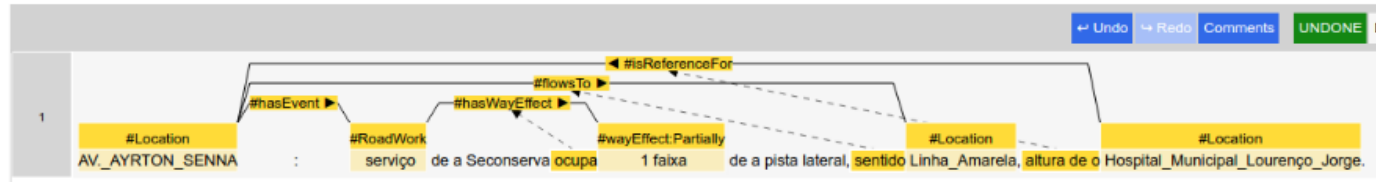

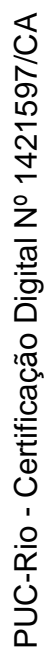

Figura A.59: exemplo 4

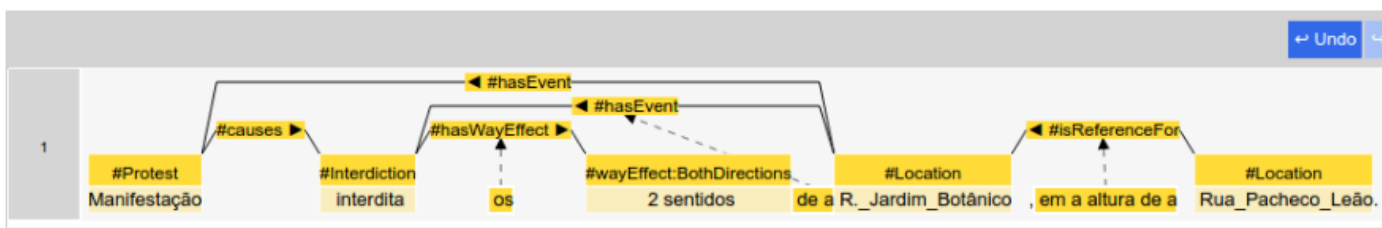

Figura A.60: exemplo 5

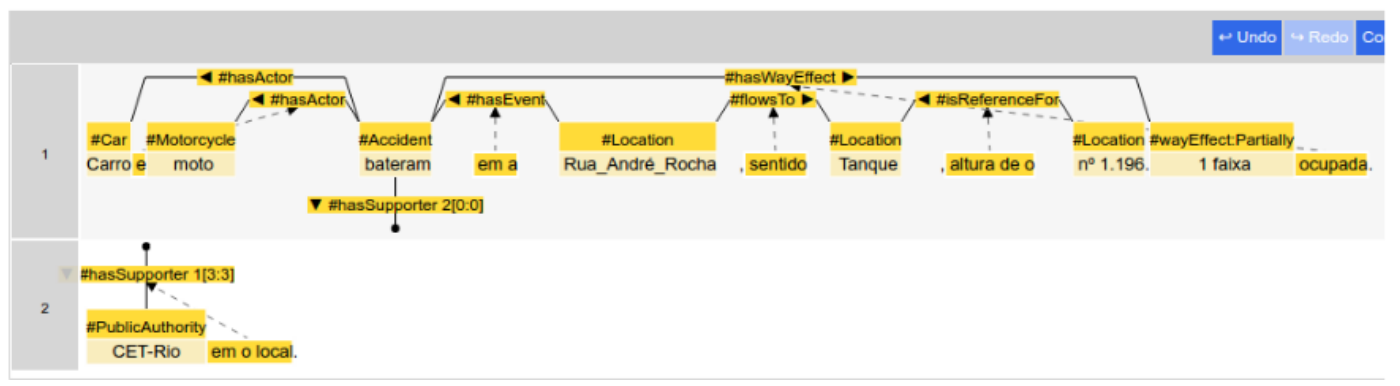

Figura A.61: exemplo 6 


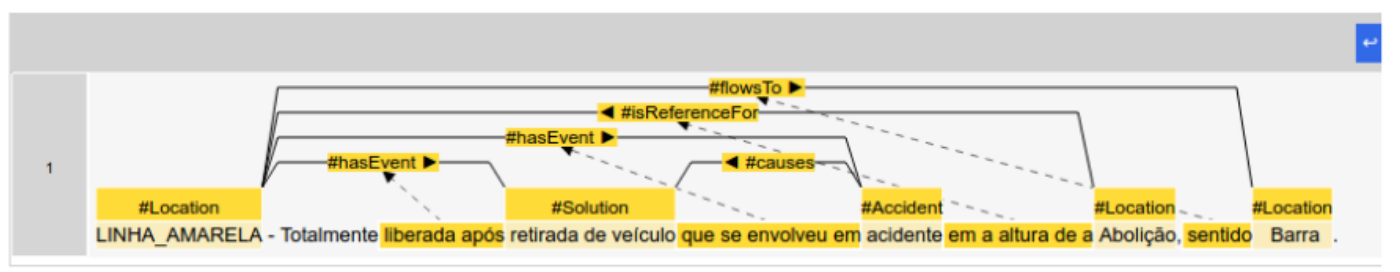

Figura A.62: exemplo 7

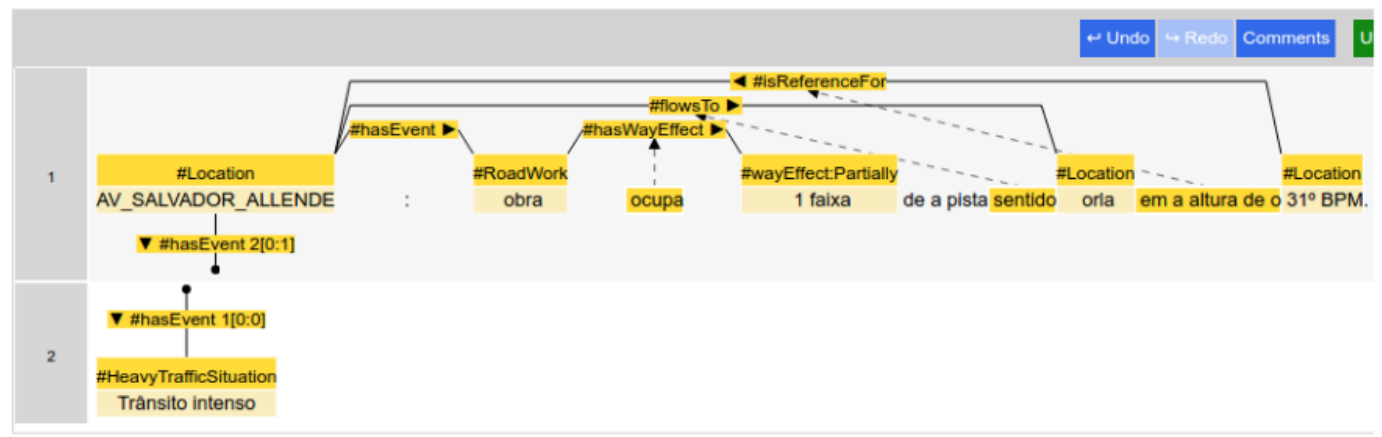

Figura A.63: exemplo 8

\section{A.3 \\ CONSIDERAÇÕES FINAIS}

Durante o processo de anotação não hesite em consultar este guia sempre que necessário para sanar dúvidas, e caso este guia não seja o suficiente para saná-las, anote o tweet da forma que achar mais coerente e deixe um comentário (como foi explicado na seção A.1) descrevendo suas dificuldades, estes comentários são muito importantes para o enriquecimento deste guia e amadurecimento da ontologia utilizada na anotação. Um ponto importante, que deve ser levado em consideração no processo de anotação, é que por enquanto apenas tweets que dizem respeito diretamente a eventos rodoviários devem ser anotados, os demais devem ser finalizados sem realizar anotações, como por exemplo, documentos que descrevam eventos ferroviários (Figura A.64), eventos climáticos (sem relação direta com um evento rodoviário, Figura A.65), informações gerais (Figura A.66) e documentos fora de contexto (como respostas de outros tweets, Figura A.67). 
1 Linha 2 de o metrô tem circulação interrompida entre Colégio e Pavuna.

2 Leia mais em @ jornalodia http : // bit.ly/2c7WrXI

Figura A.64: Tweet de evento ferroviário

1 Aviso_de_Ressaca : de 10h, de o próximo_domingo, até a as 10h_de_segunda-feira (14/11).

2 Ondas de até 2,5 metros.

3 Fonte : Marinha_do_Brasil

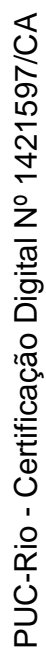

Figura A.65: Tweet de evento climático

1 DOMINGO ( 06/11 ) TEM_IRONMAN ( @ Brasillronman ) NO_RIO.

2 Veja o esquema de trânsito para o evento em o link http : // bit.ly/ironman2016tra nsito ... pic.twitter.com/XPJIz3Z23V

Figura A.66: Tweet de informação geral

Figura A.67: Tweet fora de contexto 


\section{B \\ Experimento de anotação: Comentários}

Este apêndice contém todos os comentários feitos pelos participantes do experimento de anotação descrito no capítulo 4 desta dissertação. Os comentários estão separados por documentos, onde cada bloco de comentário contém o texto do tweet que representa o documento e os comentários feitos pelos usuários. Há de se notar que apenas alguns dos 50 documentos anotados estão descritos aqui, já que não haviam comentários em todos eles, e mesmo havendo, nem todos usuários realizaram esta ação.

Tweet: Dificuldades na Av. Presidente Antônio Carlos e também na R. Primeiro de Março.

- User, 10(A,2,5): Fora de contexto.

Tweet: Av. Borges de Medeiros com retenções em direção ao Rebouças, a partir da Rua Mário Ribeiro.

- User, 10(A,2,5): Coloquei "retenções" como \#Event pois não encontrei uma rotulação de descrevesse este evento. Pensei em colocar \#Interdiction, porém interdição e retenção não são a mesma coisa.

Tweet: Lentidão na Av. Epitácio Pessoa, sentido Rebouças, a partir do Corte do Cantagalo.

- User, 09(A,2,5): Seguindo o exemplo da figura 56 do Guia, em conflito com a informação do uso do "isEdgeFor" nos termos "a partir"

Tweet: Fluxo livre nos dois sentidos da Ponte, 13 minutos.

- User, 02(A,0,5): Para esse caso, primeiro que apareceu para mim até o momento, seria interessante permitir um relação de duração de tempo. Semelhante seria o tempo para percorrer o Rebouças, ou ir do Leblon até o Centro (tem uma placa próximo a gávea indicando isso).

- User, 13(A,2,10): Em "13 minutos" fiquei na dúvida em usar \#Time (relacionado a evento) ou xsd:unsignedInt (Associado a quantidade de atores) ou nenhum dos dois.

Tweet: Via liberada!

- User, 13(A,2,10): “Via liberada" seria \#hasEvent (pelo que entendi), mas não tem \#Location neste Tweet. 
- User, 18(A,4,10): Neste não anotei nada e dei DONE. Apesar de ter evento rodoviário, não há contexto algum.

Tweet: GASÔMETRO - Lentidão na via, sentido Centro, a partir do Into.

- User, 16(A,4,5): comentario centro da cidade

- User, 08(B,0,10): SlowTrafficSituation e HeavyTrafficSituation parecem sinônimos para mim.

Tweet: Obra interdita a Estrada da Gávea, sentido Barra, altura do n ${ }^{\mathrm{o}}$ 696. Desvio: Autoestrada Lagoa-Barra.

- User, 02(A,0,5): Observação de que os atalhos deveriam ser desabilitados enquanto o usuário digita o comentário.

Tweet: RT @_ecoponte : 06:30 - 15 min. Trânsito para o Rio apresenta retenção dos acessos à Mocanguê. http:// ecoponte.com.br

- User, 08(B,0,10): Fiquei na dúvida na "retenção dos acessos a". Marquei IsReferenceFor como um chute.

Tweet: RT @_ecoponte : 05:23 - 13 min. Fluxo sentido Niterói segue normal. http:// ecoponte.com.br

- User, 16(A,4,5): TESTANDO A BAGAÇA....

Tweet: RECREIO - Acidente envolvendo ônibus e utilitário ocupa faixa da Av. das Américas, altura do BRT Salvador Allende, sentido Barra.

- User, 08(B,0,10): Acidente e interdição deveriam ser associados ao mesmo local?

Tweet: Viaduto 31 de Março apresenta lentidão no sentido Centro. Mesmo panorama no Túnel Santa Bárbara.

- User, 02(A,0,5): \#flowsTo e \#hasEvent estão sobrepostos no tweet inferior

Tweet: GÁVEA - Atropelamento envolvendo moto ocupa faixa da Av. Rodrigo Otávio, altura da R. Mário Ribeiro.

- User, 08(B,0,10): Acidente e interdição deveriam ser conectados ao mesmo local? Ou apenas interdição?

Tweet: VILA DA PENHA - Trânsito lento na Av. Meriti, sentido Largo do Bicão, entre a Av. Vicente de Carvalho e a Rua Volta.

- User, 13(A,2,10): Não sei se neste caso em que é descrita uma restrição de local usando ruas, Exemplo: Na Rua XPTO entre Rua A e Rua B. Entre Ruas $A$ e $B$ dá ideia de trecho específico, então parece que é correto usar \#isRestrictedTo ao invés de \#isReferenceFor, mas fiquei na dúvida. Então usei a seguinte regra, se aparece a palavra "Entre" em trechos "Rua tal e Rua Tal" estou usando \#isRestrictedTo. 
Tweet: ANIL - Acidente envolvendo 2 carros ocupa faixa da Est. de Jacarepaguá, sentido Grajaú, altura da R. Sd. Genaro Pedro Lima.

- User, 08(B,0,10): Quando uma via tem dois eventos, acidente e interdição, devemos ligá-la a ambos os eventos?

Tweet: PARADA DE LUCAS - Acidente entre dois carros na pista central da Av. Brasil, sentido Centro. Lentidão no loca. Uma faixa ocupada.

- User, 02(A,0,5): Assumindo que 'em o loca.' = no local

Tweet: CIDADE NOVA - Acidente envolvendo moto e carro ocupa faixa da central da Av. Pres. Vargas, sentido Candelária, altura da Cidade Nova.

- User, 06(A,0,10): tive que marca 2 palavras na mesma tag nao esta marcando so uma quando estao muito proximas.

Tweet: RT @LinhaAmarelaRJ : 6h55 No sentido Barra trânsito lento do acesso 9, \#AvBrasil , ao acesso 8, Bonsucesso, \#FluxodeVeículos

- User, 17(B,4,5): Esta sentença está bem estranha, não entendi muito bem.

Tweet: AV BRÁS DE PINA Ônibus enguiçado ocupa faixa no sentido Olaria, altura do $\mathrm{n}^{\mathrm{O}} 585$. CET-Rio na via. Lentidão.

- User, 08(B,0,10): IsRestrictedTo e IsReferenceFor são sinônimos para mim.

Tweet: AV BRASIL \#IRAJÁ Caminhão enguiçado ocupa faixa da pista central sentido Zona Oeste. CET-Rio na via. Sem retenção.

- User, 08(B,0,10): Breakdown e Interdiction deveriam ser associados a Location? Ou apenas Interdiction? 


\section{C \\ Experimento de anotação: Dados dos participantes}

Nas próximas seções, estão as informações gerais de cada participante do experimento, seguidas das respostas que deram sobre o questionário dado ao final do experimento de anotação descrito no capítulo 4. Após os questionários há uma tabela com o resumo das opiniões extraídas das respostas dos participantes.

C.1

User 01 $(A, 0,5)$

Recebeu treinamento presencial: Não

Aquecimento: 0

Passo de re-anotação: 5

Idade: 24

Escolaridade: Superior completo

Profissão: Analista de sistemas

Já participou de algum outro experimento de anotação de texto? Caso tenha participado, qual o grau de dificuldade da tarefa que acabou de executar em comparação às anteriores?

Não

Quais foram as principais dificuldades que encontrou durante a tarefa?

Nenhuma

Você tentou executar a tarefa lendo apenas parte do guia de anotação? Caso sim, acha que terminou de ler todo ele a partir de que documento finalizado?

Não

O que achou do guia de anotação? O que mudaria nele?

Nada

O que achou da ferramenta de anotação? O que mudaria nela?

Achei uma ótima ideia, diferente mas boa.

\section{C.2}

User 02(A,0,5)

Recebeu treinamento presencial: Não

Aquecimento: 0

Passo de re-anotação: 5

Idade: 29 
Escolaridade: Pós-graduação (mestrado)

Profissão: Analista de sistemas

Já participou de algum outro experimento de anotação de texto? Caso tenha participado, qual o grau de dificuldade da tarefa que acabou de executar em comparação às anteriores?

Não, primeira vez que participo desse tipo de experimento.

Quais foram as principais dificuldades que encontrou durante a tarefa?

Quando tinha dúvidas procurava um exemplo da relação do que eu estava vendo, foram um ou dois casos que não encontrei e não consigo recordarlos agora. A maior dificuldade foi utilizar o guia no formato PDF através da página. Outra dificuldade foi adicionar comentários, que não desativava as teclas de atalho enquanto o texto era digitado.

Você tentou executar a tarefa lendo apenas parte do guia de anotação? Caso sim, acha que terminou de ler todo ele a partir de que documento finalizado?

Primeiro li todo documento, quando acabei que comecei a realizar as primeiras anotações. Para saber se estava realizando uma anotação corretamente, inicialmente procurei um exemplo similar e fui comparando até terminar.

O que achou do guia de anotação? O que mudaria nele?

O guia foi fundamental para a realização da tarefa, sendo claro e sucinto. Porém, dado o contexto da ferramenta, o guia podia ser uma página web interativa. Uma mudança imediata seria reabrir o guia na página em que eu estava lendo e não na primeira.

O que achou da ferramenta de anotação? O que mudaria nela?

De forma geral o uso da ferramenta foi muito fácil, o que acabou motivando a realização da tarefa de anotação. Sugiro as seguintes melhorias:

1 - Permitir cancelar a ação clicando em qualquer lugar da página e não somente na área de anotação. Por exemplo, quando escolho uma palavra e digito $C$ para conecta-lá, para cancelar era necessário clicar na área dos tweets.

2 - Corrigir a sobreposição de rótulos entre relações de diferentes tweets.

3 - Melhorar o resize da tela. No meu notebook que tem uma pequena tela e costumo dar zoom no Windows 10 (aumento do tamanho texto de aplicativos) não ficou legal.

C.3

User 03(B,0,5)

Recebeu treinamento presencial: Sim

Aquecimento: 0

Passo de re-anotação: 5

Idade: 29

Escolaridade: Doutorado em andamento

Profissão: Estudante 
Já participou de algum outro experimento de anotação de texto? Caso tenha participado, qual o grau de dificuldade da tarefa que acabou de executar em comparação às anteriores?

Não, nunca havia participado.

Quais foram as principais dificuldades que encontrou durante a tarefa?

Talvez, de início, fazer a associação correta do termo ao subtipo especifico. Depois de algumas anotações, isso passou a ser mais fácil.

Você tentou executar a tarefa lendo apenas parte do guia de anotação? Caso sim, acha que terminou de ler todo ele a partir de que documento finalizado?

Eu li apenas uma parte do guia e assiste à explicação realizada pelo autor.

$\mathrm{O}$ que achou do guia de anotação? O que mudaria nele?

Pelo que li, o guia estava bem feito.

O que achou da ferramenta de anotação? O que mudaria nela?

A ferramenta é excelente e, por isso, gostaria de dar os parabéns ao autor. Talvez tentar diminuir o tempo de espera entre a anotação de cada termo, mas não sei se é possivel.

C. 4

User 04(B,0,5)

Recebeu treinamento presencial: Sim

Aquecimento: 0

Passo de re-anotação: 5

Idade: 30

Escolaridade: Mestrado em Informática

Profissão: Estudante

Já participou de algum outro experimento de anotação de texto? Caso tenha participado, qual o grau de dificuldade da tarefa que acabou de executar em comparação às anteriores?

Não, foi a primeira vez.

Quais foram as principais dificuldades que encontrou durante a tarefa?

Os tweets não sempre tem uma unica interpretação, o q dificulta ser coerente na anotação.

Você tentou executar a tarefa lendo apenas parte do guia de anotação? Caso sim, acha que terminou de ler todo ele a partir de que documento finalizado?

Eu não li o guia de anotação. Só segui as suas instruções com a aula practica. A verdade, acho o guia muito comprido. Pode ser q a quantidade de páginas desanime ao pessoal. Acho melhor o q fizemos, aprender na hora com exemplos.

O que achou do guia de anotação? O que mudaria nele?

Depois de anotar voltei em ele e está muito explicativo, so q comprido.

$\mathrm{O}$ que achou da ferramenta de anotação? O que mudaria nela? 
Gostei da ferramenta. O fato de ser simple e facil a anotação de atores, eventos, localizações, etc, ajuda muito. Gostei das setinhas em vermelho, pois mais de uma vez tentei fazer uma coisa que não estava certa e a ferramenta ajudou a não errar. Acho que o fato de ter shortcut para o ultimo label colocado, subliminarmente ajuda a ser organizado na anotação. Gostei do disenho da ferramenta pois é simple, limpo (não está sobrecarregado de opções) e amigavel. Agora, cuando voce finaliza a anotação poderia sair algum resultado asociado a seu desempenho (Ex: percentual de anotados corretamente, etc) Pois como está deixa uma sensação de inserteção.

\section{C.5}

User 05(A,0,10)

Recebeu treinamento presencial: Não

Aquecimento: 0

Passo de re-anotação: 10

Idade: 39

Escolaridade: Doutor em informática

Profissão: Analista

Já participou de algum outro experimento de anotação de texto? Caso tenha participado, qual o grau de dificuldade da tarefa que acabou de executar em comparação às anteriores?

$N \tilde{a} O$

Quais foram as principais dificuldades que encontrou durante a tarefa?

Somente o fato de ser algo totalmente novo.

Você tentou executar a tarefa lendo apenas parte do guia de anotação? Caso sim, acha que terminou de ler todo ele a partir de que documento finalizado?

Sim. Não li todo.

O que achou do guia de anotação? O que mudaria nele?

O guia tem bastante informação. Usuários de sistema tem preguiça de ler manual. Se fosse eu colocaria os exemplos logo no início e as informações adicionais depois.

O que achou da ferramenta de anotação? O que mudaria nela?

A ferramenta é muito boa. Não mudaria nada.

\section{C.6}

User 06(A,0,10)

Recebeu treinamento presencial: Não

Aquecimento: 0

Passo de re-anotação: 10

Idade: 34

Escolaridade: Superior Completo

Profissão: Designer Gráfico 
Já participou de algum outro experimento de anotação de texto? Caso tenha participado, qual o grau de dificuldade da tarefa que acabou de executar em comparação às anteriores?

Não

Quais foram as principais dificuldades que encontrou durante a tarefa?

Demorei um pouco para entender no começo, tive que voltar nos exemplos varias vezes ate pegar agilidade

Você tentou executar a tarefa lendo apenas parte do guia de anotação? Caso sim, acha que terminou de ler todo ele a partir de que documento finalizado?

Não

O que achou do guia de anotação? O que mudaria nele?

Poderia ser mais dinâmico, talvez um infográfico...

O que achou da ferramenta de anotação? O que mudaria nela?

Interessante, tentaria deixar ela mais didática, intuitiva...

\section{C.7}

User $07(B, 0,10)$

Recebeu treinamento presencial: Sim

Aquecimento: 0

Passo de re-anotação: 10

Idade: 49

Escolaridade: Doutorado em andamento

Profissão: Estatístico

Já participou de algum outro experimento de anotação de texto? Caso tenha participado, qual o grau de dificuldade da tarefa que acabou de executar em comparação às anteriores?

Nunca participei.

Quais foram as principais dificuldades que encontrou durante a tarefa?

Saber as rotulações mais adequadas e em alguns casos as relações.

Você tentou executar a tarefa lendo apenas parte do guia de anotação? Caso sim, acha que terminou de ler todo ele a partir de que documento finalizado?

Li quase todo o documento, mas durante as anotações consultei varias vezes.

O que achou do guia de anotação? O que mudaria nele?

O guia esta bom e foi fundamental. Poderia ter mais exemplos completos. Um cheat sheet seria útil

O que achou da ferramenta de anotação? O que mudaria nela?

Ferramenta prática e fácil de operar. Não mudaria nada. 
C.8

User 08(B,0,10)

Recebeu treinamento presencial: Sim

Aquecimento: 0

Passo de re-anotação: 10

Idade: 30

Escolaridade: Doutorado em andamento

Profissão: Analista de sistemas

Já participou de algum outro experimento de anotação de texto? Caso tenha participado, qual o grau de dificuldade da tarefa que acabou de executar em comparação às anteriores?

Sim, participei de alguns experimentos de anotação no passado. Achei este experimento mais fácil de executar por conta da ferramenta e dos exemplos práticos dados pela pessoa que realizou o experimento antes de eu iniciar a anotação.

Quais foram as principais dificuldades que encontrou durante a tarefa?

Achei algumas tags ambiguas, tais como IsReferenceFor/IsRestrictedTo e HeavyTraffic/SlowTraffic.

Você tentou executar a tarefa lendo apenas parte do guia de anotação? Caso sim, acha que terminou de ler todo ele a partir de que documento finalizado?

Praticamente não li o guia de anotação. Ajudou muito a pessoa que realizou o experimento fazer alguns exemplos práticos e depois responder algumas dúvidas ao longo do processo de anotação. A anotação foi muito fluida.

$\mathrm{O}$ que achou do guia de anotação? O que mudaria nele?

Pelo fato de não ter quase olhado o guia, não tenho propriedade para avaliá-lo. Mas exemplos práticos ajudariam muito.

O que achou da ferramenta de anotação? O que mudaria nela?

A ferramenta de anotação está ótima. Não mudaria nada nela.

\section{C.9}

User $09(A, 2,5)$

Recebeu treinamento presencial: Não

Aquecimento: 2

Passo de re-anotação: 5

Idade: 31

Escolaridade: Ensino Superior em andamento

Profissão: Militar

Já participou de algum outro experimento de anotação de texto? Caso tenha participado, qual o grau de dificuldade da tarefa que acabou de executar em comparação às anteriores?

Não. 
Quais foram as principais dificuldades que encontrou durante a tarefa?

No inicio, associar todas as sentenças, mas logo a logica ajudou no raciocínio

Você tentou executar a tarefa lendo apenas parte do guia de anotação? Caso sim, acha que terminou de ler todo ele a partir de que documento finalizado?

Não, li todo Guia antes.

O que achou do guia de anotação? O que mudaria nele?

Bem detalhado, apenas colocaria mais de um exemplo por função para comparar diversas situações de emprego das sentenças

O que achou da ferramenta de anotação? O que mudaria nela?

Muito útil, caso possivel um auto vinculo primário das sentenças possiveis para que ficasse apenas os ajustes finos por parte do usuário.

\section{C.10}

User $10(A, 2,5)$

Recebeu treinamento presencial: Não

Aquecimento: 2

Passo de re-anotação: 5

Idade: 28

Escolaridade: Mestre em Sistemas e Computação

Profissão: Programadora

Já participou de algum outro experimento de anotação de texto? Caso tenha participado, qual o grau de dificuldade da tarefa que acabou de executar em comparação às anteriores?

Nunca participei.

Quais foram as principais dificuldades que encontrou durante a tarefa?

Saber quando uma palavra era o nome de alguma rua, bairro ou outra coisa. Como não sou do Rio e não o frequento muito, eu não reconhecia alguns nomes de ruas e pontos de referência. Algumas vezes tive que pesquisar no Google para saber se era nome de Rua, ou apenas uma referência ou outra coisa. Como por exemplo a palavra Gasômetro.

Outra dificuldade foi saber o que anotar para determinada palavra. Por exemplo: "Trânsito sentido Gávea", Eu não sabia se anotava como "one direction" ou como "flow to". Acabei anotando como flow to em todos os sentidos, pois me baseei nos exemplos. Outro exemplo: A palavra "retenção", para mim retenção não é a mesma coisa que interdição, então todas as vezes coloquei como "event"

Você tentou executar a tarefa lendo apenas parte do guia de anotação? Caso sim, acha que terminou de ler todo ele a partir de que documento finalizado?

Não. Eu li ele completo antes de começar a fazer. Porém, consultei ele diversas vezes durante todo o processo de anotação.

$\mathrm{O}$ que achou do guia de anotação? O que mudaria nele? 
Achei o guia muito bom e muito bem explicado. A única coisa que mudaria nele é que colocaria uma sessão explicando alguns termos utilizados, como por exemplo: dominio, entidades, relações. No inicio estes termos já são apresentados para o leitor sem um explicação prévia, e me senti meio perdida algumas vezes. Fui captar o que cada termo significava apenas quando analisei os exemplos.

O que achou da ferramenta de anotação? O que mudaria nela? Muito boa, intuitiva, e de fácil utilização. Eu colocaria uma opção de revisão e edição das anotações finalizadas. Algumas vezes tive a impressão de que havia feito alguma anotação errada, porém não tinha como voltar para conferir. E no inicio não tenho certeza se fiz correto, pois fui pegar o jeito das anotaçôes apenas depois de algumas já finalizadas. Então seria legal poder conferir e se houver alguma errada, poder editar.

\section{C.11}

\section{User 11(B,2,5)}

Recebeu treinamento presencial: Sim

Aquecimento: 2

Passo de re-anotação: 5

Idade: 26

Escolaridade: Superior completo

Profissão: Estudante

Já participou de algum outro experimento de anotação de texto? Caso tenha participado, qual o grau de dificuldade da tarefa que acabou de executar em comparação às anteriores?

Não, nunca tinha feito.

Quais foram as principais dificuldades que encontrou durante a tarefa?

A ferramenta mostra un proceso de carga por cada paso feito, o por cada anotação. Poderia guardar so nu final de cada oracão.

Você tentou executar a tarefa lendo apenas parte do guia de anotação? Caso sim, acha que terminou de ler todo ele a partir de que documento finalizado?

Não, a gente tive um tutorial personalizado, so usei para consultar os relacionamentos.

O que achou do guia de anotação? O que mudaria nele?

Ta bom. mais para melhorar poderia gravar suas propias explicaçoes, asim como as perguntas mais frecuentes do persoal que so tem o manual.

$\mathrm{O}$ que achou da ferramenta de anotação? O que mudaria nela?

A ferramenta e muito simples e cobre as funcionalidades esperadas dela, so foi muito chato que a cada anotaçao saia o simbolo de carregando e frizaba ate acabar a carga. 
C.12

User 12(A,2,10)

Recebeu treinamento presencial: Não

Aquecimento: 2

Passo de re-anotação: 10

Idade: 30

Escolaridade: Ensino superior incompleto

Profissão: Técnico em informática

Já participou de algum outro experimento de anotação de texto? Caso tenha participado, qual o grau de dificuldade da tarefa que acabou de executar em comparação às anteriores?

Não, foi a primeira vez.

Quais foram as principais dificuldades que encontrou durante a tarefa?

Foi fazer algumas conexões e classificar algumas palavras.

Você tentou executar a tarefa lendo apenas parte do guia de anotação? Caso sim, acha que terminou de ler todo ele a partir de que documento finalizado?

$N \tilde{a} o$.

O que achou do guia de anotação? O que mudaria nele?

Bom, só achei que tava faltando algumas coisas do guia na ferramenta.

$\mathrm{O}$ que achou da ferramenta de anotação? O que mudaria nela?

Achei a ferramenta muito boa, ela é bem simples e fácil de usar.

\section{C.13}

User 13(A,2,10)

Recebeu treinamento presencial: Não

Aquecimento: 2

Passo de re-anotação: 10

Idade: 32

Escolaridade: Doutorado em andamento

Profissão: Professor

Já participou de algum outro experimento de anotação de texto? Caso tenha participado, qual o grau de dificuldade da tarefa que acabou de executar em comparação às anteriores?

Nunca participei.

Quais foram as principais dificuldades que encontrou durante a tarefa?

Nas primeiras anotações que fiz foi complicado relacionar as anotações além do básico, que é veículo, evento manutenção da via, etc. Conforme fui consultando os exemplos novamente do Guia melhorou o meu entendimento e pude fazer anotações mais completas. 
Você tentou executar a tarefa lendo apenas parte do guia de anotação? Caso sim, acha que terminou de ler todo ele a partir de que documento finalizado?

Eu li o guia todo uma vez. Depois quando tinha dúvida olhava os exemplos do guia. Foi muito útil os exemplos com todos os tipos de anotações. Ficou mais fácil de entender olhando estes exemplos completos.

O que achou do guia de anotação? O que mudaria nele?

Colocaria mais exemplos, principalmente aqueles que apresentam os vários tipos de anotações. Fica mais fácil e rápido de entender olhando os exemplos.

O que achou da ferramenta de anotação? O que mudaria nela?

Mudaria o "Menu suspenso" de modo que houvesse vários "sub menus" de acordo com os tipos de anotações mais gerais e mais específicas. Exemplo, "Carro", "Moto", "Ônibus", seria um sub menu dentro de "Veículo".

\section{C.14}

User 14(B,2,10)

Recebeu treinamento presencial: Sim

Aquecimento: 2

Passo de re-anotação: 10

Idade: 29

Escolaridade: Doutorado em andamento

Profissão: Estudante

Já participou de algum outro experimento de anotação de texto? Caso tenha participado, qual o grau de dificuldade da tarefa que acabou de executar em comparação às anteriores?

Não, esse foi meu primeiro experimento de anotação de texto.

Quais foram as principais dificuldades que encontrou durante a tarefa?

O conhecimento de alguns nomes de bairros (eu sou estrangeiro, ainda estou aprendendo Português)

Você tentou executar a tarefa lendo apenas parte do guia de anotação? Caso sim, acha que terminou de ler todo ele a partir de que documento finalizado?

Eu recebi uma aula de como usar a ferramenta.

O que achou do guia de anotação? O que mudaria nele?

Muito bem estruturado, bem feito. Não mudaria nada.

O que achou da ferramenta de anotação? O que mudaria nela?

É uma ferramenta bem feita. Gostei do fluxo para fazer as anotações, eu incluiria uma legenda com os atalhos ( $T, R$ e C), e tentaria fazê-la mais independente do servidor quando uma ação é feita... tipo enviar só quando a anotação estiver concluída, e ir guardando as mudanças num arquivo temporário se for preciso. 


\section{C.15}

User 15(A,4,5)

Recebeu treinamento presencial: Não

Aquecimento: 4

Passo de re-anotação: 5

Idade: 45

Escolaridade: Mestrado em Informática

Profissão: SysAdmin e Desenvolvedor

Já participou de algum outro experimento de anotação de texto? Caso tenha participado, qual o grau de dificuldade da tarefa que acabou de executar em comparação às anteriores?

Não.

Quais foram as principais dificuldades que encontrou durante a tarefa?

A principal dificuldade foi ter que ler um documento de 22 páginas. Onde, só no final do documento é que realmente fica claro como fazer as anotações.

Você tentou executar a tarefa lendo apenas parte do guia de anotação? Caso sim, acha que terminou de ler todo ele a partir de que documento finalizado?

Não. Consultei o documento a todo momento!

$\mathrm{O}$ que achou do guia de anotação? O que mudaria nele?

O guia de anotação é bom e bem informativo. Contudo, fica cansativo ter ler um monte de definições, para só depois, começar a parte de anotações. Na minha opinião, ficaria um pouco menos cansativo, se no início do guia as informações fossem menos detalhadas e em seguida, ter exemplos mais simples. E todos os detalhes ficariam para o final. Assim, o usuário, poderia já entenderia o que fazer e como fazer, já no início do documento.

$\mathrm{O}$ que achou da ferramenta de anotação? O que mudaria nela?

A ferramenta é muito boa. A única coisa que eu mudaria seria tirar a informação do número de documentos que faltam pra anotar. Só a porcentagem estaria boa. Esse número me deixou apreensivo, parecia que não ia terminar nunca :-)

\section{C.16}

User 16(A,4,5)

Recebeu treinamento presencial: Não

Aquecimento: 4

Passo de re-anotação: 5

Idade: 31

Escolaridade: Ensino superior incompleto

Profissão: Analista de Sistemas 
Já participou de algum outro experimento de anotação de texto? Caso tenha participado, qual o grau de dificuldade da tarefa que acabou de executar em comparação às anteriores?

Não.

Quais foram as principais dificuldades que encontrou durante a tarefa?

Algumas tags do experimento não tinham uma relação prevista na ontologia com outras, então "adaptei" com uma relação entre outras tags. Senti falta de mais infomações na tela principal. Me enrolei um pouco com os atalhos.

Você tentou executar a tarefa lendo apenas parte do guia de anotação? Caso sim, acha que terminou de ler todo ele a partir de que documento finalizado?

Como a aparência da aplicação me pareceu bastante simples, tentei fazer de maneira intuitiva. Tive algumas dificuldades e, então, recorri a documentação. Depois de ler apenas uma vez, consegui finalizar tudo normalmente.

O que achou do guia de anotação? O que mudaria nele?

Nada. Estava ótimo! Apenas retiraria algumas informações do guia e colocaria na tela principal para deixar a aplicação ainda mais gerenciável pelo usuário.

O que achou da ferramenta de anotação? O que mudaria nela?

Apenas retiraria algumas informações do guia e colocaria na tela principal para deixar a aplicação ainda mais gerenciável pelo usuário.

\section{C.17}

User 17(B,4,5)

Recebeu treinamento presencial: Sim

Aquecimento: 4

Passo de re-anotação: 5

Idade: 20

Escolaridade: Superior em andamento

Profissão: Estudante

Já participou de algum outro experimento de anotação de texto? Caso tenha participado, qual o grau de dificuldade da tarefa que acabou de executar em comparação às anteriores?

Nunca participei.

Quais foram as principais dificuldades que encontrou durante a tarefa?

A subjetividade da tarefa foi algo que me trouxe bastante dificuldade, em alguns momentos ficava em dúvida de qual seria a melhor forma de realizar a anotação. Além disso, como eram muitas anotações, tive dificuldade em manter a atenção para não deixar passar nada.

Você tentou executar a tarefa lendo apenas parte do guia de anotação? Caso sim, acha que terminou de ler todo ele a partir de que documento finalizado?

Executei a tarefa lendo pouco do guia de anotação. Baseei-me, majoritariamente, na sua explicação e nos exemplos que fez junto com o pessoal. 
O que achou do guia de anotação? O que mudaria nele?

Não li o suficiente do guia de anotação para opinar.

$\mathrm{O}$ que achou da ferramenta de anotação? O que mudaria nela?

Achei a ferramente muito boa. A forma de classificar as palavras e de construir relações entre elas é bastante intuitiva e após realizar isso o desenho formado é uma ótima forma de verificar se o que fez está certo. Realmente não sei o que mudaria, para mim está ótimo do jeito que está.

\section{C.18}

User 18(A,4,10)

Recebeu treinamento presencial: Não

Aquecimento: 4

Passo de re-anotação: 10

Idade: 30

Escolaridade: Superior completo

Profissão: Estudante

Já participou de algum outro experimento de anotação de texto? Caso tenha participado, qual o grau de dificuldade da tarefa que acabou de executar em comparação às anteriores?

Não

Quais foram as principais dificuldades que encontrou durante a tarefa?

Na hora de finalizar a anotação de um tweet. Eu ficava em dúvida se eu realmente tinha anotado tudo correto e, por existir diversas tipos de rotulações/relacionamentos, achava que sempre podia estar faltando algo a ser rotulado/relacionado/conectado.

Você tentou executar a tarefa lendo apenas parte do guia de anotação? Caso sim, acha que terminou de ler todo ele a partir de que documento finalizado?

Tentei, na verdade fiz uma leitura rápida em algumas partes do guia de anotação e com certeza não li o documento todo no primeiro estudo do guia. Acho que sim.

O que achou do guia de anotação? O que mudaria nele?

Achei completo e bom para referência em todo momento que se tinha dúvida com relação à alguma anotação. Eu colocaria a parte dos exemplos mais pro início, pois o documento é extenso e no meu caso nem cheguei a usar todas os tipos de relação. Sempre que eu tinha alguma dúvida na anotação, procurava primeiro algum exemplo parecido completamente anotado. Acho que todas as figuras apresentadas podiam estar completamente anotadas, pois pode gerar confusão quando o anotador olha para uma figura que tem um tweet parcialmente anotado e acha que o mesmo é um exemplo completamente anotado. Para começar o guia e explicar relações/conexões/rotulações, eu colocaria tweets simples nas figuras, mas sempre completamente anotados.

O que achou da ferramenta de anotação? O que mudaria nela?

Gostei da ferramenta, achei a interface boa e separa bem o texto a medida que novas informações são inseridas, deixando claro o que está sendo feito e 
visualmente legível, mesmo quando se tem muitas informações. Eu colocaria todas as opções de conexões/relações visíveis, sem a necessidade de clicar no botão direito do mouse para escolher, desta forma acredito que iria ajudar o anotador, pois com tudo visível ia ser mais fácil de decorar todas opções fazendo com que seja mais difícil o anotador esquecer de algo na anotação.

\section{C.19}

\section{User $19(A, 4,10)$}

Recebeu treinamento presencial: Não

Aquecimento: 4

Passo de re-anotação: 10

Idade: 28

Escolaridade: Superior Completo

Profissão: Analista de Sistemas

Já participou de algum outro experimento de anotação de texto? Caso tenha participado, qual o grau de dificuldade da tarefa que acabou de executar em comparação às anteriores?

Não, esta foi a primeira vez na qual participei de um experimento deste tipo. tarefa?

Quais foram as principais dificuldades que encontrou durante a

Encontrei algumas dificuldades nos casos que imagino serem os dificeis, sem atores bem claros, ou que continham muitas informações sobre sentidos e ruas. Não soube fazer alguns casos, onde não havia nada para ser anotado, até onde pude perceber.

Você tentou executar a tarefa lendo apenas parte do guia de anotação? Caso sim, acha que terminou de ler todo ele a partir de que documento finalizado?

Sim. Tentei fazer ao ler apenas as primeiras seções do documento e alguns exemplos básicos de anotações, mas não consegui ir muito longe com alguns casos difíceis. Por isso, reli a documentação, desta vez por completo e assim consegui fazer os demais.

O que achou do guia de anotação? O que mudaria nele?

O guia lhe dá um bom direcionamento, mas eu tentaria colocar talvez mais exemplos práticos. Talvez isto não seja possível, pois poderia influenciar no resultado do experimento, mas é algo a se pensar.

$\mathrm{O}$ que achou da ferramenta de anotação? O que mudaria nela?

Achei a ferramenta bem desenvolvida e bem dinâmica, mas talvez peque um pouco em usabilidade para aumentar a velocidade das anotações. Creio que deveria ser estudada alguma maneira além dos atalhos para se anotar mais rapidamente. Talvez poder, por exemplo, marcar mais de uma palavra e anotálas todas juntas, nos casos em que todas forem de tipos iguais. 


\section{20}

\section{User 20(B,4,10)}

Recebeu treinamento presencial: Sim

Aquecimento: 4

Passo de re-anotação: 10

Idade: 19

Escolaridade: Ensino Superior Incompleto

Profissão: Estudante

Já participou de algum outro experimento de anotação de texto? Caso tenha participado, qual o grau de dificuldade da tarefa que acabou de executar em comparação às anteriores?

Nunca tinha participado. Achei razoavelmente tranquilo, a partir das primeiras 5/10 anotações fica bem mais fácil.

Quais foram as principais dificuldades que encontrou durante a tarefa?

Tive um problema com comentário, não podia escrever $z$, pois ele fazia um undo. Também me confundi inicialmente com as setas de relação entre locais. O sentido delas (ex: flows To, referenceFor) acabou me confundindo.

Você tentou executar a tarefa lendo apenas parte do guia de anotação? Caso sim, acha que terminou de ler todo ele a partir de que documento finalizado?

Sim, lendo apenas a parte que você mostrou ao explicar a tarefa. Nos geral as dúvidas que eu tinha podiam ser tiradas no guia, mas você acabou respondendo pessoalmente.

O que achou do guia de anotação? O que mudaria nele?

Não li inteiro para falar a verdade.

$\mathrm{O}$ que achou da ferramenta de anotação? O que mudaria nela?

Achei muito boa. Acho bem importante ela ser super rápida, pois qualquer tempo de espera ao montar as relações pode ser tornar um pouco tedioso. Principalmente se forem feitas um grande número de anotações. O visual está bem legal e o portal está bem intuitivo. Parabéns! 


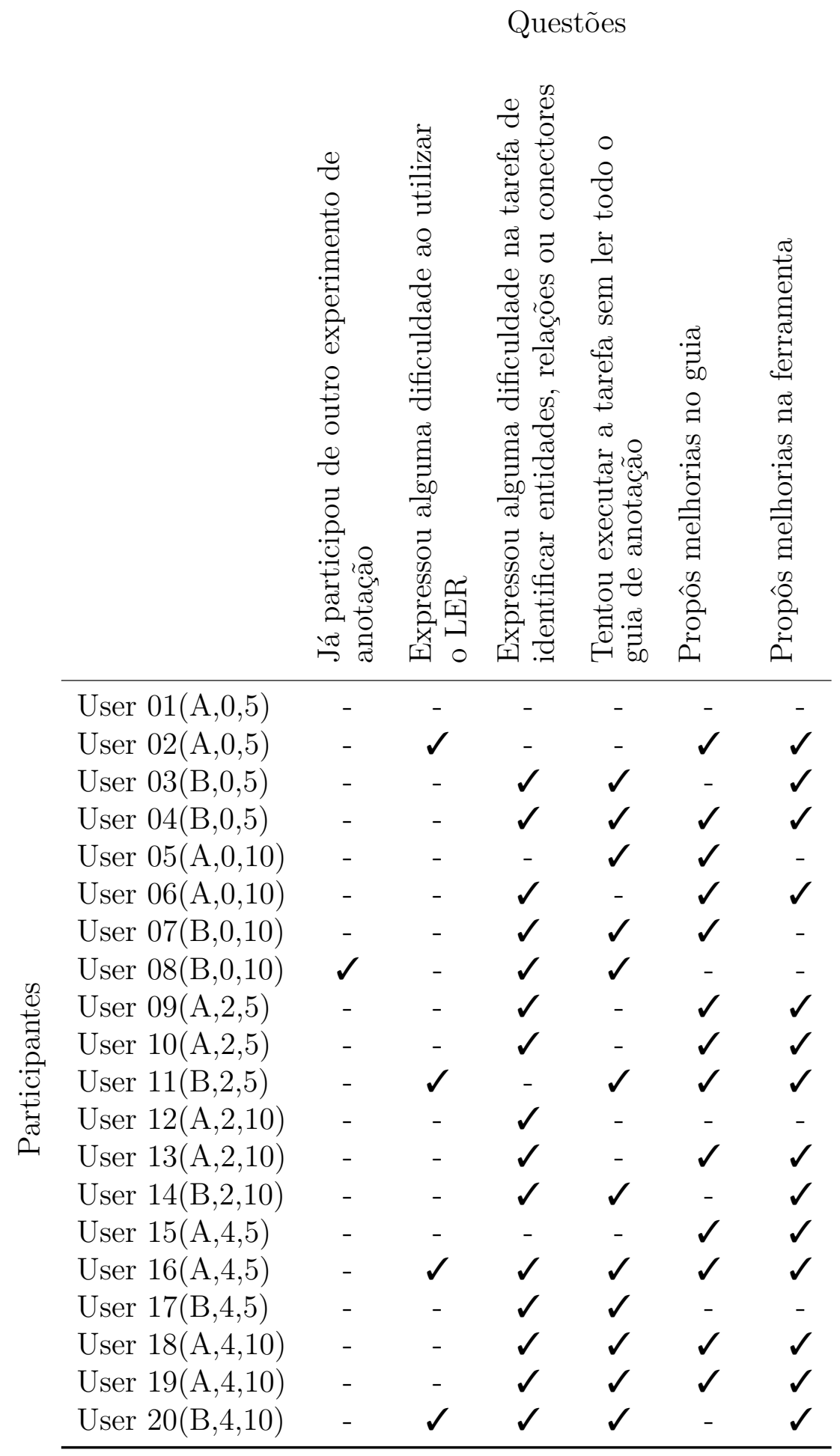

Tabela C.1: Resumo das respostas dos participantes ao questionário do experimento de anotação 
D

\section{Experimento de anotação: Tabelas e gráficos}

Este apêndice contém gráficos e tabelas com informações adicionais sobre o experimento de anotação descrito no capítulo 4 desta dissertação.

Tabela D.1: Resumo colaborações

\begin{tabular}{|c|c|c|c|c|}
\hline Colaborador & Tempo gasto & Tempo médio & \# visualizações & \# visualizações média \\
\hline User, 01(A,0,5) & $2 \mathrm{~h} 18 \mathrm{~m} 4 \mathrm{~s}$ & $2 \mathrm{~m} \mathrm{45s}(\sigma 4 \mathrm{~m} \mathrm{3s})$ & 63 & $1,26(\sigma 0,52)$ \\
\hline User, 02(A,0,5) & $2 \mathrm{~h} 51 \mathrm{~m} 45 \mathrm{~s}$ & $3 \mathrm{~m} 26 \mathrm{~s}(\sigma 5 \mathrm{~m} \mathrm{40s})$ & 126 & $2,52(\sigma 1,86)$ \\
\hline User, 03(B,0,5) & $3 \mathrm{~h} 12 \mathrm{~m} 57 \mathrm{~s}$ & $3 \mathrm{~m} 51 \mathrm{~s}(\sigma 6 \mathrm{~m} \mathrm{30s})$ & 55 & $1,10(\sigma 0,30)$ \\
\hline User, 04(B,0,5) & $2 \mathrm{~h} 42 \mathrm{~m} \mathrm{31s}$ & $3 \mathrm{~m} 15 \mathrm{~s}(\sigma 4 \mathrm{~m} \mathrm{16s})$ & 51 & $1,02(\sigma 0,14)$ \\
\hline User, 05(A,0,10) & $2 \mathrm{~h} 9 \mathrm{~m} 30 \mathrm{~s}$ & $2 \mathrm{~m} \mathrm{35s}(\sigma 5 \mathrm{~m} \mathrm{20s})$ & 61 & $1,22(\sigma 0,58)$ \\
\hline User, 06(A,0,10) & $9 \mathrm{~h} 55 \mathrm{~m} 37 \mathrm{~s}$ & $11 \mathrm{~m} 54 \mathrm{~s}(\sigma 48 \mathrm{~m} 22 \mathrm{~s})$ & 57 & $1,14(\sigma 0,40)$ \\
\hline User, 07(B,0,10) & $8 \mathrm{~h} 4 \mathrm{~m} 40 \mathrm{~s}$ & $9 \mathrm{~m} 41 \mathrm{~s}(\sigma 31 \mathrm{~m} 29 \mathrm{~s})$ & 53 & $1,06(\sigma 0,24)$ \\
\hline User, 08(B,0,10) & 1h $36 \mathrm{~m} 58 \mathrm{~s}$ & $1 \mathrm{~m} 56 \mathrm{~s}(\sigma 1 \mathrm{~m} 50 \mathrm{~s})$ & 50 & $1,00(\sigma 0,00)$ \\
\hline User, $09(\mathrm{~A}, 2,5)$ & $1 \mathrm{~d} 12 \mathrm{~m} \mathrm{43s}$ & $29 \mathrm{~m} \mathrm{3s}(\sigma 2 \mathrm{~h} 55 \mathrm{~m} 13 \mathrm{~s})$ & 58 & $1,16(\sigma 1,12)$ \\
\hline User, $10(\mathrm{~A}, 2,5)$ & $2 \mathrm{~h} 41 \mathrm{~m} 31 \mathrm{~s}$ & $3 \mathrm{~m} 13 \mathrm{~s}(\sigma 4 \mathrm{~m} 1 \mathrm{~s})$ & 52 & $1,04(\sigma 0,20)$ \\
\hline User, $11(\mathrm{~B}, 2,5)$ & $2 \mathrm{~h} 13 \mathrm{~m} \mathrm{33s}$ & $2 \mathrm{~m} 40 \mathrm{~s}(\sigma 3 \mathrm{~m} \mathrm{49s})$ & 55 & $1,10(\sigma 0,41)$ \\
\hline User, $12(\mathrm{~A}, 2,10)$ & $5 \mathrm{~h} 20 \mathrm{~m} \mathrm{20s}$ & $6 \mathrm{~m} 24 \mathrm{~s}(\sigma 34 \mathrm{~m} 5 \mathrm{~s})$ & 52 & $1,04(\sigma 0,20)$ \\
\hline User, 13(A,2,10) & $2 \mathrm{~h} 45 \mathrm{~m} 46 \mathrm{~s}$ & $3 \mathrm{~m} \mathrm{18s}(\sigma 3 \mathrm{~m} \mathrm{11s})$ & 50 & $1,00(\sigma 0,00)$ \\
\hline User, 14(B,2,10) & $2 \mathrm{~h} 8 \mathrm{~m} \mathrm{25s}$ & $2 \mathrm{~m} \mathrm{34s}(\sigma 5 \mathrm{~m} \mathrm{37s})$ & 63 & $1,26(\sigma 1,13)$ \\
\hline User, $15(\mathrm{~A}, 4,5)$ & $2 \mathrm{~h} 12 \mathrm{~m} 7 \mathrm{~s}$ & $2 \mathrm{~m} \mathrm{38s}(\sigma 6 \mathrm{~m} \mathrm{28s})$ & 300 & $6,00(\sigma 7,91)$ \\
\hline User, $16(\mathrm{~A}, 4,5)$ & $3 \mathrm{~h} 8 \mathrm{~m} \mathrm{45s}$ & $3 \mathrm{~m} 46 \mathrm{~s}(\sigma 8 \mathrm{~m} \mathrm{14s})$ & 60 & $1,20(\sigma 0,40)$ \\
\hline User, $17(\mathrm{~B}, 4,5)$ & $2 \mathrm{~h} 1 \mathrm{~s}$ & $2 \mathrm{~m} 24 \mathrm{~s}(\sigma 3 \mathrm{~m} \mathrm{24s})$ & 52 & $1,04(\sigma 0,20)$ \\
\hline User, $18(\mathrm{~A}, 4,10)$ & $5 \mathrm{~h} 3 \mathrm{~m} 8 \mathrm{~s}$ & $6 \mathrm{~m} 3 \mathrm{~s}(\sigma 8 \mathrm{~m} \mathrm{33s})$ & 134 & $2,68(\sigma 2,60)$ \\
\hline User, $19(\mathrm{~A}, 4,10)$ & $3 \mathrm{~h} 26 \mathrm{~m} \mathrm{43s}$ & $4 \mathrm{~m} 8 \mathrm{~s}(\sigma 13 \mathrm{~m} 13 \mathrm{~s})$ & 61 & $1,22(\sigma 0,41)$ \\
\hline User, $20(\mathrm{~B}, 4,10)$ & $1 \mathrm{~h} 50 \mathrm{~m} 24 \mathrm{~s}$ & $2 \mathrm{~m} 12 \mathrm{~s}(\sigma 2 \mathrm{~m} \mathrm{31s})$ & 51 & $1,02(\sigma 0,14)$ \\
\hline
\end{tabular}




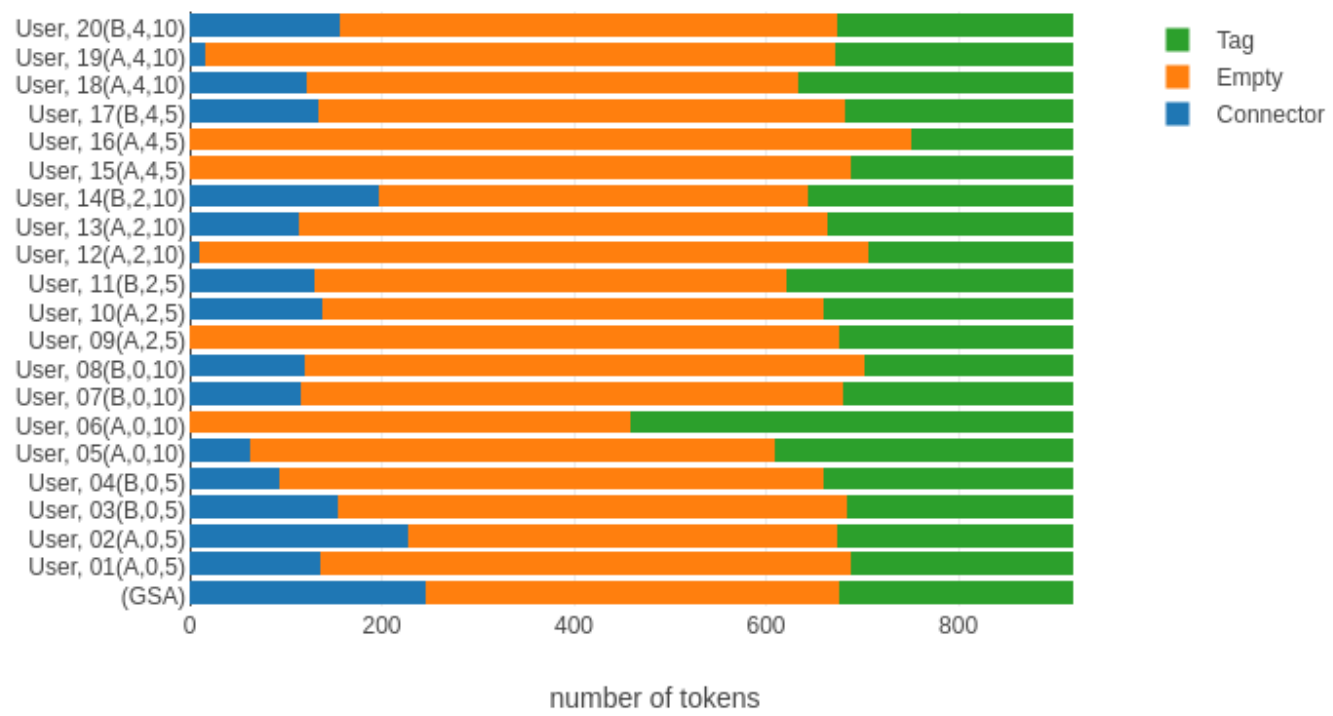

Figura D.1: Experimento de anotação, tokens

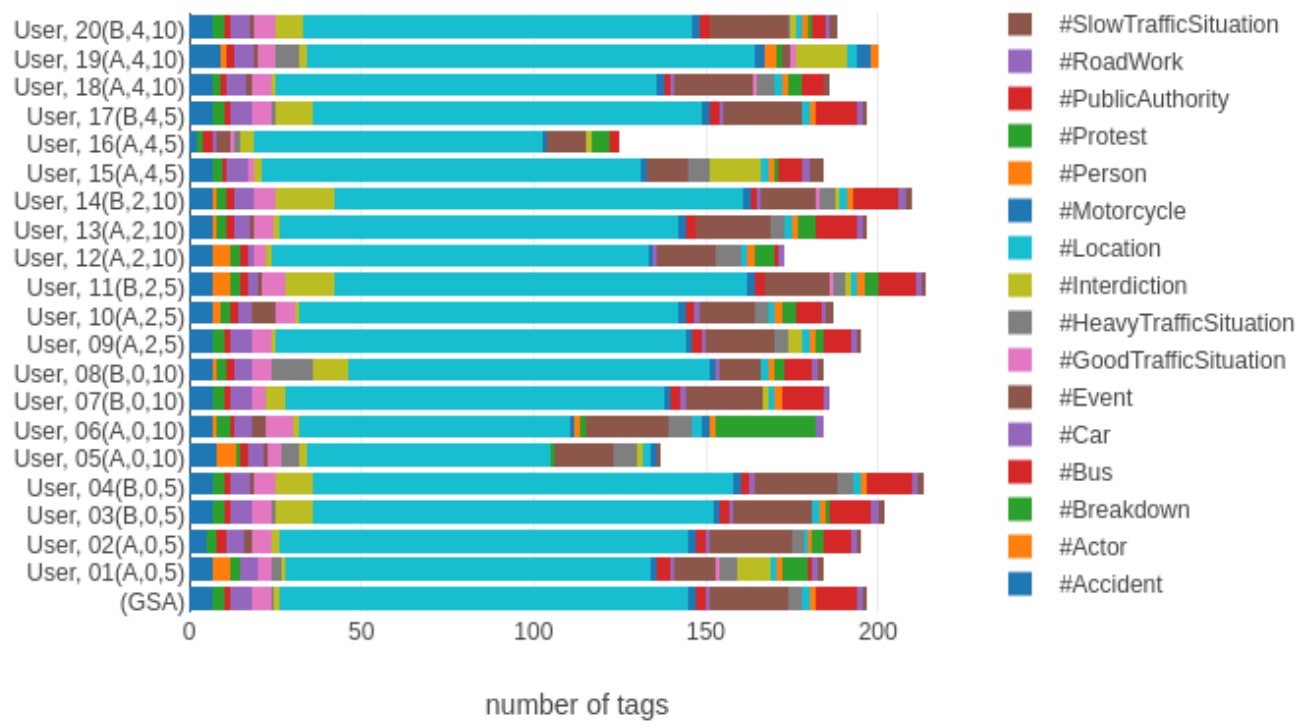

Figura D.2: Experimento de anotação, entidades 


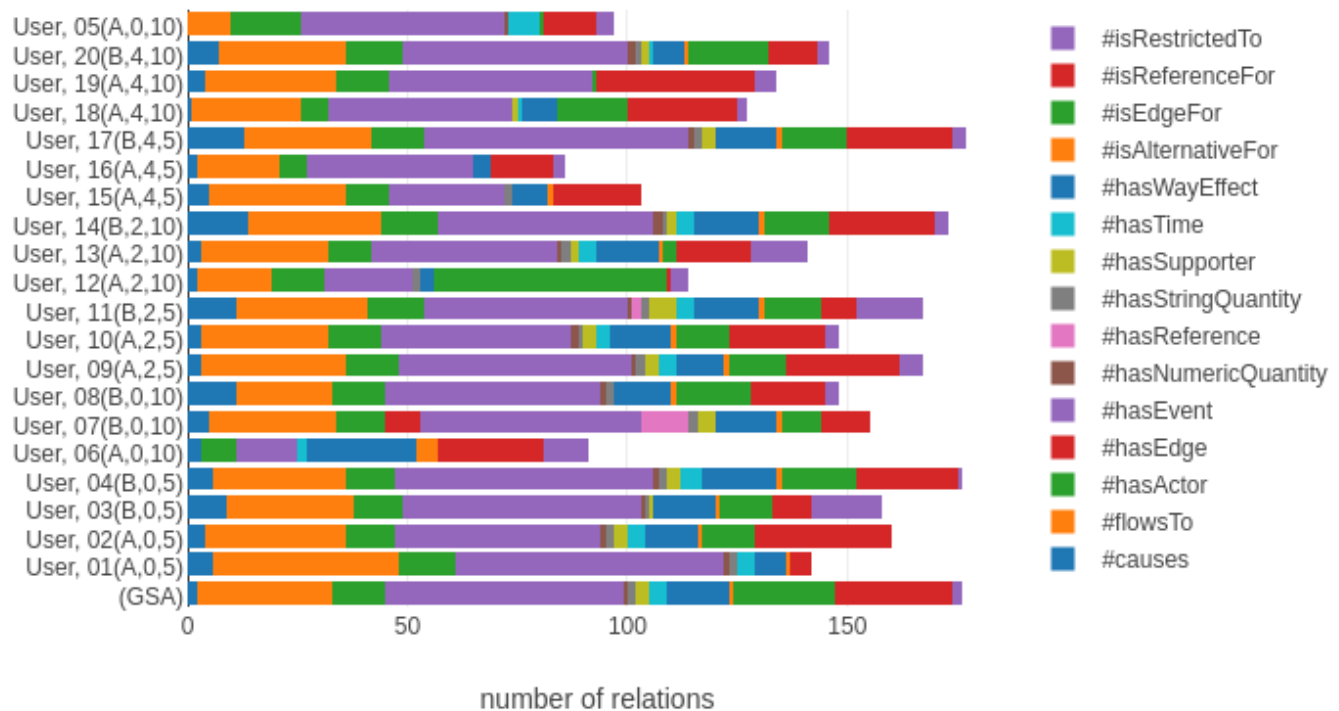

Figura D.3: Experimento de anotação: relações

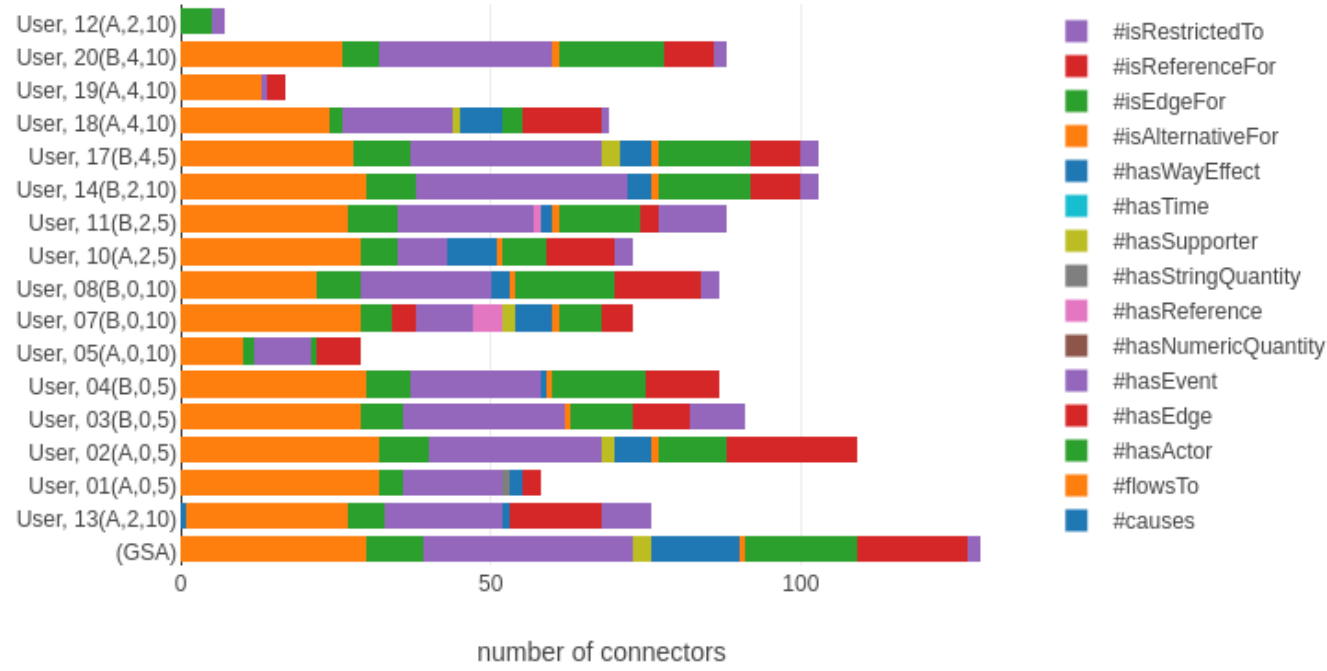

Figura D.4: Experimento de anotação, conectores 


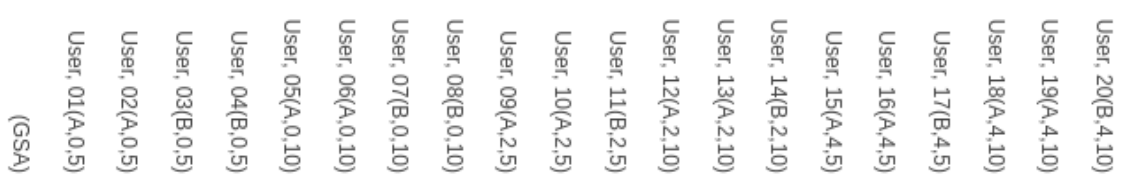

$\begin{array}{lllllllllllllllllllllll}\text { (GSA) } & 0.37 & 0.66 & 0.64 & 0.62 & 0.32 & 0.20 & 0.60 & 0.55 & 0.57 & 0.50 & 0.52 & 0.42 & 0.59 & 0.62 & 0.48 & 0.34 & 0.67 & 0.56 & 0.42 & 0.58\end{array}$

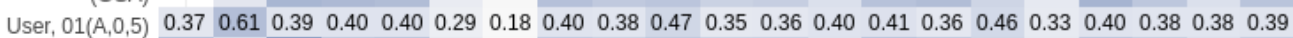
$\begin{array}{llllllllllllllllllllllll}\text { User, } 02(A, 0,5) & 0.66 & 0.39 & 0.86 & 0.58 & 0.61 & 0.34 & 0.19 & 0.57 & 0.52 & 0.56 & 0.52 & 0.53 & 0.41 & 0.61 & 0.58 & 0.48 & 0.35 & 0.60 & 0.54 & 0.43 & 0.55\end{array}$ $\begin{array}{llllllllllllllllllllllll}\text { User, } 03(B, 0,5) & 0.64 & 0.40 & 0.58 & 0.75 & 0.67 & 0.31 & 0.22 & 0.62 & 0.62 & 0.58 & 0.50 & 0.53 & 0.46 & 0.58 & 0.60 & 0.53 & 0.39 & 0.72 & 0.51 & 0.44 & 0.62\end{array}$ $\begin{array}{llllllllllllllllllllll}\text { User, } 04(B, 0,5) & 0.62 & 0.40 & 0.61 & 0.67 & 0.85 & 0.34 & 0.22 & 0.62 & 0.59 & 0.62 & 0.49 & 0.57 & 0.46 & 0.59 & 0.60 & 0.54 & 0.38 & 0.71 & 0.54 & 0.48 & 0.61\end{array}$

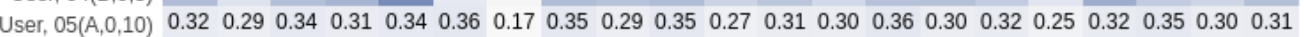
$\begin{array}{llllllllllllllllllllllll}\text { User, } 06(A, 0,10) & 0.20 & 0.18 & 0.19 & 0.22 & 0.22 & 0.17 & 0.28 & 0.22 & 0.20 & 0.22 & 0.20 & 0.19 & 0.22 & 0.22 & 0.18 & 0.21 & 0.17 & 0.21 & 0.22 & 0.22 & 0.21\end{array}$

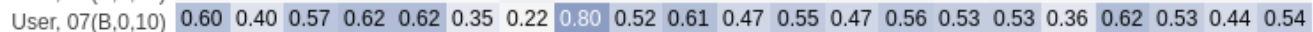

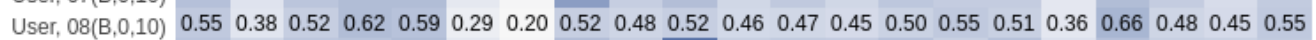
\begin{tabular}{llllllll|llllllllllllllll} 
User, $09(A, 2,5)$ & 0.57 & 0.47 & 0.56 & 0.58 & 0.62 & 0.35 & 0.22 & 0.61 & 0.52 & 0.93 & 0.51 & 0.54 & 0.53 & 0.59 & 0.51 & 0.59 & 0.41 & 0.60 & 0.51 & 0.50 & 0.54
\end{tabular} $\begin{array}{llllllllllllllllllllll}\text { User, } 10(\mathrm{~A}, 2,5) & 0.50 & 0.35 & 0.52 & 0.50 & 0.49 & 0.27 & 0.20 & 0.47 & 0.46 & 0.51 & 0.79 & 0.44 & 0.42 & 0.50 & 0.46 & 0.46 & 0.33 & 0.49 & 0.43 & 0.41 & 0.46\end{array}$ $\begin{array}{lllllllllllllllllllllllll}\text { User, } 11(B, 2,5) & 0.52 & 0.36 & 0.53 & 0.53 & 0.57 & 0.31 & 0.19 & 0.55 & 0.47 & 0.54 & 0.44 & 0.68 & 0.42 & 0.50 & 0.54 & 0.47 & 0.32 & 0.56 & 0.46 & 0.40 & 0.51\end{array}$ $\begin{array}{llllllllllllllllllllll}\text { User, } 12(\mathrm{~A}, 2,10) & 0.42 & 0.40 & 0.41 & 0.46 & 0.46 & 0.30 & 0.22 & 0.47 & 0.45 & 0.53 & 0.42 & 0.42 & 0.76 & 0.43 & 0.39 & 0.51 & 0.37 & 0.44 & 0.41 & 0.41 & 0.42\end{array}$

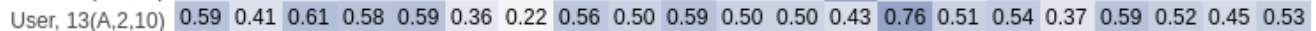
$\begin{array}{lllllllllllllllllllllll}\text { User, } 14(\mathrm{~B}, 2,10) & 0.62 & 0.36 & 0.58 & 0.60 & 0.60 & 0.30 & 0.18 & 0.53 & 0.55 & 0.51 & 0.46 & 0.54 & 0.39 & 0.51 & 0.80 & 0.46 & 0.32 & 0.66 & 0.51 & 0.39 & 0.57\end{array}$

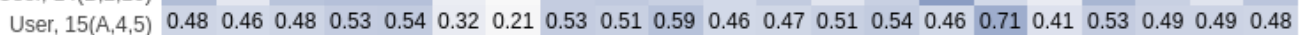

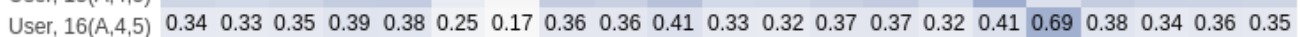

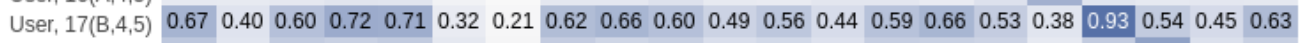
$\begin{array}{llllllllllllllllllllll}\text { User, 18(A,4,10) } & 0.56 & 0.38 & 0.54 & 0.51 & 0.54 & 0.35 & 0.22 & 0.53 & 0.48 & 0.51 & 0.43 & 0.46 & 0.41 & 0.52 & 0.51 & 0.49 & 0.34 & 0.54 & 0.78 & 0.42 & 0.51\end{array}$

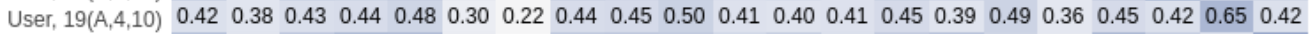
$\begin{array}{lllllllllllllllllllllllll}\text { User, } 20(B, 4,10) & 0.58 & 0.39 & 0.55 & 0.62 & 0.61 & 0.31 & 0.21 & 0.54 & 0.55 & 0.54 & 0.46 & 0.51 & 0.42 & 0.53 & 0.57 & 0.48 & 0.35 & 0.63 & 0.51 & 0.42 & 0.73\end{array}$

Figura D.5: Experimento de anotação, concordância com entidades, relações e conectores

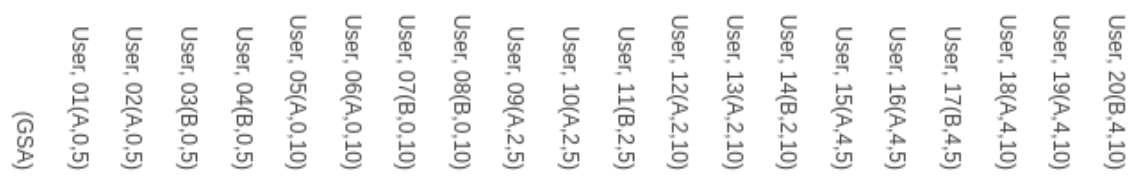

$\begin{array}{llllllllllllllllllllllll}\text { (GSA) } & 0.72 & 0.88 & 0.87 & 0.87 & 0.49 & 0.35 & 0.86 & 0.81 & 0.90 & 0.77 & 0.79 & 0.75 & 0.85 & 0.85 & 0.76 & 0.49 & 0.89 & 0.78 & 0.66 & 0.84\end{array}$ $\begin{array}{lllllllllllllllllllllllllll}\text { User, } 01(A, 0,5) & 0.72 & 0.84 & 0.72 & 0.69 & 0.70 & 0.46 & 0.30 & 0.66 & 0.65 & 0.73 & 0.62 & 0.63 & 0.65 & 0.69 & 0.69 & 0.69 & 0.43 & 0.70 & 0.65 & 0.59 & 0.67\end{array}$ $\begin{array}{llllllllllllllllllllllllllll}\text { User, 02(A,0,5) } & 0.88 & 0.72 & 0.95 & 0.85 & 0.85 & 0.49 & 0.34 & 0.81 & 0.78 & 0.87 & 0.75 & 0.79 & 0.73 & 0.84 & 0.85 & 0.75 & 0.50 & 0.85 & 0.74 & 0.62 & 0.82\end{array}$

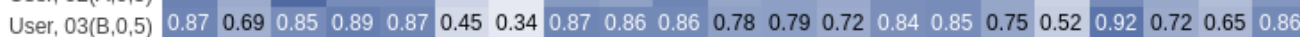
\begin{tabular}{l|llllllllllllllllllllllllll} 
User, $04(\mathrm{~B}, 0,5)$ & 0.87 & 0.70 & 0.85 & 0.87 & 0.99 & 0.51 & 0.36 & 0.85 & 0.80 & 0.85 & 0.75 & 0.81 & 0.73 & 0.82 & 0.89 & 0.77 & 0.52 & 0.90 & 0.78 & 0.67 & 0.85
\end{tabular} $\begin{array}{llllllllllllllllllllll}\text { User, 05(A, } 0,10) & 0.49 & 0.46 & 0.49 & 0.45 & 0.51 & 0.34 & 0.34 & 0.49 & 0.44 & 0.49 & 0.42 & 0.50 & 0.45 & 0.48 & 0.49 & 0.46 & 0.29 & 0.47 & 0.55 & 0.45 & 0.49\end{array}$

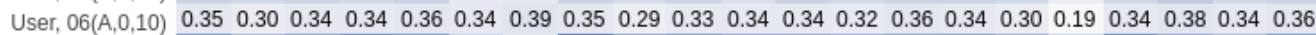
$\begin{array}{lllllllllllllllllllllllllll}\text { User, } 07(\mathrm{~B}, 0,10) & 0.86 & 0.66 & 0.81 & 0.87 & 0.85 & 0.49 & 0.35 & 0.93 & 0.80 & 0.84 & 0.75 & 0.76 & 0.71 & 0.80 & 0.82 & 0.73 & 0.48 & 0.87 & 0.75 & 0.64 & 0.85\end{array}$ $\begin{array}{lllllllllllllllllllllllll}\text { User, } 08(\mathrm{~B}, 0,10) & 0.81 & 0.65 & 0.78 & 0.86 & 0.80 & 0.44 & 0.29 & 0.80 & 0.91 & 0.78 & 0.68 & 0.73 & 0.69 & 0.76 & 0.78 & 0.73 & 0.47 & 0.85 & 0.67 & 0.63 & 0.81\end{array}$

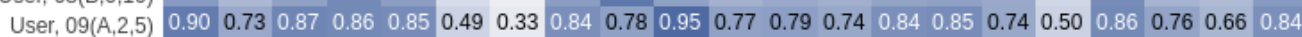
$\begin{array}{llllllllllllllllllllllllll}\text { User, } 10(A, 2,5) & 0.77 & 0.62 & 0.75 & 0.78 & 0.75 & 0.42 & 0.34 & 0.75 & 0.68 & 0.77 & 0.86 & 0.69 & 0.70 & 0.74 & 0.74 & 0.65 & 0.45 & 0.75 & 0.66 & 0.56 & 0.74\end{array}$ $\begin{array}{lllllllllllllllllllllll}\text { User, } 11(\mathrm{~B}, 2,5) & 0.79 & 0.63 & 0.79 & 0.79 & 0.81 & 0.50 & 0.34 & 0.76 & 0.73 & 0.79 & 0.69 & 0.85 & 0.67 & 0.77 & 0.83 & 0.70 & 0.43 & 0.81 & 0.69 & 0.57 & 0.77\end{array}$

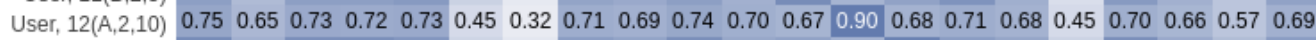
$\begin{array}{llllllllllllllllllllllll}\text { User, } 13(\mathrm{~A}, 2,10) & 0.85 & 0.69 & 0.84 & 0.84 & 0.82 & 0.48 & 0.36 & 0.80 & 0.76 & 0.84 & 0.74 & 0.77 & 0.68 & 0.88 & 0.80 & 0.75 & 0.49 & 0.84 & 0.73 & 0.62 & 0.80\end{array}$ $\begin{array}{lllllllllllllllllllllllll}\text { User, } 14(B, 2,10) & 0.85 & 0.69 & 0.85 & 0.85 & 0.89 & 0.49 & 0.34 & 0.82 & 0.78 & 0.85 & 0.74 & 0.83 & 0.71 & 0.80 & 0.92 & 0.74 & 0.46 & 0.87 & 0.76 & 0.62 & 0.83\end{array}$ $\begin{array}{llllllllllllllllllllllllll}\text { User, } 15(A, 4,5) & 0.76 & 0.69 & 0.75 & 0.75 & 0.77 & 0.46 & 0.30 & 0.73 & 0.73 & 0.74 & 0.65 & 0.70 & 0.68 & 0.75 & 0.74 & 0.84 & 0.47 & 0.75 & 0.69 & 0.59 & 0.71\end{array}$ $\begin{array}{lllllllllllllllllllllll}\text { User, } 16(A, 4,5) & 0.49 & 0.43 & 0.50 & 0.52 & 0.52 & 0.29 & 0.19 & 0.48 & 0.47 & 0.50 & 0.45 & 0.43 & 0.45 & 0.49 & 0.46 & 0.47 & 0.74 & 0.52 & 0.43 & 0.43 & 0.49\end{array}$ $\begin{array}{lllllllllllllllllllllllllll}\text { User, } 17(\mathrm{~B}, 4,5) & 0.89 & 0.70 & 0.85 & 0.92 & 0.90 & 0.47 & 0.34 & 0.87 & 0.85 & 0.86 & 0.75 & 0.81 & 0.70 & 0.84 & 0.87 & 0.75 & 0.52 & 0.96 & 0.73 & 0.66 & 0.87\end{array}$

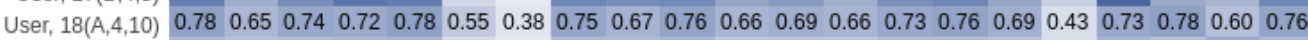

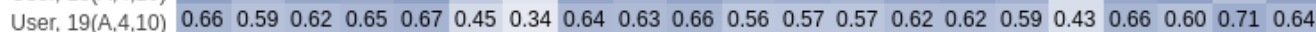

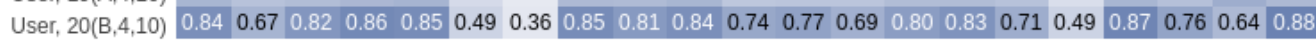

Figura D.6: Experimento de anotação, concordância com entidades 


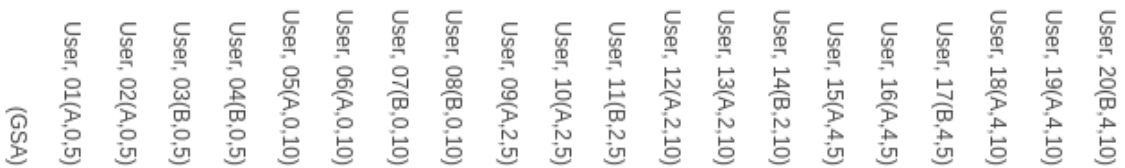

(GSA) $\quad-\quad \begin{array}{llllllllllllllllllllllll} & 0.14 & 0.45 & 0.36 & 0.42 & -0.13 & -0.23 & 0.35 & 0.17 & 0.40 & 0.15 & 0.18 & -0.11 & 0.30 & 0.32 & 0.16 & -0.18 & 0.45 & 0.22 & -0.06 & 0.29\end{array}$ User, $01(A, 0,5)-0.14-0.00-0.14-0.18-0.20-0.23-0.28-0.17-0.25-0.12-0.20-0.18-0.27-0.18-0.15-0.17-0.33-0.17-0.17-0.31-0.15$ $\begin{array}{lllllllllllllllllllllll}\text { User, } 02(A, 0,5) & 0.45 & -0.14 & 0.62 & 0.19 & 0.33 & -0.12 & -0.25 & 0.23 & 0.08 & 0.31 & 0.13 & 0.16 & -0.18 & 0.29 & 0.22 & 0.09 & -0.20 & 0.29 & 0.17 & -0.06 & 0.18\end{array}$

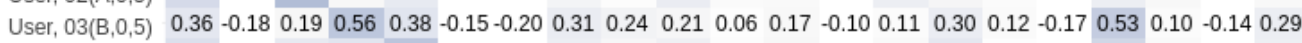
$\begin{array}{lllllllllllllllllllllll}\text { User, } 04(B, 0,5) & 0.42 & -0.20 & 0.33 & 0.38 & 0.57 & -0.16 & -0.22 & 0.29 & 0.21 & 0.27 & 0.07 & 0.20 & -0.15 & 0.16 & 0.35 & 0.06 & -0.25 & 0.47 & 0.16 & -0.09 & 0.28\end{array}$ User, $05(A, 0,10)-0.13-0.23-0.12-0.15-0.16-0.00-0.32-0.11-0.23-0.11-0.24-0.20-0.19-0.15-0.18-0.15-0.26-0.15-0.16-0.24-0.18$ User, $06(A, 0,10)-0.23-0.28-0.25-0.20-0.22-0.32-0.33-0.20-0.21-0.21-0.25-0.26-0.17-0.22-0.27-0.19-0.22-0.22-0.23-0.21-0.22$ $\begin{array}{lllllllllllllllllllllll}\text { User, } 07(B, 0,10) & 0.35 & -0.17 & 0.23 & 0.31 & 0.29 & -0.11 & -0.20 & 0.63 & 0.05 & 0.30 & 0.02 & 0.19 & -0.06 & 0.14 & 0.21 & 0.11 & -0.24 & 0.33 & 0.12 & -0.17 & 0.16\end{array}$

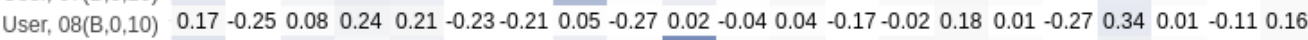

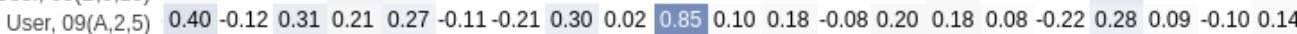

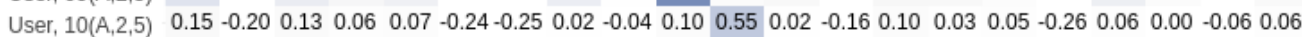
$\begin{array}{llllllllllllllllllllllll}\text { User, } 11(B, 2,5) & 0.18 & -0.18 & 0.16 & 0.17 & 0.20 & -0.20 & -0.26 & 0.19 & 0.04 & 0.18 & 0.02 & 0.47 & -0.11 & 0.05 & 0.17 & 0.04 & -0.21 & 0.20 & 0.04 & -0.11 & 0.09\end{array}$ User, 12(A, 2,10) $-0.11-0.27-0.18-0.10-0.15-0.19-0.17-0.06-0.17-0.08-0.16-0.110 .05-0.20-0.13-0.15-0.30-0.13-0.24-0.28-0.20$

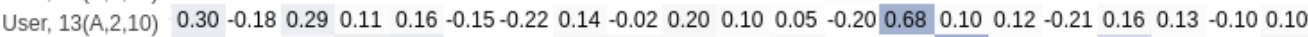
$\begin{array}{llllllllllllllllllllll}\text { User, } 14(B, 2,10) & 0.32 & -0.15 & 0.22 & 0.30 & 0.35 & -0.18 & -0.27 & 0.21 & 0.18 & 0.18 & 0.03 & 0.17 & -0.13 & 0.10 & 0.69 & 0.09 & -0.21 & 0.45 & 0.09 & -0.12 & 0.23\end{array}$

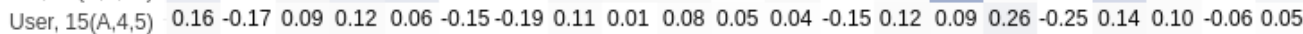
User, $16(A, 4,5)-0.18-0.33-0.20-0.17-0.25-0.26-0.22-0.24-0.27-0.22-0.26-0.21-0.30-0.21-0.21-0.250 .10-0.18-0.20-0.35-0.27$ $\begin{array}{llllllllllllllllllllllll}\text { User, } 17(B, 4,5) & 0.45 & -0.17 & 0.29 & 0.53 & 0.47 & -0.15 & -0.22 & 0.33 & 0.34 & 0.28 & 0.06 & 0.20 & -0.13 & 0.16 & 0.45 & 0.14 & -0.18 & 0.88 & 0.15 & -0.10 & 0.33\end{array}$

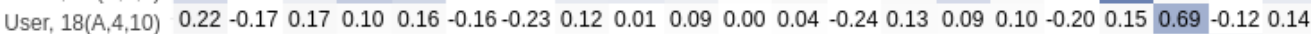
User, $19(A, 4,10)-0.06-0.31-0.06-0.14-0.09-0.24-0.21-0.17-0.11-0.10-0.06-0.11-0.28-0.10-0.12-0.06-0.35-0.10-0.12-0.31-0.15$

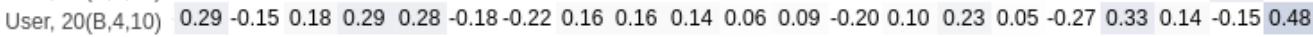

Figura D.7: Experimento de anotação, concordância com relações

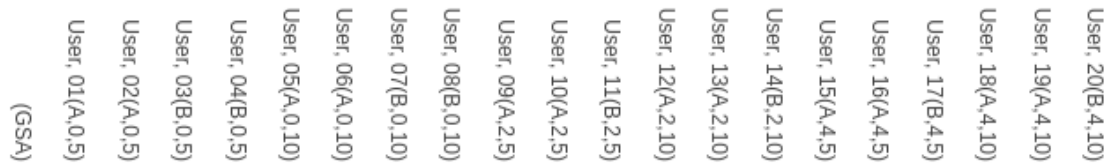

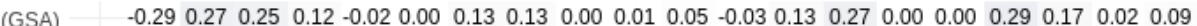
User, 01 ( $A, 0,5)-0.290 .31-0.32-0.39-0.40-0.390 .00-0.38-0.37 \quad 0.00-0.40-0.38-0.08-0.39-0.300 .000 .00-0.38-0.38-0.20-0.33$ $\begin{array}{lllllllllllllllllllllll}\text { User, } 02(A, 0,5) & 0.27 & -0.32 & 0.75 & 0.11 & 0.12 & 0.00 & 0.00 & 0.12 & 0.04 & 0.00 & 0.05 & 0.03 & -0.04 & 0.17 & 0.15 & 0.00 & 0.00 & 0.14 & 0.12 & 0.03 & 0.04\end{array}$ $\begin{array}{llllllllllllllllllllllllll}\text { User, } 03(B, 0,5) & 0.25 & -0.39 & 0.11 & 0.40 & 0.16 & -0.24 & 0.00 & -0.01 & 0.09 & 0.00 & -0.08 & -0.11 & -0.07 & 0.03 & 0.16 & 0.00 & 0.00 & 0.22 & -0.04 & -0.01 & 0.08\end{array}$

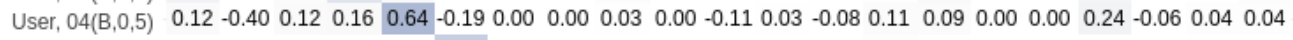
User, $05(A, 0,10)-0.02-0.390 .00-0.24-0.190 .52 \quad 0.00-0.09-0.25 \quad 0.00-0.23-0.14-0.120 .06-0.08 \quad 0.00 \quad 0.00 \quad-0.16-0.07-0.11-0.24$

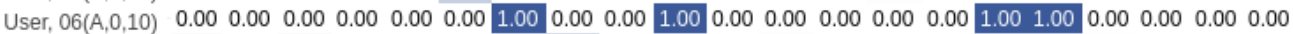

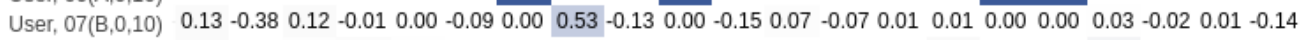

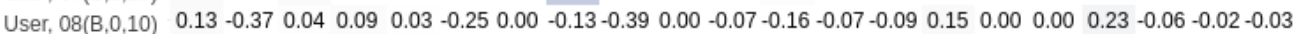
$\begin{array}{lllllllllllllllllllllllll}\text { User, } 09(A, 2,5) & 0.00 & 0.00 & 0.00 & 0.00 & 0.00 & 0.00 & 1.00 & 0.00 & 0.00 & 1.00 & 0.00 & 0.00 & 0.00 & 0.00 & 0.00 & 1.00 & 1.00 & 0.00 & 0.00 & 0.00 & 0.00\end{array}$ User, $10(A, 2,5) \quad 0.01-0.400 .05-0.08-0.11-0.23 \quad 0.00-0.15-0.07 \quad 0.00 \quad 0.66-0.17-0.04-0.11-0.03 \quad 0.00 \quad 0.00-0.11-0.190 .01-0.18$ $\begin{array}{lllllllllllllllllllllll}\text { User, 11(B, 2.5) } & 0.05 & -0.38 & 0.03 & -0.11 & 0.03 & -0.14 & 0.00 & 0.07 & -0.16 & 0.00 & -0.17 & 0.36 & -0.06 & -0.07 & 0.05 & 0.00 & 0.00 & 0.01 & -0.10 & 0.00 & -0.06\end{array}$ User, 12(A,2,10) $-0.03-0.08-0.04-0.07-0.08-0.120 .00-0.07-0.07 \quad 0.00-0.04-0.06 \quad 1.00-0.07-0.03 \quad 0.00 \quad 0.00-0.06-0.07-0.30-0.05$

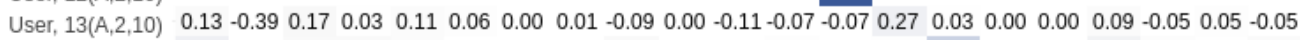

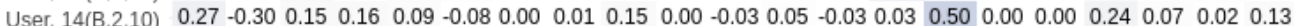

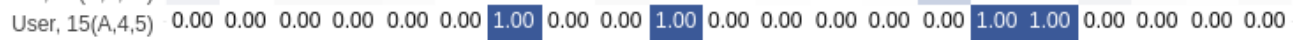
$\begin{array}{lllllllllllllllllllllllll}\text { User, } 16(A, 4,5) & 0.00 & 0.00 & 0.00 & 0.00 & 0.00 & 0.00 & 1.00 & 0.00 & 0.00 & 1.00 & 0.00 & 0.00 & 0.00 & 0.00 & 0.00 & 1.00 & 1.00 & 0.00 & 0.00 & 0.00 & 0.00\end{array}$ $\begin{array}{llllllllllllllllllllll}\text { User, 17(B, 4,5) } & 0.29 & -0.38 & 0.14 & 0.22 & 0.24 & -0.16 & 0.00 & 0.03 & 0.23 & 0.00 & -0.11 & 0.01 & -0.06 & 0.09 & 0.24 & 0.00 & 0.00 & 0.76 & 0.09 & 0.03 & 0.08\end{array}$

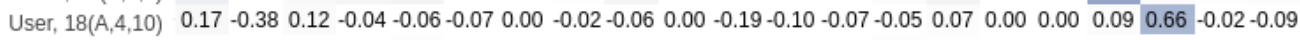

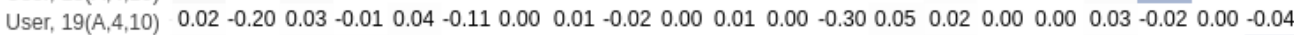

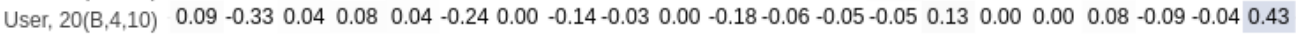

Figura D.8: Experimento de anotação, concordância com conectores 


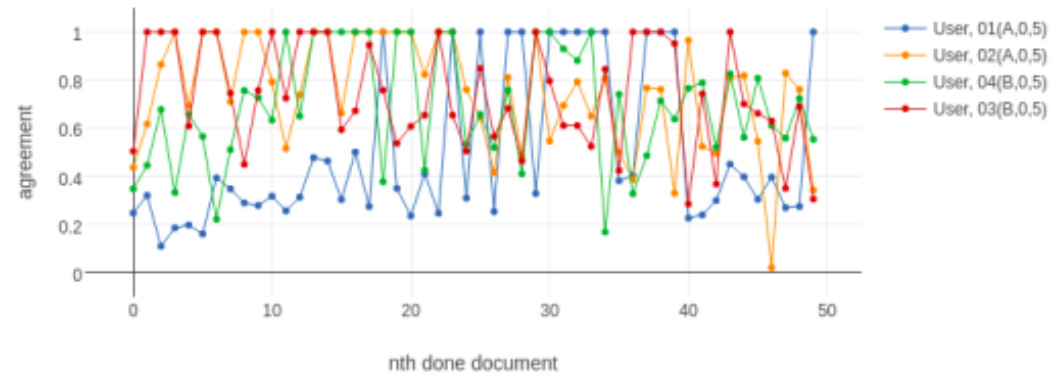

(a)

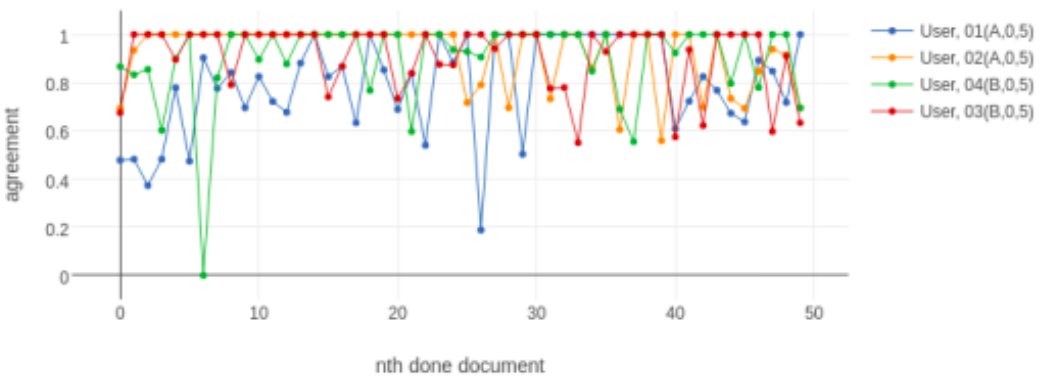

(b)

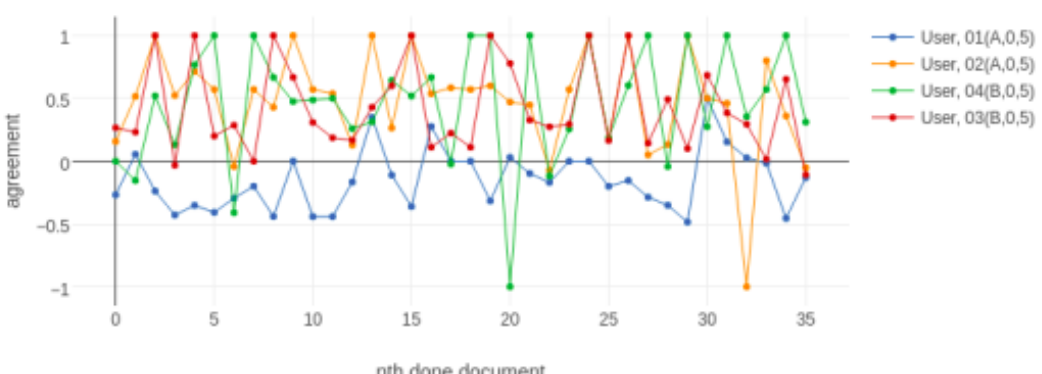

(c)

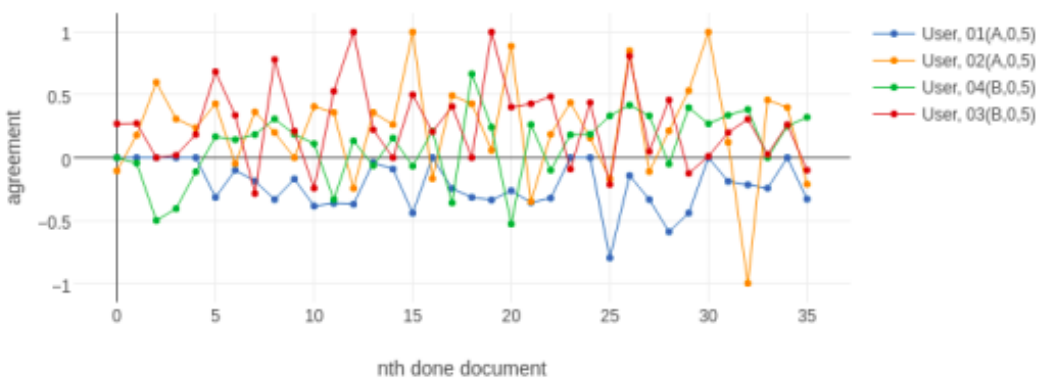

(d)

Figura D.9: Experimento de anotação, concordância com GSA ao longo do tempo do grupo $(0,5)$ : (a) entidades, relações e conectores; (b) entidades; (c) relações; (d) conectores 


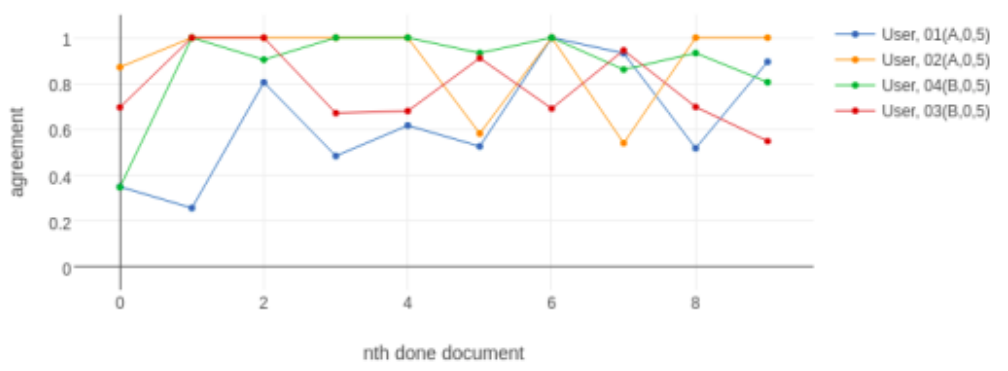

(a)

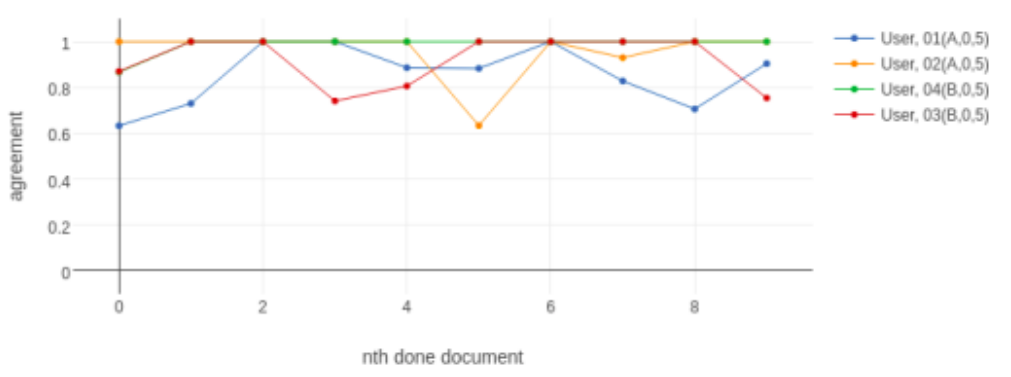

(b)

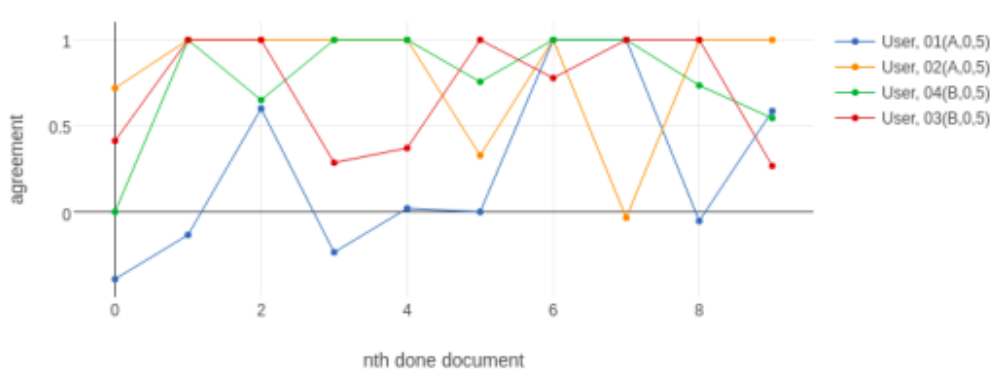

(c)

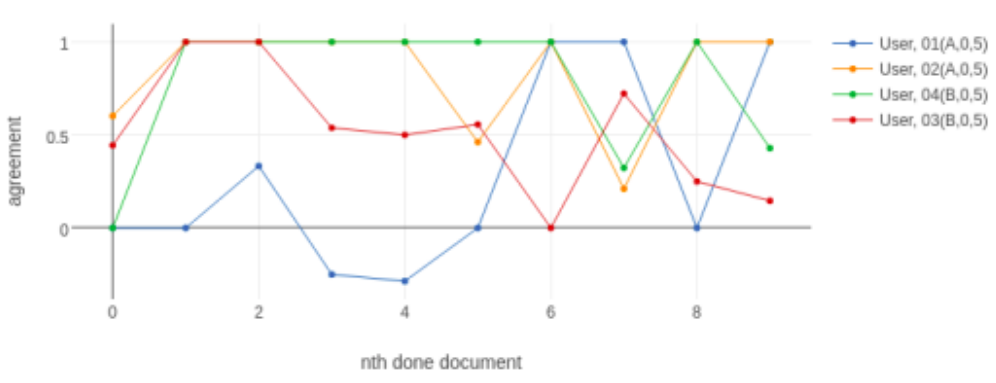

(d)

Figura D.10: Experimento de anotação, auto-concordância ao longo do tempo do grupo $(0,5)$ : (a) entidades, relações e conectores; (b) entidades; (c) relações; (d) conectores 


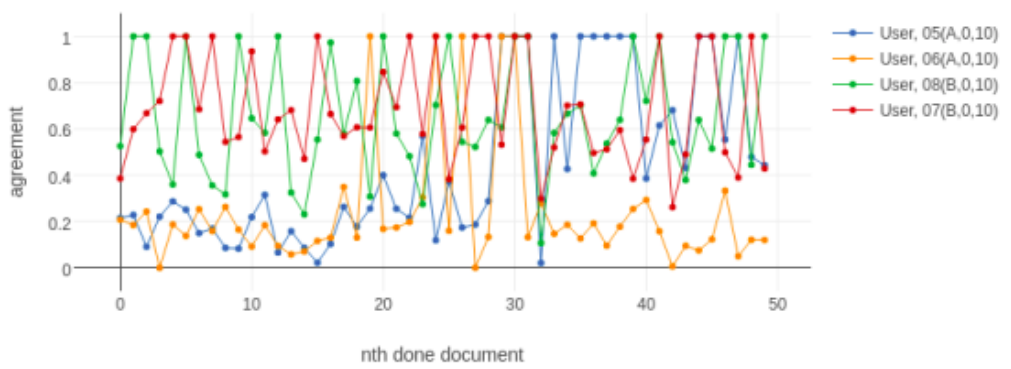

(a)

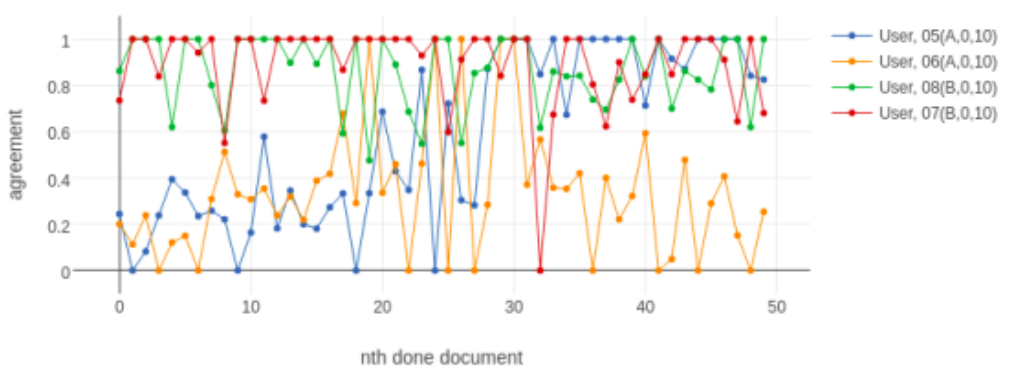

(b)

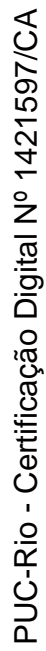

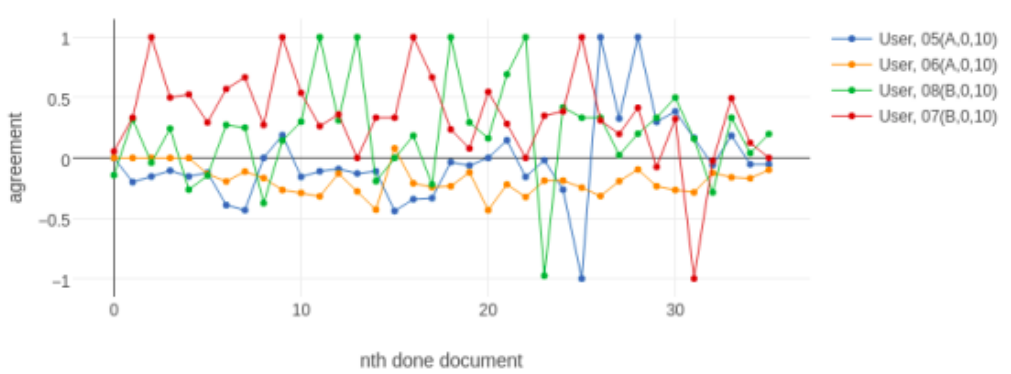

(c)

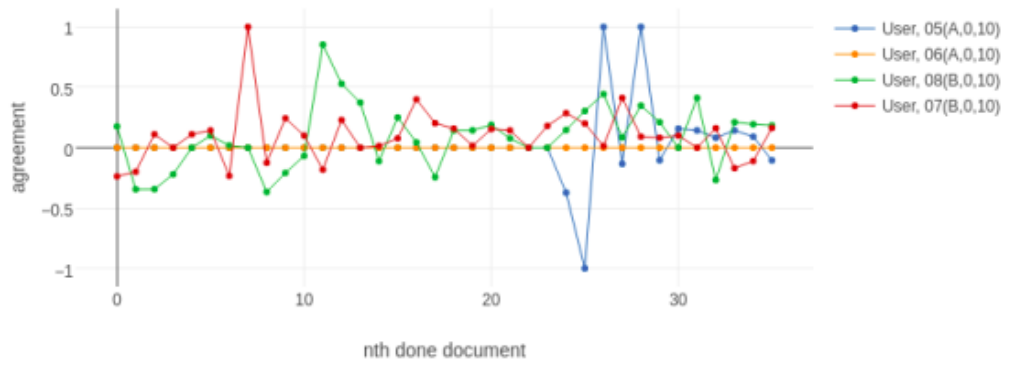

(d)

Figura D.11: Experimento de anotação, concordância com GSA ao longo do tempo do grupo $(0,10)$ : (a) entidades, relações e conectores; (b) entidades; (c) relações; (d) conectores 


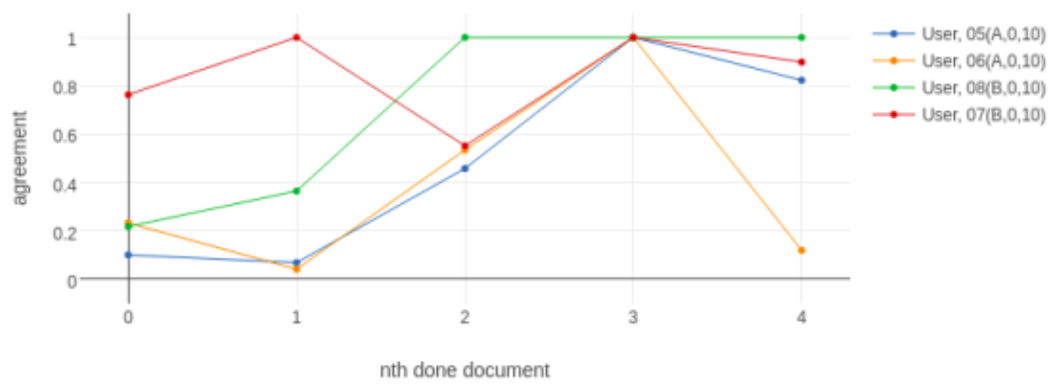

(a)

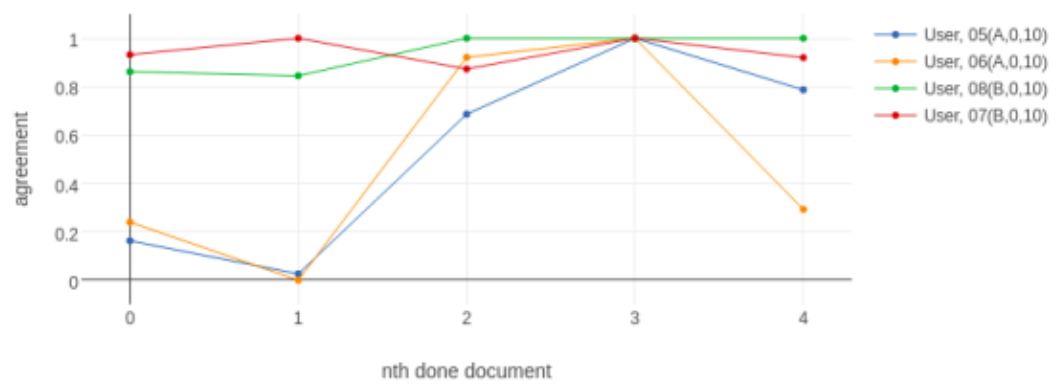

(b)

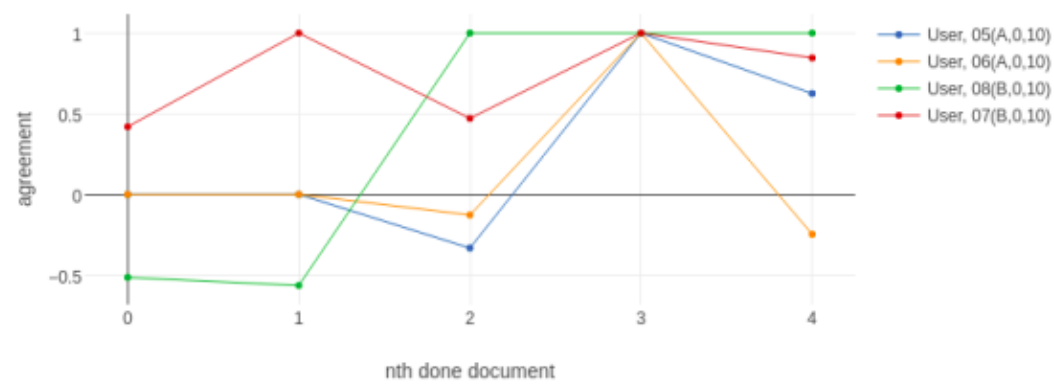

(c)

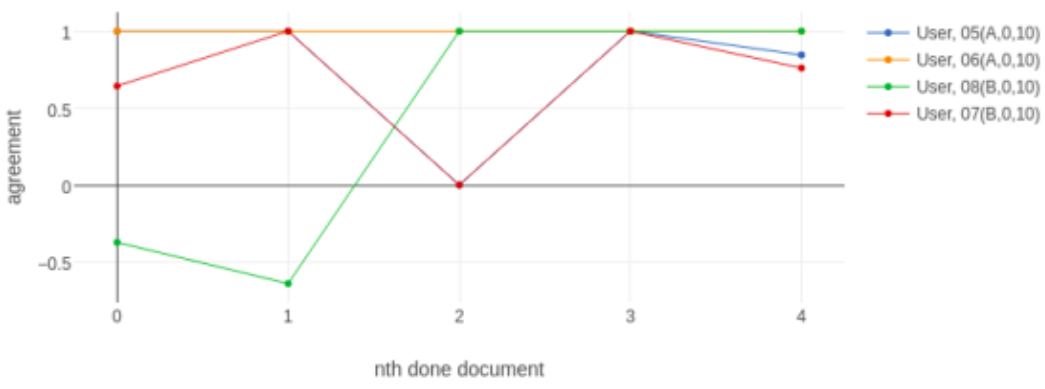

(d)

Figura D.12: Experimento de anotação, auto-concordância ao longo do tempo do grupo $(0,10)$ : (a) entidades, relações e conectores; (b) entidades; (c) relações; (d) conectores 


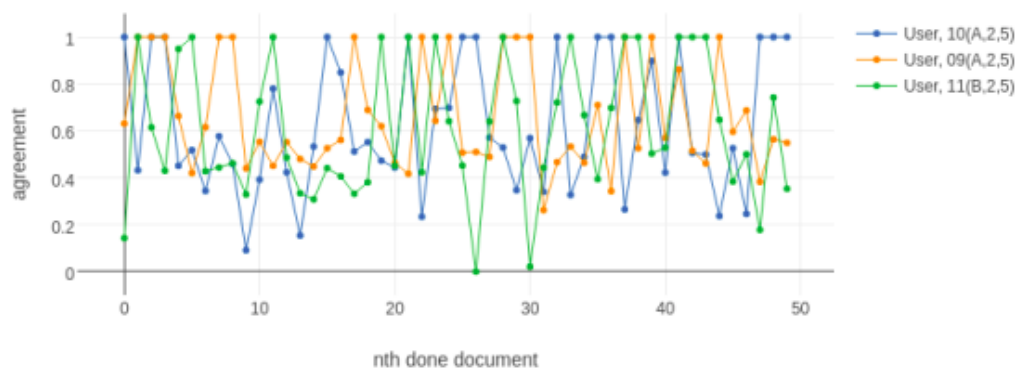

(a)

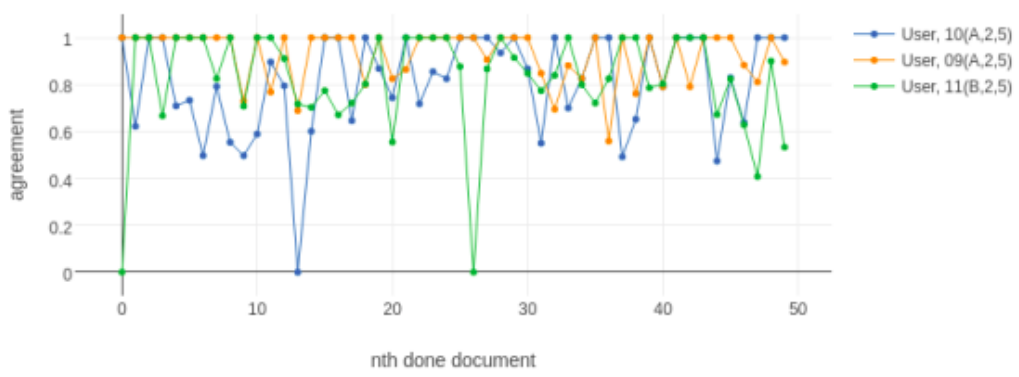

(b)

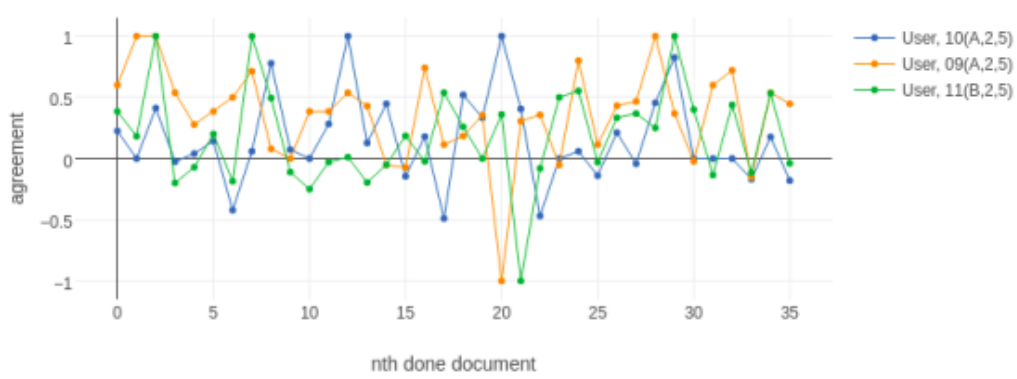

(c)

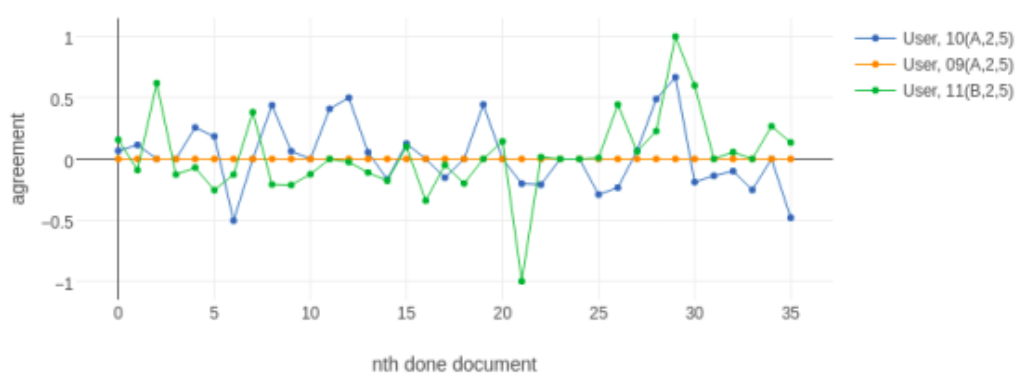

(d)

Figura D.13: Experimento de anotação, concordância com GSA ao longo do tempo do grupo $(2,5)$ : (a) entidades, relações e conectores; (b) entidades; (c) relações; (d) conectores 


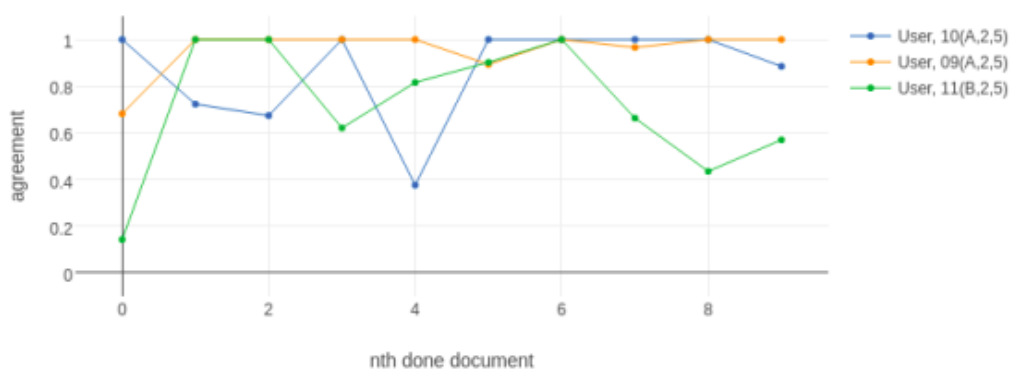

(a)

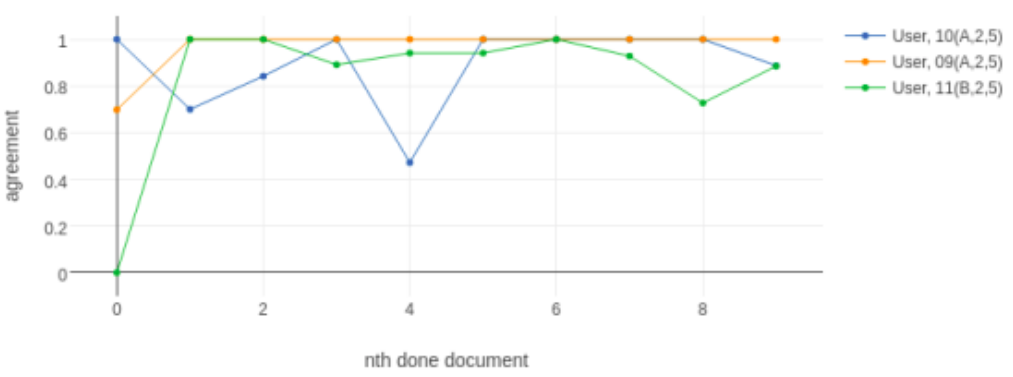

(b)

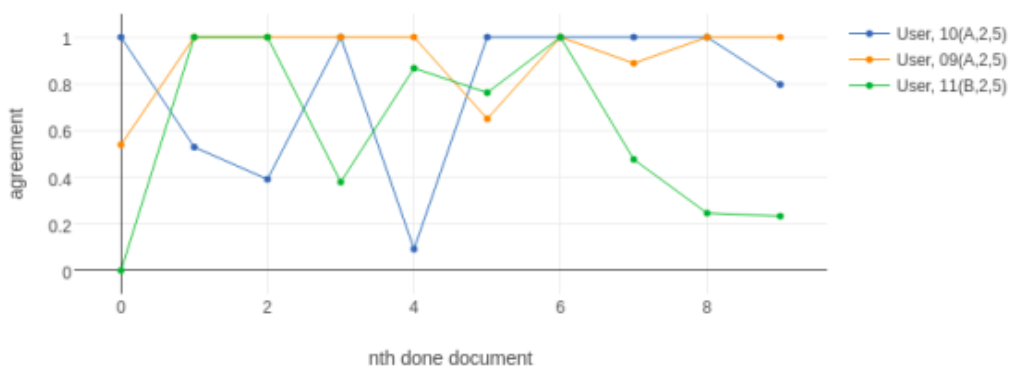

(c)

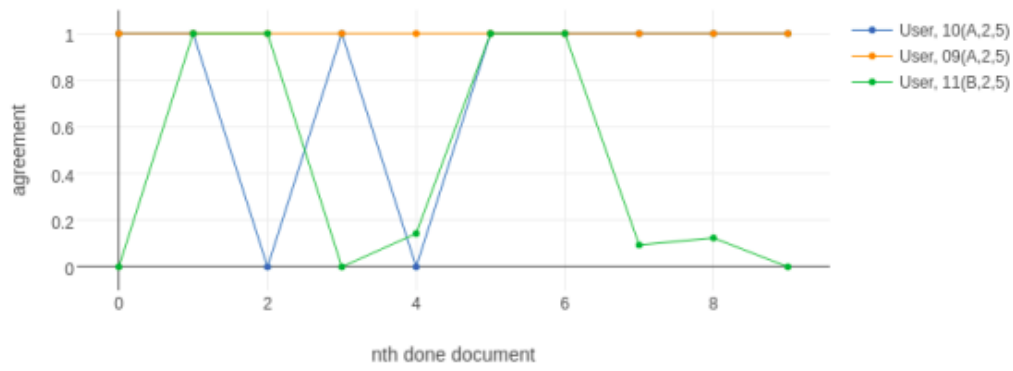

(d)

Figura D.14: Experimento de anotação, auto-concordância ao longo do tempo do grupo (2,5): (a) entidades, relações e conectores; (b) entidades; (c) relações; (d) conectores 


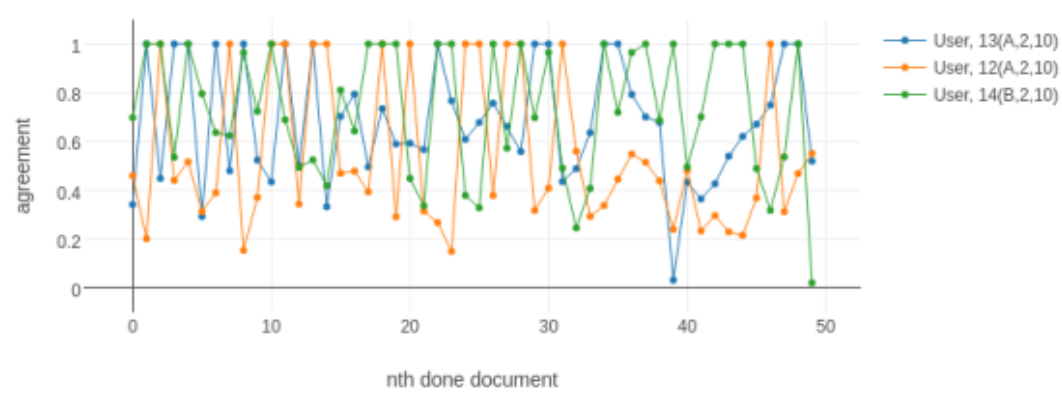

(a)

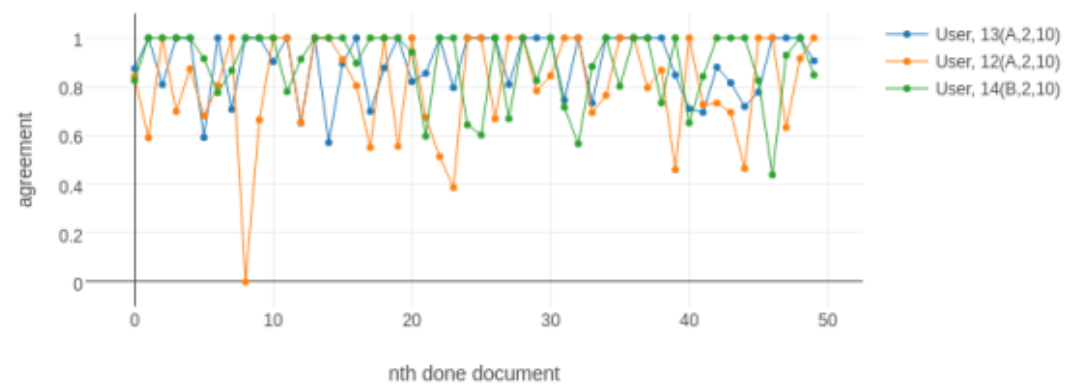

(b)

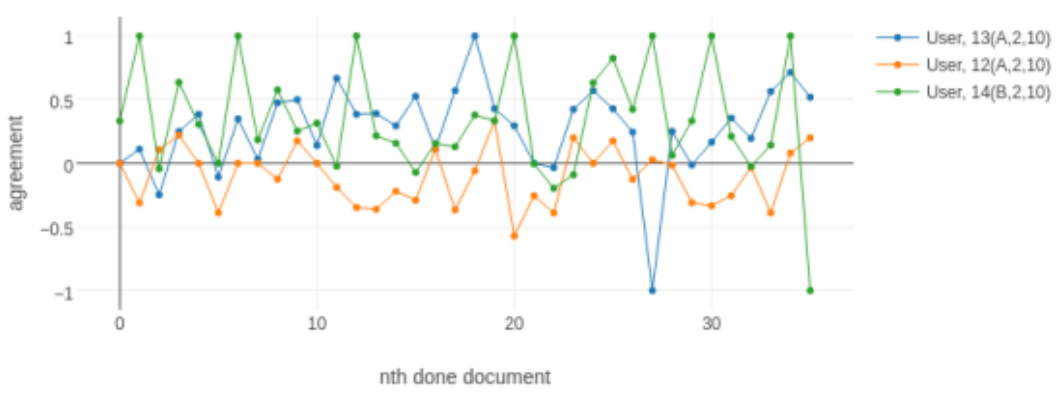

(c)

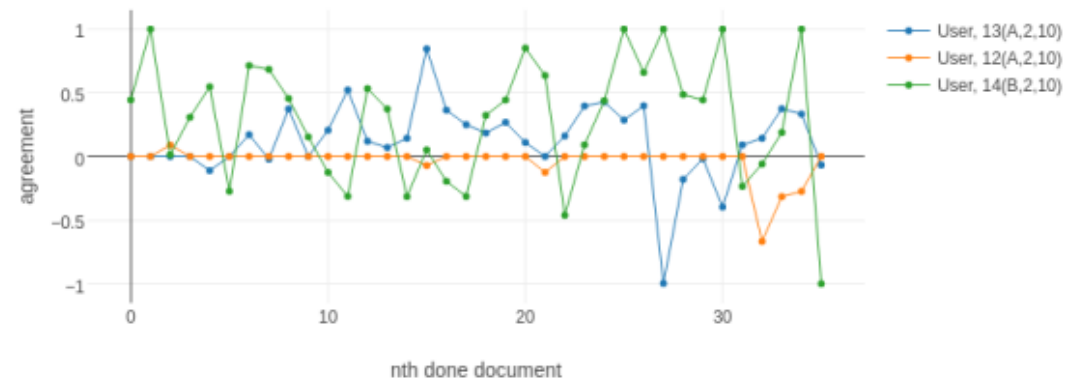

(d)

Figura D.15: Experimento de anotação, concordância com GSA ao longo do tempo do grupo (2,10): (a) entidades, relações e conectores; (b) entidades; (c) relações; (d) conectores 


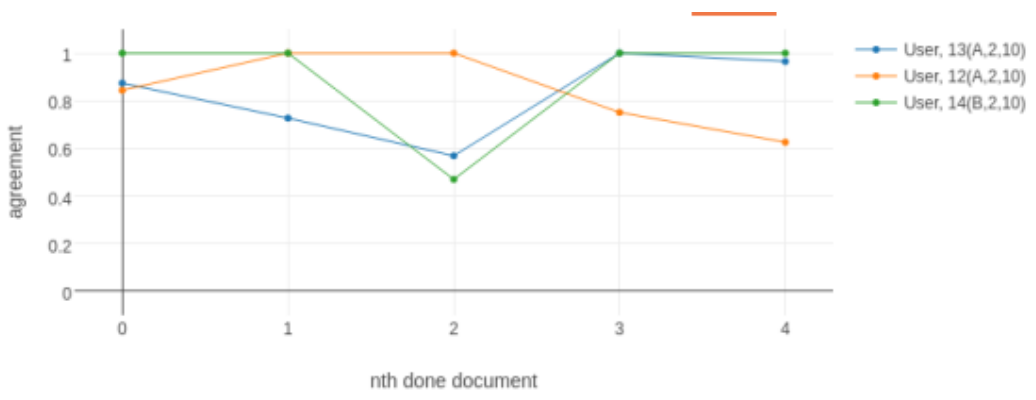

(a)

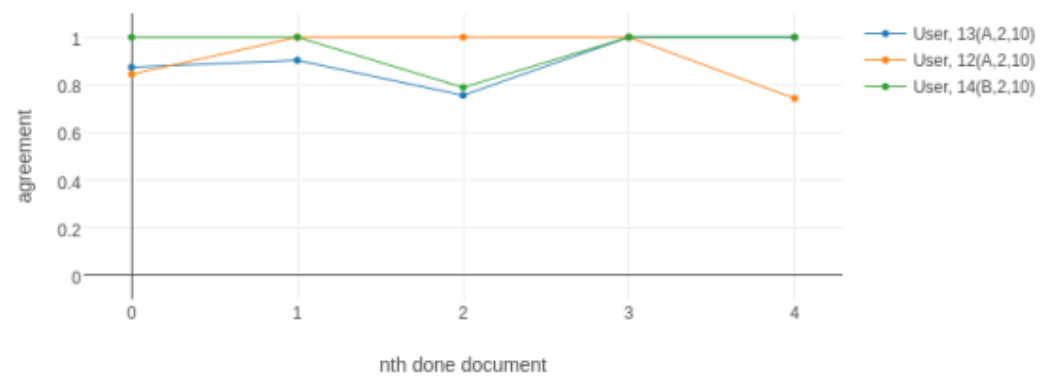

(b)

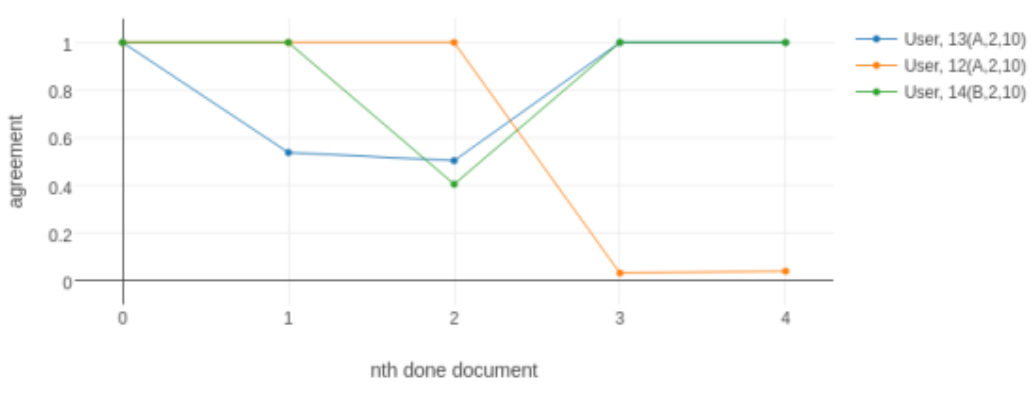

(c)

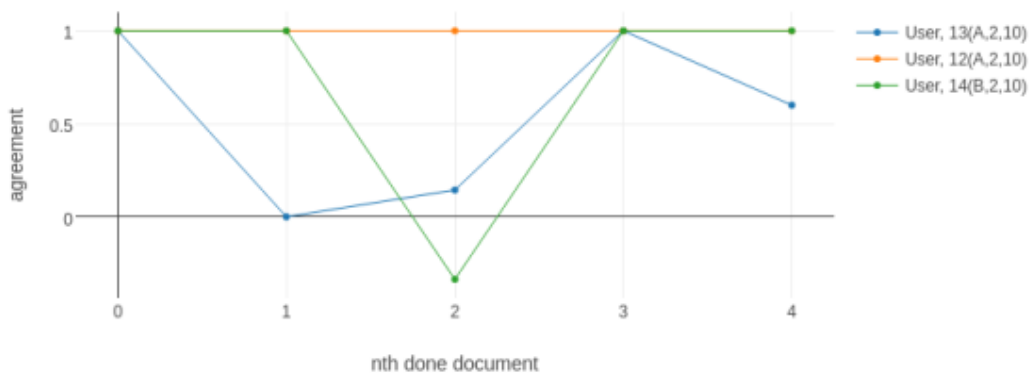

(d)

Figura D.16: Experimento de anotação, auto-concordância ao longo do tempo do grupo (2,10): (a) entidades, relações e conectores; (b) entidades; (c) relações; (d) conectores 


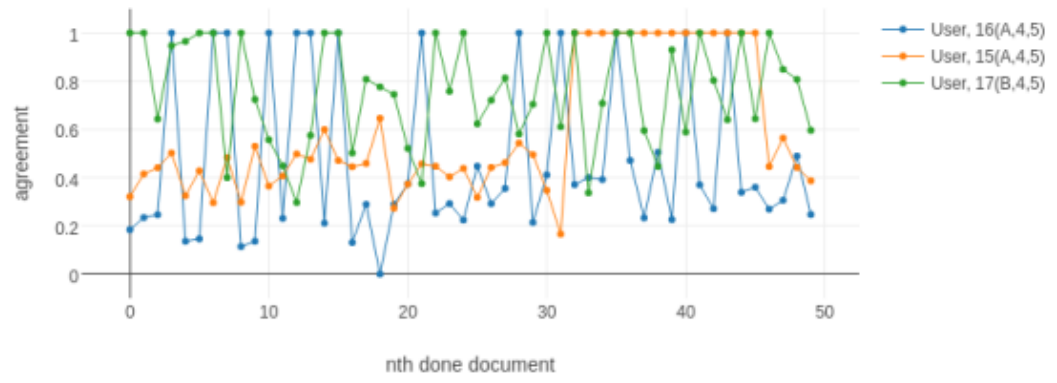

(a)

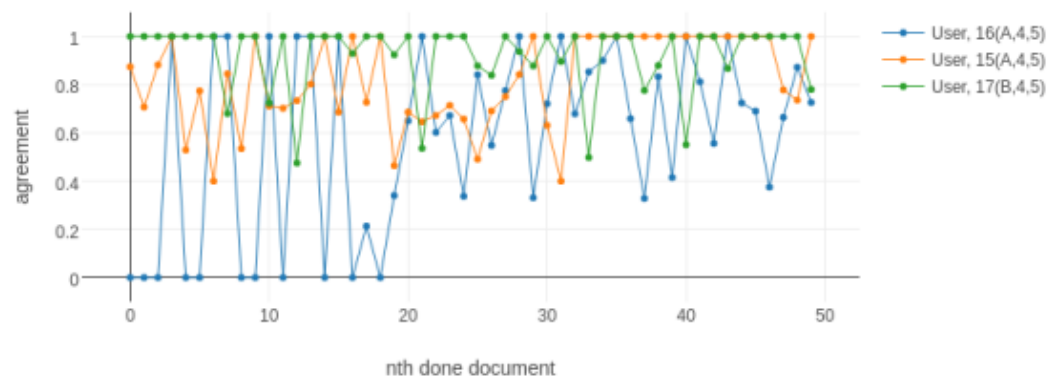

(b)

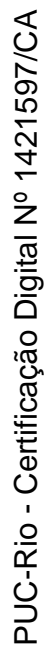

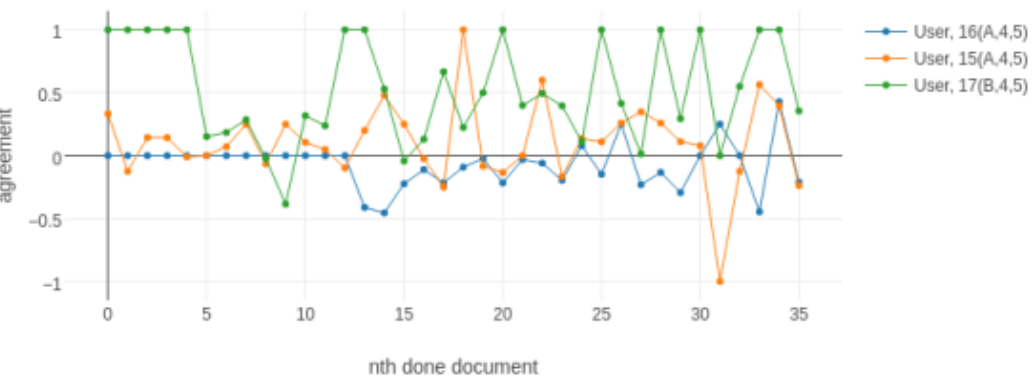

(c)

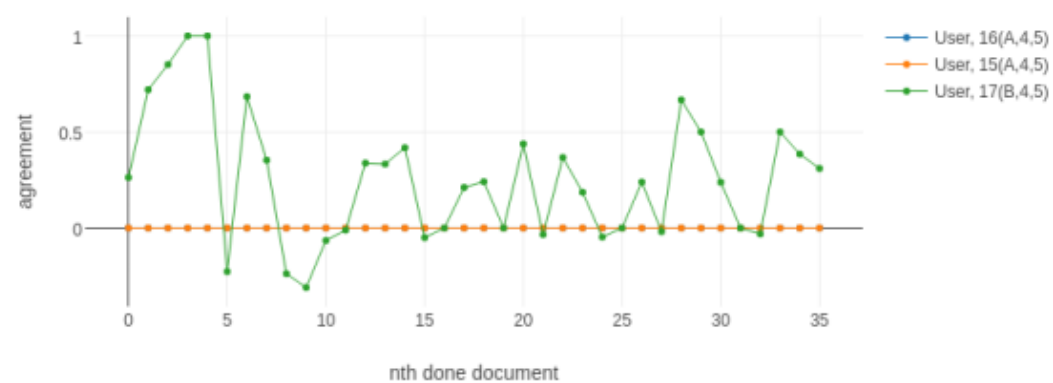

(d)

Figura D.17: Experimento de anotação, concordância com GSA ao longo do tempo do grupo $(4,5)$ : (a) entidades, relações e conectores; (b) entidades; (c) relações; (d) conectores 


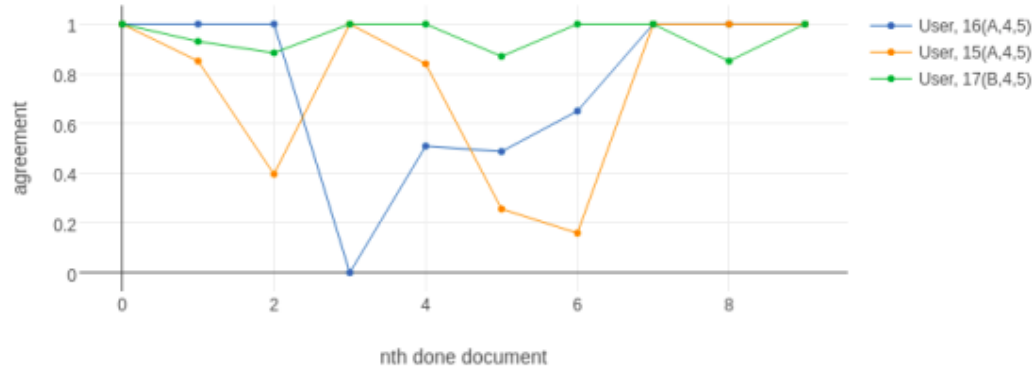

(a)

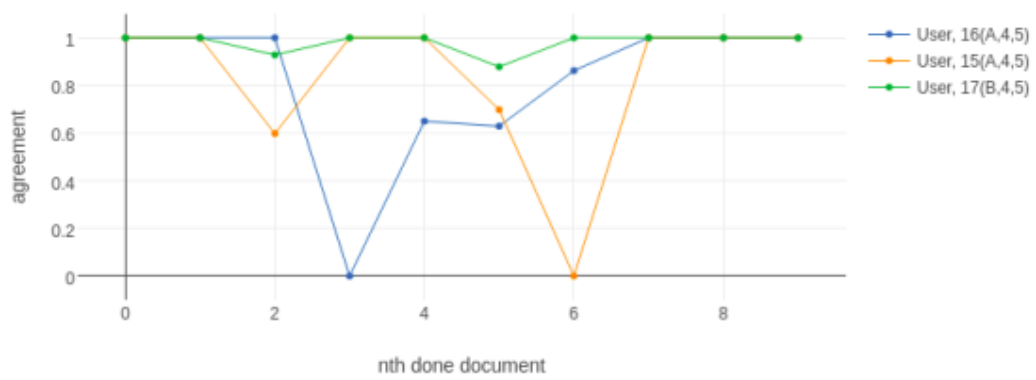

(b)

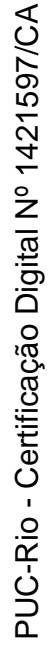

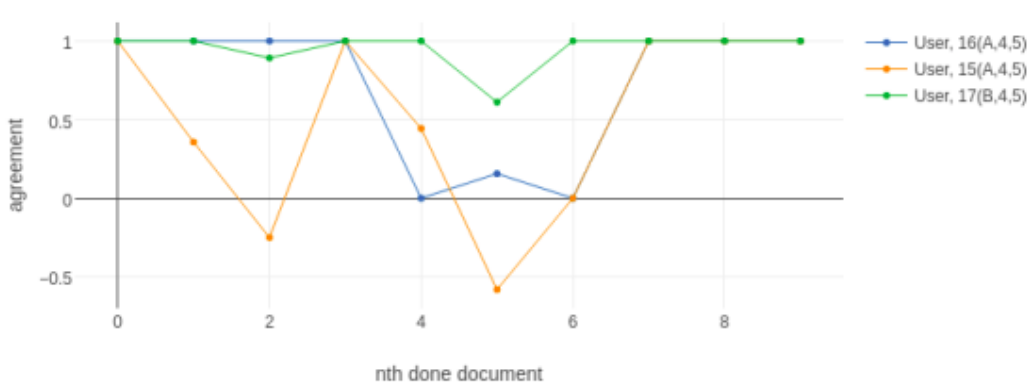

(c)

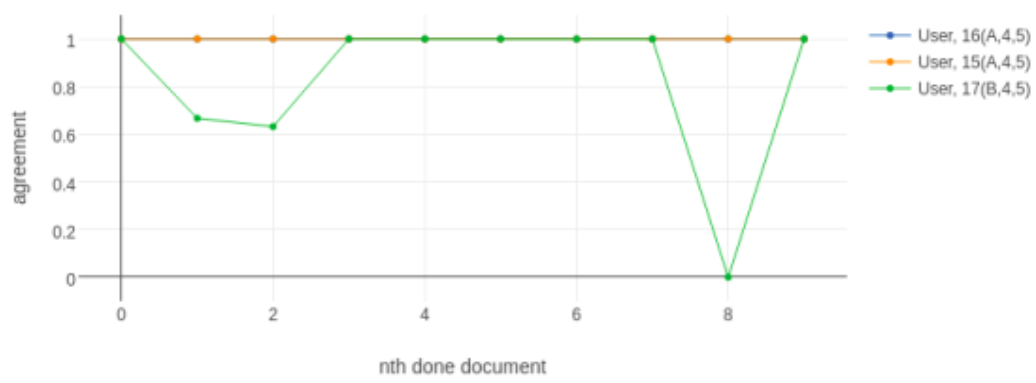

(d)

Figura D.18: Experimento de anotação, auto-concordância ao longo do tempo do grupo $(4,5)$ : (a) entidades, relações e conectores; (b) entidades; (c) relações; (d) conectores 


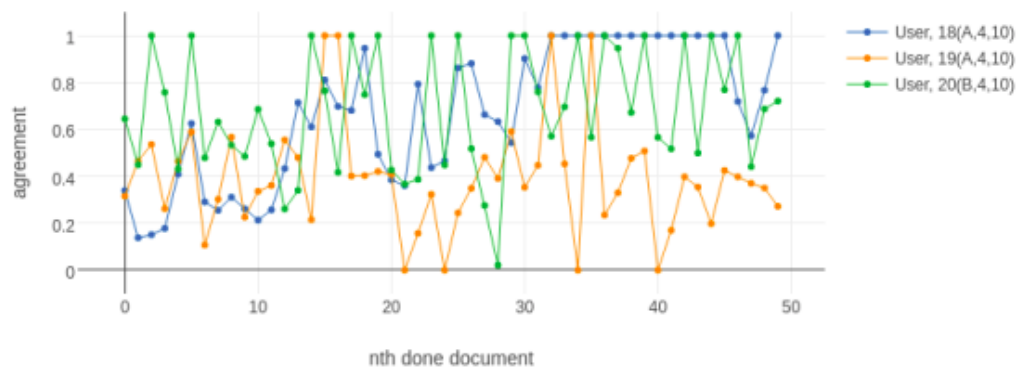

(a)

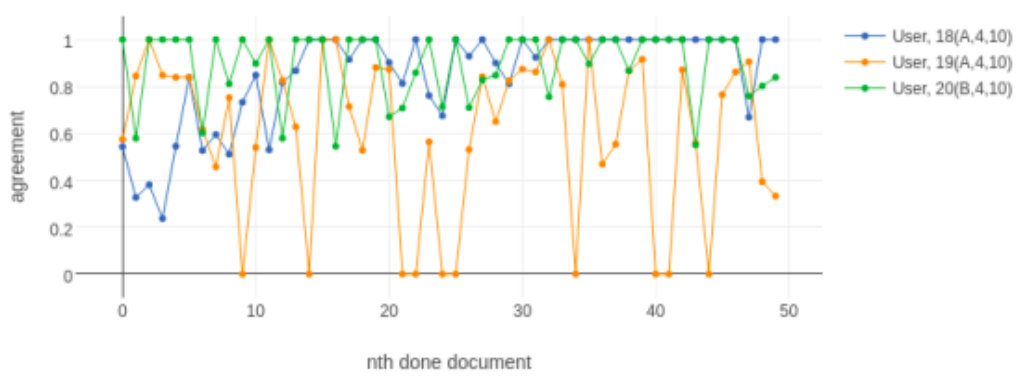

(b)

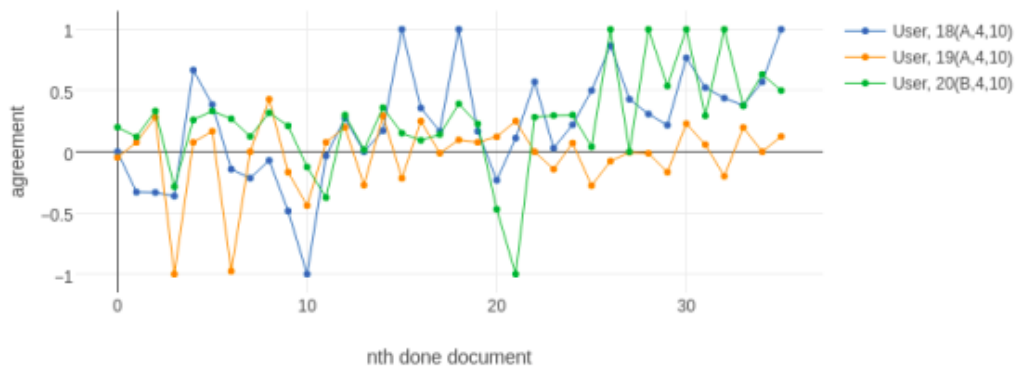

(c)

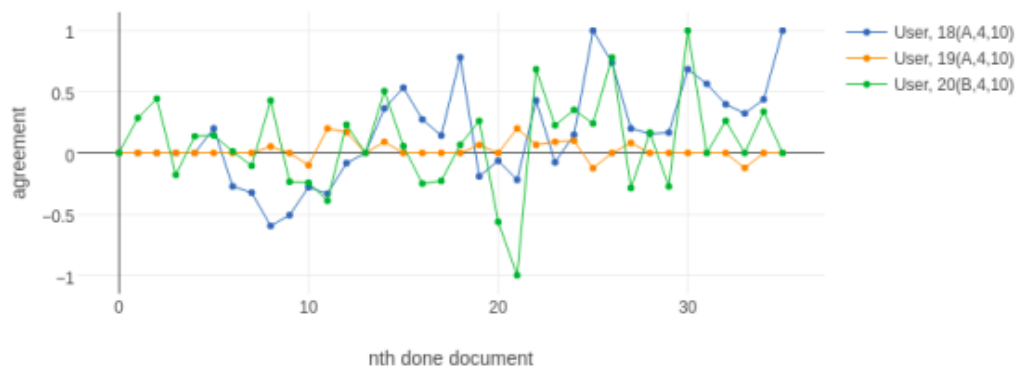

(d)

Figura D.19: Experimento de anotação, concordância com GSA ao longo do tempo do grupo $(4,10)$ : (a) entidades, relações e conectores; (b) entidades; (c) relações; (d) conectores 


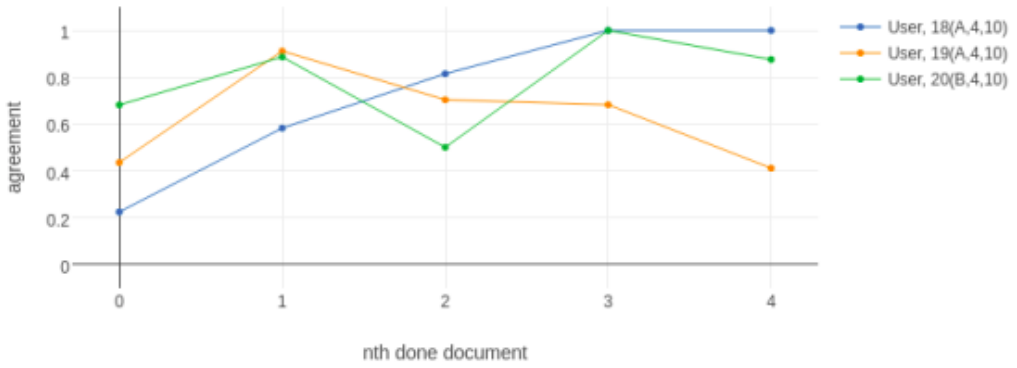

(a)

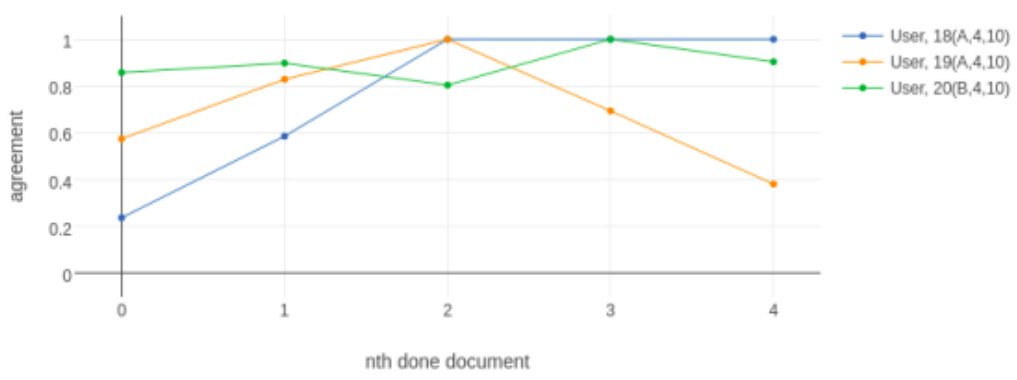

(b)

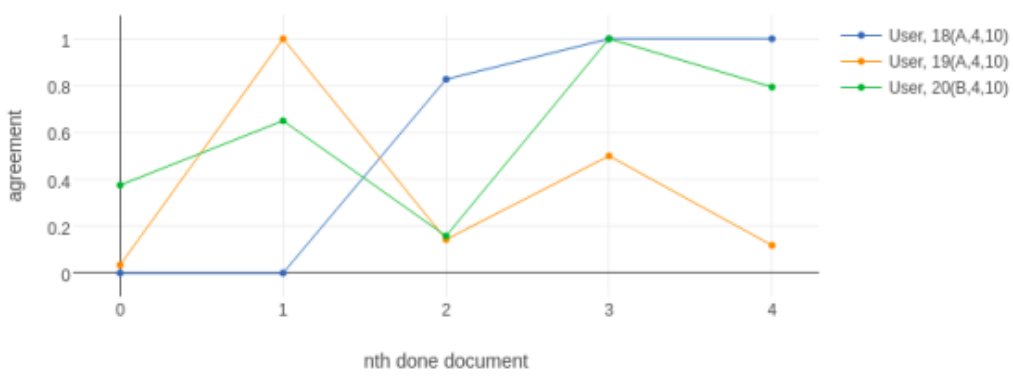

(c)

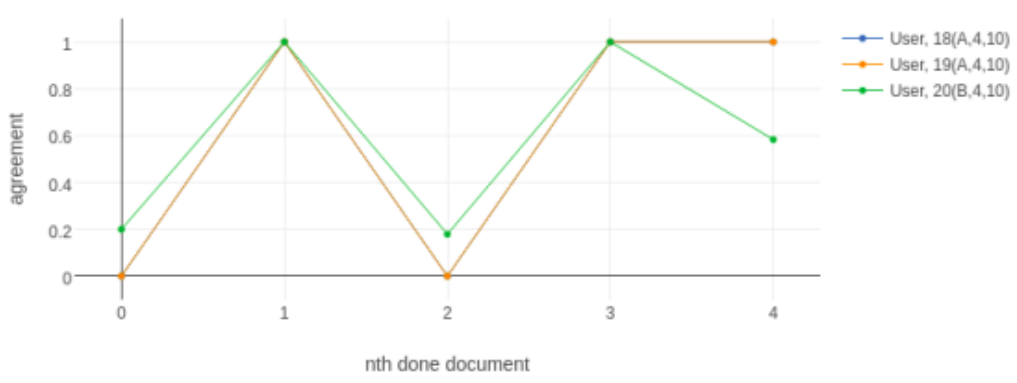

(d)

Figura D.20: Experimento de anotação, auto-concordância ao longo do tempo do grupo (4,10): (a) entidades, relações e conectores; (b) entidades; (c) relações; (d) conectores 
E

\section{Experimento de aprendizado automático: Tabelas e gráficos}

Este apêndice contém gráficos e tabelas com informações adicionais sobre o experimento de aprendizado automático descrito no capítulo 4 desta dissertação.

Tabela E.1: Training scores: model-fscore-TEDO-NER-RF-0

\begin{tabular}{|c|c|c|c|c|c|}
\hline Class & Support & Accuracy, $\sigma \mathbf{C V}$ & Recall, $\sigma \mathbf{C V}$ & Precision, $\sigma \mathbf{C V}$ & $\mathbf{F} 1, \sigma \mathbf{C V}$ \\
\hline $\mathrm{O}$ & 5262 & $0.925,0.018$ & $0.978,0.011$ & $0.912,0.019$ & $0.944,0.014$ \\
\hline B-\#Accident & 114 & $0.996,0.002$ & $0.795,0.162$ & $0.921,0.096$ & $0.843,0.119$ \\
\hline B-\#BadTrafficSituation & 273 & $0.991,0.005$ & $0.863,0.093$ & $0.868,0.097$ & $0.863,0.084$ \\
\hline B-\#Breakdown & 14 & $0.999,0.000$ & $0.531,0.440$ & $0.625,0.484$ & $0.565,0.450$ \\
\hline B-\#Bus & 31 & $0.997,0.001$ & $0.646,0.313$ & $0.777,0.323$ & $0.693,0.306$ \\
\hline B-\#Car & 103 & $0.997,0.002$ & $0.798,0.284$ & $0.826,0.288$ & $0.810,0.284$ \\
\hline B-\#Event & 32 & $0.995,0.001$ & $0.138,0.314$ & $0.125,0.259$ & $0.130,0.282$ \\
\hline B-\#GoodTrafficSituation & 29 & $0.996,0.002$ & $0.178,0.299$ & $0.350,0.450$ & $0.213,0.312$ \\
\hline B-\#Interdiction & 141 & $0.994,0.003$ & $0.631,0.238$ & $0.853,0.290$ & $0.720,0.255$ \\
\hline B-\#Location & 1270 & $0.956,0.011$ & $0.859,0.083$ & $0.856,0.054$ & $0.854,0.054$ \\
\hline B-\#Motorcycle & 18 & $0.998,0.001$ & $0.799,0.258$ & $0.831,0.207$ & $0.800,0.218$ \\
\hline B-\#Protest & 16 & $0.993,0.002$ & $0.000,0.000$ & $0.000,0.000$ & $0.000,0.000$ \\
\hline B-\#PublicAuthority & 55 & $0.996,0.002$ & $0.311,0.327$ & $0.500,0.471$ & $0.366,0.355$ \\
\hline B-\#RoadWork & 31 & $0.998,0.001$ & $0.568,0.268$ & $0.873,0.311$ & $0.672,0.282$ \\
\hline B-\#Solution & 45 & $0.996,0.003$ & $0.580,0.270$ & $0.875,0.330$ & $0.687,0.282$ \\
\hline B-\#Time & 17 & $0.998,0.001$ & $0.428,0.494$ & $0.428,0.494$ & $0.428,0.494$ \\
\hline B-\#Truck & 24 & $0.997,0.002$ & $0.320,0.448$ & $0.380,0.468$ & $0.322,0.431$ \\
\hline B-\#wayEffect:BothDirections & 19 & $0.999,0.000$ & $0.583,0.478$ & $0.600,0.489$ & $0.590,0.483$ \\
\hline B-\#wayEffect:OneDirection & 3 & $0.998,0.000$ & $0.000,0.000$ & $0.000,0.000$ & $0.000,0.000$ \\
\hline B-\#wayEffect:Partially & 123 & $0.997,0.001$ & $0.741,0.263$ & $0.887,0.296$ & $0.805,0.273$ \\
\hline I-\#BadTrafficSituation & 85 & $0.997,0.002$ & $0.867,0.132$ & $0.925,0.065$ & $0.891,0.090$ \\
\hline I-\#Event & 8 & $0.998,0.000$ & $0.300,0.400$ & $0.333,0.421$ & $0.314,0.408$ \\
\hline I-\#GoodTrafficSituation & 28 & $0.997,0.002$ & $0.300,0.378$ & $0.500,0.500$ & $0.350,0.390$ \\
\hline I-\#Location & 306 & $0.974,0.014$ & $0.399,0.239$ & $0.741,0.277$ & $0.500,0.247$ \\
\hline I-\#Protest & 2 & $0.998,0.000$ & $0.500,0.000$ & $1.000,0.000$ & $0.666,0.000$ \\
\hline I-\#PublicAuthority & 9 & $0.997,0.001$ & $0.576,0.318$ & $0.809,0.269$ & $0.655,0.285$ \\
\hline I-\#Time & 8 & $0.995,0.001$ & $0.000,0.000$ & $0.000,0.000$ & $0.000,0.000$ \\
\hline I-\#wayEffect:BothDirections & 22 & $0.999,0.001$ & $0.700,0.400$ & $0.766,0.395$ & $0.723,0.391$ \\
\hline I-\#wayEffect:Partially & 2 & $0.998,0.000$ & $0.500,0.000$ & $1.000,0.000$ & $0.666,0.000$ \\
\hline & & $0.992,0.015$ & $.513,0.275$ & $0.640,0.309$ & $0.554,0.281$ \\
\hline
\end{tabular}


Tabela E.2: Revalidation scores: model-fscore-TEDO-NER-RF-0

\begin{tabular}{|c|c|c|c|c|c|}
\hline Class & Support & Accuracy & Recall & Precision & F1 \\
\hline $\mathrm{O}$ & 1195 & 0.940 & 0.986 & 0.923 & 0.954 \\
\hline B-\#Accident & 27 & 0.996 & 0.888 & 0.857 & 0.872 \\
\hline B-\#BadTrafficSituation & 66 & 0.990 & 0.909 & 0.845 & 0.875 \\
\hline B-\#Breakdown & 3 & 0.999 & 0.666 & 1.000 & 0.800 \\
\hline B-\#Bus & 8 & 0.997 & 0.625 & 0.833 & 0.714 \\
\hline B-\#Car & 23 & 0.998 & 0.869 & 1.000 & 0.930 \\
\hline B-\#Event & 5 & 0.996 & 0.000 & 0.000 & 0.000 \\
\hline B-\#GoodTrafficSituation & 16 & 0.994 & 0.312 & 1.000 & 0.476 \\
\hline B-\#Interdiction & 24 & 0.997 & 0.916 & 0.916 & 0.916 \\
\hline B-\#Location & 316 & 0.964 & 0.892 & 0.895 & 0.893 \\
\hline B-\#Motorcycle & 4 & 0.998 & 0.750 & 0.750 & 0.750 \\
\hline B-\#Protest & 1 & 0.999 & 0.000 & 0.000 & 0.000 \\
\hline B-\#PublicAuthority & 8 & 0.999 & 0.875 & 1.000 & 0.933 \\
\hline B-\#RoadWork & 1 & 1.000 & 1.000 & 1.000 & 1.000 \\
\hline B-\#Solution & 10 & 0.998 & 0.700 & 1.000 & 0.823 \\
\hline B-\#Time & 3 & 1.000 & 1.000 & 1.000 & 1.000 \\
\hline B-\#Truck & 6 & 0.996 & 0.166 & 0.333 & 0.222 \\
\hline B-\#wayEffect:BothDirections & 11 & 0.999 & 0.909 & 1.000 & 0.952 \\
\hline B-\#wayEffect:OneDirection & 1 & 0.999 & 0.000 & 0.000 & 0.000 \\
\hline B-\#wayEffect:Partially & 23 & 0.999 & 0.956 & 1.000 & 0.977 \\
\hline I-\#BadTrafficSituation & 20 & 0.999 & 0.950 & 1.000 & 0.974 \\
\hline I-\#GoodTrafficSituation & 15 & 0.996 & 0.000 & 0.000 & 0.000 \\
\hline I-\#Location & 90 & 0.969 & 0.600 & 1.000 & 0.749 \\
\hline I-\#wayEffect:BothDirections & 12 & 0.998 & 0.422 & 0.883 & 0.571 \\
\hline
\end{tabular}

Tabela E.3: Training scores: model-fscore-TEDO-NER-SGD-0

\begin{tabular}{|c|c|c|c|c|c|}
\hline Class & Support & Accuracy, $\sigma \mathbf{C V}$ & Recall, $\sigma \mathbf{C V}$ & Precision, $\sigma \mathbf{C V}$ & $\mathbf{F} 1, \sigma \mathbf{C V}$ \\
\hline $\mathrm{O}$ & 5262 & $0.923,0.022$ & $0.957,0.013$ & $0.928,0.033$ & $0.942,0.015$ \\
\hline B-\#Accident & 114 & $0.998,0.001$ & $0.888,0.070$ & $1.000,0.000$ & $0.939,0.039$ \\
\hline B-\#BadTrafficSituation & 273 & $0.991,0.003$ & $0.918,0.075$ & $0.858,0.091$ & $0.881,0.046$ \\
\hline B-\#Breakdown & 14 & $0.999,0.000$ & $0.687,0.428$ & $0.750,0.433$ & $0.708,0.422$ \\
\hline B-\#Bus & 31 & $0.998,0.001$ & $0.918,0.153$ & $0.902,0.184$ & $0.887,0.130$ \\
\hline B-\#Car & 103 & $0.998,0.001$ & $0.938,0.065$ & $0.983,0.032$ & $0.959,0.035$ \\
\hline B-\#Event & 32 & $0.996,0.001$ & $0.259,0.312$ & $0.412,0.405$ & $0.281,0.281$ \\
\hline B-\#GoodTrafficSituation & 29 & $0.996,0.002$ & $0.202,0.318$ & $0.310,0.406$ & $0.204,0.277$ \\
\hline B-\#Interdiction & 141 & $0.994,0.004$ & $0.837,0.160$ & $0.775,0.235$ & $0.788,0.174$ \\
\hline B-\#Location & 1270 & $0.950,0.013$ & $0.864,0.081$ & $0.840,0.073$ & $0.846,0.038$ \\
\hline B-\#Motorcycle & 18 & $0.999,0.000$ & $0.854,0.204$ & $0.934,0.124$ & $0.873,0.145$ \\
\hline B-\#Protest & 16 & $0.994,0.001$ & $0.327,0.061$ & $0.750,0.353$ & $0.419,0.117$ \\
\hline B-\#PublicAuthority & 55 & $0.996,0.002$ & $0.467,0.394$ & $0.592,0.465$ & $0.511,0.411$ \\
\hline B-\#RoadWork & 31 & $0.999,0.001$ & $0.698,0.361$ & $0.833,0.314$ & $0.728,0.317$ \\
\hline B-\#Solution & 45 & $0.997,0.001$ & $0.841,0.184$ & $0.925,0.139$ & $0.856,0.112$ \\
\hline B-\#Time & 17 & $0.997,0.001$ & $0.380,0.451$ & $0.309,0.382$ & $0.333,0.398$ \\
\hline B-\#Truck & 24 & $0.999,0.000$ & $0.760,0.388$ & $0.765,0.388$ & $0.760,0.384$ \\
\hline B-\#wayEffect:BothDirections & 19 & $0.999,0.001$ & $0.600,0.489$ & $0.525,0.453$ & $0.552,0.461$ \\
\hline B-\#wayEffect:OneDirection & 3 & $0.998,0.000$ & $0.000,0.000$ & $0.000,0.000$ & $0.000,0.000$ \\
\hline B-\#wayEffect:Partially & 123 & $0.996,0.001$ & $0.757,0.293$ & $0.851,0.290$ & $0.791,0.278$ \\
\hline I-\#BadTrafficSituation & 85 & $0.998,0.001$ & $0.779,0.284$ & $0.835,0.290$ & $0.800,0.279$ \\
\hline I-\#Event & 8 & $0.998,0.000$ & $0.459,0.407$ & $0.533,0.452$ & $0.492,0.425$ \\
\hline I-\#GoodTrafficSituation & 28 & $0.997,0.002$ & $0.393,0.482$ & $0.335,0.431$ & $0.355,0.443$ \\
\hline I-\#Location & 306 & $0.964,0.014$ & $0.359,0.342$ & $0.609,0.356$ & $0.382,0.255$ \\
\hline I-\#Protest & 2 & $0.998,0.000$ & $0.260,0.000$ & $0.272,0.000$ & $0.266,0.000$ \\
\hline I-\#PublicAuthority & 9 & $0.996,0.001$ & $0.089,0.126$ & $0.259,0.366$ & $0.133,0.188$ \\
\hline I-\#Time & 8 & $0.995,0.001$ & $0.000,0.000$ & $0.000,0.000$ & $0.000,0.000$ \\
\hline I-\#wayEffect:BothDirections & 22 & $0.998,0.000$ & $0.318,0.322$ & $0.386,0.415$ & $0.309,0.322$ \\
\hline I-\#wayEffect:Partially & 2 & $0.998,0.000$ & $0.500,0.000$ & $1.000,0.000$ & $0.666,0.000$ \\
\hline
\end{tabular}


Tabela E.4: Revalidation scores: model-fscore-TEDO-NER-SGD-0

\begin{tabular}{|c|c|c|c|c|c|}
\hline Class & Support & Accuracy & Recall & Precision & F1 \\
\hline $\mathrm{O}$ & 1195 & 0.927 & 0.960 & 0.927 & 0.943 \\
\hline B-\#Accident & 27 & 0.998 & 0.925 & 0.961 & 0.943 \\
\hline B-\#BadTrafficSituation & 66 & 0.986 & 0.984 & 0.730 & 0.838 \\
\hline B-\#Breakdown & 3 & 0.999 & 0.666 & 1.000 & 0.800 \\
\hline B-\#Bus & 8 & 1.000 & 1.000 & 1.000 & 1.000 \\
\hline B-\#Car & 23 & 0.998 & 0.956 & 0.956 & 0.956 \\
\hline B-\#Event & 5 & 0.997 & 0.400 & 0.666 & 0.500 \\
\hline B-\#GoodTrafficSituation & 16 & 0.993 & 0.437 & 0.636 & 0.518 \\
\hline B-\#Interdiction & 24 & 0.999 & 0.958 & 1.000 & 0.978 \\
\hline B-\#Location & 316 & 0.961 & 0.936 & 0.850 & 0.891 \\
\hline B-\#Motorcycle & 4 & 0.999 & 1.000 & 0.800 & 0.888 \\
\hline B-\#Protest & 1 & 1.000 & 1.000 & 1.000 & 1.000 \\
\hline B-\#PublicAuthority & 8 & 1.000 & 1.000 & 1.000 & 1.000 \\
\hline B-\#RoadWork & 1 & 0.999 & 1.000 & 0.500 & 0.666 \\
\hline B-\#Solution & 10 & 0.998 & 0.900 & 0.818 & 0.857 \\
\hline B-\#Time & 3 & 1.000 & 1.000 & 1.000 & 1.000 \\
\hline B-\#Truck & 6 & 0.999 & 0.833 & 1.000 & 0.909 \\
\hline B-\#wayEffect:BothDirections & 11 & 0.995 & 0.181 & 1.000 & 0.307 \\
\hline B-\#wayEffect:OneDirection & 1 & 0.998 & 0.000 & 0.000 & 0.000 \\
\hline B-\#wayEffect:Partially & 23 & 0.999 & 1.000 & 0.958 & 0.978 \\
\hline I-\#BadTrafficSituation & 20 & 0.999 & 1.000 & 0.952 & 0.975 \\
\hline I-\#GoodTrafficSituation & 15 & 0.997 & 0.000 & 0.000 & 0.000 \\
\hline I-\#Location & 90 & 0.958 & 0.733 & 1.000 & 0.846 \\
\hline I-\#wayEffect:BothDirections & 12 & 0.995 & 0.144 & 0.866 & 0.247 \\
\hline
\end{tabular}

Tabela E.5: Training scores: model-fscore-TEDO-NER-SVC-0

\begin{tabular}{|c|c|c|c|c|c|}
\hline Class & Support & Accuracy, $\sigma \mathbf{C V}$ & Recall, $\sigma \mathbf{C V}$ & Precision, $\sigma \mathbf{C V}$ & $\mathbf{F} 1, \sigma \mathbf{C V}$ \\
\hline $\mathrm{O}$ & 5262 & $0.805,0.017$ & $0.959,0.009$ & $0.787,0.020$ & $0.865,0.013$ \\
\hline B-\#Accident & 114 & $0.985,0.004$ & $0.000,0.000$ & $0.000,0.000$ & $0.000,0.000$ \\
\hline B-\#BadTrafficSituation & 273 & $0.966,0.008$ & $0.000,0.000$ & $0.000,0.000$ & $0.000,0.000$ \\
\hline B-\#Breakdown & 14 & $0.997,0.001$ & $0.000,0.000$ & $0.000,0.000$ & $0.000,0.000$ \\
\hline B-\#Bus & 31 & $0.995,0.001$ & $0.000,0.000$ & $0.000,0.000$ & $0.000,0.000$ \\
\hline B-\#Car & 103 & $0.987,0.004$ & $0.000,0.000$ & $0.000,0.000$ & $0.000,0.000$ \\
\hline B-\#Event & 32 & $0.995,0.001$ & $0.000,0.000$ & $0.000,0.000$ & $0.000,0.000$ \\
\hline B-\#GoodTrafficSituation & 29 & $0.996,0.002$ & $0.000,0.000$ & $0.000,0.000$ & $0.000,0.000$ \\
\hline B-\#Interdiction & 141 & $0.982,0.007$ & $0.000,0.000$ & $0.000,0.000$ & $0.000,0.000$ \\
\hline B-\#Location & 1270 & $0.910,0.012$ & $0.876,0.038$ & $0.662,0.048$ & $0.753,0.042$ \\
\hline B-\#Motorcycle & 18 & $0.997,0.001$ & $0.000,0.000$ & $0.000,0.000$ & $0.000,0.000$ \\
\hline B-\#Protest & 16 & $0.993,0.002$ & $0.000,0.000$ & $0.000,0.000$ & $0.000,0.000$ \\
\hline B-\#PublicAuthority & 55 & $0.992,0.005$ & $0.000,0.000$ & $0.000,0.000$ & $0.000,0.000$ \\
\hline B-\#RoadWork & 31 & $0.995,0.002$ & $0.000,0.000$ & $0.000,0.000$ & $0.000,0.000$ \\
\hline B-\#Solution & 45 & $0.993,0.005$ & $0.000,0.000$ & $0.000,0.000$ & $0.000,0.000$ \\
\hline B-\#Time & 17 & $0.996,0.001$ & $0.000,0.000$ & $0.000,0.000$ & $0.000,0.000$ \\
\hline B-\#Truck & 24 & $0.997,0.002$ & $0.000,0.000$ & $0.000,0.000$ & $0.000,0.000$ \\
\hline B-\#wayEffect:BothDirections & 19 & $0.997,0.001$ & $0.000,0.000$ & $0.000,0.000$ & $0.000,0.000$ \\
\hline B-\#wayEffect:OneDirection & 3 & $0.998,0.000$ & $0.000,0.000$ & $0.000,0.000$ & $0.000,0.000$ \\
\hline B-\#wayEffect:Partially & 123 & $0.984,0.005$ & $0.000,0.000$ & $0.000,0.000$ & $0.000,0.000$ \\
\hline I-\#BadTrafficSituation & 85 & $0.989,0.004$ & $0.000,0.000$ & $0.000,0.000$ & $0.000,0.000$ \\
\hline I-\#Event & 8 & $0.998,0.000$ & $0.000,0.000$ & $0.000,0.000$ & $0.000,0.000$ \\
\hline I-\#GoodTrafficSituation & 28 & $0.996,0.002$ & $0.000,0.000$ & $0.000,0.000$ & $0.000,0.000$ \\
\hline I-\#Location & 306 & $0.962,0.022$ & $0.000,0.000$ & $0.000,0.000$ & $0.000,0.000$ \\
\hline I-\#Protest & 2 & $0.997,0.000$ & $0.000,0.000$ & $0.000,0.000$ & $0.000,0.000$ \\
\hline I-\#PublicAuthority & 9 & $0.996,0.001$ & $0.000,0.000$ & $0.000,0.000$ & $0.000,0.000$ \\
\hline I-\#Time & 8 & $0.995,0.001$ & $0.000,0.000$ & $0.000,0.000$ & $0.000,0.000$ \\
\hline I-\#wayEffect:BothDirections & 22 & $0.997,0.001$ & $0.000,0.000$ & $0.000,0.000$ & $0.000,0.000$ \\
\hline I-\#wayEffect:Partially & 2 & $0.997,0.000$ & $0.000,0.000$ & $0.000,0.000$ & $0.000,0.000$ \\
\hline
\end{tabular}


Tabela E.6: Revalidation scores: model-fscore-TEDO-NER-SVC-0

\begin{tabular}{|c|c|c|c|c|c|}
\hline Class & Support & Accuracy & Recall & Precision & F1 \\
\hline $\mathrm{O}$ & 1195 & 0.798 & 0.963 & 0.773 & 0.857 \\
\hline B-\#Accident & 27 & 0.985 & 0.000 & 0.000 & 0.000 \\
\hline B-\#BadTrafficSituation & 66 & 0.965 & 0.000 & 0.000 & 0.000 \\
\hline B-\#Breakdown & 3 & 0.998 & 0.000 & 0.000 & 0.000 \\
\hline B-\#Bus & 8 & 0.995 & 0.000 & 0.000 & 0.000 \\
\hline B-\#Car & 23 & 0.987 & 0.000 & 0.000 & 0.000 \\
\hline B-\#Event & 5 & 0.997 & 0.000 & 0.000 & 0.000 \\
\hline B-\#GoodTrafficSituation & 16 & 0.991 & 0.000 & 0.000 & 0.000 \\
\hline B-\#Interdiction & 24 & 0.987 & 0.000 & 0.000 & 0.000 \\
\hline B-\#Location & 316 & 0.909 & 0.863 & 0.682 & 0.762 \\
\hline B-\#Motorcycle & 4 & 0.997 & 0.000 & 0.000 & 0.000 \\
\hline B-\#Protest & 1 & 0.999 & 0.000 & 0.000 & 0.000 \\
\hline B-\#PublicAuthority & 8 & 0.995 & 0.000 & 0.000 & 0.000 \\
\hline B-\#RoadWork & 1 & 0.999 & 0.000 & 0.000 & 0.000 \\
\hline B-\#Solution & 10 & 0.994 & 0.000 & 0.000 & 0.000 \\
\hline B-\#Time & 3 & 0.998 & 0.000 & 0.000 & 0.000 \\
\hline B-\#Truck & 6 & 0.996 & 0.000 & 0.000 & 0.000 \\
\hline B-\#wayEffect:BothDirections & 11 & 0.994 & 0.000 & 0.000 & 0.000 \\
\hline B-\#wayEffect:OneDirection & 1 & 0.999 & 0.000 & 0.000 & 0.000 \\
\hline B-\#wayEffect:Partially & 23 & 0.987 & 0.000 & 0.000 & 0.000 \\
\hline I-\#BadTrafficSituation & 20 & 0.989 & 0.000 & 0.000 & 0.000 \\
\hline I-\#GoodTrafficSituation & 15 & 0.992 & 0.000 & 0.000 & 0.000 \\
\hline I-\#Location & 90 & 0.952 & 0.000 & 0.000 & 0.000 \\
\hline I-\#wayEffect:BothDirections & 12 & 0.993 & 0.000 & 0.000 & 0.000 \\
\hline
\end{tabular}

Tabela E.7: Training scores: model-fscore-TEDO-NER-RF-1

\begin{tabular}{|c|c|c|c|c|c|}
\hline Class & Support & Accuracy, $\sigma \mathbf{C V}$ & Recall, $\sigma \mathbf{C V}$ & Precision, $\sigma \mathbf{C V}$ & $\mathbf{F} 1, \sigma \mathbf{C V}$ \\
\hline $\mathrm{O}$ & 5262 & $0.937,0.017$ & $0.982,0.007$ & $0.926,0.020$ & $0.953,0.012$ \\
\hline B-\#Accident & 114 & $0.997,0.001$ & $0.863,0.068$ & $0.916,0.098$ & $0.886,0.069$ \\
\hline B-\#BadTrafficSituation & 273 & $0.991,0.002$ & $0.867,0.076$ & $0.865,0.057$ & $0.865,0.060$ \\
\hline B-\#Breakdown & 14 & $0.999,0.000$ & $0.531,0.440$ & $0.625,0.484$ & $0.565,0.450$ \\
\hline B-\#Bus & 31 & $0.998,0.000$ & $0.785,0.177$ & $0.944,0.157$ & $0.831,0.119$ \\
\hline B-\#Car & 103 & $0.996,0.002$ & $0.746,0.302$ & $0.781,0.288$ & $0.759,0.293$ \\
\hline B-\#Event & 32 & $0.995,0.000$ & $0.253,0.313$ & $0.440,0.419$ & $0.288,0.298$ \\
\hline B-\#GoodTrafficSituation & 29 & $0.997,0.002$ & $0.274,0.325$ & $0.600,0.489$ & $0.342,0.351$ \\
\hline B-\#Interdiction & 141 & $0.993,0.002$ & $0.778,0.129$ & $0.872,0.148$ & $0.812,0.107$ \\
\hline B-\#Location & 1270 & $0.973,0.009$ & $0.910,0.094$ & $0.875,0.092$ & $0.892,0.091$ \\
\hline B-\#Motorcycle & 18 & $0.998,0.001$ & $0.703,0.356$ & $0.633,0.342$ & $0.656,0.340$ \\
\hline B-\#Protest & 16 & $0.994,0.002$ & $0.133,0.188$ & $0.333,0.471$ & $0.190,0.269$ \\
\hline B-\#PublicAuthority & 55 & $0.996,0.001$ & $0.398,0.382$ & $0.555,0.496$ & $0.456,0.419$ \\
\hline B-\#RoadWork & 31 & $0.998,0.000$ & $0.444,0.316$ & $0.750,0.408$ & $0.531,0.326$ \\
\hline B-\#Solution & 45 & $0.997,0.001$ & $0.727,0.302$ & $0.850,0.327$ & $0.775,0.300$ \\
\hline B-\#Time & 17 & $0.998,0.001$ & $0.380,0.451$ & $0.428,0.494$ & $0.399,0.465$ \\
\hline B-\#Truck & 24 & $0.997,0.001$ & $0.370,0.388$ & $0.530,0.443$ & $0.390,0.353$ \\
\hline B-\#wayEffect:BothDirections & 19 & $0.999,0.000$ & $0.500,0.500$ & $0.500,0.500$ & $0.500,0.500$ \\
\hline B-\#wayEffect:OneDirection & 3 & $0.998,0.000$ & $0.000,0.000$ & $0.000,0.000$ & $0.000,0.000$ \\
\hline B-\#wayEffect:Partially & 123 & $0.996,0.002$ & $0.773,0.282$ & $0.869,0.296$ & $0.815,0.284$ \\
\hline I-\#BadTrafficSituation & 85 & $0.996,0.002$ & $0.766,0.275$ & $0.861,0.293$ & $0.805,0.274$ \\
\hline I-\#Event & 8 & $0.998,0.000$ & $0.521,0.434$ & $0.420,0.355$ & $0.455,0.372$ \\
\hline I-\#GoodTrafficSituation & 28 & $0.997,0.002$ & $0.291,0.375$ & $0.350,0.450$ & $0.315,0.403$ \\
\hline I-\#Location & 306 & $0.976,0.014$ & $0.380,0.336$ & $0.681,0.449$ & $0.461,0.353$ \\
\hline I-\#Protest & 2 & $0.998,0.000$ & $0.500,0.000$ & $1.000,0.000$ & $0.666,0.000$ \\
\hline I-\#PublicAuthority & 9 & $0.997,0.001$ & $0.178,0.127$ & $0.583,0.424$ & $0.271,0.191$ \\
\hline I-\#Time & 8 & $0.995,0.001$ & $0.192,0.038$ & $0.672,0.227$ & $0.297,0.069$ \\
\hline I-\#wayEffect:BothDirections & 22 & $0.999,0.000$ & $0.592,0.389$ & $0.684,0.389$ & $0.608,0.362$ \\
\hline I-\#wayEffect:Partially & 2 & $0.998,0.000$ & $0.500,0.000$ & $1.000,0.000$ & $0.666,0.000$ \\
\hline
\end{tabular}


Tabela E.8: Revalidation scores: model-fscore-TEDO-NER-RF-1

\begin{tabular}{|c|c|c|c|c|c|}
\hline Class & Support & Accuracy & Recall & Precision & F1 \\
\hline $\mathrm{O}$ & 1195 & 0.949 & 0.989 & 0.935 & 0.961 \\
\hline B-\#Accident & 27 & 0.997 & 0.925 & 0.925 & 0.925 \\
\hline B-\#BadTrafficSituation & 66 & 0.989 & 0.893 & 0.819 & 0.855 \\
\hline B-\#Breakdown & 3 & 0.999 & 0.666 & 1.000 & 0.800 \\
\hline B-\#Bus & 8 & 0.999 & 0.875 & 1.000 & 0.933 \\
\hline B-\#Car & 23 & 0.997 & 0.956 & 0.846 & 0.897 \\
\hline B-\#Event & 5 & 0.996 & 0.000 & 0.000 & 0.000 \\
\hline B-\#GoodTrafficSituation & 16 & 0.995 & 0.437 & 1.000 & 0.608 \\
\hline B-\#Interdiction & 24 & 0.997 & 0.916 & 0.880 & 0.897 \\
\hline B-\#Location & 316 & 0.970 & 0.911 & 0.911 & 0.911 \\
\hline B-\#Motorcycle & 4 & 0.998 & 0.500 & 1.000 & 0.666 \\
\hline B-\#Protest & 1 & 1.000 & 1.000 & 1.000 & 1.000 \\
\hline B-\#PublicAuthority & 8 & 1.000 & 1.000 & 1.000 & 1.000 \\
\hline B-\#RoadWork & 1 & 1.000 & 1.000 & 1.000 & 1.000 \\
\hline B-\#Solution & 10 & 0.998 & 0.700 & 1.000 & 0.823 \\
\hline B-\#Time & 3 & 1.000 & 1.000 & 1.000 & 1.000 \\
\hline B-\#Truck & 6 & 0.996 & 0.166 & 0.333 & 0.222 \\
\hline B-\#wayEffect:BothDirections & 11 & 1.000 & 1.000 & 1.000 & 1.000 \\
\hline B-\#wayEffect:OneDirection & 1 & 0.999 & 0.000 & 0.000 & 0.000 \\
\hline B-\#wayEffect:Partially & 23 & 0.999 & 0.956 & 1.000 & 0.977 \\
\hline I-\#BadTrafficSituation & 20 & 0.998 & 0.950 & 0.904 & 0.926 \\
\hline I-\#GoodTrafficSituation & 15 & 0.996 & 0.533 & 1.000 & 0.695 \\
\hline I-\#Location & 90 & 0.969 & 0.411 & 0.902 & 0.564 \\
\hline I-\#wayEffect:BothDirections & 12 & 1.000 & 1.000 & 1.000 & 1.000 \\
\hline
\end{tabular}

Tabela E.9: Training scores: model-fscore-TEDO-NER-SGD-1

\begin{tabular}{|c|c|c|c|c|c|}
\hline Class & Support & Accuracy, $\sigma \mathbf{C V}$ & Recall, $\sigma \mathbf{C V}$ & Precision, $\sigma \mathbf{C V}$ & $\mathbf{F} 1, \sigma \mathbf{C V}$ \\
\hline $\mathrm{O}$ & 5262 & $0.939,0.014$ & $0.974,0.011$ & $0.935,0.019$ & $0.954,0.010$ \\
\hline B-\#Accident & 114 & $0.997,0.002$ & $0.881,0.127$ & $0.938,0.138$ & $0.897,0.110$ \\
\hline B-\#BadTrafficSituation & 273 & $0.993,0.002$ & $0.896,0.073$ & $0.899,0.066$ & $0.894,0.037$ \\
\hline B-\#Breakdown & 14 & $0.999,0.000$ & $0.593,0.466$ & $0.600,0.469$ & $0.593,0.462$ \\
\hline B-\#Bus & 31 & $0.999,0.000$ & $0.955,0.125$ & $0.962,0.104$ & $0.950,0.094$ \\
\hline B-\#Car & 103 & $0.998,0.001$ & $0.829,0.284$ & $0.850,0.291$ & $0.836,0.281$ \\
\hline B-\#Event & 32 & $0.995,0.001$ & $0.244,0.312$ & $0.425,0.438$ & $0.274,0.310$ \\
\hline B-\#GoodTrafficSituation & 29 & $0.997,0.001$ & $0.329,0.342$ & $0.454,0.433$ & $0.343,0.337$ \\
\hline B-\#Interdiction & 141 & $0.995,0.002$ & $0.837,0.146$ & $0.903,0.194$ & $0.840,0.144$ \\
\hline B-\#Location & 1270 & $0.966,0.006$ & $0.882,0.053$ & $0.868,0.102$ & $0.871,0.062$ \\
\hline B-\#Motorcycle & 18 & $0.999,0.000$ & $0.896,0.174$ & $0.896,0.174$ & $0.870,0.133$ \\
\hline B-\#Protest & 16 & $0.993,0.001$ & $0.219,0.086$ & $0.777,0.314$ & $0.296,0.052$ \\
\hline B-\#PublicAuthority & 55 & $0.996,0.002$ & $0.229,0.340$ & $0.333,0.471$ & $0.266,0.385$ \\
\hline B-\#RoadWork & 31 & $0.999,0.000$ & $0.704,0.319$ & $0.841,0.309$ & $0.750,0.295$ \\
\hline B-\#Solution & 45 & $0.998,0.000$ & $0.825,0.330$ & $0.833,0.333$ & $0.820,0.321$ \\
\hline B-\#Time & 17 & $0.997,0.001$ & $0.523,0.466$ & $0.488,0.437$ & $0.493,0.432$ \\
\hline B-\#Truck & 24 & $0.999,0.001$ & $0.481,0.424$ & $0.570,0.469$ & $0.511,0.430$ \\
\hline B-\#wayEffect:BothDirections & 19 & $0.998,0.001$ & $0.433,0.472$ & $0.500,0.500$ & $0.450,0.471$ \\
\hline B-\#wayEffect:OneDirection & 3 & $0.998,0.000$ & $0.000,0.000$ & $0.000,0.000$ & $0.000,0.000$ \\
\hline B-\#wayEffect:Partially & 123 & $0.996,0.002$ & $0.846,0.288$ & $0.840,0.293$ & $0.841,0.287$ \\
\hline I-\#BadTrafficSituation & 85 & $0.997,0.001$ & $0.731,0.342$ & $0.809,0.310$ & $0.726,0.309$ \\
\hline I-\#Event & 8 & $0.998,0.000$ & $0.860,0.195$ & $0.860,0.195$ & $0.860,0.195$ \\
\hline I-\#GoodTrafficSituation & 28 & $0.996,0.002$ & $0.366,0.411$ & $0.382,0.412$ & $0.368,0.407$ \\
\hline I-\#Location & 306 & $0.973,0.014$ & $0.347,0.372$ & $0.622,0.417$ & $0.392,0.352$ \\
\hline I-\#Protest & 2 & $0.998,0.000$ & $0.304,0.000$ & $0.583,0.000$ & $0.400,0.000$ \\
\hline I-\#PublicAuthority & 9 & $0.996,0.001$ & $0.430,0.156$ & $0.809,0.269$ & $0.503,0.128$ \\
\hline I-\#Time & 8 & $0.995,0.001$ & $0.000,0.000$ & $0.000,0.000$ & $0.000,0.000$ \\
\hline I-\#wayEffect:BothDirections & 22 & $0.999,0.000$ & $0.666,0.387$ & $0.742,0.408$ & $0.673,0.368$ \\
\hline I-\#wayEffect:Partially & 2 & $0.998,0.000$ & $1.000,0.000$ & $1.000,0.000$ & $1.000,0.000$ \\
\hline
\end{tabular}


Tabela E.10: Revalidation scores: model-fscore-TEDO-NER-SGD-1

\begin{tabular}{|c|c|c|c|c|c|}
\hline Class & Support & Accuracy & Recall & Precision & F1 \\
\hline $\mathrm{O}$ & 1195 & 0.945 & 0.975 & 0.940 & 0.957 \\
\hline B-\#Accident & 27 & 0.998 & 0.925 & 1.000 & 0.961 \\
\hline B-\#BadTrafficSituation & 66 & 0.991 & 1.000 & 0.804 & 0.891 \\
\hline B-\#Breakdown & 3 & 0.999 & 0.666 & 1.000 & 0.800 \\
\hline B-\#Bus & 8 & 1.000 & 1.000 & 1.000 & 1.000 \\
\hline B-\#Car & 23 & 0.998 & 0.956 & 0.956 & 0.956 \\
\hline B-\#Event & 5 & 0.994 & 0.400 & 0.200 & 0.266 \\
\hline B-\#GoodTrafficSituation & 16 & 0.995 & 0.625 & 0.833 & 0.714 \\
\hline B-\#Interdiction & 24 & 0.998 & 0.958 & 0.958 & 0.958 \\
\hline B-\#Location & 316 & 0.967 & 0.924 & 0.884 & 0.904 \\
\hline B-\#Motorcycle & 4 & 0.998 & 0.500 & 1.000 & 0.666 \\
\hline B-\#Protest & 1 & 0.998 & 1.000 & 0.333 & 0.500 \\
\hline B-\#PublicAuthority & 8 & 0.999 & 0.875 & 1.000 & 0.933 \\
\hline B-\#RoadWork & 1 & 1.000 & 1.000 & 1.000 & 1.000 \\
\hline B-\#Solution & 10 & 1.000 & 1.000 & 1.000 & 1.000 \\
\hline B-\#Time & 3 & 1.000 & 1.000 & 1.000 & 1.000 \\
\hline B-\#Truck & 6 & 0.999 & 1.000 & 0.857 & 0.923 \\
\hline B-\#wayEffect:BothDirections & 11 & 0.995 & 0.272 & 1.000 & 0.428 \\
\hline B-\#wayEffect:OneDirection & 1 & 0.999 & 0.000 & 0.000 & 0.000 \\
\hline B-\#wayEffect:Partially & 23 & 0.998 & 1.000 & 0.884 & 0.938 \\
\hline I-\#BadTrafficSituation & 20 & 0.998 & 0.900 & 0.947 & 0.923 \\
\hline I-\#GoodTrafficSituation & 15 & 0.995 & 0.400 & 1.000 & 0.571 \\
\hline I-\#Location & 90 & 0.968 & 0.377 & 0.918 & 0.535 \\
\hline I-\#wayEffect:BothDirections & 12 & 0.997 & 0.666 & 1.000 & 0.800 \\
\hline
\end{tabular}

Tabela E.11: Best parameters: model-fscore-TEDO-NER-SVC-1

\begin{tabular}{rrr}
\hline Parameter & Values & Best value \\
\hline Kernel & Radial Basis Function, Linear, Polynomial, Sigmoidal & Linear \\
\hline
\end{tabular}


Tabela E.12: Training scores: model-fscore-TEDO-NER-SVC-1

\begin{tabular}{|c|c|c|c|c|c|}
\hline Class & Support & Accuracy, $\sigma \mathbf{C V}$ & Recall, $\sigma \mathbf{C V}$ & Precision, $\sigma \mathbf{C V}$ & $\mathbf{F} 1, \sigma \mathbf{C V}$ \\
\hline $\mathrm{O}$ & 5262 & $0.948,0.014$ & $0.976,0.008$ & $0.946,0.017$ & $0.960,0.010$ \\
\hline B-\#Accident & 114 & $0.997,0.002$ & $0.862,0.155$ & $0.948,0.081$ & $0.898,0.123$ \\
\hline B-\#BadTrafficSituation & 273 & $0.995,0.002$ & $0.927,0.054$ & $0.930,0.028$ & $0.928,0.034$ \\
\hline B-\#Breakdown & 14 & $0.999,0.000$ & $0.718,0.422$ & $0.750,0.433$ & $0.732,0.425$ \\
\hline B-\#Bus & 31 & $1.000,0.000$ & $1.000,0.000$ & $1.000,0.000$ & $1.000,0.000$ \\
\hline $\mathrm{B}-\# \mathrm{Car}$ & 103 & $0.999,0.000$ & $0.975,0.039$ & $0.941,0.066$ & $0.956,0.042$ \\
\hline B-\#Event & 32 & $0.996,0.001$ & $0.411,0.324$ & $0.603,0.400$ & $0.459,0.327$ \\
\hline B-\#GoodTrafficSituation & 29 & $0.997,0.002$ & $0.481,0.331$ & $0.800,0.400$ & $0.577,0.335$ \\
\hline B-\#Interdiction & 141 & $0.997,0.002$ & $0.890,0.098$ & $0.958,0.054$ & $0.920,0.066$ \\
\hline B-\#Location & 1270 & $0.976,0.008$ & $0.929,0.029$ & $0.919,0.032$ & $0.924,0.025$ \\
\hline B-\#Motorcycle & 18 & $0.999,0.000$ & $0.916,0.166$ & $1.000,0.000$ & $0.947,0.108$ \\
\hline B-\#Protest & 16 & $0.995,0.003$ & $0.419,0.282$ & $1.000,0.000$ & $0.537,0.273$ \\
\hline B-\#PublicAuthority & 55 & $0.998,0.001$ & $0.653,0.374$ & $0.757,0.408$ & $0.694,0.381$ \\
\hline B-\#RoadWork & 31 & $1.000,0.000$ & $0.888,0.314$ & $0.888,0.314$ & $0.888,0.314$ \\
\hline B-\#Solution & 45 & $0.998,0.001$ & $0.898,0.165$ & $0.975,0.066$ & $0.923,0.106$ \\
\hline B-\#Time & 17 & $0.998,0.002$ & $0.571,0.494$ & $0.542,0.474$ & $0.555,0.482$ \\
\hline B-\#Truck & 24 & $0.999,0.000$ & $0.650,0.450$ & $0.687,0.451$ & $0.659,0.442$ \\
\hline B-\#wayEffect:BothDirections & 19 & $0.999,0.000$ & $0.969,0.062$ & $1.000,0.000$ & $0.983,0.033$ \\
\hline B-\#wayEffect:OneDirection & 3 & $0.998,0.000$ & $0.500,0.500$ & $0.500,0.500$ & $0.500,0.500$ \\
\hline B-\#wayEffect:Partially & 123 & $0.997,0.001$ & $0.822,0.281$ & $0.802,0.304$ & $0.802,0.282$ \\
\hline I-\#BadTrafficSituation & 85 & $0.997,0.001$ & $0.869,0.151$ & $0.901,0.143$ & $0.876,0.127$ \\
\hline I-\#Event & 8 & $0.998,0.000$ & $0.386,0.474$ & $0.386,0.474$ & $0.386,0.474$ \\
\hline I-\#GoodTrafficSituation & 28 & $0.997,0.001$ & $0.539,0.443$ & $0.660,0.439$ & $0.555,0.416$ \\
\hline I-\#Location & 306 & $0.977,0.010$ & $0.542,0.124$ & $0.754,0.209$ & $0.611,0.128$ \\
\hline I-\#Protest & 2 & $0.998,0.000$ & $0.500,0.000$ & $1.000,0.000$ & $0.666,0.000$ \\
\hline I-\#PublicAuthority & 9 & $0.998,0.001$ & $0.666,0.471$ & $0.666,0.471$ & $0.666,0.471$ \\
\hline I-\#Time & 8 & $0.995,0.001$ & $0.000,0.000$ & $0.000,0.000$ & $0.000,0.000$ \\
\hline I-\#wayEffect:BothDirections & 22 & $0.999,0.000$ & $0.929,0.112$ & $0.951,0.096$ & $0.939,0.101$ \\
\hline I-\#wayEffect:Partially & 2 & $0.998,0.000$ & $0.500,0.000$ & $1.000,0.000$ & $0.666,0.000$ \\
\hline
\end{tabular}

Tabela E.13: Revalidation scores: model-fscore-TEDO-NER-SVC-1

\begin{tabular}{|c|c|c|c|c|c|}
\hline Class & Support & Accuracy & Recall & Precision & F1 \\
\hline $\mathrm{O}$ & 1195 & 0.958 & 0.982 & 0.953 & 0.967 \\
\hline B-\#Accident & 27 & 0.997 & 0.925 & 0.925 & 0.925 \\
\hline B-\#BadTrafficSituation & 66 & 0.996 & 1.000 & 0.916 & 0.956 \\
\hline B-\#Breakdown & 3 & 0.999 & 0.666 & 1.000 & 0.800 \\
\hline B-\#Bus & 8 & 1.000 & 1.000 & 1.000 & 1.000 \\
\hline B-\#Car & 23 & 0.998 & 0.956 & 0.916 & 0.936 \\
\hline B-\#Event & 5 & 0.997 & 0.400 & 0.666 & 0.500 \\
\hline B-\#GoodTrafficSituation & 16 & 0.998 & 0.875 & 1.000 & 0.933 \\
\hline B-\#Interdiction & 24 & 1.000 & 1.000 & 1.000 & 1.000 \\
\hline B-\#Location & 316 & 0.976 & 0.911 & 0.944 & 0.927 \\
\hline B-\#Motorcycle & 4 & 0.998 & 0.750 & 0.750 & 0.750 \\
\hline B-\#Protest & 1 & 1.000 & 1.000 & 1.000 & 1.000 \\
\hline B-\#PublicAuthority & 8 & 0.999 & 1.000 & 0.888 & 0.941 \\
\hline B-\#RoadWork & 1 & 1.000 & 1.000 & 1.000 & 1.000 \\
\hline B-\#Solution & 10 & 0.999 & 0.900 & 1.000 & 0.947 \\
\hline B-\#Time & 3 & 1.000 & 1.000 & 1.000 & 1.000 \\
\hline B-\#Truck & 6 & 1.000 & 1.000 & 1.000 & 1.000 \\
\hline B-\#wayEffect:BothDirections & 11 & 1.000 & 1.000 & 1.000 & 1.000 \\
\hline B-\#wayEffect:OneDirection & 1 & 0.999 & 0.000 & 0.000 & 0.000 \\
\hline B-\#wayEffect:Partially & 23 & 0.998 & 1.000 & 0.920 & 0.958 \\
\hline I-\#BadTrafficSituation & 20 & 0.999 & 0.950 & 1.000 & 0.974 \\
\hline I-\#GoodTrafficSituation & 15 & 0.999 & 0.933 & 1.000 & 0.965 \\
\hline I-\#Location & 90 & 0.969 & 0.533 & 0.750 & 0.623 \\
\hline I-\#wayEffect:BothDirections & 12 & 1.000 & 1.000 & 1.000 & 1.000 \\
\hline
\end{tabular}


Tabela E.14: Best parameters: model-fscore-TEDO-NER-RF-2

\begin{tabular}{rrr}
\hline Parameter & Values & Best value \\
\hline Class weight & balanced, None & None \\
Criterion & gini, entropy & gini \\
Max features & sqrt(n_features), log2(n_features), $\mathrm{n}$ features & $\mathrm{n} \_$features \\
Number of trees in the forest & $10,50,100$ & 50 \\
Use out-of-bag samples to estimate accuracy & true, false & true \\
One vs Rest & true, false & true \\
\hline
\end{tabular}

Tabela E.15: Training scores: model-fscore-TEDO-NER-RF-2

\begin{tabular}{|c|c|c|c|c|c|}
\hline Class & Support & Accuracy, $\sigma \mathbf{C V}$ & Recall, $\sigma \mathbf{C V}$ & Precision, $\sigma \mathbf{C V}$ & $\mathbf{F} 1, \sigma \mathbf{C V}$ \\
\hline $\mathrm{O}$ & 5262 & $0.959,0.017$ & $0.976,0.012$ & $0.961,0.017$ & $0.968,0.013$ \\
\hline B-\#Accident & 114 & $0.998,0.001$ & $0.954,0.062$ & $0.945,0.088$ & $0.946,0.058$ \\
\hline B-\#BadTrafficSituation & 273 & $0.996,0.001$ & $0.955,0.038$ & $0.942,0.051$ & $0.947,0.025$ \\
\hline B-\#Breakdown & 14 & $1.000,0.000$ & $1.000,0.000$ & $1.000,0.000$ & $1.000,0.000$ \\
\hline B-\#Bus & 31 & $1.000,0.000$ & $1.000,0.000$ & $1.000,0.000$ & $1.000,0.000$ \\
\hline B-\#Car & 103 & $0.999,0.000$ & $0.990,0.029$ & $1.000,0.000$ & $0.994,0.015$ \\
\hline B-\#Event & 32 & $0.998,0.001$ & $0.670,0.334$ & $0.814,0.318$ & $0.701,0.311$ \\
\hline B-\#GoodTrafficSituation & 29 & $0.997,0.002$ & $0.336,0.350$ & $0.525,0.453$ & $0.378,0.359$ \\
\hline B-\#Interdiction & 141 & $0.999,0.001$ & $0.964,0.060$ & $0.994,0.017$ & $0.978,0.036$ \\
\hline B-\#Location & 1270 & $0.980,0.007$ & $0.965,0.018$ & $0.916,0.030$ & $0.940,0.023$ \\
\hline B-\#Motorcycle & 18 & $0.999,0.000$ & $0.944,0.157$ & $1.000,0.000$ & $0.962,0.104$ \\
\hline B-\#Protest & 16 & $0.998,0.001$ & $0.736,0.289$ & $1.000,0.000$ & $0.811,0.221$ \\
\hline B-\#PublicAuthority & 55 & $0.998,0.001$ & $0.795,0.329$ & $0.861,0.314$ & $0.812,0.311$ \\
\hline B-\#RoadWork & 31 & $0.999,0.000$ & $0.935,0.122$ & $1.000,0.000$ & $0.961,0.072$ \\
\hline B-\#Solution & 45 & $0.999,0.000$ & $0.875,0.330$ & $0.850,0.327$ & $0.861,0.327$ \\
\hline B-\#Time & 17 & $0.998,0.001$ & $0.571,0.494$ & $0.447,0.438$ & $0.484,0.447$ \\
\hline B-\#Truck & 24 & $1.000,0.000$ & $0.900,0.300$ & $0.900,0.300$ & $0.900,0.300$ \\
\hline B-\#wayEffect:BothDirections & 19 & $0.999,0.000$ & $0.983,0.049$ & $0.925,0.160$ & $0.943,0.103$ \\
\hline B-\#wayEffect:OneDirection & 3 & $0.998,0.000$ & $0.500,0.500$ & $0.250,0.250$ & $0.333,0.333$ \\
\hline B-\#wayEffect:Partially & 123 & $0.997,0.001$ & $0.791,0.273$ & $0.858,0.292$ & $0.820,0.277$ \\
\hline I-\#BadTrafficSituation & 85 & $0.997,0.002$ & $0.878,0.162$ & $0.928,0.135$ & $0.886,0.121$ \\
\hline I-\#Event & 8 & $0.998,0.000$ & $0.300,0.400$ & $0.400,0.489$ & $0.333,0.421$ \\
\hline I-\#GoodTrafficSituation & 28 & $0.997,0.003$ & $0.675,0.419$ & $0.590,0.381$ & $0.615,0.380$ \\
\hline I-\#Location & 306 & $0.975,0.015$ & $0.472,0.149$ & $0.768,0.212$ & $0.572,0.155$ \\
\hline I-\#Protest & 2 & $0.998,0.000$ & $0.500,0.000$ & $1.000,0.000$ & $0.666,0.000$ \\
\hline I-\#PublicAuthority & 9 & $0.997,0.002$ & $0.500,0.408$ & $0.666,0.471$ & $0.555,0.415$ \\
\hline I-\#Time & 8 & 0.001 & $0.000,0.000$ & $0.000,0.000$ & $0.000,0.000$ \\
\hline I-\#wayEffect:BothDirections & 22 & $0.999,0.000$ & $0.769,0.395$ & $0.736,0.383$ & $0.747,0.382$ \\
\hline I-\#wayEffect:Partially & 2 & $0.997,0.000$ & $0.500,0.000$ & $0.500,0.000$ & $0.500,0.000$ \\
\hline & & $.995,0.008$ & $739,0.255$ & $0.785,0.256$ & $\overline{745,0.2}$ \\
\hline
\end{tabular}


Tabela E.16: Revalidation scores: model-fscore-TEDO-NER-RF-2

\begin{tabular}{|c|c|c|c|c|c|}
\hline Class & Support & Accuracy & Recall & Precision & F1 \\
\hline $\mathrm{O}$ & 1195 & 0.970 & 0.991 & 0.962 & 0.976 \\
\hline B-\#Accident & 27 & 1.000 & 1.000 & 1.000 & 1.000 \\
\hline B-\#BadTrafficSituation & 66 & 0.997 & 0.954 & 0.984 & 0.969 \\
\hline B-\#Breakdown & 3 & 0.999 & 0.666 & 1.000 & 0.800 \\
\hline B-\#Bus & 8 & 1.000 & 1.000 & 1.000 & 1.000 \\
\hline B-\#Car & 23 & 1.000 & 1.000 & 1.000 & 1.000 \\
\hline B-\#Event & 5 & 0.998 & 0.600 & 0.750 & 0.666 \\
\hline B-\#GoodTrafficSituation & 16 & 0.997 & 0.937 & 0.833 & 0.882 \\
\hline B-\#Interdiction & 24 & 1.000 & 1.000 & 1.000 & 1.000 \\
\hline B-\#Location & 316 & 0.979 & 0.939 & 0.936 & 0.938 \\
\hline B-\#Motorcycle & 4 & 1.000 & 1.000 & 1.000 & 1.000 \\
\hline B-\#Protest & 1 & 1.000 & 1.000 & 1.000 & 1.000 \\
\hline B-\#PublicAuthority & 8 & 1.000 & 1.000 & 1.000 & 1.000 \\
\hline B-\#RoadWork & 1 & 1.000 & 1.000 & 1.000 & 1.000 \\
\hline B-\#Solution & 10 & 1.000 & 1.000 & 1.000 & 1.000 \\
\hline B-\#Time & 3 & 1.000 & 1.000 & 1.000 & 1.000 \\
\hline B-\#Truck & 6 & 1.000 & 1.000 & 1.000 & 1.000 \\
\hline B-\#wayEffect:BothDirections & 11 & 1.000 & 1.000 & 1.000 & 1.000 \\
\hline B-\#wayEffect:OneDirection & 1 & 0.999 & 0.000 & 0.000 & 0.000 \\
\hline B-\#wayEffect:Partially & 23 & 0.998 & 0.956 & 0.916 & 0.936 \\
\hline I-\#BadTrafficSituation & 20 & 1.000 & 1.000 & 1.000 & 1.000 \\
\hline I-\#GoodTrafficSituation & 15 & 0.998 & 1.000 & 0.882 & 0.937 \\
\hline I-\#Location & 90 & 0.974 & 0.511 & 0.901 & 0.652 \\
\hline I-\#wayEffect:BothDirections & 12 & 1.000 & 1.000 & 1.000 & 1.000 \\
\hline
\end{tabular}

Tabela E.17: Best parameters: model-fscore-TEDO-NER-SGD-2

\begin{tabular}{rrr}
\hline Parameter & Values & Best value \\
\hline Class weight & balanced, None & None \\
Learning rate & constant, optimal, invscaling & \\
Loss function & Hinge, Log, Modified huber, Epsilon insensitive, & \\
& Squared epsilon insensitive, Squared hinge, Perceptron, Huber, & Hinge \\
& Epsilon insensitive, Squared epsilon insensitive & true, false \\
One vs Rest & true \\
Penalty & None, 11, 12, elasticnet & elasticnet \\
\hline
\end{tabular}


Tabela E.18: Training scores: model-fscore-TEDO-NER-SGD-2

\begin{tabular}{|c|c|c|c|c|c|}
\hline Class & Support & Accuracy, $\sigma \mathbf{C V}$ & Recall, $\sigma \mathbf{C V}$ & Precision, $\sigma \mathrm{CV}$ & $\mathbf{F} 1, \sigma \mathbf{C V}$ \\
\hline $\mathrm{O}$ & 5262 & $0.941,0.012$ & $0.964,0.021$ & $0.946,0.018$ & $0.955,0.009$ \\
\hline B-\#Accident & 114 & $0.998,0.001$ & $0.902,0.099$ & $0.967,0.060$ & $0.929,0.063$ \\
\hline B-\#BadTrafficSituation & 273 & $0.994,0.001$ & $0.929,0.070$ & $0.897,0.063$ & $0.909,0.035$ \\
\hline B-\#Breakdown & 14 & $0.999,0.000$ & $0.843,0.329$ & $0.875,0.330$ & $0.857,0.327$ \\
\hline B-\#Bus & 31 & $1.000,0.000$ & $1.000,0.000$ & $1.000,0.000$ & $1.000,0.000$ \\
\hline B-\#Car & 103 & $0.998,0.001$ & $0.844,0.287$ & $0.871,0.293$ & $0.857,0.289$ \\
\hline B-\#Event & 32 & $0.995,0.002$ & $0.366,0.343$ & $0.486,0.417$ & $0.374,0.309$ \\
\hline B-\#GoodTrafficSituation & 29 & $0.997,0.002$ & $0.418,0.358$ & $0.633,0.433$ & $0.485,0.369$ \\
\hline B-\#Interdiction & 141 & $0.996,0.002$ & $0.879,0.095$ & $0.941,0.082$ & $0.905,0.073$ \\
\hline B-\#Location & 1270 & $0.969,0.008$ & $0.909,0.054$ & $0.871,0.068$ & $0.888,0.053$ \\
\hline B-\#Motorcycle & 18 & $0.999,0.000$ & $0.870,0.176$ & $0.901,0.164$ & $0.863,0.137$ \\
\hline B-\#Protest & 16 & $0.995,0.002$ & $0.344,0.122$ & $0.888,0.157$ & $0.468,0.099$ \\
\hline B-\#PublicAuthority & 55 & $0.996,0.002$ & $0.617,0.407$ & $0.650,0.397$ & $0.608,0.375$ \\
\hline B-\#RoadWork & 31 & $0.999,0.001$ & $0.807,0.328$ & $0.888,0.314$ & $0.837,0.314$ \\
\hline B-\#Solution & 45 & $0.997,0.002$ & $0.877,0.130$ & $0.850,0.162$ & $0.847,0.111$ \\
\hline B-\#Time & 17 & $0.997,0.002$ & $0.285,0.451$ & $0.250,0.400$ & $0.265,0.421$ \\
\hline B-\#Truck & 24 & $0.999,0.001$ & $0.673,0.384$ & $0.766,0.395$ & $0.709,0.381$ \\
\hline B-\#wayEffect:BothDirections & 19 & $0.999,0.001$ & $0.633,0.458$ & $0.700,0.458$ & $0.650,0.450$ \\
\hline B-\#wayEffect:OneDirection & 3 & $0.998,0.000$ & $0.500,0.500$ & $0.500,0.500$ & $0.500,0.500$ \\
\hline B-\#wayEffect:Partially & 123 & $0.996,0.001$ & $0.836,0.289$ & $0.860,0.297$ & $0.846,0.290$ \\
\hline I-\#BadTrafficSituation & 85 & $0.997,0.001$ & $0.807,0.277$ & $0.831,0.282$ & $0.818,0.277$ \\
\hline I-\#Event & 8 & $0.998,0.000$ & $0.575,0.471$ & $0.480,0.410$ & $0.518,0.430$ \\
\hline I-\#GoodTrafficSituation & 28 & $0.997,0.002$ & $0.570,0.405$ & $0.611,0.419$ & $0.586,0.406$ \\
\hline I-\#Location & 306 & $0.968,0.014$ & $0.444,0.326$ & $0.653,0.376$ & $0.484,0.304$ \\
\hline I-\#Protest & 2 & $0.997,0.000$ & $0.347,0.000$ & $0.533,0.000$ & $0.421,0.000$ \\
\hline I-\#PublicAuthority & 9 & $0.996,0.001$ & $0.444,0.350$ & $0.411,0.340$ & $0.383,0.272$ \\
\hline I-\#Time & 8 & $0.995,0.001$ & $0.269,0.269$ & $0.175,0.175$ & $0.212,0.212$ \\
\hline I-\#wayEffect:BothDirections & 22 & $0.999,0.001$ & $0.450,0.471$ & $0.444,0.471$ & $0.447,0.471$ \\
\hline I-\#wayEffect:Partially & 2 & $0.998,0.000$ & $1.000,0.000$ & $1.000,0.000$ & $1.000,0.000$ \\
\hline
\end{tabular}

Tabela E.19: Revalidation scores: model-fscore-TEDO-NER-SGD-2

\begin{tabular}{|c|c|c|c|c|c|}
\hline Class & Support & Accuracy & Recall & Precision & F1 \\
\hline $\mathrm{O}$ & 1195 & 0.942 & 0.994 & 0.920 & 0.956 \\
\hline B-\#Accident & 27 & 0.998 & 0.925 & 1.000 & 0.961 \\
\hline B-\#BadTrafficSituation & 66 & 0.994 & 0.954 & 0.900 & 0.926 \\
\hline B-\#Breakdown & 3 & 0.999 & 0.666 & 1.000 & 0.800 \\
\hline B-\#Bus & 8 & 0.998 & 0.750 & 1.000 & 0.857 \\
\hline B-\#Car & 23 & 0.998 & 0.913 & 0.954 & 0.933 \\
\hline B-\#Event & 5 & 0.997 & 0.400 & 0.666 & 0.500 \\
\hline B-\#GoodTrafficSituation & 16 & 0.995 & 0.500 & 1.000 & 0.666 \\
\hline B-\#Interdiction & 24 & 0.999 & 0.958 & 1.000 & 0.978 \\
\hline B-\#Location & 316 & 0.970 & 0.889 & 0.933 & 0.910 \\
\hline B-\#Motorcycle & 4 & 0.998 & 0.750 & 0.750 & 0.750 \\
\hline B-\#Protest & 1 & 1.000 & 1.000 & 1.000 & 1.000 \\
\hline B-\#PublicAuthority & 8 & 0.998 & 0.625 & 1.000 & 0.769 \\
\hline B-\#RoadWork & 1 & 1.000 & 1.000 & 1.000 & 1.000 \\
\hline B-\#Solution & 10 & 1.000 & 1.000 & 1.000 & 1.000 \\
\hline B-\#Time & 3 & 1.000 & 1.000 & 1.000 & 1.000 \\
\hline B-\#Truck & 6 & 0.999 & 0.833 & 1.000 & 0.909 \\
\hline B-\#wayEffect:BothDirections & 11 & 1.000 & 1.000 & 1.000 & 1.000 \\
\hline B-\#wayEffect:OneDirection & 1 & 0.999 & 0.000 & 0.000 & 0.000 \\
\hline B-\#wayEffect:Partially & 23 & 0.999 & 1.000 & 0.958 & 0.978 \\
\hline I-\#BadTrafficSituation & 20 & 0.998 & 0.950 & 0.950 & 0.950 \\
\hline I-\#GoodTrafficSituation & 15 & 0.997 & 0.800 & 0.923 & 0.857 \\
\hline I-\#Location & 90 & 0.963 & 0.288 & 0.866 & 0.433 \\
\hline I-\#wayEffect:BothDirections & 12 & 0.998 & 0.750 & 1.000 & 0.857 \\
\hline
\end{tabular}


Tabela E.20: Best parameters: model-fscore-TEDO-NER-SVC-2

\begin{tabular}{rrr}
\hline Parameter & Values & Best value \\
\hline Penalty parameter C & $0.1,1,10,100$ & 1 \\
Class weight & balanced, None & None \\
One vs Rest & true, false & true \\
Use Shrinking heuristic & true, false & true \\
\hline
\end{tabular}

Tabela E.21: Training scores: model-fscore-TEDO-NER-SVC-2

\begin{tabular}{|c|c|c|c|c|c|}
\hline Class & Support & Accuracy, $\sigma \mathbf{C V}$ & Recall, $\sigma \mathbf{C V}$ & Precision, $\sigma \mathbf{C V}$ & $\mathbf{F} 1, \sigma \mathbf{C V}$ \\
\hline $\mathrm{O}$ & 5262 & $0.956,0.013$ & $0.975,0.009$ & $0.958,0.016$ & $0.966,0.010$ \\
\hline B-\#Accident & 114 & $0.999,0.001$ & $0.961,0.049$ & $0.975,0.039$ & $0.967,0.038$ \\
\hline B-\#BadTrafficSituation & 273 & $0.996,0.001$ & $0.961,0.045$ & $0.933,0.035$ & $0.946,0.022$ \\
\hline B-\#Breakdown & 14 & $0.999,0.000$ & $1.000,0.000$ & $0.975,0.066$ & $0.986,0.036$ \\
\hline B-\#Bus & 31 & $0.999,0.000$ & $1.000,0.000$ & $0.907,0.107$ & $0.948,0.060$ \\
\hline B-\#Car & 103 & $0.999,0.000$ & $0.884,0.296$ & $0.891,0.298$ & $0.887,0.296$ \\
\hline B-\#Event & 32 & $0.996,0.001$ & $0.490,0.266$ & $0.731,0.313$ & $0.570,0.263$ \\
\hline B-\#GoodTrafficSituation & 29 & $0.997,0.002$ & $0.459,0.370$ & $0.625,0.436$ & $0.509,0.379$ \\
\hline B-\#Interdiction & 141 & $0.998,0.001$ & $0.970,0.047$ & $0.968,0.036$ & $0.968,0.028$ \\
\hline B-\#Location & 1270 & $0.976,0.009$ & $0.943,0.030$ & $0.900,0.038$ & $0.921,0.033$ \\
\hline B-\#Motorcycle & 18 & $0.999,0.000$ & $0.938,0.155$ & $0.987,0.035$ & $0.953,0.104$ \\
\hline B-\#Protest & 16 & $0.998,0.000$ & $0.669,0.239$ & $1.000,0.000$ & $0.774,0.194$ \\
\hline B-\#PublicAuthority & 55 & $0.997,0.002$ & $0.758,0.312$ & $0.796,0.331$ & $0.758,0.299$ \\
\hline B-\#RoadWork & 31 & $1.000,0.000$ & $0.814,0.355$ & $0.888,0.314$ & $0.833,0.333$ \\
\hline B-\#Solution & 45 & $0.999,0.000$ & $0.950,0.093$ & $0.909,0.118$ & $0.925,0.091$ \\
\hline B-\#Time & 17 & $0.998,0.001$ & $0.523,0.466$ & $0.542,0.474$ & $0.526,0.460$ \\
\hline B-\#Truck & 24 & $0.999,0.000$ & $0.900,0.300$ & $0.783,0.325$ & $0.824,0.303$ \\
\hline B-\#wayEffect:BothDirections & 19 & $0.999,0.001$ & $0.900,0.300$ & $0.800,0.331$ & $0.833,0.307$ \\
\hline B-\#wayEffect:OneDirection & 3 & $0.998,0.001$ & $0.500,0.500$ & $0.500,0.500$ & $0.500,0.500$ \\
\hline B-\#wayEffect:Partially & 123 & $0.997,0.001$ & $0.847,0.184$ & $0.970,0.047$ & $0.889,0.136$ \\
\hline I-\#BadTrafficSituation & 85 & $0.998,0.001$ & $0.941,0.082$ & $0.926,0.092$ & $0.928,0.063$ \\
\hline I-\#Event & 8 & $0.998,0.000$ & $0.375,0.460$ & $0.400,0.489$ & $0.386,0.474$ \\
\hline I-\#GoodTrafficSituation & 28 & $0.997,0.002$ & $0.508,0.402$ & $0.685,0.450$ & $0.558,0.401$ \\
\hline I-\#Location & 306 & $0.977,0.011$ & $0.546,0.260$ & $0.674,0.272$ & $0.596,0.262$ \\
\hline I-\#Protest & 2 & $0.997,0.000$ & $0.347,0.000$ & $0.800,0.000$ & $0.484,0.000$ \\
\hline I-\#PublicAuthority & 9 & $0.997,0.001$ & $0.583,0.311$ & $0.777,0.314$ & $0.522,0.109$ \\
\hline I-\#Time & 8 & $0.995,0.001$ & $0.416,0.006$ & $0.540,0.100$ & $0.465,0.034$ \\
\hline I-\#wayEffect:BothDirections & 22 & $0.999,0.000$ & $0.706,0.397$ & $0.694,0.396$ & $0.687,0.383$ \\
\hline I-\#wayEffect:Partially & 2 & $0.998,0.000$ & $0.500,0.000$ & $1.000,0.000$ & $0.666,0.000$ \\
\hline
\end{tabular}


Tabela E.22: Revalidation scores: model-fscore-TEDO-NER-SVC-2

\begin{tabular}{|c|c|c|c|c|c|}
\hline Class & Support & Accuracy & Recall & Precision & F1 \\
\hline $\mathrm{O}$ & 1195 & 0.958 & 0.984 & 0.952 & 0.967 \\
\hline B-\#Accident & 27 & 0.998 & 0.925 & 1.000 & 0.961 \\
\hline B-\#BadTrafficSituation & 66 & 0.996 & 0.969 & 0.941 & 0.955 \\
\hline B-\#Breakdown & 3 & 0.999 & 0.666 & 1.000 & 0.800 \\
\hline B-\#Bus & 8 & 1.000 & 1.000 & 1.000 & 1.000 \\
\hline B-\#Car & 23 & 1.000 & 1.000 & 1.000 & 1.000 \\
\hline B-\#Event & 5 & 0.997 & 0.600 & 0.600 & 0.600 \\
\hline B-\#GoodTrafficSituation & 16 & 0.996 & 0.687 & 0.916 & 0.785 \\
\hline B-\#Interdiction & 24 & 1.000 & 1.000 & 1.000 & 1.000 \\
\hline B-\#Location & 316 & 0.976 & 0.927 & 0.933 & 0.930 \\
\hline B-\#Motorcycle & 4 & 0.999 & 1.000 & 0.800 & 0.888 \\
\hline B-\#Protest & 1 & 1.000 & 1.000 & 1.000 & 1.000 \\
\hline B-\#PublicAuthority & 8 & 1.000 & 1.000 & 1.000 & 1.000 \\
\hline B-\#RoadWork & 1 & 1.000 & 1.000 & 1.000 & 1.000 \\
\hline B-\#Solution & 10 & 1.000 & 1.000 & 1.000 & 1.000 \\
\hline B-\#Time & 3 & 1.000 & 1.000 & 1.000 & 1.000 \\
\hline B-\#Truck & 6 & 1.000 & 1.000 & 1.000 & 1.000 \\
\hline B-\#wayEffect:BothDirections & 11 & 0.998 & 0.818 & 1.000 & 0.900 \\
\hline B-\#wayEffect:OneDirection & 1 & 0.999 & 0.000 & 0.000 & 0.000 \\
\hline B-\#wayEffect:Partially & 23 & 0.998 & 1.000 & 0.884 & 0.938 \\
\hline I-\#BadTrafficSituation & 20 & 1.000 & 1.000 & 1.000 & 1.000 \\
\hline I-\#GoodTrafficSituation & 15 & 0.998 & 1.000 & 0.882 & 0.937 \\
\hline I-\#Location & 90 & 0.968 & 0.477 & 0.767 & 0.589 \\
\hline I-\#wayEffect:BothDirections & 12 & 0.998 & 0.833 & 1.000 & 0.909 \\
\hline
\end{tabular}

Tabela E.23: Training scores: model-fscore-TEDO-NER-RF-FINAL

\begin{tabular}{|c|c|c|c|c|c|}
\hline Class & Support & Accuracy, $\sigma \mathbf{C V}$ & Recall, $\sigma \mathbf{C V}$ & Precision, $\sigma \mathbf{C V}$ & $\mathbf{F} 1, \sigma \mathbf{C V}$ \\
\hline $\mathrm{O}$ & 6457 & $0.964,0.016$ & $0.980,0.010$ & $0.964,0.019$ & $0.972,0.012$ \\
\hline B-\#Accident & 141 & $0.999,0.000$ & $0.962,0.053$ & $0.991,0.025$ & $0.975,0.028$ \\
\hline B-\#BadTrafficSituation & 339 & $0.996,0.002$ & $0.948,0.046$ & $0.944,0.044$ & $0.945,0.032$ \\
\hline B-\#Breakdown & 17 & $0.999,0.000$ & $0.962,0.104$ & $0.944,0.157$ & $0.940,0.115$ \\
\hline B-\#Bus & 39 & $1.000,0.000$ & $1.000,0.000$ & $1.000,0.000$ & $1.000,0.000$ \\
\hline B-\#Car & 126 & $0.999,0.000$ & $0.983,0.049$ & $1.000,0.000$ & $0.990,0.027$ \\
\hline B-\#Event & 37 & $0.998,0.000$ & $0.667,0.204$ & $0.925,0.114$ & $0.749,0.131$ \\
\hline B-\#GoodTrafficSituation & 45 & $0.997,0.002$ & $0.546,0.307$ & $0.625,0.370$ & $0.560,0.315$ \\
\hline B-\#Interdiction & 165 & $0.999,0.001$ & $0.974,0.043$ & $0.995,0.014$ & $0.984,0.026$ \\
\hline B-\#Location & 1586 & $0.980,0.007$ & $0.960,0.017$ & $0.920,0.036$ & $0.939,0.024$ \\
\hline B-\#Motorcycle & 22 & $0.999,0.000$ & $0.944,0.157$ & $1.000,0.000$ & $0.962,0.104$ \\
\hline B-\#Protest & 17 & $0.999,0.000$ & $0.802,0.275$ & $1.000,0.000$ & $0.858,0.208$ \\
\hline B-\#PublicAuthority & 63 & $0.998,0.001$ & $0.854,0.212$ & $0.870,0.204$ & $0.839,0.183$ \\
\hline B-\#RoadWork & 32 & $0.999,0.000$ & $0.925,0.138$ & $1.000,0.000$ & $0.955,0.083$ \\
\hline B-\#Solution & 55 & $0.999,0.000$ & $0.916,0.220$ & $1.000,0.000$ & $0.937,0.165$ \\
\hline B-\#Time & 20 & $0.998,0.001$ & $0.600,0.447$ & $0.604,0.447$ & $0.586,0.426$ \\
\hline B-\#Truck & 30 & $1.000,0.000$ & $1.000,0.000$ & $1.000,0.000$ & $1.000,0.000$ \\
\hline B-\#wayEffect:BothDirections & 30 & $0.999,0.000$ & $0.980,0.059$ & $0.901,0.153$ & $0.929,0.092$ \\
\hline B-\#wayEffect:OneDirection & 4 & $0.998,0.000$ & $0.000,0.000$ & $0.000,0.000$ & $0.000,0.000$ \\
\hline B-\#wayEffect:Partially & 146 & $0.998,0.001$ & $0.840,0.285$ & $0.846,0.299$ & $0.838,0.284$ \\
\hline I-\#BadTrafficSituation & 105 & $0.997,0.002$ & $0.872,0.167$ & $0.904,0.109$ & $0.878,0.124$ \\
\hline I-\#Event & 8 & $0.998,0.000$ & $0.200,0.400$ & $0.200,0.400$ & $0.200,0.400$ \\
\hline I-\#GoodTrafficSituation & 43 & $0.997,0.002$ & $0.732,0.329$ & $0.825,0.290$ & $0.750,0.288$ \\
\hline I-\#Location & 396 & $0.976,0.013$ & $0.617,0.206$ & $0.754,0.161$ & $0.657,0.141$ \\
\hline I-\#Protest & 2 & $0.997,0.000$ & $0.500,0.000$ & $0.500,0.000$ & $0.500,0.000$ \\
\hline I-\#PublicAuthority & 9 & $0.998,0.001$ & $0.500,0.408$ & $0.666,0.471$ & $0.555,0.415$ \\
\hline I-\#Time & 8 & $0.995,0.001$ & $0.270,0.270$ & $0.450,0.450$ & $0.338,0.338$ \\
\hline I-\#wayEffect:BothDirections & 34 & $0.999,0.000$ & $0.800,0.400$ & $0.713,0.379$ & $0.748,0.382$ \\
\hline I-\#wayEffect:Partially & 2 & $0.998,0.000$ & $0.500,0.000$ & $1.000,0.000$ & $0.666,0.000$ \\
\hline
\end{tabular}


Tabela E.24: Test scores: model-fscore-TEDO-NER-RF-FINAL

\begin{tabular}{rrrrrr}
\hline Class & Support & Accuracy & Recall & Precision & F1 \\
\hline B-\#Accident & 1553 & 0.962 & 0.981 & 0.960 & 0.971 \\
B-\#BadTrafficSituation & 36 & 0.999 & 0.972 & 1.000 & 0.985 \\
B-\#Breakdown & 72 & 0.997 & 0.986 & 0.946 & 0.965 \\
B-\#Bus & 5 & 1.000 & 1.000 & 1.000 & 1.000 \\
B-\#Car & 11 & 1.000 & 1.000 & 1.000 & 1.000 \\
B-\#Event & 28 & 0.999 & 0.964 & 1.000 & 0.981 \\
B-\#Interdiction & 5 & 0.999 & 0.800 & 0.800 & 0.800 \\
B-\#Location & 390 & 0.998 & 0.800 & 0.923 & 0.857 \\
B-\#Motorcycle & 7 & 0.999 & 0.976 & 1.000 & 0.988 \\
B-\#Protest & 9 & 1.000 & 0.938 & 0.917 & 0.927 \\
B-\#-GoodTrafficSituation & 1.000 & 1.000 & 1.000 & 1.000 \\
B-\#PublicAuthority & 18 & 0.997 & 0.777 & 1.000 & 1.000 \\
B-\#RoadWork & 12 & 0.999 & 0.916 & 1.000 & 0.848 \\
B-\#Solution & 20 & 0.997 & 0.800 & 0.941 & 0.956 \\
B-\#Time & 4 & 0.999 & 0.750 & 1.000 & 0.864 \\
B-\#Truck & 7 & 0.999 & 0.857 & 1.000 & 0.923 \\
B-\#wayEffect:BothDirections & 8 & 0.999 & 1.000 & 0.888 & 0.941 \\
B-\#wayEffect:Partially & 42 & 0.996 & 0.000 & 0.000 & 0.000 \\
I-\#BadTrafficSituation & 24 & 0.999 & 0.857 & 0.947 & 0.900 \\
I-\#GoodTrafficSituation & 13 & 0.998 & 0.958 & 0.958 & 0.958 \\
I-\#Location & 115 & 0.976 & 0.846 & 0.916 & 0.879 \\
I-\#Time & 5 & 0.997 & 0.626 & 0.827 & 0.712 \\
I-\#wayEffect:BothDirections & 10 & 1.000 & 0.000 & 0.000 & 0.000 \\
I-\#wayEffect:Partially & 2 & 0.998 & 0.200 & 0.250 & 0.222 \\
\hline Average, $\sigma$ & & $\mathbf{0 . 9 9 5 , 0 . 0 0 9}$ & $\mathbf{0 . 8 0 0 , 0 . 2 8 9}$ & $\mathbf{0 . 8 4 8 , 0 . 2 9 0}$ & $\mathbf{0 . 8 2 1 , 0 . 2 8 7}$
\end{tabular}

Tabela E.25: Training scores: model-fscore-TEDO-NER-RF-FINALAGRUPADO

\begin{tabular}{|c|c|c|c|c|c|}
\hline Class & Support & Accuracy, $\sigma \mathbf{C V}$ & Recall, $\sigma \mathbf{C V}$ & Precision, $\sigma \mathbf{C V}$ & $\mathbf{F} 1, \sigma \mathbf{C V}$ \\
\hline $\mathrm{O}$ & 6605 & $0.965,0.016$ & $0.981,0.009$ & $0.966,0.019$ & $0.973,0.012$ \\
\hline B-\#Accident & 141 & $0.999,0.000$ & $0.962,0.053$ & $0.984,0.046$ & $0.972,0.033$ \\
\hline B-\#Actor & 217 & $0.999,0.000$ & $0.983,0.035$ & $1.000,0.000$ & $0.991,0.018$ \\
\hline B-\#BadTrafficSituation & 339 & $0.995,0.002$ & $0.942,0.053$ & $0.937,0.039$ & $0.938,0.031$ \\
\hline B-\#Breakdown & 17 & $0.999,0.000$ & $0.962,0.104$ & $1.000,0.000$ & $0.977,0.062$ \\
\hline B-\#Event & 37 & $0.998,0.001$ & $0.636,0.161$ & $0.925,0.114$ & $0.733,0.086$ \\
\hline B-\#GoodTrafficSituation & 45 & $0.996,0.002$ & $0.531,0.315$ & $0.556,0.351$ & $0.517,0.314$ \\
\hline B-\#Interdiction & 165 & $0.999,0.001$ & $0.974,0.043$ & $0.995,0.014$ & $0.984,0.026$ \\
\hline B-\#Location & 1586 & $0.980,0.007$ & $0.957,0.019$ & $0.922,0.033$ & $0.939,0.024$ \\
\hline B-\#Protest & 17 & $0.999,0.000$ & $0.833,0.288$ & $1.000,0.000$ & $0.875,0.216$ \\
\hline B-\#PublicAuthority & 63 & $0.998,0.001$ & $0.854,0.212$ & $0.925,0.159$ & $0.857,0.154$ \\
\hline B-\#RoadWork & 32 & $0.999,0.000$ & $0.925,0.138$ & $1.000,0.000$ & $0.955,0.083$ \\
\hline B-\#Solution & 55 & $0.999,0.000$ & $0.916,0.220$ & $0.987,0.033$ & $0.930,0.163$ \\
\hline B-\#Time & 20 & $0.998,0.001$ & $0.433,0.453$ & $0.500,0.500$ & $0.458,0.465$ \\
\hline B-\#wayEffect:BothDirections & 30 & $0.999,0.000$ & $0.980,0.059$ & $0.889,0.169$ & $0.920,0.102$ \\
\hline B-\#wayEffect:OneDirection & 4 & $0.998,0.000$ & $0.000,0.000$ & $0.000,0.000$ & $0.000,0.000$ \\
\hline I-\#BadTrafficSituation & 105 & $0.997,0.003$ & $0.785,0.303$ & $0.822,0.290$ & $0.798,0.290$ \\
\hline I-\#Event & 8 & $0.998,0.000$ & $0.200,0.400$ & $0.133,0.266$ & $0.160,0.320$ \\
\hline I-\#GoodTrafficSituation & 43 & $0.997,0.002$ & $0.757,0.339$ & $0.851,0.300$ & $0.774,0.299$ \\
\hline I-\#Location & 396 & $0.976,0.013$ & $0.618,0.202$ & $0.777,0.168$ & $0.665,0.138$ \\
\hline I-\#Protest & 2 & $0.997,0.000$ & $0.500,0.000$ & $0.500,0.000$ & $0.500,0.000$ \\
\hline I-\#PublicAuthority & 9 & $0.998,0.001$ & $0.575,0.422$ & $0.538,0.411$ & $0.555,0.415$ \\
\hline I-\#Time & 8 & $0.995,0.001$ & $0.270,0.270$ & $0.460,0.460$ & $0.340,0.340$ \\
\hline I-\#wayEffect:BothDirections & 34 & $0.999,0.000$ & $0.900,0.300$ & $0.747,0.295$ & $0.808,0.286$ \\
\hline
\end{tabular}


Tabela E.26: Test scores: model-fscore-TEDO-NER-RF-FINAL-AGRUPADO

\begin{tabular}{rrrrrr}
\hline Class & Support & Accuracy & Recall & Precision & F1 \\
\hline O & 1597 & 0.962 & 0.979 & 0.964 & 0.971 \\
B-\#Accident & 36 & 1.000 & 1.000 & 1.000 & 1.000 \\
B-\#Actor & 53 & 0.999 & 0.981 & 1.000 & 0.990 \\
B-\#BadTrafficSituation & 72 & 0.997 & 0.986 & 0.946 & 0.965 \\
B-\#Breakdown & 5 & 1.000 & 1.000 & 1.000 & 1.000 \\
B-\#Event & 5 & 0.999 & 0.800 & 1.000 & 0.888 \\
B-\#GoodTrafficSituation & 15 & 0.997 & 0.800 & 0.857 & 0.827 \\
B-\#Interdiction & 43 & 0.999 & 0.976 & 1.000 & 0.988 \\
B-\#Location & 390 & 0.978 & 0.946 & 0.922 & 0.934 \\
B-\#Protest & 9 & 1.000 & 1.000 & 1.000 & 1.000 \\
B-\#PublicAuthority & 18 & 0.997 & 0.777 & 0.875 & 0.823 \\
B-\#RoadWork & 12 & 0.999 & 0.916 & 1.000 & 0.956 \\
B-\#Solution & 20 & 0.997 & 0.800 & 0.941 & 0.864 \\
B-\#Time & 4 & 0.998 & 0.750 & 0.600 & 0.666 \\
B-\#wayEffect:BothDirections & 8 & 0.999 & 1.000 & 0.888 & 0.941 \\
I-\#BadTrafficSituation & 24 & 0.999 & 0.000 & 0.000 & 0.000 \\
I-\#GoodTrafficSituation & 13 & 0.998 & 0.958 & 0.958 & 0.958 \\
I-\#Location & 115 & 0.975 & 0.846 & 0.916 & 0.879 \\
I-\#Time & 5 & 0.996 & 0.608 & 0.833 & 0.703 \\
I-\#wayEffect:BothDirections & 10 & 1.000 & 0.000 & 0.000 & 0.000 \\
\hline Average, $\sigma$ & & $\mathbf{0 . 9 9 5 , 0 . 0 0 9}$ & $\mathbf{0 . 8 0 6}, \mathbf{0 . 2 8 9}$ & $\mathbf{0 . 8 3 5 , 0 . 2 9 2}$ & $\mathbf{0 . 8 1 8 , 0 . 2 8 7}$
\end{tabular}

Tabela E.27: Training scores: model-fscore-TEDO-RE-SP-0

\begin{tabular}{rrrrrr}
\hline Class & Support & Accuracy, $\sigma$ CV & Recall, $\sigma$ CV & Precision, $\sigma$ CV & F1, $\sigma$ CV \\
\hline O & 11274 & $0.885,0.013$ & $0.957,0.019$ & $0.911,0.017$ & $0.933,0.008$ \\
\#affectsFlowTo & 313 & $0.984,0.005$ & $0.603,0.171$ & $0.741,0.063$ & $0.647,0.110$ \\
\#causes & 218 & $0.991,0.002$ & $0.692,0.144$ & $0.801,0.149$ & $0.717,0.084$ \\
\#hasActor & 186 & $0.997,0.002$ & $0.975,0.049$ & $0.908,0.094$ & $0.936,0.055$ \\
\#hasAlternative & 16 & $0.998,0.000$ & $0.000,0.000$ & $0.000,0.000$ & $0.000,0.000$ \\
\#hasEdge & 226 & $0.984,0.006$ & $0.234,0.202$ & $0.441,0.324$ & $0.295,0.240$ \\
\#hasEvent & 710 & $0.953,0.008$ & $0.347,0.147$ & $0.609,0.168$ & $0.428,0.133$ \\
\#hasReference & 307 & $0.971,0.009$ & $0.234,0.198$ & $0.366,0.254$ & $0.230,0.151$ \\
\#hasSupporter & 96 & $0.998,0.001$ & $0.809,0.245$ & $0.807,0.280$ & $0.773,0.251$ \\
\#hasTime & 18 & $0.997,0.002$ & $0.545,0.379$ & $0.678,0.398$ & $0.565,0.366$ \\
\hline Average, $\sigma$ & & $\mathbf{0 . 9 7 6 , 0 . 0 3 3}$ & $\mathbf{0 . 5 3 9 , 0 . 3 1 2}$ & $\mathbf{0 . 6 2 6 , 0 . 2 7 0}$ & $\mathbf{0 . 5 5 2 , 0 . 2 9 4}$
\end{tabular}

Tabela E.28: Revalidation scores: model-fscore-TEDO-RE-SP-0

\begin{tabular}{rrrrrr}
\hline Class & Support & Accuracy & Recall & Precision & F1 \\
\hline O & 2523 & 0.888 & 0.982 & 0.894 & 0.936 \\
\#affectsFlowTo & 77 & 0.987 & 0.558 & 0.934 & 0.699 \\
\#causes & 43 & 0.991 & 0.441 & 0.904 & 0.593 \\
\#hasActor & 44 & 0.996 & 0.886 & 0.906 & 0.896 \\
\#hasAlternative & 2 & 0.999 & 0.500 & 0.500 & 0.500 \\
\#hasEdge & 53 & 0.983 & 0.150 & 0.666 & 0.246 \\
\#hasEvent & 154 & 0.957 & 0.292 & 0.703 & 0.412 \\
\#hasReference & 83 & 0.969 & 0.084 & 0.304 & 0.132 \\
\#hasSupporter & 16 & 0.999 & 0.875 & 1.000 & 0.933 \\
\#hasTime & 3 & 1.000 & 1.000 & 1.000 & 1.000 \\
\hline Average, $\sigma$ & & $\mathbf{0 . 9 7 7 , 0 . 0 3 2}$ & $\mathbf{0 . 5 7 7 , 0 . 3 2 5}$ & $\mathbf{0 . 7 8 1 , 0 . 2 2 1}$ & $\mathbf{0 . 6 3 5 , 0 . 2 9 3}$
\end{tabular}


Tabela E.29: Training scores: model-fscore-TEDO-RE-FWSSVM-0

\begin{tabular}{rrrrrr}
\hline Class & Support & Accuracy, $\sigma$ CV & Recall, $\sigma$ CV & Precision, $\sigma$ CV & F1, $\sigma$ CV \\
\hline O & 11274 & $0.905,0.010$ & $0.968,0.007$ & $0.922,0.009$ & $0.944,0.006$ \\
\#affectsFlowTo & 313 & $0.987,0.004$ & $0.679,0.108$ & $0.805,0.089$ & $0.729,0.076$ \\
\#causes & 218 & $0.992,0.004$ & $0.762,0.126$ & $0.809,0.119$ & $0.774,0.093$ \\
\#hasActor & 186 & $0.998,0.001$ & $0.970,0.059$ & $0.928,0.079$ & $0.945,0.041$ \\
\#hasAlternative & 16 & $0.998,0.000$ & $0.000,0.000$ & $0.000,0.000$ & $0.000,0.000$ \\
\#hasEdge & 226 & $0.983,0.008$ & $0.423,0.227$ & $0.548,0.201$ & $0.451,0.200$ \\
\#hasEvent & 710 & $0.962,0.006$ & $0.570,0.088$ & $0.710,0.148$ & $0.620,0.077$ \\
\#hasReference & 307 & $0.977,0.008$ & $0.000,0.000$ & $0.000,0.000$ & $0.000,0.000$ \\
\#hasSupporter & 96 & $0.998,0.000$ & $0.950,0.124$ & $0.872,0.203$ & $0.885,0.154$ \\
\#hasTime & 18 & $0.999,0.001$ & $0.764,0.306$ & $1.000,0.000$ & $0.825,0.237$ \\
\hline Average, $\sigma$ & & $\mathbf{0 . 9 8 0 , 0 . 0 2 7}$ & $\mathbf{0 . 6 0 9 , 0 . 3 4 7}$ & $\mathbf{0 . 6 5 9 , 0 . 3 5 0}$ & $\mathbf{0 . 6 1 7 , 0 . 3 4 0}$
\end{tabular}

Tabela E.30: Revalidation scores: model-fscore-TEDO-RE-FWSSVM-0

\begin{tabular}{|c|c|c|c|c|c|}
\hline Class & Support & Accuracy & Recall & Precision & F1 \\
\hline $\mathrm{O}$ & 2523 & 0.912 & 0.969 & 0.929 & 0.949 \\
\hline \#affectsFlowTo & 77 & 0.988 & 0.610 & 0.921 & 0.734 \\
\hline \#causes & 43 & 0.995 & 0.790 & 0.894 & 0.839 \\
\hline \#hasActor & 44 & 0.997 & 0.931 & 0.911 & 0.921 \\
\hline \#hasAlternative & 2 & 0.999 & 0.000 & 0.000 & 0.000 \\
\hline \#hasEdge & 53 & 0.986 & 0.660 & 0.614 & 0.636 \\
\hline \#hasEvent & 154 & 0.968 & 0.694 & 0.690 & 0.692 \\
\hline \#hasReference & 83 & 0.972 & 0.000 & 0.000 & 0.000 \\
\hline \#hasSupporter & 16 & 0.999 & 0.937 & 1.000 & 0.967 \\
\hline \#hasTime & 3 & 1.000 & 1.000 & 1.000 & 1.000 \\
\hline
\end{tabular}

Tabela E.31: Best parameters: model-fscore-TEDO-RE-SP-1

\begin{tabular}{rrr}
\hline Parâmetro & Valores testados & Melhor valor \\
\hline Average & true, false & true \\
Batch learning & true, false & false \\
\hline
\end{tabular}

Tabela E.32: Training scores: model-fscore-TEDO-RE-SP-1

\begin{tabular}{rrrrrr}
\hline Class & Support & Accuracy, $\sigma$ CV & Recall, $\sigma \mathbf{C V}$ & Precision, $\sigma$ CV & F1, $\sigma$ CV \\
\hline $\mathrm{O}$ & 11274 & $0.899,0.009$ & $0.961,0.008$ & $0.922,0.013$ & $0.941,0.005$ \\
\#affectsFlowTo & 313 & $0.987,0.003$ & $0.700,0.105$ & $0.762,0.070$ & $0.726,0.074$ \\
\#causes & 218 & $0.991,0.003$ & $0.762,0.104$ & $0.778,0.122$ & $0.763,0.096$ \\
\#hasActor & 186 & $0.998,0.001$ & $0.979,0.042$ & $0.922,0.086$ & $0.947,0.049$ \\
\#hasAlternative & 16 & $0.998,0.000$ & $0.047,0.116$ & $0.142,0.349$ & $0.071,0.174$ \\
\#hasEdge & 226 & $0.984,0.006$ & $0.373,0.185$ & $0.600,0.252$ & $0.438,0.183$ \\
\#hasEvent & 710 & $0.959,0.006$ & $0.549,0.098$ & $0.658,0.089$ & $0.589,0.069$ \\
\#hasReference & 307 & $0.976,0.009$ & $0.138,0.070$ & $0.406,0.252$ & $0.198,0.105$ \\
\#hasSupporter & 96 & $0.998,0.000$ & $0.912,0.108$ & $0.902,0.151$ & $0.892,0.098$ \\
\#hasTime & 18 & $0.998,0.002$ & $0.735,0.328$ & $0.919,0.160$ & $0.780,0.271$ \\
\hline Average, $\sigma$ & & $\mathbf{0 . 9 7 9 , 0 . 0 2 9}$ & $\mathbf{0 . 6 1 6 , 0 . 3 1 5}$ & $\mathbf{0 . 7 0 1 , 0 . 2 4 6}$ & $\mathbf{0 . 6 3 4 , 0 . 2 9 1}$
\end{tabular}


Tabela E.33: Revalidation scores: model-fscore-TEDO-RE-SP-1

\begin{tabular}{rrrrrr}
\hline Class & Support & Accuracy & Recall & Precision & F1 \\
\hline O & 2523 & 0.903 & 0.964 & 0.924 & 0.944 \\
\#affectsFlowTo & 77 & 0.987 & 0.701 & 0.794 & 0.744 \\
\#causes & 43 & 0.995 & 0.790 & 0.894 & 0.839 \\
\#hasActor & 44 & 0.997 & 0.954 & 0.893 & 0.923 \\
\#hasAlternative & 2 & 0.998 & 0.000 & 0.000 & 0.000 \\
\#hasEdge & 53 & 0.983 & 0.396 & 0.552 & 0.461 \\
\#hasEvent & 154 & 0.966 & 0.610 & 0.706 & 0.655 \\
\#hasReference & 83 & 0.968 & 0.072 & 0.272 & 0.114 \\
\#hasSupporter & 16 & 0.999 & 0.937 & 1.000 & 0.967 \\
\#hasTime & 3 & 1.000 & 1.000 & 1.000 & 1.000 \\
\hline Average, $\sigma$ & & $\mathbf{0 . 9 8 0 , 0 . 0 2 8}$ & $\mathbf{0 . 6 4 2 ,} \mathbf{0 . 3 5 2}$ & $\mathbf{0 . 7 0 3 , 0 . 3 1 7}$ & $\mathbf{0 . 6 6 5 , 0 . 3 4 2}$
\end{tabular}

Tabela E.34: Best parameters: model-fscore-TEDO-RE-FWSSVM-1

\begin{tabular}{rrr}
\hline Parâmetro & Valores testados & Melhor valor \\
\hline Penalty parameter C & $0.1,1,10,100$ & 100 \\
Use weight averaging & true, false & false \\
\hline
\end{tabular}

Tabela E.35: Training scores: model-fscore-TEDO-RE-FWSSVM-1

\begin{tabular}{rrrrrr}
\hline Class & Support & Accuracy, $\sigma$ CV & Recall, $\sigma$ CV & Precision, $\sigma$ CV & F1, $\sigma$ CV \\
\hline O & 11274 & $0.885,0.015$ & $0.929,0.036$ & $0.935,0.023$ & $0.931,0.010$ \\
\#affectsFlowTo & 313 & $0.986,0.007$ & $0.769,0.108$ & $0.743,0.121$ & $0.746,0.086$ \\
\#causes & 218 & $0.991,0.004$ & $0.762,0.136$ & $0.768,0.111$ & $0.751,0.084$ \\
\#hasActor & 186 & $0.998,0.001$ & $0.983,0.038$ & $0.952,0.070$ & $0.965,0.040$ \\
\#hasAlternative & 16 & $0.997,0.001$ & $0.226,0.341$ & $0.309,0.440$ & $0.242,0.353$ \\
\#hasEdge & 226 & $0.980,0.009$ & $0.478,0.273$ & $0.411,0.202$ & $0.411,0.222$ \\
\#hasEvent & 710 & $0.957,0.006$ & $0.649,0.206$ & $0.647,0.162$ & $0.598,0.092$ \\
\#hasReference & 307 & $0.968,0.016$ & $0.218,0.213$ & $0.303,0.316$ & $0.199,0.196$ \\
\#hasSupporter & 96 & $0.998,0.001$ & $0.962,0.089$ & $0.874,0.145$ & $0.905,0.100$ \\
\#hasTime & 18 & $0.999,0.001$ & $0.792,0.293$ & $0.966,0.066$ & $0.833,0.234$ \\
\hline Average, $\sigma$ & & $\mathbf{0 . 9 7 6 , 0 . 0 3 3}$ & $\mathbf{0 . 6 7 7 , 0 . 2 6 8}$ & $\mathbf{0 . 6 9 1 , 0 . 2 4 9}$ & $\mathbf{0 . 6 5 8 , 0 . 2 6 9}$
\end{tabular}

Tabela E.36: Revalidation scores: model-fscore-TEDO-RE-FWSSVM-1

\begin{tabular}{|c|c|c|c|c|c|}
\hline Class & Support & Accuracy & Recall & Precision & F1 \\
\hline $\mathrm{O}$ & 2523 & 0.815 & 0.799 & 0.976 & 0.879 \\
\hline \#affectsFlow To & 77 & 0.982 & 0.870 & 0.614 & 0.720 \\
\hline \#causes & 43 & 0.994 & 0.813 & 0.833 & 0.823 \\
\hline \#hasActor & 44 & 0.997 & 0.954 & 0.893 & 0.923 \\
\hline \#hasAlternative & 2 & 0.998 & 1.000 & 0.400 & 0.571 \\
\hline \#hasEdge & 53 & 0.962 & 0.886 & 0.305 & 0.454 \\
\hline \#hasEvent & 154 & 0.938 & 0.974 & 0.455 & 0.621 \\
\hline \#hasReference & 83 & 0.927 & 0.554 & 0.202 & 0.296 \\
\hline \#hasSupporter & 16 & 0.999 & 0.937 & 1.000 & 0.967 \\
\hline \#hasTime & 3 & 1.000 & 1.000 & 1.000 & 1.000 \\
\hline
\end{tabular}


Tabela E.37: Training scores: model-fscore-TEDO-RE-FWSSVM-FINAL

\begin{tabular}{rrrrrr}
\hline Class & Support & Accuracy, $\sigma$ CV & Recall, $\sigma$ CV & Precision, $\sigma$ CV & F1, $\sigma$ CV \\
\hline O & 13797 & $0.885,0.019$ & $0.917,0.033$ & $0.944,0.017$ & $0.930,0.013$ \\
\#affectsFlowTo & 390 & $0.987,0.003$ & $0.826,0.068$ & $0.714,0.069$ & $0.763,0.051$ \\
\#causes & 261 & $0.992,0.003$ & $0.804,0.144$ & $0.778,0.072$ & $0.782,0.086$ \\
\#hasActor & 230 & $0.998,0.001$ & $0.965,0.043$ & $0.956,0.078$ & $0.958,0.044$ \\
\#hasAlternative & 18 & $0.998,0.001$ & $0.166,0.267$ & $0.214,0.364$ & $0.185,0.304$ \\
\#hasEdge & 279 & $0.979,0.012$ & $0.522,0.325$ & $0.438,0.290$ & $0.420,0.240$ \\
\#hasEvent & 864 & $0.957,0.008$ & $0.707,0.186$ & $0.598,0.104$ & $0.626,0.080$ \\
\#hasReference & 390 & $0.966,0.012$ & $0.314,0.175$ & $0.289,0.198$ & $0.292,0.174$ \\
\#hasSupporter & 112 & $0.998,0.001$ & $0.923,0.136$ & $0.934,0.074$ & $0.919,0.079$ \\
\#hasTime & 21 & $0.999,0.000$ & $0.900,0.223$ & $0.958,0.093$ & $0.904,0.157$ \\
\hline Average, $\sigma$ & & $\mathbf{0 . 9 7 6 , 0 . 0 3 3}$ & $\mathbf{0 . 7 0 4 , 0 . 2 6 4}$ & $\mathbf{0 . 6 8 2 , 0 . 2 7 1}$ & $\mathbf{0 . 6 7 8 , 0 . 2 7 0}$
\end{tabular}

Tabela E.38: Test scores: model-fscore-TEDO-RE-FWSSVM-FINAL

\begin{tabular}{|c|c|c|c|c|c|}
\hline Class & Support & Accuracy & Recall & Precision & F1 \\
\hline $\mathrm{O}$ & 3442 & 0.913 & 0.966 & 0.932 & 0.949 \\
\hline \#affectsFlowTo & 99 & 0.990 & 0.747 & 0.860 & 0.799 \\
\hline \#causes & 71 & 0.992 & 0.690 & 0.830 & 0.753 \\
\hline \#hasActor & 57 & 0.997 & 0.859 & 0.942 & 0.899 \\
\hline \#hasAlternative & 8 & 0.997 & 0.125 & 0.200 & 0.153 \\
\hline \#hasEdge & 52 & 0.990 & 0.615 & 0.640 & 0.627 \\
\hline \#hasEvent & 226 & 0.966 & 0.623 & 0.726 & 0.671 \\
\hline \#hasReference & 100 & 0.976 & 0.240 & 0.558 & 0.335 \\
\hline \#hasSupporter & 33 & 0.999 & 0.939 & 1.000 & 0.968 \\
\hline \#hasTime & 4 & 0.999 & 0.750 & 1.000 & 0.857 \\
\hline
\end{tabular}

Tabela E.39: Training scores: model-fscore-TEDO-RE-FWSSVM-FINALAGRUPADO

\begin{tabular}{rrrrrr}
\hline Class & Support & Accuracy, $\sigma \mathbf{C V}$ & Recall, $\sigma \mathbf{C V}$ & Precision, $\sigma \mathbf{C V}$ & F1, $\sigma \mathbf{C V}$ \\
\hline $\mathrm{O}$ & 11817 & $0.863,0.048$ & $0.906,0.081$ & $0.927,0.022$ & $0.913,0.037$ \\
\#affectsFlowTo & 390 & $0.986,0.005$ & $0.745,0.107$ & $0.790,0.113$ & $0.755,0.062$ \\
\#causes & 261 & $0.990,0.004$ & $0.784,0.146$ & $0.771,0.083$ & $0.766,0.084$ \\
\#hasActor & 230 & $0.998,0.001$ & $0.960,0.051$ & $0.965,0.064$ & $0.960,0.043$ \\
\#hasAlternative & 18 & $0.997,0.001$ & $0.095,0.233$ & $0.071,0.174$ & $0.081,0.199$ \\
\#hasEdge & 279 & $0.975,0.011$ & $0.446,0.300$ & $0.407,0.269$ & $0.358,0.196$ \\
\#hasEvent & 864 & $0.946,0.019$ & $0.691,0.180$ & $0.614,0.146$ & $0.615,0.078$ \\
\#hasReference & 390 & $0.961,0.026$ & $0.226,0.198$ & $0.305,0.238$ & $0.210,0.170$ \\
\#hasSupporter & 112 & $0.999,0.000$ & $0.971,0.057$ & $0.908,0.101$ & $0.933,0.059$ \\
\#hasTime & 21 & $0.999,0.000$ & $0.858,0.224$ & $0.958,0.093$ & $0.880,0.152$ \\
\hline Average, $\sigma$ & & $\mathbf{0 . 9 7 1 , 0 . 0 3 9}$ & $\mathbf{0 . 6 6 8 , 0 . 2 9 3}$ & $\mathbf{0 . 6 7 2 , 0 . 2 9 6}$ & $\mathbf{0 . 6 4 7 , 0 . 3 0 4}$
\end{tabular}


Tabela E.40: Test scores: model-fscore-TEDO-RE-FWSSVM-FINALAGRUPADO

\begin{tabular}{rrrrrr}
\hline Class & Support & Accuracy & Recall & Precision & F1 \\
\hline O & 2884 & 0.889 & 0.963 & 0.906 & 0.934 \\
\#affectsFlowTo & 99 & 0.988 & 0.666 & 0.891 & 0.763 \\
\#causes & 71 & 0.991 & 0.661 & 0.870 & 0.752 \\
\#hasActor & 57 & 0.997 & 0.912 & 0.945 & 0.928 \\
\#hasAlternative & 8 & 0.996 & 0.125 & 0.125 & 0.125 \\
\#hasEdge & 52 & 0.983 & 0.673 & 0.454 & 0.542 \\
\#hasEvent & 226 & 0.957 & 0.473 & 0.781 & 0.589 \\
\#hasReference & 100 & 0.970 & 0.130 & 0.448 & 0.201 \\
\#hasSupporter & 33 & 0.998 & 0.878 & 1.000 & 0.935 \\
\#hasTime & 4 & 0.999 & 0.750 & 1.000 & 0.857 \\
\hline Average, $\sigma$ & & $\mathbf{0 . 9 7 7 , 0 . 0 3 2}$ & $\mathbf{0 . 6 2 3 , 0 . 2 8 2}$ & $\mathbf{0 . 7 4 2 , \mathbf { 0 . 2 8 1 }}$ & $\mathbf{0 . 6 6 2 , \mathbf { 0 . 2 8 2 }}$
\end{tabular}

